Portland State University

PDXScholar

1996

\title{
Student Perceptions of Riots and Boycotts in Secondary Schools in Kenya's Kirinyaga District
}

Margaret Wangeci Gatimu

Portland State University

Follow this and additional works at: https://pdxscholar.library.pdx.edu/open_access_etds Let us know how access to this document benefits you.

\section{Recommended Citation}

Gatimu, Margaret Wangeci, "Student Perceptions of Riots and Boycotts in Secondary Schools in Kenya's Kirinyaga District" (1996). Dissertations and Theses. Paper 1151.

https://doi.org/10.15760/etd.1150

This Dissertation is brought to you for free and open access. It has been accepted for inclusion in Dissertations and Theses by an authorized administrator of PDXScholar. Please contact us if we can make this document more accessible: pdxscholar@pdx.edu. 


\title{
STUDENT PERCEPTIONS OF RIOTS AND BOYCOTTS IN SECONDARY SCHOOLS IN KENYA'S \\ KIRINYAGA DISTRICT
}

\author{
by \\ MARGARET WANGECI GATIMU
}
A dissertation submitted in partial fulfillment of the requirements for the degree of

\author{
DOCTOR OF EDUCATION \\ in \\ EDUCATIONAL LEADERSHIP: \\ ADMINISTRATION
}

\author{
Portland State University \\ 01996
}




\section{DISSERTATION APPROVAL}

The abstract and dissertation of Margaret Wangeci Gatimu for the Doctor of Education in Educational Leadership: Administration were presented June 12, 1996, and accepted by the dissertation committee and the doctoral program.

COMMITTEE APPROVALS:
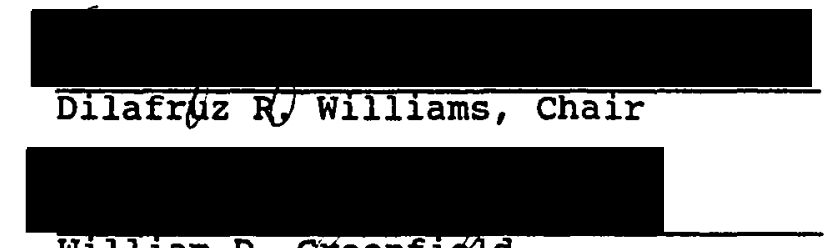

William D. Greenfield
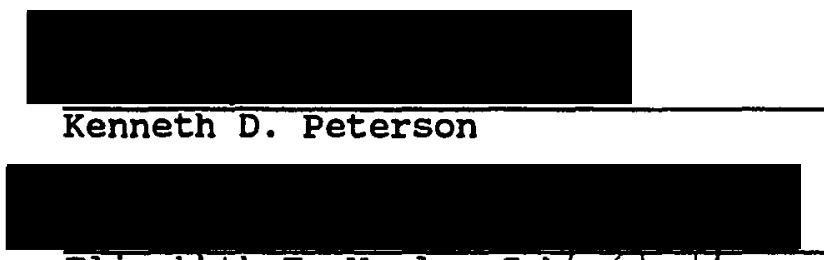

Elizabeth T. Wosley-Ge\&rge

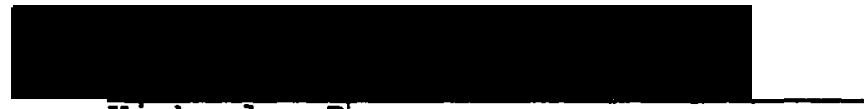

Kimber ley Brown

Representative of the office of Graduate studies

DOCTORAL PROGRAM APPROVAL: Robert B. Everhart, Dean School of Education

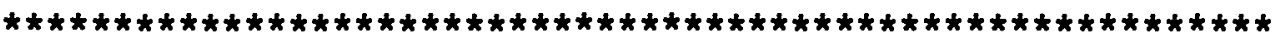

ACCEPTED FOR PORTLAND STATE UNIVERSITY BY THE LIBRARY on 14 Asuguet 1996 


\begin{abstract}
An abstract of the dissertation of Margaret Wangeci Gatimu for the Doctor of Education in Educational Leadership: Administration presented June 12, 1996.
\end{abstract}

Title: Student Perceptions of Riots and Boycotts in Secondary Schools in Kenya's Kirinyaga District

In recent years, a number of secondary schools in the Kirinyaga district of Central Province of Kenya have experienced riots and boycotts. The major objective of this study was to understand why students disrupt the normal processes of schooling. Students' perceptions were obtained by examining their attitudes, ideas, opinions, morals, and myths about these uprisings. The study was phenomenological in nature and was informed by the symbolic interactionism (Bogdan \& Biklen, 1992). Data were collected from six diverse secondary schools: three all boys schools, two all girls schools, and one co-educational school. Multiple sources of data and methods of collection allowed for triangulation. In-depth interviews were conducted with 29 ex-students, nine staff members, and one central office administrator. Interviews were open-ended, interactive, and designed to 
encourage the respondents to share their stories, beliefs, and standpoints. Written case histories, school-level and district-level documents, and students' records helped contextualize the interviews and past events. Data were analyzed using constant comparative analysis (Glaser \& Strauss, 1967). Respondents spoke to causes, dimensions, conditions, types, processes, and consequences of the disruptions.

It was found that some disruptions were spontaneous and fueled by students' established cultural norms which dictated fights for power and status. Other disruptions were carefully planned to draw the attention of school administrators and teachers to perceived grievances and issues that students cared about. The data also indicated that some of the disruptions were instigated by adult members of the community who were motivated by financial and power gains. Furthermore, respondents narrated experiences of physical hurt and psychological harm, plus damage to school property and financial losses incurred during riots and boycotts.

It. was observed that the secondary students were not motivated about their schooling experiences. For many students schools lacked relevance given the rapid changes and dislocations experienced by their culture, and the uncertainties of employment. The study acknowledges it is difficult for schools to respond adequately to deep-seated 
stresses of modernization processes. The study concludes by recommending fundamental changes in educational structure and certification in order to overcome archaic vestiges of the British system in formerly colonized Kenya. 


\section{DEDICATION}

This dissertation is dedicated to God, from whom all good things come, to my parents for instilling in me a spirit of endurance and determination and to Nyamu Mureithi who supported and encouraged me during the entire process. 


\section{ACKNOWLEDGEMENTS}

The completion of this degree work would not have been possible without the support and encouragement of many people. I wish to acknowledge the faith that my interview panel had on my ability to work towards this degree and consequently admitted me into the doctoral program when I was miles away.

I wish to acknowledge the patience and concern of my advisor Professor Dilafruz Williams. I give special thanks to Professor Bill Greenfield who gave me invaluable academic counsel and advice; and Professor Ken Peterson whose support, encouragement and advice was indispensable. These three professors gave me confidence and trust that I so desperately needed as a foreign student. I also owe thanks to Professors Elizabeth Wosley-George and Kimberley Brown for their readiness to work in my dissertation committee.

God promises never to leave us or forsake his own.

He never did. I was blessed by special love, concern, and encouragement of my "seven sisters of success" Rima Akkary, Donna Biegle, Cindy Pemberton, Jane Sowers, Maureen Musser and Eileen White. These women understood my language when no one else did. Their presence made an otherwise foreign land, home. 
I wish to acknowledge the help of David Bullock the MISL Director without whose help the word processing of this document would have been handicapped. 
TABLE OF CONTENTS

PAGE

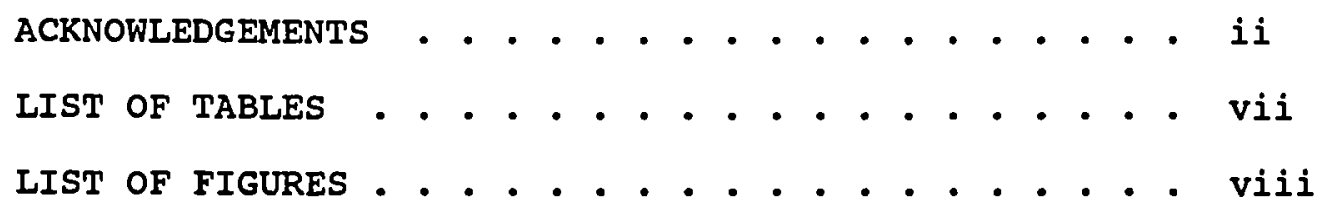

CHAPTER

I INTRODUCTION . . . . . . . . . 1

Background Information ...... 1

The setting . . . . . . . . . 3

The Kenyan Education System

The Growth of Secondary

Schooling Before and After

Independence in 1963

Statement of the Problem . . . . 23

Purpose of the study . . . . . . 26

Rationale of the Study . . . . . 29

II IITERATURE REVIEW . . . . . . . . 4 42

Adolescence ............ 44

Generation Gap Between High School

Students and the Teachers ... . 50

Alienation: Causes and Effects . . 59

Social Change and Its Effects . . 69

Modernization/Development

Student Disruptions as a Form

of Collective Behavior ...... 84 


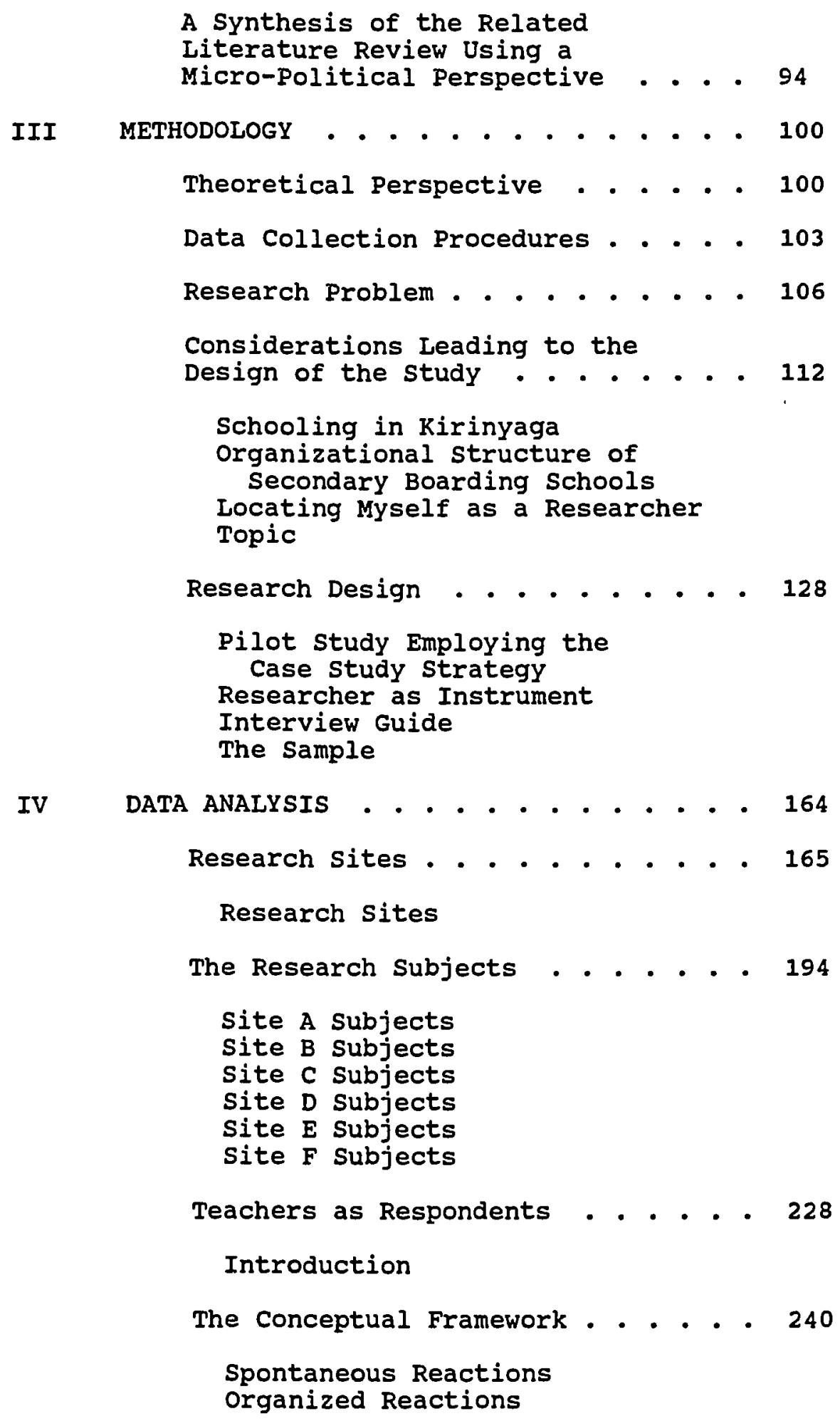


Outside Interference

Loss

V

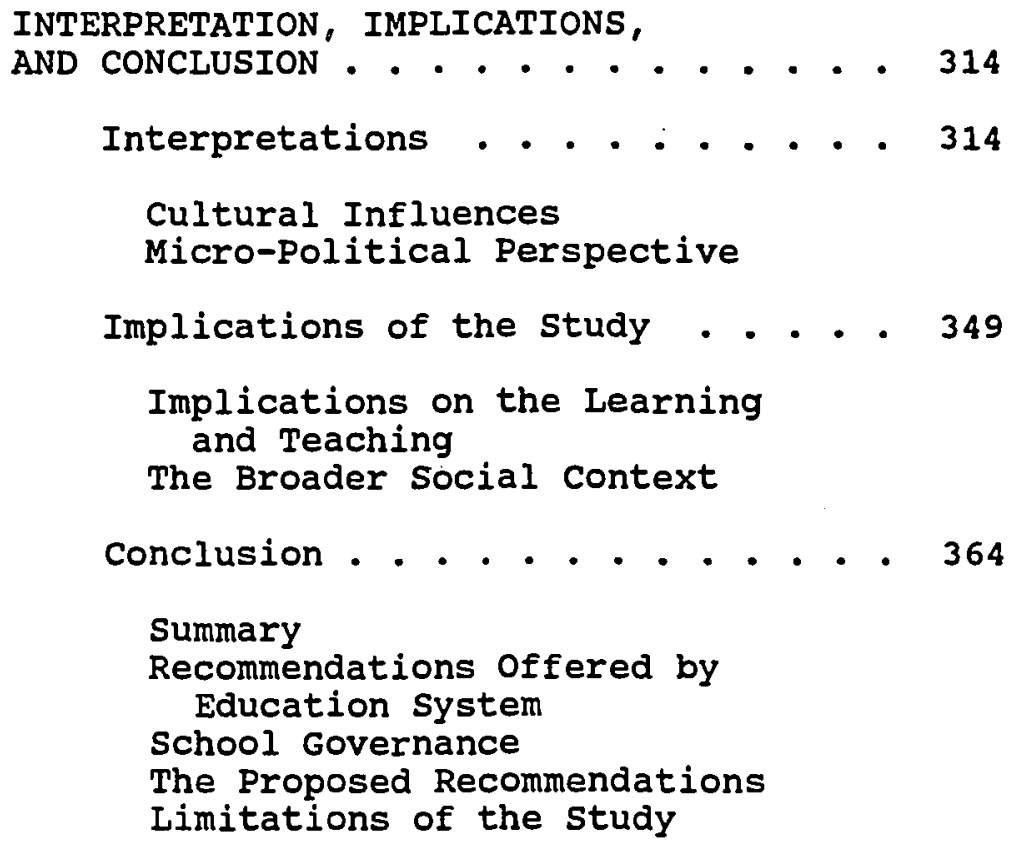

A SAMPLE OF RULES AND REGULATIONS AND A SAMPLE OF THE DAILY PROGRAM OBTAINED FROM TWO OF THE SELECTED SITES . . . . . 401

B CHARTS 1, 2, AND 3...........4405

C COPIES OF THE DOCUMENTS OBTAINED FROM THE KENYA GOVERNMENT FOR AUTHORITY TO CONDUCT RESEARCH .. . . . . . . . 409

D MAPS SHOWING KIRINYAGA IN RELATION TO OTHER DISTRICTS IN THE CENTRAL 
IIST OF TABLES

TABLE

PAGE

1. Kenya's Provinces and Ethnic Groups . 4

2. Distribution of Secondary Schools

in Provinces--1994... . . . . . . 14

3. Participation Rates of Secondary

Schooling in Central Province . . . 20

4. Distribution of Students According

to Type of school and Number of

students .............. 156

5. The Distribution of subjects by

School Sites...... . . . . . 158

6. The Distribution of Staff Members

Interviewed by Site and Status . . . . 159

7. To Map Disruptions outside the Sampled Schools Mentioned During the Field Study and Recorded in the Field Notes . . . . . . . . 163

8. Boycotts Affecting 1991-1994 Cohort in School A . . . . . . ... . . 171

9. Properties of Category 1: Spontaneous Reactions ............ . 277

10. Properties of Category 2: Organized

Reactions . . . . . . . . . 299

11. Properties of Category 3: Outside Interference . . . . . . . . . 307

12. Properties of Category 4: The Losses . . 313 


\section{LIST OF FIGURES}

FIGURE

PAGE

1. Sketch Map of Kenya showing

Kirinyaga District . . . . . . . . 5 
CHAPTER I

INTRODUCTION

Background Information

Disruptive unrest in the form of class boycotts and riots in secondary schools has steadily increased in Kenya since the mid-1970s. These disruptions result in the destruction of school property and contribute to the loss of instruction time. Moreover, the teacher-student relationships suffer a loss of respect. As a developing third-world country, Kenya can barely afford the financial costs of school riots and class boycotts. Understanding the circumstances that surround this phenomenon is important so that school and education leaders may gain the necessary tools to restore normal functioning of the schooling process in many schools. The research question addressed in the investigation was: Why do secondary school students in Kirinyaga district in Kenya engage in $\downarrow$ activities that disrupt the normal schooling processes?

This dissertation is divided into five chapters. The first chapter comprises the description of the setting and an analysis of the national education system in Kenya. This description depicts what a child expects from the system upon his or her entry into a school at the age of 
six or seven. The second section of the chapter is the statement of the problem, as well as rationale and purpose of the study. Included in this section are the definitions of terms, concepts, and constructs found in the literature about the phenomenon of school disruption. clarification of terms such as disruption, crime, violence, and riot, for instance, is important when an empirical study of disruptions is conducted. The second chapter is the review of the related literature. The third chapter defines the methodology used in the collection and analysis of the data while the fourth chapter comprises the substantive grounded theory or the conceptual framework. The fifth chapter is the interpretation and implication of the study. This last chapter also comprises the concluding remarks, the limitations of the study, and recommendations to the practitioner.

To keep the focus of the related literature on the research problem, a summary of each section is provided in order to connect the literature to the research problem. This is in keeping with what Yvonna Lincoln, who is an authority in the field of qualitative research methods, described as "conversation in matrix" in a speech delivered at Portland State University on April 25, 1996. 
The setting

Kenya is divided into eight administrative provinces. The provincial boundaries are not random because they separate different ethnic groups. The eight provinces are further divided into districts for administrative purposes. If a province encloses several ethnic groups, then the districts' boundaries separate the different ethnic groupings in a province. Historically, boundaries were created by the British colonial regime at the beginning of this century. They served the purpose of ensuring efficient administration of the colony and they kept different ethnic groups separate so that they would not form a united opposition against the oppressive colonial administration. The eight provinces and the major ethnic groups and the number of districts in each province are shown in Table 1.

The proposed study focuses on Kirinyaga district which is one of the five districts in Central province. District administration ensures efficient governance of governmental institutions, including educational administration. 
Table 1

Kenya's Provinces and Ethnic Groups

\begin{tabular}{|c|c|c|}
\hline Province & Major Ethnic Group & Number of Districts \\
\hline 1. Central & Gikuyu & 5 \\
\hline 2. Western & Luyha & 3 \\
\hline 3. Coast & Taita, Mijikenda & 5 \\
\hline 4. Eastern & Meru, Kamba, Boran & 6 \\
\hline 5. Nairobi & Metropolitan Area & 6 \\
\hline 6. Rif Valley & Kalenjin, Masai & 13 \\
\hline 7. Nyanza & Luo, Kisii & 4 \\
\hline 8. North Eastern & Somali & 3 \\
\hline
\end{tabular}

Source: Area Handbook for Kenya, 1976

Figure 1 is a sketch map of Kenya showing the relative location of Kirinyaga. The sketches showing other provinces and their districts are in Appendix D. Kirinyaga district is the smallest of the five districts in Central province. It has a population of approximately half a million people. There are 184 primary schools and 48 secondary schools in the district, according to the official records in the District Education office files consulted during the field study. The central government is responsible for most of the primary schools except for a very few privately owned primary schools. However, the government does not take full responsibility for all the secondary schools. in the district. More than half of the secondary schools are community-owned and were built with funds raised from the local residents through fund drives 


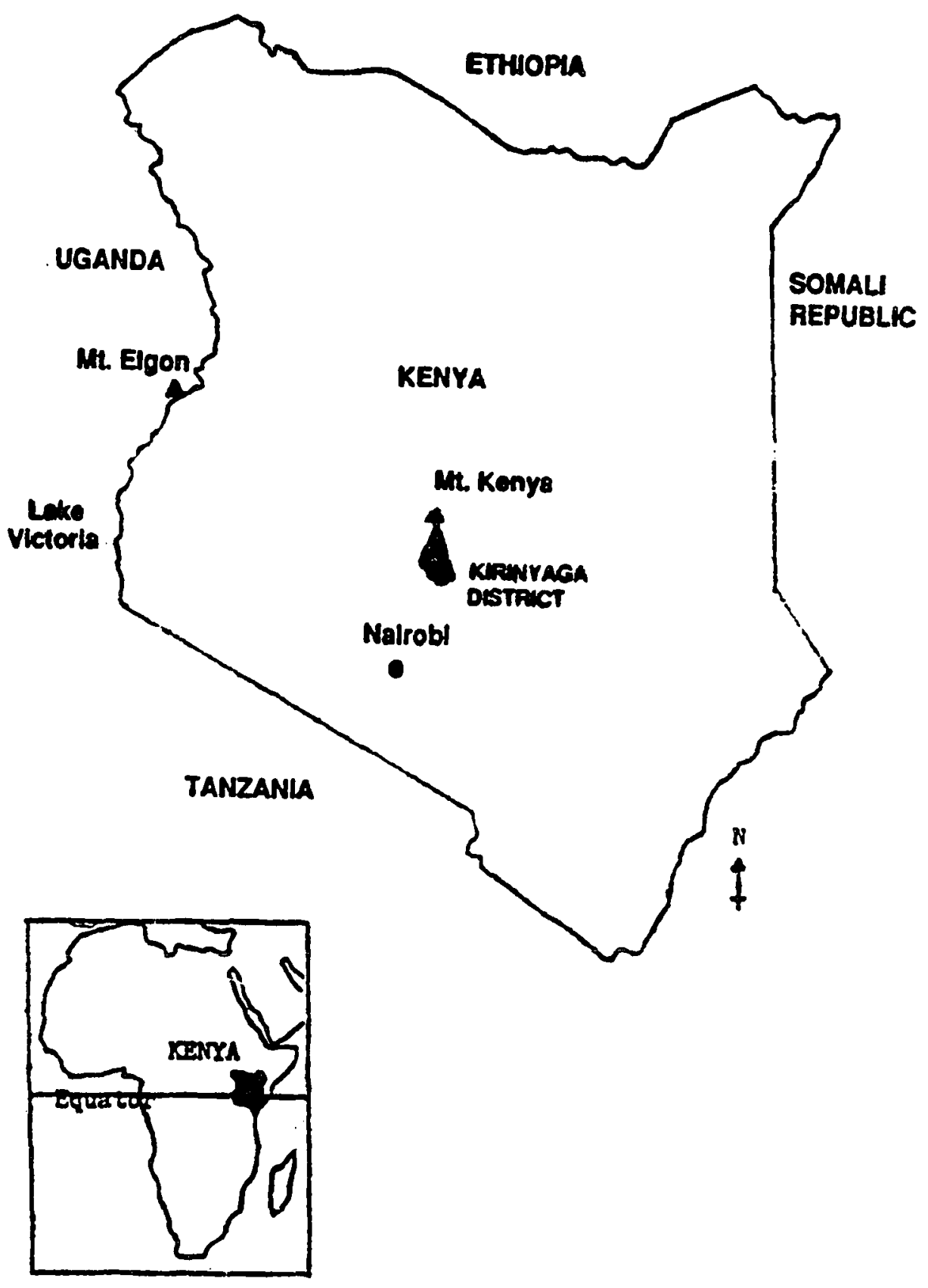

Figure 1. Sketch map of Kenya showing Kirinyaga District. 
popularly known as "harambee." Harambee is a Kiswahili

word that stands for communal spirit, that is, people collecting their resources together to accomplish a common goal. Indeed, politicians have to demonstrate their devotion to the harambee movement in order to endear themselves to their constituents. Since these types of schools are built through the effort of the harambee funddrives, the term harambee describes all schools built through the effort of local communities.

of all the secondary schools, harambee schools have the poorest teaching and learning facilities. The students who are normally selected to study in these institutions are those who failed, or barely passed, the national examination taken at the end of eight years of primary school education. occasionally, the central government upgrades the harambee schools and posts trained teachers who have been hired by the government. If a harambee school acquires teachers from the government its status is upgraded to that of the "district" category. They are district schools because they have a government mandate to admit students from an entire district. Despite the upgrading, the district schools do not necessarily have better learning and teaching facilities than the harambee schools. There is no doubt that students who are admitted into the district schools aspire to study in schools with better facilities. It is likely 
that these students are aware that their chances of going on to college or to professional training facilities in the country are slim. Some of these students actually repeated the secondary entry examination several times in order to qualify for an admission to a good school. However, as district school students they are less likely to pass the national examination taken by every student after four years of secondary school. Most of the schools that have frequent disruptions in Kirinyaga district are the district secondary schools. Whether this observation is a coincidence or there is another covert reason may be revealed in the course of the proposed study.

The focus of this study was to understand why secondary school students in Kirinyaga district engaged in activities that disrupted the normal schooling processes. of the 45 districts, Kirinyaga was chosen for three reasons. First, the district has had one of the most visible disruptions in the country's secondary schools. Secondly, the district is small in size and for practical reasons it was possible for me to go to any school from the District Education office in a reasonable amount of time and at a reasonable cost. Thirdly, by focusing on only one school district, I was likely to get a holistic understanding of the disruptions occurring at various sites. 
Six out of 24 boarding secondary schools in the district category were selected for the study. The schools included in the sample were those district schools that had at least one disruption between 1990 and 1994 . In theoretical sampling, the actual number of "cases" studied is relatively unimportant. What is important is the potential for each case to aid the researcher in developing theoretical insights (Bogdan \& Taylor, 1984).

\section{The Kenyan Education System}

Historical perspective. Prior to the establishment of a British protectorate over East Africa in 1895, and establishment of an effective administration over that area, educational policy was determined by the missionaries who had been working on the Kenyan coast since 1844 (Schilling \& Harik, 1984). By the turn of the century, the East African protectorate was very well established and the colonial administrators, the settlers, and the commercial leaders began to look toward the church for help. Their demand for skilled native labor caused them to look to the missions to break down the tribal solidarity, force the Africans into a money economy, and educate them to be of service to the white man (Urch, 1968).

When Sir James Hayes Sadler was appointed governor in 1905, he took immediate interest in the educational problems confronting the East African protectorate and 
provided the necessary administrative initiative to keep attention focused on education throughout his period in office. Sadler believed that African education would have to be left in the hands of the missions but that the government should impose some uniformity on their education work (Schilling \& Harik, 1984). With this in mind, in 1909, the government invited Professor J. Nelson Fraser, principal of the Training College at Bombay University, to the protectorate to advise on all matters relating to education. Fraser felt that the white man was obligated to urge the native into industrial education because white civilization required the services of the African. Fraser's report in tone and principle was sympathetic to the views of white hierarchy and tended to substantiate its belief that the African must be educated for the benefit, directly and indirectly, of the European. In 1911, following Fraser's recommendation, the colonial government appointed John orr as the first director of education. To assist him in administrating the new founded education department, the governor appointed an advisory board composed of government officials, commercial men, and representatives of the missions and of the settlers' association (Urch, 1968).

In 1915, the government for the first time stepped directly into the business of educating the African by opening a technical school at the town of Machakos. In 
1917, out of a native population of nearly three million people, approximately 30,000 were learning to read and write at mission schools. The missions were given credit for the establishment of 410 schools (Schilling \& Harik, $1984)$.

From the time the colonial government became involved in the education of the Africans in 1915, to the time the country regained her independence from the British government in 1963, formal education can only be understood in terms of political and economic realities of the colonial regime. The political life of Kenya during this period "was largely defined by the settler efforts to create a white man's country" (Schilling \& Harik, 1984, p. 51). The image of a white gentry class was to be sustained by the toil of poorly paid African labor. The settlers demanded that the government pass a compulsory work law which the missionaries opposed. In 1919, the report of the Education Commission of the East African protectorate defined the government's role in education. It was to allocate funds to missionary schools on the basis of the overall efficiency of the school through a system of "payment by result."

In 1923, the African's interest in his own welfare was guaranteed with the pronouncement of the British Government's Devonshire White Paper which declared: "Kenya is an African territory... and the interest of the African 
natives must be paramount" (Urch, 1968, p. 38). In addition to the White Paper, the Phelps-Stoke report created an interest in African education. The PhelpsStoke was a commission appointed by the British government to study the development of African education. The British government assumed a greater role in the education of the indigenous people. The liberal spirit of the League of Nations played a key role in the attitude of the British and other colonial powers soon after World War I. The mid-1920s marked a new stage in African response to the colonial system as a whole and to the education system in particular. African political organizations attempted to affect policy by drafting petitions and memoranda to effect change in the policy enacted for the African education. In effect, the demands for better education went hand in hand with the demands for independence. Through the local Native Councils, Africans reflected the growing demand for more and better schools by voting relatively large sums of money for education. As a last resort, the Africans relied on direct action in the form of school boycotts and development of alternative schools to challenge any objectionable policy. Africans vehemently rejected vocational and industrial education because they realized that the white man intended them to have only such type of education that would lead them to occupy low level positions in the white dominated economy. 
Pushed by the need to pay higher taxes and pulled by the economic rewards of the modern sector, the Africans began to perceive education as a valuable investment. Thus, the Africans of the 1920 s linked western education with books, recitation, examinations, and diplomas. Indeed, they did not have to look far to see that the Europeans themselves sought academic education and not industrial or vocational education. Bowing to the African pressure, the Protestant missionaries established the first African secondary school, the Alliance High School, in 1926.

The Growth of Secondary Schooling Before and After Independence in 1963

As enrollment at the Alliance High school grew and the quality of students improved, the school gradually adapted the structure of a British public school in its curriculum and assumed a role as an elite institution. In 1940, the Alliance students wrote the first Cambridge School Certificate Examination. Alliance High School, approximating the British public school, provided significantly greater opportunities to the Africans for further education as well as more remunerative employment in the colonial economy. Thus, the Alliance High school became the model for the type of education that Africans wanted to have. The academic nature of schooling in Kenya finds its roots in the political arena during colonial rule. The character of secondary education has not 
changed to date despite numerous efforts by the government of independent Kenya to make education more relevant to Kenya's needs.

After independence in 1963, the thirst that the people had for an academic type of secondary education was encouraged by the laissez-fare attitude of the government of independent Kenya. Virtually any community had authority to raise funds through a "harambee" effort. Unfortunately, the secondary schools that the communities built did not reflect the needs of the local areas nor their economy. To date, harambee schools assume the structure of elite schools, which is to teach academic subjects despite the fact that many of these schools do not have science laboratories for the teaching and learning of basic and applied sciences. Additionally, the harambee schools employ untrained teachers who are available and also cheap to hire. When Kenya regained her independence in 1963 there were 151 public secondary schools. The number of secondary schools has steadily grown and in 1994 the Ministry of Education reported that there were 2,660 public secondary schools in the country. Public schools include all schools except the privately owned. Table 2 shows the distribution of the 2,660 public schools in the eight provinces. 
Table 2

Distribution of Secondary Schools

in Provinces--1994

The Provinces

No. of Public Secondary Schools

\begin{tabular}{||l|l|}
\hline Central & 522 \\
\hline Coast & 146 \\
\hline Eastern & 650 \\
\hline North Eastern & 16 \\
\hline Nairobi & 45 \\
\hline Nyanza & 444 \\
\hline Rift Valley & 501 \\
\hline Western & 336 \\
\hline
\end{tabular}

Source: Ministry of Education Statistics, 1994

Due to the overwhelming increase of schools in the secondary sector, there initially evolved four categories of schools: national, provincial, district, and harambee. The criteria used in the classification are: facilities that are available for the teaching and learning processes, qualifications and experience of the teaching staff, and the academic qualifications of the students admitted. However, the government changed the classification policy in 1985 due to political pressure. All schools except the privately owned were classified simply as public. Due to this policy, the government no longer indicates which schools are national, provincial, district, or harambee in status. On paper, the government recognizes only two categories of schools, that is, the 
public and the private schools. However, in practice the admission process is still stratified and influenced by the former classification that indicated excellent, good, and poor quality of schooling. Most importantly, the attitude of the Kenyans toward the former classification was not modified despite the government policy. To date, Kenyans still think in terms of the national, provincial, district, and harambee schools. For the purpose of this study, it is assumed that the four categories comprising the national, provincial, district, and harambee schools functionally classify secondary schooling in Kenya. Most of the best schools are boarding schools and many parents feel that boarding schools provide quality education for their children. These attitudes are reflected in the fact that most secondary schools in all categories are boarding. Although the running and maintenance of boarding schools is an expensive venture, parents are willing to forego personal comfort in order to pay for secondary education at a boarding school.

"National" schools have the best teaching and learning facilities, as well as the most experienced and qualified teaching staff. Consequently, the students admitted to the national schools have the highest scores in the national examination, commonly referred to as the Kenya Certificate of Primary Education (KCPE). All students in the country are eligible to be admitted by the 
national schools, hence the name. The "provincial" schools are a few good schools in a province mandated to select the above-average students in each of the eight provinces. "District" schools admit students of average academic ability. For example, a student who completes his examination in Central province can only apply and be admitted in a national school or a provincial school in Central province, depending on his scores. If that student fails to be admitted to a national or provincial school, he may be admitted to a district school. If he does not qualify for admission into the national, provincial, or district schools, his parents seek a harambee school. The selection process is guided by a score card. A child who obtains the highest score has the best chance for quality secondary education. On the other hand, children with average and below-average academic abilities are admitted in poorer secondary schools; these schools have less-experienced teachers and inadequate facilities for learning and teaching.

To make this process easy, all children fill an application form before they take the KaPE. In the application form, a student indicates four schools that she prefers in the national, provincial, and district categories. After the examination results are published, all children in a district are listed on a computergenerated merit sheet. The student who obtains the 
highest score in a district tops the list while the child who has the lowest score in the examination appears at the bottom of the score sheet of his district. The students who acquire the highest scores are admitted to the best schools (that is, the national or provincial schools), while students with the lowest scores are made to repeat school, to quit school, or to seek a place in a harambee secondary school. Overall, the majority of the students end up in the district and harambee schools. For the most part, the selection process is fairly objective, but it underlines the competitive nature of the opportunities for quality secondary education.

Ordinarily, harambee schools require parents to pay for all expenses including the teaching staff salaries and the educational materials. Until very recently, the government provided recurrent and capital expenditure money only to the national and provincial schools, making it cheaper for parents to educate their children in these schools. However, economic constraints forced the government to require parents in all schools to contribute a substantial amount of money for the education of their children. The perception that the national and provincial schools are inexpensive has not vanished from the minds of many Kenyans, partly because these schools are the best in terms of the criteria discussed above. 
The secondary school admission system of Kenya implies that when a Kenyan child is able to study in a national or in a good provincial secondary school he or she is fortunate. On the other hand, students who are forced to go to the district or the harambee schools are significantly disadvantaged. These children have only a slim chance of passing the national examination, chiefly because they are inadequately prepared and also confront inadequate teaching and learning processes.

During the colonial era, the Africans struggled to have an education that would place them at par with the white people. Through political means, they succeeded in obtaining that type of education. Today, the relevance of academic education that secondary students receive from all Kenyan secondary schools should be scrutinized. The general and certification-oriented education in Kenya established during the colonial era is unable to meet the development needs of the country. This problem is critical because education should cater to the needs of Kenyans 20 years old and younger; they compose $60 \%$ of the entire population of the country (Eshiwani, 1990). To date, the Kenyan education system has been marked by a stiff selection process that takes place at least twice during the course of a student's educational life. Educational attainment has been symbolized by certificates and diplomas linked to preferred categories of employment 
and social status. The most important selection point for a student is at the end of eight years of primary education. At standard 8 (grade 8 ), as many as $60 \%$ of the primary graduates are denied the opportunity of proceeding to a secondary school. The examination at the end of standard 8 and the consequent selection and rejection of students is perceived as visible and objective evidence against official discrimination. It is an objective criterion that gives an equal chance to all Kenyan children who are successful. Since many students compete for a place in a national or a provincial school, students plan to repeat the examination as many times as possible. There has been an increased level of what the World Bank has called educational wastage in Kenya, in recent years. Table 3 depicts the participation rates of the students in Central province. Participation rate is the quantified percentage of the students who should be in secondary school relative to the students who are actually in school. The participation rate depicts the drop-out rate and the rate at which children fail to acquire secondary schooling. In general only about $32 \%$ of the secondary school age population join a secondary school in Central province. 
Table 3

Participation Rates of Secondary Schooling in Central Province

\begin{tabular}{|c|c|c|}
\hline District & Enrolled Students & Participation Rate \\
\hline Kirinyaga & 12,030 & $26.0 \%$ \\
\hline Muranga & 32,008 & $31.6 \%$ \\
\hline Kiambu & 42,249 & $41.7 \%$ \\
\hline Nyeri & 30,505 & $43.1 \%$ \\
\hline Nyandarua & 12,916 & $32.0 \%$ \\
\hline
\end{tabular}

Source: Ministry of Education Statistics (1994)

The participation rate in Kirinyaga is the lowest in the province. The reasons for the low participation are multi-faceted, but the current instability of the secondary schools cannot be ruled out as a contributory factor.

The recruitment to secondary schools has an important social significance for parents and students. Indeed, it can be viewed as a massive national tracking of students based on test scores. The national and some provincial schools admit the college-bound, above-average students. On the other hand, students whose scores indicate average or below-average ability end up in schools that are ineffective and inefficient in teaching and learning. It is obvious the education system is discriminatory of students who should otherwise have the best learning and teaching process and an effective delivery system. However, to satisfy political and social 
demands, education planners provide young people different and unequal chances that operate what Datta (1984) referred to as graded series of take-off ramps into the labor market.

The social implication of a system that leaves a section of the population dissatisfied can be devastating. This by no means suggests that students in some secondary schools become dissenters simply because they are made to study in schools that give them only a slim chance of qualifying for college admission. However, it is reasonable to expect that some students might become dissatisfied after being sent to poor schools. This dissatisfaction could provide a conducive climate for riots and dissension. The education planners, however, are less likely to change the admission system because of the mind set of African policy planners.

Policy planners in Sub-Saharan Africa assume the world is rational rather than messy, and that sound policies would meet no effective resistance (Craig, 1990). The rational model, also known as the functional model, used in Africa treats scarcity as a central and potentially manageable problem. These policies assume that cooperation and consensus are more natural than conflict and that collective actions are rooted in shared values directed toward common goals (Mitchell, 1984). While adopting the rational or top-down model, the policy 
makers in Africa assume that policies have clear and consistent objectives, that the administration is neutral, benign, and well informed, and that implementation is an entirely separate enterprise that occurs after the policy is formulated (Craig, 1990). It is felt that education planners in Kenya will need to make a paradigm shift as far as student admission policies are concerned, because the perceived fairness in giving average students what they deserve may have run its course.

Summary. In 1987, the Kenyan government appointed a commission to review the present education system and make recommendations for education and training for the future. In their review the Working Party stated that educational "wastage in primary education was caused by the large number of drop-outs as well as repeaters within the school system" (p. 23). Repeaters are a worse problem than dropouts, because repeaters still believe that the system can remedy their failure. Since no parent wants his or her child to be declared a failure, students are under enormous pressure to pass the national examinations. Teachers are also under pressure to enable students to pass the examination. In effect, most teachers in both the secondary and primary sectors of the education system are likely to teach to the test, and more students repeat the examination every year. While the government assesses the education wastage in financial terms, nobody has 
assessed the cost of the system to families and individual students, especially when rioting and disruptions occur frequently.

In order to understand why students engage in disruptive behavior, one should examine the meaning that students have formed about the school system in general, and particularly the examination and the screening procedures. Do the students perceive the procedures in the education system as fair and equitable? What do the students feel about the examinations that determine their future prospects?

statement of the Problem

Most societies assume that it is the responsibility of the schools to socialize and educate the young in order to prepare them for the adult world. In order for schools to carry out this responsibility on behalf of the society, students are expected to behave well by obeying school rules and regulations. The undesirable behavior by students in public schools is supposed to be dealt with by teachers and school administrators.

The picture of secondary schools in Kirinyaga district in Kenya has increasingly changed during the last generation. Not only has violence increased, but teachers and school officials have had to request the assistance of the police in dealing with violent confrontations of 
school administrators, teachers, and students. Much of what is taken for granted today would have been shocking 20 years ago. The character of violence has undergone drastic changes. In 1987, for example, following a soccer match between two secondary schools in Kirinyaga, some boys from the school that had been defeated took revenge by beating a student from the school that had won the match. Unfortunately, the boy died about two miles from his school campus. The boy may not have realized why he was receiving the beating because he was not at the soccer field. His school uniform was his enemy because it identified him to his killers. This case is an extreme example of how increasingly violent secondary students have become.

As a teacher and a former school administrator, the changes in the behavior of secondary school students in the district have intrigued me over the years and I have been interested in understanding why students become violent and disruptive. The research problem that will be the focus of this study is to understand why secondary school students in Kirinyaga district engage in activities that disrupt normal schooling processes.

In the past, several attempts have been made to address school disruptions. The board of governors at individual schools interpret student misbehavior as unwarranted and punishable. After an incident that 
provoked an international outcry in 1991 where 19 girls lost their lives, Kenya's president commissioned an investigation to look into the causes of the violent disruptive student misbehavior. As in most policy processes, the commission members, most of whom were politicians, did not try to understand the issues from the point of view of the students. Instead the commissioners determined what the issues were based on their own interests. After the report was out, there was no attempt to change the way that schools did their business. Because there have been no disruptions that have called for an international outcry since 1991, many schools continue to perform business as usual.

Every case of school disruption is dealt with in what the school administrators and the Board of Governors of the affected school perceive as even-handedness. Students are usually sent home for at least two weeks while arrangements for payments in respect of damages to school property and other penalties for wrongdoers are discussed and agreed upon by the school administrators, the District Education office, and the Board of Governors. This procedure has been practiced by many schools in the country for many years and therefore students know what to expect when they riot and/or disrupt normal school processes. 
Literature that addresses the issue of student disruptions contains what adults have determined is the reason for the disruptions. However satisfactory this method may be, a complete picture of why students disrupt the schooling processes cannot be obtained until the participants are asked to tell their stories in their own words.

\section{Purpose of the Study}

The purpose of the study is to explore school disruptions from the perspective of the students. Although literature about students, schools and violence is available, there appears to be an absence of literature about what students think about the violence, the vandalism, and the school disruptions which affect their schooling. The view of this study departs from the perspective that appears in the literature where a student's actions or behavior are seen as a product of factors that play upon or through him or her. The perspective of this study draws upon the understanding of a student as one who is able:

to identify what he or she wants, establishes an objective or goal, maps out a prospective line of behavior, notes and interprets the actions of others, sizes up a situation, checks himself or herself at this or that point, figures out what to do at other points. (Blumer, 1969, p. 64)

The fact that a student misinterprets things or exercises poor judgment does not belie the fact that acts 
by a student are still constructed by him out of what he takes into account. This perspective sees action as conduct which is constructed by the actor instead of as a response elicited from some kind of preformed organization in him or her.

Thus, one tries to elicit in the words of the students what they feel with respect to their schooling and what the meaning of the disruptions is to them. As Blumer (1969) observed, all objects are social products in that they are formed and transformed by the defining processes that take place in social interaction.

Students are seen as living in a world of meaningful objects, not in an environment of stimuli or self constituted entities. Following this argument, it is possible that different secondary school students develop different worlds and these worlds change as the objects that compose them change in meaning. To identify and understand the life of a student, it is necessary to identify his world of objects which includes other students and/or teachers. This identification has to be in terms of the meanings that objects have for the students (Blumer, 1969). Objects in this sense include other human beings.

This study views any joint action, e.g., riot or class boycott, as having a history. In having a history, its course and fate are contingent on what happens during 
its formation. The history is repetitious by virtue of common definition that the school disruption has among its participants. Such common definitions are the source of the established and regulated social behavior that is envisioned in the concept of culture (Blumer, 1969). While the main purpose is to understand the formation of the acts of school disruptions, school records examination will reveal the trends, the kinds, and the patterns of the disruptions. These school records will also provide data showing how many disruptions the selected schools have had during the last six years, what kind of disruptions they have had, and what patterns they portray. The financial cost of disruptions where there have been damages will be assessed and a general picture of the loss of instruction time will be analyzed.

The other purpose of this study is to find the common themes that the subjects use in describing the disruption phenomenon. Their own words will provide meaning for these themes. Ultimately the common themes will be the basis for construction of a grounded theory. According to Glaser and Strauss (1967), grounded theory:

fits empirical situations and is understandable to the sociologists and to layman alike. Most important, it works, provides us with relevant predictions, explanations, interpretations, and applications. (p. 1)

Using grounded theory as a conceptual framework for understanding school disruptions, explanations and 
descriptions will be illuminated. Further, this study will establish the need for study of other areas of violent student behavior such as assault and vandalism.

\section{Rationale of the study}

While the focus of this study is on the problems in Kenya, this inquiry has the potential to inform similar events in other locations. Rubel (1977) posited that secondary school disruptions in the United States had a very brief rise and fall in the period between 1967 and 1970. The major issue of contention was race. In January 1969, the National Association of Secondary Schools Principals (NASSP) reported that $10 \%$ of the principals who had responded to its survey had experienced race-related protests (Gudridge, 1969). Other studies by Bailey (1970), Erickson (1969), and Havighust (1973) reported race as an important issue in the causes of disruptions. Additionally, unlike the college students, secondary school students tended to disrupt schools' normal processes over issues of school organization and basic constitutional rights of dress and speech. The disruptions discontinued after the courts repeatedly ruled in favor of the students. Thus courts forced schools to change many of the administrative practices relating to student rights in ways that met many of the demands of the protests staged by students. This being the case, by the 
early 1970s, public expression of concern had shifted from disruptions to crime.

Rubel's (1977) views are corroborated by Block, Haan, and Smith (1973) who noted:

The unpredicted change in the ethos of the youth from the "silent" generation of the 1950 s to the "protesting" students of 1960 s now followed by the equally unpredicted apparent decline of protest and disruption in the 1970 s has challenged sociologists, and social-psychologists for explanation. (p. 330)

Travers (1982) echoed the same observation when he noted that unconventional political activity, both in society and on college and secondary school campuses, appeared to diminish greatly by the end of the 1970 s.

It is apparent that when secondary school and college disruptions ceased to be of public concern and for that matter an issue in the United States, scholars focused on the issues that troubled schools and the members of the public such as vandalism, rape, and assault in secondary schools and college campuses. With the demise of the concern about school disruptions, there is an absence of empirical studies on the subject of school disruptions. Consequently, there is a notable absence of current literature about this topic. The literature consulted to frame this study is about 20 to 25 years old. This study will therefore provide a more recent empirical understanding of school disruptions thus bridging the existing gap. Disruptions, unlike crimes, are characterized by students acting in a group, undertaking 
an activity calculated to disrupt the functioning of the school using collective protest techniques.

School disruptions are currently of major concern to the schooling processes in Kenya. The focus of this study will be in selected Kirinyaga secondary schools that have frequent disruptions. This study will add to the existing knowledge about school disruptions from a perspective that may not have race as an issue. The fact that this study is set in another country which is different culturally, geographically, and economically provides a broader perspective as to why students disrupt schooling activities.

It is apparent that researchers and administrators were concerned with what they themselves interpreted as the causes of student riots and class-boycotts. These studies (Bailey, 1970; Baird, 1970; Flacks, 1970; DeMartini, 1983) gave a list of factors such as family backgrounds, social class, race, academic ability, and age as the determinants of students' boycotts and protests. However, a phenomenological perspective on why students become disruptive is absent in the literature. There is therefore a need for empirical data reflecting the experiences and feelings of participants.

Additionally, the literature on this topic uses concepts and constructs developed by psychologists and sociologists to fit western culture and developed nations' 
perspectives. Concepts such as middle class, socioeconomic status, income level, and race relations may not have an exact match when referring to a rural population in a developing country. This study will investigate the phenomenon of school disruptions where alternative concepts such as landlessness, modern versus traditional economy, and inability to pay fees and school tuition are perceived as the relevant variables in the target population. Thus, this investigation attempts to broaden the conceptual framework of the causes of school disruption.

There have been inconsistencies with regard to the characteristics of students who protest and the type of protests prevalent in secondary schools. Some of the literature implies that alienated students have no stake in what their schools have to offer and often choose to opt out (Adler, 1974; Wehlage, Rutter, Smith, Lesco, \& Fernandez, 1989). Others argue that the above-average students from middle class families participate in protests aimed at changing the way schools do business (Flacks, 1970). The focus of this study is on students who appear to want to change the ways that their schools do business, but unlike students quoted in the literature, the subjects of this study are neither college-bound nor above-average in academic ability. This perspective also widens the scope of this study accordingly. 
Definition of terms, concepts, and constructs. The literature concerning the issue of school unrest and school violence does not consistently use terms that apply to the same concepts and constructs. In his review of literature concerning school disruption and protest, Bailey (1970) posited that it was difficult to make comparisons of the school disruptions phenomenon because the research he studied used different samples and different definitions. In his review of literature about school violence, crime and disruption, Rubel (1977) noted that it was difficult to prove increases of violence because the methods for recording disruptions involve overlapping categories that precluded drawing hard precise conclusions from the data. He further noted that disruptions calculated to disrupt the functioning of the school using the techniques of collective protest was a major concern to school administrators and the government in the United States. However, after 1975, the major concern in the United States became school crime, violent acts of assault and vandalism (U.S.A. Today News, Nov. 23, $1994)$.

Differences in definitions confirm that school unrest is a complex human behavior. According to Freedman and Kanzer (1970), no matter how complete an analysis of a social event like a strike or riot is, there is always room for more understanding. Historical, economic, and 
political disciplines must be called upon to explain events of such great complexity.

The term "student unrest" is an imprecise term and is attractive to use because the parameters of students' alienation, activism, dissent and disruption are somewhat hard to define. Friedenberg (1972) argued that the phrase "student unrest" is content free: it refers to no specific source of grievance but rather identifies a prevalent pathology" (Friedenberg, 1972, p. 272).

Given the imprecise nature of the term "student unrest," Rubel (1977) defined the concepts and constructs which scholars use in student unrest empirical studies. The generic term "student unrest" refers to misbehavior judged as unacceptable by school administrators. The misbehavior ranges from talking out of turn in the classroom to riots and violence. Within the general term "misbehavior," there are three specific groups: disorders, disruptions, and crimes. Misbehavior may or may not involve violence. According to Rubel (1977):

Violence, either physical or mental, is implicit in the three categories of misbehavior; that is, disorder, disruption, and crime. violence in disorder category may range from the relatively mild trauma of a student talking back to the more serious trauma felt by an entire class when a youngster poisons the laboratory animals and is suspended. Violence, or the threat of violence, is increasingly associated with disruption and crime in schools. (p. 3)

The purpose of this study is not to examine every type of misbehavior that students are involved in. The focus is 
on school disruptions as a distinct type of school

misbehavior. But a definition of crime is fitting because as Rubel (1977) has noted, violence or the threat to violence is increasingly associated with disruption and crime. Since crime and disruptions are associated with violence, professional literature concerned with violence does not distinguish between crime and disruption. According to Rubel (1977) disruption is:

Some kind of organized group misbehavior (criminal or non-criminal), specifically characterized as an activity designed to accomplish a planned goal or establish a point of contention. Any such action undertaken must additionally have the effect of interfering with education of other students. Examples of actions that fit these definitions are: boycotts, sit-ins, walk-outs, and riots. (p. 83)

This definition stipulates that disruption must involve a group misbehavior and should be intended to interfere with education of other students. This study will investigate student disruptions as defined by Rubel (1977). The disruptions that will be investigated are group activities that are characterized by interfering with the education of others. The disruptions that will be investigated involve incidents or activities organized by a group of students that result in school closure and considerable loss of instruction time. The objective of the study is to find out the goal that students desire to accomplish when they engage in misbehavior or the point of contention they wish to establish while they employ disruptive activities. To do this, the problem that guides the 
empirical study is why students resort to acts of school disruption.

crime often is violent but it is distinct from disruption because as Rubel (1977) noted, crime may be the work of an isolated group or an individual. "A crime is an act that is forbidden by public law and that, if committed, can cause an adult to be arrested" (Rubel 1977, p. 4). The purpose of this study is not to investigate crimes committed by individual students, but study criminal activities organized as a constituent part of the intended disruption. The criminal activities in this respect are what smelser (1962) described as "hostile outbursts."

Individual criminal acts differ from disruption because criminals accept the existing social arrangements more than the adherents of a protest. Crime feeds on the existing arrangements by stealing, pilfering, blackmailing, and extorting. on the other hand, participants in a protest may break the law as in riot or revolutionary outburst but the aim is not to profit from defiance. In a riot, law breaking is generally a concomitant of a headlong attempt to modify some aspect of social action (Smelser, 1962). For example, when students attacked another school, the intent was not to profit from the action; the purpose was to punish the opponents so that they might modify their behavior. 
In addition to the definition of concepts and terms that describe student misbehavior, the literature defines the types of students who are involved in violent activities. One such type of student is bent on violating the established authority by any means necessary including acts of vandalism, assault, and theft. The other type of student is one whose primary motive for rebellion or protest is to question the established authority.

In trying to distinguish the empirical difference between disruption and crime in schools, Friedenberg (1972) noted that the two acts of misbehavior involve middle class, college-bound students and the prototype that he refers to as "ghetto" students, respectively. He indicated that ghetto students are increasingly resistant both to the constraints and empty rhetoric of schools. When the ghetto students revolt, their revolt is thus much harder to put down than that of the middle class, collegebound students since the middle class students can be tempted into prescribed routines of protest, negotiation, and atonement. Ghetto students, on the other hand, are innocent of ideology and take over areas of the school life and make it their own. The staff either allows this or re-establishes control with police authority. Sharing few values with the school authorities, ghetto students have little basis for mutual respect and nothing to play bureaucratic games with. If an equilibrium is established 
in a school, school officials are forced to tolerate as much vandalism and truancy as may be needed to prevent their positions from being threatened.

In examining the prototype that Friedenberg described as "ghetto" students, Bailey (1970) observed that this type of high school student is almost wholly absorbed by economic security or social mobility at a comparatively low level, and does not expect much more from education. According to Bailey (1970), the most difficult educational message being attempted by schools is to convince lowincome youngsters that impulsive and spontaneous behavior is not the route to riches. Educators talk about "gratification" and postponement, a hard concept to sell to young people who have a fingernail hold on the world in which they live.

Describing the same concept, Bloch (1957) indicated that when a deprived person has an impulse to strike out, it is foolhardy to attempt to stop his activities with simple counsel of reason. A person who has suffered much deprivation finds the concept of social system meaningless and an abstract entity. Social system on the other hand, cannot be smashed on the face nor can blows be rained on the body politic. It is therefore only feasible and possible to strike an individual or a group of individuals. Even an inanimate object may prove a satisfactory butt of aggression. 
Keniston (1970) observed that there are as many forms of dissent as there are individual dissenters, and any effort to define dissenters by pointing at distinct types runs the risk of oversimplifying at a lower level of abstraction. His theory is that student dissenters generally fall somewhere along a continuum that runs between two ideal types. The first type is the political activist or protester, whereas the second type is the withdrawn, culturally alienated student. The political activist characteristically feels that some injustice has been done and attempts to "take a stand" or "demonstrate" in some fashion to express her conviction. On the extreme side of the continuum is the alienated student. According to Keniston the real campus of the alienated is the absurd. Such students find it psychologically and ideologically impossible to take part in organized activities any length of time, particularly when expected to assume responsibilities for leadership. So while the protester tries to change the world around him or her, the alienated student is convinced that meaningful change in the political and social world is impossible. To an alienated student, dropping out appears to be the real option.

Summary. The purpose of this section in relation to this study was to limit the concepts and constructs that 
the scholars use in describing and the explaining the student unrest phenomenon.

The terms used to describe student unrest have been delineated and this study will concentrate on group activities that are organized to achieve an identifiable goal or to establish a point of contention. This study will interpret an act as a school disruption when student misbehavior significantly interrupts the education of other students. In this study disruption is also the term used to indicate boycotts of meals, classes, or other school activity. Additionally, any behavior that involves a group of students that significantly disrupts the learning process of all or some of the students in a school is termed a disruption. This study will not address the issue of student prototypes who are likely to be engaged in one type of disruptive activity or other as defined by Friedenberg (1972). The view that this study adopts is that students act toward the objects that have meaning for them. Since the subjects live in a boarding school, this factor provides them an opportunity to have common meanings of their every day experience which are formed as they interpret what they encounter individually and collectively. This view does not classify any students as alienated or activists until they have an opportunity to give their story and their perspective. 
Reflections and stories pertinent to disruptive activities are relevant to this study. 
CHAPTER II

\section{LITERATURE REVIEW}

A topical organization of the related literature gives an insight into school disruptions. This literature helps to explain some of the factors that are believed to be the causes of youth problems in general and are therefore relevant in explaining some student misbehavior. This study was guided by six ideas rooted in theoretical underpinnings that provide a useful understanding and meaning of the riots and boycotts among adolescents.

These ideas are:

1. Adolescence is a period when young adults form and build an ideology which may be radically different from their parents' ideology and that of other significant adults (Block, Haan, \& Smith, 1973).

2. Social change results in turmoil, confusion, and conflict which affects schools since schools cannot be isolated from the society within which they exist (Eisenstadt, 1965).

3. Collective behavior is the result of perceived structural strains or problematic situations. Activists protest with the intention of providing solution to the perceived problematic situations (Smelser, 1962). 
4. Student perspectives on school riots and class boycotts are as important as the perspectives of teachers, education officials, or parents.

5. Every secondary school is a social system in its own right and has its unique ethos and socio-political framework (Iannaccone, 1991).

6. An alienated person is likely to reject conventional norms and values through rebellion or withdrawal (Keniston, 1965).

To put into perspective the social-psychological and age determinants of behavior in young people, studies and theories of adolescence, generation gap, and social change provide a framework which underlines the factors that make students more likely to have conflicts with the adults in their lives. On the other hand, literature and research on collective behavior and social change provide an analytical framework for school disruptions. Since a school is a social system in its own right, it is important to understand how the factors analyzed and discussed in the theories are played in the every day life of a school. In order to understand how social and political factors are played out in a school, a socialpolitical framework is employed. A socio-political framework portrays the conflicts and confrontations in the relationships and interactions among teachers and students of a school. Ultimately, the socio-political framework is 
employed to interpret the conflicts that lead to disruptive behavior.

Adolescence

Havighust (1973) has defined adolescence as the age period from 12-18, though occasionally extending the upper limit to age 20. Since most students attend secondary schools between the ages 15 and 18 , secondary school students can be defined as adolescents. According to Coleman (1965), school encompasses the total community of adolescents. In other words, the adolescents have their own little society with special symbols and language, special interests and activities. Their society is of people without responsibilities or subject to outside control. While students can afford to take risks, the adults in society cannot afford to take such risks because they are saddled with family and other responsibilities. Scholars underscore the fact that adolescents have a prolonged dependent status and delayed adult responsibilities (Coleman, 1965; Block, Haan, \& Smith, 1973; Cross \& Pruyn, 1973; Fuhrmann, 1985). It is also in adolescence that young people take charge of themselves. Their lives become their own while they adopt a private life which they do not share with their parents. This process also includes the formation of an ideology. An adolescent between the ages of 13-15 experiences feelings 
about himself or herself relative to abstract ideals. The adolescent is able to articulate a set of ideals based upon what could be real for one's self and one's society and evaluate oneself relative to those ideals. The scrutiny of self in relationship to historically significant members and who were previously unquestioned is a daring maneuver emotionally that is not handled with skill or grace by many adolescents (Keniston, 1970; Block, Haan, \& Smith, 1973; Havighust, 1973).

In favorable cases, the outcome of late adolescence is a shift in emphasis from experiencing, questioning, and experimenting to integrating. Developmentally, late adolescence is when the young adult adjusts to outer reality as she recognizes aspects of life that cannot be changed or helped. An adolescent is at this stage when he or she develops a political and social sensitivity to confront life with its disparities and contradictions. After integrating the professed values and ideals of society and the actual societal context and contemporary institutions, young people may decide to protest or dissent against their social institutions, especially the school. Alternatively, a young person may engage in prosocial action or may decide to be apathetic and withdrawn (Keniston 1965; Block, Haan, \& Smith, 1973). Depending on various factors such as social class, education, academic ability, and rearing practices 
adolescents react as rebels, dissenters, radicals, activists, beatniks, or constructivists (Flacks, 1967; Watts \& Whittaker, 1968; Keniston, 1970; Block, Haan, \& Smith, 1973).

There are two dimensions in conceptualizing the political stances and social activity of the adolescent. on one hand there is an indication that a middle class background gives students an advantage in school and unintentionally provides them with a sense of efficacy. Thus adolescents reared in middle class homes are more likely to be principled in moral judgment. According to Kolberg's Moral Judgment Scale, the principled young adults have an orientation that is ordained by an appeal to logical universality and consistency (Block, Haan, \& Smith, 1968). Additionally, they are more likely to have higher levels of education and to have overcome feelings of seclusion at adolescence (Flacks, 1967; Keniston, 1968). Since these young people are principled and are academically and intellectually above average, they are also more likely to take a stand on social issues and to dedicate themselves to fight, demonstrate, and protest actively against policies and institutions which they perceive as violating their sense of human justice.

On the other hand, there are other young people whose moral orientation is opportunistic and premoral. This group is likely to have inconsistency between indulgence 
and intrusiveness in the way they are reared leading to a conflicted, unsatisfying relationship, and a plausible dynamic basis for rebellion. These adolescents appear not to have been encouraged by parents and other significant adults to evolve a sense of responsibility and autonomy. They are concerned with personal fulfillment and their protest or dissent is likely to flow from self-centered impulsiveness and opportunism.

Block, Haan, and Smith (1973) have identified other adolescents who are less likely to engage in disruptions. These are the alienated youth who have rejected values and the roles of the society and elect to escape from the culture by opting out. Then there are the constructivists who are committed to effect social change in ways that involve working within the existing frameworks. Such young adults lack the zeal of the revolutionary but feel committed to work constructively to alleviate the ills of society. Finally, there are the young people who accept the traditional values and authority of their society and are committed to maintaining the status quo.

If the theory of adolescents analyzed above can apply to all adolescents, then school disruptions that we observe in Kirinyaga district are provoked by the principled high school students who are fighting against perceived injustice. on the other hand, the riots and class boycotts could be organized by the immature, 
indulgent students who have no sense of responsibility, who lack autonomy, and whose dissent flows from selfcentered impulsiveness or opportunism.

Larkin (1974) argued that student unrest mirrors the larger society and protest is not so much directed at the personnel who are in positions of power but at the structure of power. One way to attack the structure is either to violate, circumvent, or ridicule the rules. Thus by being rude and indecorous, disruptive, obscene, destructive, and disrespectful to people, students attack the organization and power structure. Disruptions are therefore meant to attack the moral basis of structure.

Erickson (1969) corroborated Larkin's (1974) argument by suggesting that student disruptions are fostered by a general conviction that few people listen to the quiet or powerless people and by amassing and accumulating power in whichever way possible, including destructive behavior, they pave a way to acquire power. And as coleman (1965) suggested, a high school is a society composed of people without responsibility whose norms are to encourage leadership that asserts itself against adult demands. Thus protest and dissension amongst adolescents is likely to breed into confrontations and disruptions in high schools. After all it is in high schools where large numbers of adolescents congregate and interact with one another. However in Kenya where not all adolescents 
attend high school, values and norms of the young people outside the school may also affect the adolescents within the school system.

The Kenya secondary school student. The concept of adolescence did not exist in the traditional Gikuyu society. This concept can appropriately be viewed as one of the factors associated with the modernization process. In the traditional Gikuyu society, adolescents had an abrupt break with childhood. This break was signaled by the ability to endure the circumcision pain with stoicism (Davison, 1989).

The social system of secondary school students in Kenya extends beyond the school system because not all adolescents are able to go to secondary schools for a variety of reasons, which include failure to pass the examination after the primary schooling, lack of money for the tuition and boarding fees, or sheer choice. One may therefore argue that the students in secondary school in Kirinyaga district in Kenya are influenced by factors outside the school. Additionally, there are many schoolassociated problems that a secondary school student in Kenya has to think about. For example, pressure to pass the qualifying examination that he sits for after four years of secondary education and fear that his parents may not be able to pay the tuition and school fees in time. From the above suggestions, one may argue that an average 
Kenyan secondary school adolescent has a lot of ambivalent situations that he has to confront while he is at school.

As Block, Haan, and Smith (1973) have indicated, adolescence is the period when young men and women develop their ideology with reference to their experiences. This study will investigate the ideology that is formed by young people in Kirinyaga district.

The study will be investigating the meaning of the social and abstract objects in the adolescent's world. For example, what is the meaning of school administration? What is the meaning of the learning and teaching processes? What is the meaning of class boycott or riot? How are one's classmates viewed? What are the general patterns of the relationships and interactions between students of different age groups and classes? What do these individuals value? How do they define power, popularity, and self-worth? These are some of the probes that will be used in the investigation in order to understand the individual ideology of students and their feelings about the social and abstract objects that exist in their world. Generation Gap Between High School
students and the Teachers

Social changes that took a century to occur now take place in less than a generation. Recently, new family structures, technological advancements, and uncertainties 
of a known world have occurred in less than a generation (Keniston, 1970). As a result, the past grows progressively more remote and irrelevant psychologically. secondly, the future too grows more remote and uncertain. The kind of society that today's students will confront as mature adults is almost impossible for them or anyone to anticipate. of the greatest psychological importance, the relations between the generations are weakened as the rate of change increases. The wisdom and skills of fathers cannot be transmitted to sons with the assurance that they will be appropriate for them. Truth is as often created by children as learned from parents.

In the traditional societies of our parents' generation, identity was defined by the society. Today's generation has to create an identity that will link their past, the present, and the future. As Keniston (1970) suggested, the achievement of identity for an adolescent today is difficult because the past generation has become more distant and the future more unpredictable. The task is more difficult in a rapid ideological change because it involves selecting from many different ideologies that are the basic outlooks on the world which orient one's actions in adult life.

The sudden and rapid changes that have taken place in Kenya in the last 90 years have had significant influence on intergenerational differences. To begin with, there 
was colonialism and its oppressive regime, then a decade of liberation struggle and independence. Independence came with a rapid rise in population growth, significant ethnic conflicts and an overwhelming influence of the industrialized world and an international outlook in our national culture.

These factors have produced sudden changes that find the Kirinyaga district residents unprepared. Once the changes have been assimilated in the course of time, the historical truths have been distorted, and at times completely destroyed, leaving the future generations with a sense of generation discontinuity. For example, the century-old notions of land ownership and the extended family connections have been destroyed. Due to lack of generation continuity, what the parental generation says today does not remain relevant to the young.

In a similar observation, Block, Haan, and Smith (1973) suggested that the very rapidity of change makes the past irrelevant to the present and the continuity with history that eases the task of identification and adaptation is weakened. The generation gap is widened by accelerating changes. Patterns for the solution of today's problems cannot be found in the experiences of the past, thereby leading to "dehumanization." In the traditional Gikuyu society, there was nothing as important as knowing one's social status which was determined by age 
and, as Davison (1989) noted, a girl or a boy did not question the wisdom of the elders. An explicit part of the ritual process was learning the social mores that governed adult behavior, that is, learning how to behave around the elders and how to act with different agegroups. Consequently, transition to a new age status required learning a new set of behaviors identified with particular social status.

One of Davison's (1989) research subjects, an elderly woman in her 80 s captures this age status behavior code when she says:

We who are older, can have trouble from children who attend school because sometimes they can abuse (in this context the person is referring to verbal abuse) somebody who is not schooled - even an older person like a parent! Long ago, when I was growing up, nobody dared to abuse somebody in an older age-group. (p. 25)

Commenting about this remark, Davison (1989) noted that "older Gikuyu women view school as the institution that breaks normative social structures and causes lack of respect for elders among children and grandchildren" (Davison, 1989, p. 217). The older people feel defenseless in the face of the young people's power. The result is not different from the generation gap that exists between immigrant parents and their children. A gap thus develops when the children have access to schooling in a new country. 
The feeling that students should respect school authority is rooted in strong cultural mores. Since the older members of the school community feel they deserve the respect of the young members of the society, students and school administrators rarely have platform to discuss school issues. School rules and regulations are designed and enforced by the authorities. Whenever there is a school disruption, the administrators always use might and forcefully ask the students to leave school campuses. Sometimes they request the police officers to assist them to throw the "rascals" out. The wrong doers are punished and penalized for their participation in what is normally perceived as gross student misbehavior and which can be corrected by heavy punishment. The question remains as to why students continue to disrupt schools even when they expect stiff penalties and punishments.

In describing the concept of "generation gap," Mannheim (1972) identified it as an identity in time, embracing related groups who are embedded in a historicalsocial process. According to this theory, a generation is limited to specific potential experiences which are predisposed to a certain characteristic mode of thought and experience.

So when the older woman in Davison's (1989) study suggests that schooling is the cause of differences between age-groups, she is expressing the perception of a 
distinct generation unit. Generation units are sub-groups of young adults who, during specific periods in history, develop a consciousness of common purpose with others in their generation and a willingness to act upon the beliefs that emerge from it (Mannheim, 1972).

Following the lead of this theory, one may argue that today's generation does not consider the "truth" that the older generation deserves their respect. This is partly because the adults' attitudes and behaviors are often directly challenged by the adolescent's emerging consciousness and ideology. The membership of adolescents in a generation unit can have an impact on the parentchild relationship or for that matter on the studentteacher relationship and can be a source of conflict between the generations.

Research by Fendvich and Lovoy (1988), DeMartini (1983), and Bengston and Dunham (1994) demonstrated that the activists of the 1960s maintained a similar political stance for many years after the 1960 s protests. The research emphasized Mannheim's thesis that generational units share a common political consciousness. Mannheim's theory is corroborated by Battleheim (Bengston, 1972) who suggested that since the family today is playing a decreasing role in socialization of the young, the older generation is no longer the only source for the knowledge of coping with the world. The factors that traditionally 
mitigated generational conflict are feeble and inoperative. Mead (1970) explained that different generations are pulled apart by different environmental experiences. Thus, a 20-year-old in 1930 is different from a twenty year old in 1970 and 1990. Furthermore, in societies that are undergoing rapid changes, for example, the Gikuyu society of Kenya, generational discontinuity is more adaptive since old responses become inappropriate to radically new situations, and parents must learn from their children. One may argue that the perceived lack of respect the older generations experience is based on the premise that adolescents lack the skill and tact of expressing the inappropriateness of old responses to new situations.

As Mead (1970) indicated, the perception that schooling has been responsible for the changes is because for the first time human beings throughout the world have information about one another and responses to one another has made the world a community united by shared knowledge. Indeed, world wide rapid air-travel and globe encircling television satellites have turned us into one community in which events taking place on one side of the earth become immediately and simultaneously available to people everywhere. More importantly, these changes have taken place almost simultaneously within the lifetime of one 
generation and the impact of knowledge of change is worldwide.

In the midst of the rapid changes, the older generation's interpretation of events binds them to the past, to the world as it existed in their childhood and youth. In the Gikuyu society, there is a culture shock when the young people do not appear to respect the older generation. School riots and boycotts that have sprayed the school landscape are still interpreted through the eyes of the older generation who could not have dreamt of being disobedient to their teachers or the education officials.

According to Mead (1970), the young people in developing nations are lashing out against the controls to which they are subjected to, for as children of pioneers, they have no access to the landscape memories which still move their parents to tears. Thus, the young generation in Kenya cannot share their parents' responses to past events.

on the other hand, the older generation does not know what the children know. No generation has ever known, experienced and incorporated such rapid changes. Today's generation has watched the sources of power, means of communication, the definition of humanity, the uncertainties of a known world and limited world all change. At the breaking point are two radically different 
and closely related generation groups. The older generation knows that the younger generation will never experience what they have experienced and the older generation can never experience what the younger generation has experienced. The sense of distance creates a feeling of lack of connection between the generations (Mead, 1970).

Summary. Traditional societies assigned definite and permanent identities to their members. In modern societies due to the unprecedented rates of geographical mobility and travel and the enormous amount of information available through the media, youths are aware that one's culture, including its basic values, is relative in space and time.

One basic cultural value amongst the Gikuyu people is respect. The meaning of respect is deep and far reaching. It means that a young person cannot answer back, be rude, loud, or disobey an older person. When formal schooling was introduced, students were also expected to be respectful of their teachers. Being respectful of one's teachers likewise meant that students could not talk back, disobey, or be rude to teachers under any circumstances. Foote (1970) argues that value is discovered in experience, and experience is limited to what one is exposed to from birth. When students go to a secondary school, they broaden their experience by sharing the 
experiences of other students and the values that they thought were immutable are made relative. One may argue that secondary school experience enables students to change their views about the meaning of respect. According to Eisenstadt (1965), various types of youth organizations always appear with the transition from traditional or feudal societies to modern societies. Such youth organizations in Kenya are highly visible in the transportation business which is run by youths popularly known as the "makanga." To compete for customers, the "makanga" were among the first group of young adults to break the code of respect. They were rude, rough, and loud toward all people of all ages, something virtually unknown in the traditional society. One may argue that secondary school students are influenced by the very dramatic "makanga" code of ethics. After all, schools have open boundaries and what happens on the outside has direct influence on what goes on inside the school. This supports Bailey's (1970) contention that the causes of high school disruptions run on a circular continuum from the wider society through the schools and back to the wider society.

\section{Alienation: Causes and Effects}

Alienation theory is considered in this study because it helps to explain some behavior that is unique to high 
school students in particular and the young adults in general. In a research study on alienation, Keniston (1965) reported his findings of a qualitative study of a group of 12 extremely alienated students at Harvard University. He argued that in psychology there is an outstanding tradition of studying the extreme in order to understand the typical. His study cannot be used to generalize about the behavior of the alienated, but it can be used as an analytical tool to understand the problems and stresses of typical lives and the processes by which others attempt to cope with problems and issues.

In every era and society, at least a few exceptional individuals have spurned their societies and from the ranks of the alienated in every age have come misfits, malcontents, innovators, and revolutionaries who have changed their world for the better to suit their discontents and idealism. However, alienation in modern industrial society is new. "It is a new form of rebellion without cause, of rejection without program, of refusal of what is without a vision of what should be" (Keniston, 1965, p. 6). This attitude is corroborated by watt and Whittaker (1968) in their study conducted among the nonstudents who lived around Berkeley University, California, in the $1960 \mathrm{~s}$. This community of young people referred to as the "fringe" or the "underground" population was characterized by need for self-expression, identity 
seeking, and mild social defiance. According to watt and Whittaker's (1968) study, the majority of the non students had prematurely discontinued their formal education with 60\% stating that they had completed from one to three years of college. They appeared to have dropped out of school of their own volition due to basic dissatisfaction with the education that they were receiving. The predominant theme for dropping out was boredom, meaningless curriculum, and lack of creativity. According to Keniston (1965), an extremely alienated person is more likely to have high scores on distrust, pessimism, resentment, anxiety, egocentricity, a sense of being an outsider, the rejection of conventional values, rejection of happiness as a goal, and a feeling of distance from others. An alienated person is also more likely to be disaffiliated along with a pessimistic rejection of any social, political, or civic commitment.

The reason why young adults become alienated is rooted in two major traditions. In the characteristic American view alienation is a "personal problem." This view implies that the cause of alienation lies in individual life and "personal" pathology. The other tradition views alienation as a reaction to the stresses, inconsistencies, or injustices in our social order. The alienated youth is seen as the victim of his or her society and the problems are imposed upon the youth by a 
tyrannical system or by politicians who ignore people's interest or by employers who exploit the labor of workers. This line of argument would view alienated students as victims of an educational system or an individual school that is not sensitive to their needs. This second case views students as victims of an economic system that denies the educated young persons employment and social mobility (Keniston, 1965).

The focus of this study is on individual students and the meanings that social situations have for them. The focus is also on students as members of a social system and on what meanings their social world has for them. The two traditions have some relevance to the purpose of this study.

The first concern is how students in Kirinyaga district interpret their education system. In this context, the sources of conflict appear to reside in three overlapping areas: the goals and functions of the school, the nature of the roles as defined by these functions, and the style in which these roles are played out (Spady, 1974). The social organization of the school system in Kenya, as noted, tracks students according to their academic ability and labels most of its graduates as failures if they are not able to pass the two most important national examinations. The tracking system gives a clear message to all students. To the above- 
average and college-bound students, the message is that they have a chance of getting professional careers because these students are selected to the best schools in the country and have the chance of social mobility in the future. Other students who are not in the exclusive group are equally given the message that their chance of a social mobility based on professional training is slim. One may argue that the tracking method treats students like standardized abstract units. All students in the country are listed according to their scores in the national primary and secondary examinations. The best students are accorded opportunities that the poor are denied.

Newmann (1989) has argued that human relationships are alienating when people are treated as objects or standardized abstract units. As can be expected, the students who do not succeed to go to the schools of their choice or those who go to schools that they know offer limited chances for passing the examinations are less likely to develop social bonding with their respective schools. Instead, they are more likely to feel unattached, uncommitted, uninvolved, and may not believe in the norms and activities of their schools (Wehlage et al., 1989). In other words, these students do not share the educational purposes offered to them. 
Newmann (1989) argued that clear and consistent goals may reduce the alienation of students. Whereas there are clear goals for schools that prepare the college-bound students, the goals of the majority of secondary schools are rather inconsistent and at times ambiguous. There are some parents who take their children to the harambee or district schools to give them a chance to mature or to avoid having them stay at home. on the other hand, some parents want their children to get good certificates. These are conflicting goals and may add to the alienation of students.

Additionally, when the adolescents go to schools which have inadequate teaching and learning facilities, they are encouraged to develop a sense of cynicism, making the students acutely aware of the inequality which exists in educational opportunities. The cynicism is likely to help develop a perception that the students do not have a stake in the world of opportunities for the advancement and market placement. If and when the students develop this perception, the school loses its power to control them because the school people no longer possess critical resources in the name of certificates to manipulate. As a consequence, the students may feel justified not to be involved in the instructional processes for they have no fear of any negative future consequences of their poor academic performance (Spady, 1974). 
In the worse case scenario, Spady (1974) suggested that students who are disaffected by a school may even reject grades as legitimate indices of their performance as well as reject competition as context for academic involvement. This disaffection may ultimately lead to withdrawal of support and manifestation of alienation which underlies conflict and unrest. Alienation is a result of an individual or individuals' rejection of major cultural goals or the institutionalized means such as the schooling process and the school system as a whole. The response to alienation is either innovation, ritualism, retreatism, or rebellion.

To corroborate Spady's (1974) theory of alienation, Adler (1974) suggested that student revolt is one of the ways students react to a series of perceived deprivations resulting from their social position and condition. One such condition is the personal insecurities of students in the face of the ever-growing competition of the modern professional life as well as their uncertainties as to their future. In reaction to the deprivation perception, students are more likely to search for a milieu of peers who are in similar position and in a group they seek to ease their anxiety through student militancy and disruptive activities. Although the militant students are as a rule the minority, it appears they are "representative minorities" and they represent a much 
larger group of students, who, although not members of militant group, tend to sympathize with them and lend them their passive support. According to Adler (1974), conditions of development are anxiety-provoking and challenging to students. Students are affected by personal and general uncertainties entailed in a process of rapid and far-reaching transition. This theory is supported by Eisenstadt (1965) who argued that emergence of all youth groups is associated with the breakdown of traditional settings, the onset of modernization, urbanization, secularization, and industrialization. The period of rapid social change is marked with crisis of meaning, people find much that does not make sense and little that is basic and reliable to hang on (Adler, 1974).

For adolescents there is a psychological overload as they try to adhere to rules at home and at school and at the same time deal with the inherent conflict of values. The psychological overload, according to Adler (1974) leads to adolescents' aggression and apathy. The revolt and apathy emanates from the lack of confidence in the adult systems which embrace corruption and double standards. For example, how can a teacher tell students that they must not smoke or else they will be punished while students see their teachers smoking in the school campus every day. Or what is essentially wrong if an 
adult instigates a riot and students go to the road and demand that they are paid a fee before any motorists is allowed to pass in peace?

In reactions to the double standards which pervade the school polity, some students choose to challenge the power of the school by revolt that forms the dramatic and visible "student unrest" commonly referred to as protest or rebellion. other students react by passively accepting fate within the school through apathy or withdrawal (Spady, 1974).

The alienation theoretical framework discussed by Spady (1974), Adler (1974), and Eisenstadt (1965) can be used to analyze the factors that lead to school disruptions in Kirinyaga district of Kenya. Kenya is a rapidly-changing society and the changes are likely to make students feel uncertain about their future, especially when they witness how difficult it becomes for their school mates to get employment in the formal economic sector. The competition in the labor market grows each year for students with high school certificates. Additionally, Kenyan society has become increasingly corrupt and many students know that bribery is no longer immoral in most systems controlled by adults, including the school system itself. If, as Fuhrmann (1985) argued, adolescents are unable to deal with the inherent value conflicts in the adult system without 
becoming aggressive, it appears that a Kirinyaga adolescent faces a tremendous dilemma when dealing with the teachers, head teachers, parents, and other adults in his or her secondary school and the society at large. Summary. Alienated students feel rejected by the school and therefore they, in turn, feel justified rejecting it. A student will feel uncommitted if and when he or she concludes that conformity to school demands do not yield a worthwhile pay-off.

According to Blumer (1970), a human being acts toward his world by inspecting it, ascertaining its meaning, and determining its possibilities and then directs her action with regard to it. Thus one acts toward one's world, interpreting what confronts her and organizing action on the basis of that interpretation. Using this theoretical framework as an analytical tool, it is possible to identify the areas of school life that students reject, find worthless and illegitimate. After all, students act not according to what the school is supposed to be, or what administrators say it is, but rather according to how they see it.

The literature and research on alienation does not explain what motivates an alienated person to protest or rebel, or what meaning an alienated person is likely to derive from protest activities. Using symbolic interaction as an analytical framework, one should be able 
to find out why uncommitted students and their peers may desire to rebel against the school. This section suggests the questions as relevant to addressing the major objective of this study:

Why are students uncommitted, uninvolved in the school activities? Do students feel that the school processes, e.g., certification and selection, are legitimate and fair? How do the students see their teachers, their school headmaster or headmistress? What do they say is the main purpose of their being in school?

\section{Social Change and Its Effects}

Social change underlines the fact that the things which were once held as immutable and timeless are replaced and lost or transformed in the cause of human history (Bloch, 1957). Social change underscores reasons for alienation, for generational differences and other social upheavals that beset the so-called Third World countries. A basic unit of Gikuyu society was the "mbari" or lineage which consisted of the descendants of a single man. The members of a "mbari," who usually numbered in the hundreds, were the joint owners of a piece of land called their "githaka." The original acquisition of a "githaka" took place when a man undertook the first clearing of virgin land or when he purchased it. Land was distributed to members of each successive generations 
according to their need for it. When a "githaka" became overcrowded, more land was acquired or part of the "mbari" split off and acquired more unclaimed land elsewhere. As generations followed each other the Gikuyu people were expanding the boundaries of their territory. In the normal course of events, each person was able to claim a piece of land for his use as the need for it arose (Leo, 1984).

It might be rightly argued that colonialism was the origin of the current changes which have spurned this century. When the Europeans arrived around 1895, they claimed unrestricted right to seize unoccupied land. Such seizures robbed the Gikuyu land tenure system of its dynamic element and very quickly brought about distortions, not only in land tenure but also in the social system as a whole. From the Gikuyu perspective, the presence of Europeans on the fringes of their territory meant the end of a way of life. The colonial system began to spawn landlessness, inflicting from the Gikuyu point of view an unheard of deprivation and committing an unspeakable outrage (Leo, 1984). Landlessness may have many meanings. Its meaning in industrial countries is different from that of a largely rural agrarian society like Kenya (International Labor organization Geneva, 1972). In a more recent study set in a location in Kirinyaga district, the researcher indicated 
"a major concern of these women today is that there will be enough land for all their children" (Davison, 1989, p. 16). To have a piece of land in Kirinyaga district is the ultimate achievement of a Kenyan dream just as owning a house in Portland, oregon is an aspect of realizing an American dream. This notion is echoed by one of Davison's subjects who remarks, "To be without land, say the Gikuyu, is to be nothing" (Davison, 1989, p. 84).

In the pre-colonial Gikuyu society, relationships among members of a community were subtle and complex but they tended to bind all the members closely together. The sources of solidarity in the Gikuyu life were the extended family and the practical interdependence within the tribal unit. The network of kinship embraced all the needs and the activities of life. Adherence to the demands of the kin group gave the individual a sense of security and identification, for a person's kin group was one on which he could depend and to which he owed allegiance (Urch, 1968).

When the land was taken by the Europeans, some Gikuyu people realized that opportunities were closed to people without the European style of education. Thus, the Gikuyu were lured to join the mission schools. One may argue that the breakdown of the Gikuyu culture was so rapid because the Gikuyu way of life, like other African culture, did not consist of collections of beliefs and 
customs which existed independently of each other, parts of which might be changed without affecting other parts; rather, culture was an indivisible whole in which various parts were interdependent. These parts included systems of land holding, kinship ties, religious beliefs, and modes of decision-making (Thompson, 1981).

The impact of western society and money economy tended to bring about the emergence of the "individual" Gikuyu from his corporate society. The Gikuyu child was removed from his traditional role in the labor force and educated to be of service to the new society. The formal education undermined traditional pattern not only through the introduction of the western culture, but through the offer of an opportunity to acquire individual wealth through the service of the Europeans (Urch, 1968). Additionally, with the movement to the towns away from the traditional enclave, the Gikuyu became socially disorganized. And, as Thompson (1981) indicated, relationships between people is central to the concern about social change because social change is fundamentally a question of changes in relationships between individuals. The growth of the modern sector tends to weaken the pattern of relationship which enabled communities in the traditional sector to preserve their own way of living. The problems are exacerbated to date because the patterns of relationships between the 
traditional and modern sector are difficult to integrate in a single society.

\section{Modernization/Development}

Many people assume that a developing society must be patterned on the model of the modern industrialized societies. Based on this notion, the western world offers African societies shortcuts in technological and organizational practices which are readily adopted. Development is conceived in economic terms since poverty is perceived as the root cause of under-development. Following this line of argument, educational planning is no longer the exclusive concern of the ministries of education but an integral part of general development planning (Thompson, 1981). Education is widely accepted as a major instrument for promoting socio-economic development. The motivating factor is that large investment in education would pay off in economic terms. This perspective reinforces African leaders' long-standing faith in education as a means of remedying a whole range of social, economic, and political problems. Just as governments believe education is an economic investment, individuals aspire to enroll their children into the education system for an economic advantage. And so in Kenya, educational attainment, which to date is symbolized by certificates and degrees, is closely linked in preferred categories of employment and social status. 
When so much is at stake, anxieties mount high as examinations and admissions time approaches (Coombs, 1968).

After the students leave school, they face the reality of a dual economy, the traditional and the modern ones. The modern economic sector reflects a priority emphasis by the capitalist state on the production of goods for consumption abroad by high income groups. The traditional economy, on the other hand, produces "wage goods" that are consumed by domestic earners. The duality in the production sector reflects high wages in the modern technology and complex division of labor. There are also less wages and less extensive division of labor in the traditional sector (Carnoy, 1977).

The devastating result of the dual economy is that the rural farmers give more attention to cash crops such as tea and coffee in Kirinyaga, and less attention to food production. Furthermore, the educated unemployed are not prepared to go back to the land after attaining their certificates and diplomas. The perception since the colonial days is that the educated deserve jobs in the modern sector where they can earn more money as a pay of for working hard in school to get the certificates and diplomas. The purpose of education which should be to adapt students to their society and also equip them to alter it does not exist in the Kenyan system of education. 
Since the colonial days, education has been largely viewed as an escape hatch where students obtain access to modern sector benefits.

Thompson (1981) has argued that a society embraces three broad dimensions--its material culture, its social institutions, and its underlying complex of norms and values. The three parts are integral and interdependent in a society's way of life. Any change in one part of the three dimensions is likely to lead to further changes in the other two components. Similar social change was felt here in the United States at the beginning of this century during the heavy European immigration, internal migration, rapid urbanization, and consequent decline of small towns. These social changes had a heavy toll on the people as the intensified industrialization and the growth of monopoly capital resulted in social turmoil, confusion, and conflict.

After the Kenyans regained their independence in 1963, the material culture, social institutions, and hence values and norms have increasingly changed. The population growth in the country has increased to approximately $4 \%$ per year, one of the highest in the world. The economy that was doing very well in the 1970 s has increasingly weakened in the face of declining prices of coffee and tea in the world market. These factors have 
contributed to a very high unemployment rate estimated at 40\% (Eshiwani, 1990).

The social institutions have felt the ripple effect of the changes in the material culture and technology. The hospitals are unable to meet the needs of the average Kenyan adequately while the government is unable to maintain roads and the transportation structures. Additionally, the school system has been attempting to make education relevant and meaningful to the needs of the Kenyan people for the last two decades without much success. While all these apparently sad things are happening, a small percentage of the population becomes even richer increasing the disparity between the poor and the rich. As Thompson (1981) indicated, changes in the social institutions and the material culture increasingly affect values and norms that governed a once fairly orderly society. Some years ago corruption, bribery, and the abuse of office were abhorred by the majority of Kenyans. Today people are not afraid of asking for or giving bribes in the public and private sectors. In fact these vices are so common that if one abhors them, one is regarded as being unusual.

As Leo (1984) suggested, the influence of the Europeans on the Gikuyu society was similar to a boulder crashing into a pond and its waves rippling the African society and changing forever. According to Eisenstadt 
(1966), modernization entails continual changes in all major spheres of society involving processes of disorganization and dislocation giving way to development of social problems, cleavages, and conflicts between various groups. Modernization brought together the different ethnic groups in the formation of Kenya as a nation. The traditional societies did not have to contend with other people of different languages or dissimilar cultures. As witnessed most recently by the Rwanda massacre, conflicts in Africa can breed enormous animosity and violence. Even when the animosity and hatred do not lead to war, there is anger and a propensity for people to act emotionally when those in power are perceived to favor their own ethnic groups at the expense of others in the society. There is no doubt the wider societal problems affect students in what they perceive and interpret as their concerns. The problems in the broader societal context contribute directly or indirectly to the sense of uncertainty that students experience.

It may be as Sampson (1970) suggested, by rebelling or protesting the students, particularly in African societies, are calling attention of the establishment to their concerns. Alternatively, as Lifton (1972) argued, the students merely want to mock and express contempt at the accepted conventional behavior of which schooling is a part. For according to Iifton (1972), mockery breaks down 
the false boundaries imposed by victimization because through it people are able to tease the absurdity of accepted behavior. The above suggestions support Eisenstadt's (1966) thesis that rapid change creates ruptures in consensus and integration, thus forming ephemeral types of panic or mob outbursts. The outbursts and panic may eventually lead to a crystalline subculture and anti-culture among the young.

An empirical perspective of how large socio-economic changes affect peoples' values is recorded in the United Nations Children Fund Position Paper (1972). This paper posited that the existing world conditions are creating a relatively unhealthy, disheartened, and troubled population who are growing up with more severe problems of adjustments than ever before. According to this paper, problems can be linked to increasing poverty and new deprivations from the changing social support. As Thompson (1981) suggested, social change is about change in relationships so when social changes are all pervasive, the most vulnerable members of the society that is the young and the old pay the highest cost. The new deprivation falls into four headings:

- A diminishing fabric of social support There is strong evidence of a decrease in the support of the extended family (grandparents, uncles, aunts, and cousins). In Africa, and for that matter among the 
Gikuyu, communities are an important component of social organization and the failure of family support extends to the whole community.

- Decreasing opportunities for socialization

Parents in the Third World are overburdened by the responsibilities of working for basic needs. This is true among the Gikuyu. Many are forced to work for long hours in the farms and in factories in order to provide shelter and food for their families especially in the midst of increasing inflation. The absence of parents from their children has been attributed to the poor socialization of the young.

- Lack of opportunities to consolidate one's self worth in the broader societal sphere

Deprivation is related to issues of wants and opportunities. The roadside advertisement and the culture of consumer goods are important symbols of social value for the marginalized adolescents. If an adolescent lives in poverty, her frustration is compounded because she is more likely to find no opportunity of realizing self worth symbolized by the consumer goods culture.

\section{- Lack of control}

A feeling of not belonging in the present and a fear of what the future will bring are the two causes of stress. The major factor of this concept is the inability of individuals or communities to control the very events that determine their lives. Medical doctors and 
psychiatrists increasingly recognize the negative effects of lack of control on the events that determine people's lives.

Referring to social changes in America, Keniston (1965) posited that intensification of technological change has been at the expense of human values. The absence of articulated social goals and the deification of technological progress at the expense of social concerns has dehumanized society. If this can be said of America where progress took at least a more "natural" pace, then one may argue that in African societies which were literally uprooted from their past and placed in the present technological advancement makes it harder for its members to define their lives' meanings. commenting on this phenomenon, siaka stevens, a former president of Sierra Leone, is quoted in Thompson (1981) as having lamented:

The most serious danger which confronts us today as a people is the danger of losing our hold on our traditional past and heritage while we have not fully grasped the cultures and traditions presented to us... Most of us are 'displaced persons' from the educational and cultural point of view. (p. 93)

However serious Stevens' comments are, Africans are losing or have lost their hold on the traditional values and have let the technological advancement of the western world define their society. The social changes among the Gikuyu have not only "dehumanized" people, they have disoriented society as the past which defined the values 
and norms has become increasingly distant and therefore irrelevant.

Gandhi's perspective on modernization. The precolonial Gikuyu society practiced Gandhi's concept of trusteeship. It was a society as Leo (1984) suggested that everyone had a right to an honorable livelihood for the excessive riches of the wealthy belonged to the community for its welfare. The rich were only trustees of their property and would use it mainly in the public interest. However, modernization has placed the pursuit of self-interest at the center of our society's existence. Many of the Gikuyu entrepreneurs' material well-being is focused on acquiring as much riches as possible. As if referring to some aspects of the economic sector of the Gikuyu, Gandhi suggested that the working classes are debased and cannot work and live naturally with the consequence of poverty and unemployment. The gap between the rich and the poor grows every year because once a person appropriates more than he really needs, he reduces his neighbor into destitution. Gandhi logically concludes that starvation and poverty in several parts of the world is due to people elsewhere seizing much more than they need.

Gandhi's philosophy is based on rigorous social analysis but is a moral response to what he perceives as the evils of modernization. Modernization, according to 
Gandhi's moral code, is based on a insatiable desire to amass wealth in a situation marked by resource limitation leading inevitably to violence both at the individual and the collective levels. Amassing of wealth by one individual necessarily means preventing others from having access to what they need for themselves. This situation creates a social order in which inequality, oppression, and deprivation prevail to mutilate and destroy human dignity. Accompanying deprivation is a relentless competition for acquisition as a means of raising the level of material well-being which expresses itself in opposition of man-to-man and of group-to-another. violence is the inevitable result that underlies modernization and its institutions and as long as modernization continues to shape man's destiny, violence will be the natural consequence (Ramashay, 1984). Gandhi's view about modernization and its effects provides an analytical framework of interpreting the problems in Kenya's secondary schools. It illustrates what Bailey (1970) has described as societal pressures that make in-school problems a chemistry of pungent difficulties.

Summary. The section on social change has outlined the social problems that undoubtedly impact experiences of students and their outlook of society's social structures which include the system of education. 
Travers (1982) and Park (1993) indicated that heightened political atmosphere maneuvers increases opportunities and incentives for young people to participate in various unconventional political activities. Bakke (1967) also suggested that students are influenced in their interpretation of their world and in what they attempt to be and to do by the same problems faced by all citizens in the country. Therefore, student disruptions are at least in part one aspect of the response of all citizens to the society's shared problems. Hence it would be relevant to probe how far corruption, abuse of power, and bribery that students have witnessed in the society have impacted their behavior.

Foote (1970) argued that an adolescent acquires and becomes committed to a particular identity through experience. Using Foote's (1970) theoretical framework, one may want to find out how far the subjects of this study have been influenced by the volatile politics of Kirinyaga district. Does the political atmosphere that often provokes deep hatred towards people of the opposite camps have anything to do with school disruptions? This probing is essential because many people in the district feel that students get their cue from the political ideologies and affiliations of adults in the district. 
Student Disruptions as a Form of Collective Behavior

The focus of this study was on group events designed to accomplish a planned goal or for that matter establish a point of contention. A theoretical framework based on collective behavior was used as an analytical tool for school misbehavior.

Brown (Smelser, 1962) distinguished two types of collective behavior, the mobs and the audiences. His groupings appear to be based on the different goals of a collectivity. He further divided mob behavior into the aggressive, which includes lynching, rioting, and terrorizing behaviors. The patterns of aggressive mob behavior arise when a known value is in conflict with other compelling values. For example, the value of "showing a thief no mercy" may be in conflict with the value for the respect of law and belief in its efficacy. Since the value of "showing the thief no mercy" cannot always be attained through the due process advocated by the rule of law and belief in its efficacy, people engage in aggressive behavior.

The other type of mob behavior is the panic. Panic is employed merely as a vivid term to refer to any kind of behavior that occurs when people feel afraid or worried. Panic behavior is characteristic in situations where there is partial entrapment, where there is only one, or at best 
an extremely limited number of escape routes from the situation. Panic behavior is salient where there is perceived physical or psychological threat. Acquisitive behavior or looting, on the other hand, is associated with the breakdown of law and order when people find a window of opportunity to take advantage of times of unrest. Bengston's (1972) theory of collective behavior has four basic groupings; the acting crowd, the expressive crowd, the mass, and the public. The acting crowd has a goal or objective whereas the expressive crowd expends its impulse and feelings in expressive actions such as the dancing crowd of a religious sect. The mass is heterogeneous, more anonymous, less organized, and less intimately engaged in interaction. Mass behavior is, in fact, a convergence of large numbers of individuals on the basis of vague impulses and feelings while the public is a dispersed group of people interested in and divided about an issue.

According to Smelser (1962) collective behavior is guided by various kinds of beliefs as people assess the social situation and build up wishes and expectations. collective behavior involves a:

Belief in the existence of extraordinary forces, conspiracies, etc., which are at work in the universe. They also include as assessment of the extraordinary consequences which will follow if the collective attempt is successful. (p. 22) 
The beliefs on which collective behavior is based are thus akin to magical beliefs. Conventional behavior is based on established expectations but "collective behavior involves a collective redefinition of an unstructured situation" (Smelser, 1962, p. 23).

Lofland's (1985) picture of unstructured situation is dramatic and comprehensive. According to Lofland (1985), an unstructured or problematic situation is perceived when an actor's attitude of everyday life suddenly changes. The changes force actors to have a perception that something unusual is happening to them or around them. After a while, the actors suspend the attitude of everyday life as well as "the frame of ordinary reality, the taken for granted world is made problematic" (Lofland, 1985, p. 37). The problematic or unstructured situation is to some extent defined as unordinary, extraordinary, and perhaps as unreal. Such a suspension is the beginning of collective behavior.

Smelser (1962) argued that collective behavior is likely to occur if there is a strain in a social organization. A strain is an ambiguous or what one may describe as a problematic situation. In any social organization, there are structured and unstructured situations. The unstructured ambiguity is the irregular or the abnormal events, unanticipated information, and dangers of unknown proportions. This ambiguity occurs 
fortuitously and beyond the realm of institutionalized expectations. If a problematic situation is experienced, activity cannot be directed toward one goal creating a feeling of helplessness and paralysis among actors. Structured ambiguity, on the other hand, is part of the definition of a social situation. In the field of athletics, a football coach commands some means to win, the power to substitute a player, the power to call special training sessions. But he cannot control the strength of the opposing team, he cannot direct the movement of his players once the ball has been snapped-these are some of the kinds of uncertainty that is built into social situations. In the same way a principal commands some means to enable students to do well in his or her school, but there are other means that lie beyond his or her control. Unstructured and structured ambiguity involve the actors' limited capacity to overcome some unknown or unpredictable elements. According to Smelser (1962), human beings maintain stability of their egos through a consistency in the reactions built up in relation to physical or social anchorages. If a person's ego is in a state of real or perceived tension, one becomes uncertain of one's physical or social grounds in the present or future and is said to be anxious. Such a person is also said to be faced with an ambiguous or a problematic situation. Generalized 
beliefs or rumors structure people's anxieties because they purport to explain past events, report a present one or predict a future one. The rumors or generalized beliefs effectively reduce ambiguity inherent in a situation.

The persons who accept a belief about some threat have the motivation to flee from established patterns of social interaction in order to preserve their life, property, or power. The threat is specific and the participants in a collective behavior are aware of what makes them afraid. According to smelser (1962), if there are no conducive structural conditions, the reaction to a rumor is panic. Panics and hostile outbursts occur in sequence. In panic after panic, the collapse of organized behavior is followed by attack on persons or agencies perceived to be responsible for the debacle. Hostile outbursts, or aggressive behavior, or acting crowd explain the phenomenon that is the focus of this study (Bengston, 1972) •

Hostility ranges all the way from a mild irritation to a violent and illegal attack. The degree of the intensity depends on the degree of the ambiguity of the situation and how effectively leaders can mobilize aggrieved persons using effective social control. Further, hostility can range from an uncoordinated brawl to a highly organized conspirators' attack. The level of 
organization depends on the character of the belief underlying the outburst, the kind of mobilization, and the influence of social control.

Theoretical underpinnings of collective behavior provided by Smelser (1962) can be used to analyze school disruptions that are calculated to disrupt the normal functioning of a school. The questions and probes in the field would be directed at social situations that are perceived to be out of the ordinary. Through an investigation based on collective behavior theory, the researcher may learn who identified the situation and how the generalized beliefs or rumors explained the problem and its possible solution.

In order for a behavior to become collective, some form of communication must be available. According to Smelser (1962), no single form of communication or interaction constitutes a defining characteristic of collective behavior. The belief may be communicated by gesture, sign, face to face rumor, by mass media, or common ideology amongst the actors. The form of communication may be a dialogue, an uncontrolled circular reaction, or one-way communication.

Literature does not establish how people involved in collective behavior organize themselves to react in unison. The forms of communication that evolve in school disruptions are of interest to this study in order to 
understand how the regular students are drawn into disruptive behavior and what logic or emotions motivate them. Foote (1970) suggested that motivation to participate depends on "the degree to which a human being in the on-going social process defines a problematic situation as calling for the performance of a particular act with anticipated consummation and consequences" (Foote, 1970, p. 82). Thus, action must be meaningful to the actor in order for him to sustain the energy in the performance of the act.

According to Hirsch (1990), recruitment and : commitment in protest activities are best explained by analyzing group level political processes such as consciousness-raising, collective empowerment, politicization, and collective decision-making. Potential recruits are not likely to join protest activities unless they develop an ideological commitment to the group and a belief that only non-institutionalized means can further that cause. Predisposing factors such as prior political socialization may make certain individuals susceptible to some appeals and unsympathetic to others. Collective empowerment or the "band-wagon effect" tactics are easily viewed as powerful if they are highly visible, dramatic, and disrupt normal institutional routine. Polarization of two opposing camps convinces each side the opponent is wrong, making compromise and negotiation less likely. It 
leads each side to develop the independent goal of harming the opponent and the participants are more likely to lose sight of their original cause. Finally, participation in a protest is a complex group decision-making process and not the consequence of many isolated, rational, individual decisions.

Using Travisano's (1970) theory of "conversion" and "alternation" one may be able to explain how and why students join the protesters in high school. "Conversion" is signaled by a radical reorganization of identity, meaning, and life. Thus after a "conversion" a person becomes something which was prohibited in his earlier socialization. Conversion therefore involves great trauma and a period of inner struggle. An actor's new orientation requires him to negate the values and meanings that had previously identified him. On the other hand, "alternation" is the process where the actor is learning well a new part of a world he was always committed to, with the help of his established others. There is no trauma or inner struggle involved in the process of alternation. Using this theory as an analytical framework, it will be possible to establish whether students joined the protest through coercion or persuasion.

According to Keniston (1970), in order for a rebellion or protest to occur, there must be sufficient 
numbers of protest-prone students to form a group. These students must have the opportunity to interact with each other and must have leaders to initiate and mount protest. The nature of this study is to understand the interaction that goes on among the students since such interactions and relationship shape the picture of the student world.

In his study of the participants of the Mississippi Freedom Summer Project, McAdam (1986) suggested that conversion tends to occur in groups that demand loyalties of its members and maintain a hostile stance toward the mainstream society. Another study by McAdam and Paulsen (1993) indicated that people are embedded in many relationships, and decisions are mediated by a significant subset of those relationships. When applied to the recruitment process, this perspective suggests that the decision to join or not to join in a protest activity is mediated by the identity involved in the protest.

Using the line of argument of McAdam (1986) and McAdam and Paulsen (1993), one may want to investigate whether subjects of this study experienced trauma or inner struggle when they decided to join activities disruptive of school. The objective of the study was to try and understand whether recruitment of the rioters was a "conversion" or an "alternation" process (Travisano, 1970). Are the students remorseful for what they do? Do they blame their friends? Or are they convinced that it 
was the right thing to do from a ideological point of view? or do the students merely join a fairly visible and dramatic event, i.e., the "bandwagon effect?"

Many of the studies in the literature on collective behavior emphasize the importance of predisposing factors and place no importance in perspectives of students in regard to protests. Studies by Flacks (1967), Baird (1970), Keniston (1968), and Block, Haan, and Smith (1968) conclude that college activists are more likely to be recruited from high income families and were raised in homes where autonomy and self-expression were fostered. These authors argue that these students rank intellectual pursuits ahead of conventional careers and are brought up by politically liberal parents.

on the other hand, a study by Bowers and Kahn (1970) indicated that the students described in the above-quoted studies are the leaders of protest activities but that the rank-and-file activists do not fit into the profile discussed above. Following the lead of this suggestion, it appears that the students of the profile discussed by Flacks (1967) and other scholars quoted above were the original protesters who were able to take a risk in an area that was unknown. Their strong commitment and high academic standing gave the young men and women the efficacy to believe that what they were doing was worthwhile. Later, the protests became imitative and were 
more likely to take on some of the mindlessness of the panty raids or the fraternity riots (Foster, 1970). The focus of this study is on students who have grown up in a different culture and in a different ideological atmosphere and it would be insightful to understand how they differ from the students discussed in this literature.

Summary. Undoubtedly, there are school-based causes of the disruptive behavior. The collective behavior theoretical framework will enable the investigation to probe problematic situations that provoke student misbehavior. Students in Kirinyaga district secondary schools have normally complained of school issues such as perceived teachers' inability to teach effectively, poor food, strict and unfair rules and regulations, school uniform, and also perceived poor school administration. The purpose of this study is to find out whether overt complaints are a camouflage of deeper problems. What are the students' perceptions of problematic situations which exist in individual schools? Who do they blame for the perceived structural strains? What ideological standpoint motivates the students to join in the protests?

A Synthesis of the Related Literature Review Using a Micro-Political Perspective

In responding to the problem of violence in schools, it is tempting to ignore the possibility of school- 
specific aspects of school violence and to look for explanations and solutions in what we know about violence rather than what we know about schools (Wenk \& Harlow, 1978)

The focus of this study allows us to examine a school as a society on its own merit. Every school displays its own life, social climate, organizational culture, ethos, and social systems. That is why no two schools are similar even when they are located in the same neighborhond (Iannaccone, 1991).

Following the lead of the above perspective, one may argue that a school's social organization mediates the difficulties of adolescence and other social problems that students have. The type of mediation provided by the school results into either student apathy, protest, withdrawal, or rebellion. A school's social system includes for practical purposes the ideology of teachers, administrators, students, parents, and the classified staff who contribute to the political environment of any school. The perspective of a school as a social system provides a framework in which one can study the reality that is created through the power of language, symbols, and interactions. In all social organizations, those with power determine the issues that are normal, relevant, and wrong. In the social organization of a school, power is with the school principal and perhaps with other senior 
members of staff. Most importantly, a theoretical framework that views a school as a polity provides one with an opportunity of studying how students who are the powerless members in the political system ruled by adults are likely to construct their own meaning of power through force or violence (Marshall \& Scribner, 1991).

Underlying all social processes are contests of control, different visions of goals, and divergent political positions. Using a socio-political perspective of a school, one may describe the year-long daily dynamics of a school, its classrooms, its dormitories, its cafeteria, and its playing fields. For as Blase (1991) suggested, understanding the everyday life of students is understanding about power and how people use it to influence others and to protect themselves. It is about having an insight into the conflicts, cleavages, and details of how people compete with each other to get what they want. In order to enter into an examination of how students define social processes and situations that affect them every day, it is important to know what they think about their school settings. Additionally, it is important to know what they have strong feelings about but what is so often unspoken and not easily observed.

Iannaccone (1991) suggested that a school site is a polity like a school district within a state and nation. In all polities, the most characteristic is the essence of 
conflict and more specifically conflict that has a tendency toward contagion. The pivotal fact distinguishing a polity from other organizations is the contagiousness of its conflicts and the tendency of a polity to expand scope of the conflicts.

Schattschneider (1975) noted that students cannot become citizens of their polities. And when the highest number of a polity's members is a class of persons who neither share in its governance by right nor are able to acquire that right through effort, i.e., there is no route to get citizen status, the polity involved is a caste system. Caste differences in interests, values, activities, social norms, and language are greater than class differences. The potential conflict between castes is vastly greater than between other population groups.

The above analysis demonstrates that a school can be viewed as polity with a caste system. This means that student interests, values, activities, social norms, and language are more likely to be different from that of teachers and school administrators. If this is true, it is difficult for teachers and administrators to know the interests, values, norms, or languages of their students because each caste in a polity conceals its inner workings.

Following the lead of the above suggestion, it is difficult to imagine that teachers, students, and school 
administrators understand each others' values fully. As Optow (1991) suggested, adolescent conflicts, excitement, moral curiosity as well as personal and intellectual growth are closely linked. But in most schooling processes, academic studies fail to address the whole student, particularly the moral content of academia. To answer these questions, Iannaccone (1991) argued that caste societies display more petty value conflicts than do other organizations precisely because they try to avoid confronting most significant tensions. As Freedman and Kanzer (1970) indicated, rebellion and protest are complex human behavior, therefore a polity evolves within a complicated, contradictory, dynamic, and interwoven world. There are no clear or specific answers to questions about disruptive behavior in schools. To understand the everyday processes of a school and its political complexity, one must employ interpretative and theory-generating approach to explain and describe the actual processes by which power and control are practiced. It is one of the objectives of this study to understand the everyday processes of a school as a polity through the students' perceptions of the dynamic situations that make the school work or not work for them. Perhaps that which makes a school be perceived by students as problematic and frustrating are likely to be the 
reasons that lead to negative reactions expressed as riots and boycotts.

Summary. The literature consulted in this study is divergent in scope because the study involves understanding a complex human behavior. This study requires that the behavior of adolescents in general be acknowledged and that one be aware of the socio-political climate that has a great impact in the world of young adults born into a rapidly changing society. When a student goes into a classroom, into the play field, and into the dormitory, she should be understood as a human being whose world view is bound to be different from that of her teachers and her parents. The political implication of the value differences between teachers, administrators, and students is important because it is at the core of what brings about conflicts and confrontations in a secondary school. 
CHAPTER III

METHODOLOGY

Theoretical Perspective

The term methodology refers to the way in which we approach problems and seek answers. Our assumptions, interests, and purposes shape which methodology we choose (Bogdan \& Taylor, 1984). The assumption of this study was that students act toward things on the basis of the meanings that things have for them. Things in this case included everything that they note in their world such as other human beings, ideals, activities, and the situations that they encounter in their daily lives.

It is also assumed that meaning arises in the process of interaction between people. It is a social product created and formed through the defining activities of people as they interact. What people say and do is a product of how people define their world. The major objective of this study was to understand the perspective of students as actors in school disruptions. Reality was what students perceived it to be (Blumer, 1969). This perspective is rooted in the theoretical underpinning known as symbolic interactionism. The origin of symbolic interactionism emanates from the work of George H. Mead, a 
social behaviorist, who laid the foundation for this theoretical construct as a way to study human society. According to Blumer (1969), symbolic interactionism views meaning as social products, as creations that are formed in and through the defining activities of people as they interact. The use of meanings by a person in his action involves an interpretive process. First, the actor indicates to himself the things toward which he is acting; he has to point out to himself the things that have meaning. The making of such indications is an internalized social process in that the actor is interacting with himself. In this process of communicating with himself, interpretation becomes a matter of handling meanings. "The actor selects, checks, suspends, regroups, and transforms the meanings in the light of the situation in which he is placed and the direction of his action" (Blumer, 1969, p. 5). Interpretation is not a mere automatic application of established meanings but is a formative process in which meanings are used and revised as instruments for the guidance and formation of action. It is necessary to see that meanings play their part in action through a process of self-interaction.

secondly, in a society or a community such as a school, activities of the members occur predominantly in response to one another or in relation to one another. 
Social interactionism is a process that forms human conduct. Human beings in interacting with one another have to take account of what each is doing or is about to do, they are forced to direct their own conduct or handle their situations in terms of what they take into account. Activities of others enter as positive factors in the formation of their own conduct. In the face of the actions of others one may abandon an intention, or purpose, check or suspend it, intensify it or replace it. The actions of others enter into and shape what one plans to do (Blumer, 1969).

This study is also grounded in the assumption that the perspective of the student is just as important as the perspective of the school head teachers, teachers, and other education officials. A school is a system that is created to serve students, and therefore as educators we must be willing to listen to students if we are ever going to find a solution to the most pertinent problems facing schools. We must work with young people in our schools in order to understand their moral struggles, their successes, and failures in securing their destiny in a world too often at variance with their hopes and ideals (Biklen \& Bogdan, 1992). By initiating a forum for students to describe the things that influenced them to engage in violent behavior, the perspective of students toward social reality will be noted. It is an opportunity 
to discover the meanings that students attach to the behavior that we adults define as unbecoming and unacceptable. If social interaction is a process that forms human conduct, the symbolic interaction framework can be employed as a tool to investigate the processes of interpretation. The objective is to understand how students interpret riots and class boycotts in secondary schools.

\section{Data Collection Procedures}

This chapter comprises the theoretical underpinning which informs this qualitative study and the data collecting strategies employed in the study. The issues that shaped the research design are addressed, while an explanation of how the constant comparative methodology is used in the discovery of the grounded theory is provided. The theoretical framework of this study spoke to the day to day life in a boarding school. What was important to students in the presence and absence of teachers was essential to the purpose and goal of this study. It addressed the issues and actions that students valued and thought about. Specifically, the symbolic interactionist perspective directs attention to what human beings feel, perceive, think, and do in situations (Douglas, Adler, Adler, Fonyana, Freeman, \& Kotarba, 1980). 
Everyday life begins with the experience and observation of people interacting in concrete, face to face situations. Symbolic interaction perspective begins with an analysis of the members' meanings or everyday meanings. During the field study I wanted to know the feelings, perceptions, emotions, moods, thoughts, ideas, beliefs, values, and morals of the subjects (Douglas et al., 1980). In short, I wanted to find out the internal experiences of the students that were most pertinent to "inter-school conflicts," "inter-class disputes and fights," "learning," "rules and regulations," and other informal activities that students engaged in during their schooling career. Since this study was grounded in the sociology of everyday life perspective, I did not impose my own meanings on the interpretations of the students. Instead, I observed what they took into account in their interpretations and meanings. My concern was primarily with what the subjects perceived, felt, and thought (Douglas et al., 1980).

The studies in the literature review concerning the student disruptions (Baird, 1970; Bowers \& Kahn, 1970; Flacks, 1970), were guided by the assumption that researchers' hypotheses were authentic and valid. That standpoint gave us a plethora of reasons why young people rebelled against authority and rioted against institutions of learning. This study departed from that perspective. 
It was guided by the assumption that it was important to try to understand the young people from their standpoint. The key question to the investigation was: Why did the students engage in activities that disrupted their learning and consequently affected their future?

The understanding referred to here was informed by cultural perspective elucidated by Wax (1971). Wax emphasized that as a field worker one approached the subjects as strange people who understood many things that the field worker did not. Thus,

one of the strangers may make a particular gesture, whereupon all the other strangers laugh. They share in the understanding of what that gesture means, but the field worker does not. When he does share it, he begins to 'understand.' He possesses a part of the "insiders" view. (Wax, 1971, p. 11)

Although the subjects and I shared a language and a culture, their use of the language and perception was strange to me. My experience with the subjects was similar to that of Spradley (1979) when he studied the skid row men in seattle. In that study spradley observed:

I understood the English words but recognized them as interesting words with slightly different usages. As months passed my tramp informants taught me more and more, helping me to understand the subtle meanings attached to them. (p. 18) (emphasis not original)

since understanding was the basis of data collection, as a field worker I began as an outsider confronting beliefs that most often I found rather bewildering and inexplicable. I started initially without understanding many of the actions that subjects described as "survival," 
"summary," "monolization." The term monolization is defined and exemplified later in chapter four. Briefly, it involves a process where students in upper-level classes harass students in lower-level classes for no apparent reason. Survival refers to the act of snatching food and denying those who have a mandate to eat the right to do so in an orderly atmosphere. Summary is the process of giving previous newcomers to the school a higher status. Learning the meaning of these terms was similar to learning a new language. Gradually, I was able to categorize the interactions and relationships. Understanding in this respect means gaining familiarity with the subjects' culture to the degree that their behaviors and language were neither inexplicable nor bewildering at the end of the study.

Research Problem

The intent of this study was to understand why students in secondary schools in Kirinyaga district, Kenya engaged in activities that disrupted normal schooling processes. The disruptions were portrayed in various types of riots and class boycotts. The disruptions were more likely to be violent and endangered the lives of the students and the teachers. Besides, they disrupted learning and teaching in the affected schools. 
The position of symbolic interaction perspective is that the "worlds" that exist for human beings and their groups are composed of "objects" and these objects are the product of symbolic interaction. Riots and boycotts which disrupted normal schooling processes were abstract objects. They had meaning for the people who had observed them or indeed lived through them. Although the disruptions under investigation were similar to the riots that rocked campuses here in the United states during the 1960s, the pictures of the riots in Kirinyaga schools had a local flavor. In Kirinyaga, school disruptions were tangible and identifiable objects. They had changed not only the character of schooling but the lives of individuals. Anecdotes as told by a deputy headmaster, a student, and a teacher depicted the concrete situations of disruptions, and the lived everyday life experience. The goal of this study was to focus on the relevant behavior in concrete situations. The descriptions that follow depicted such situations and behaviors. The anecdotes quoted below allow the reader to hear people in the concrete situations. In other words, the anecdotes defined concrete situations of abstract objects as noted by the individuals who knew the experiences the best. 
1991 Riot at site B

Narrated July 20, 1995 by "Mr. Bridge"

The most terrifying riot experience that I witnessed was in 1991. The experience was so terrifying that I still remember it with horror to date. It was during the night study time at $8: 20 \mathrm{p.m}$. The lights went

out. I and several other teachers thought there was an electrical fault. Suddenly, stones started to "rain" on the roof of the staff-room. Apparently, there was a group of students who were determined to destroy the staff-room and beat up the teachers. I realized that there was yet another group of students who did not share the feelings of this group and were chasing the rioting gang out of the campus. When we realized the rioting gang had been chased out of the campus, I and other teachers thought the problem was over. An apparent calm was restored.

Later, at around 11:00 p.m., the boys who had been chased out earlier came back to the campus with vengeance. They had consumed bhang. The term bhang is a East Indian name for the hemp plant Cannabis sativa, but applied specially to the leaves dried and prepared for use as a narcotic drug. Its violent effects are delirium of a peculiar kind, and the production of a cataleptic condition (Encyclopedia Britannica, 9th Edition). After consuming bhang, the students stoned the roofs more violently than before. They were determined to knock the doors down. They collected the heavy mason's stones and hit all the doors and within no time all the staff-room's doors came tumbling down.

After the doors were knocked down the boys went on rampage. They started to throw stones into the staff-room. It was dark and the stones landed anywhere. The noise caused by the rampage was overwhelming. Our ears were hurting because the noise was extremely violent. My colleagues tried to hide against any available object as stones flew across the room. Some stones missed my stomach by an inch. I escaped through a tiny bathroom window.

To this day, I am frightened at the thought of that night's terror. I cannot and I will not live in the campus at the staff quarters. 
Riot as Reported on the Log Book by School Headmaster at "Site D" on Sunday March 26, 1995

During the course of the day there were no visible signs of any tension or unrest. Things went on as per Sunday program. Evening study started at 7:00 $\mathrm{p} . \mathrm{m}$. and ended the usual time at 10:30 p.m. At about 10:30 p.m., matters took a different course altogether when all the boys came out of their dormitories. They broke all the kitchen storage and collected the axes, mallets, wedges, and machetes. They went to the deputy headmistress' house. They broke the door and got inside. Fortunately, the deputy headmistress had taken refuge in another teacher's house. The boys looked for her in her house but all in vain. They did not steal or damage the property in the house.

After breaking into the deputy headmistress' house, the boys went to the girls' dormitory. They broke all the doors and the windows and ordered the girls out. The entire student population deserted the school campus at night despite the effort by the teachers and the watchmen to control them. Some sought accommodation from the neighbors, others slept in the woods. The police arrived at midnight. All students were gone at that time. Two policemen guarded the campus.

The students came on Monday morning at 6:30 a.m. We decided to close the school temporarily. Three girls reported they had been sexually assaulted and they knew the culprits. The seven culprits were taken to police custody for further investigation and the girls were taken to hospital for a medical examination and treatment.

An Attack on "Valley secondary School," a Coeducational Institution, on November 3,1991 by Students from "Site c" Narrated July 28,1995 by one of the subjects

We had a school captain who was a small-bodied boy but a criminal. our captain visited valley Secondary School because it was their open day. While visiting, the captain was beaten up by some boys of Valley secondary School. He returned at 5:00 p.m. The captain explained to us what had happened to him at valley secondary school. We felt really provoked and were annoyed. 
We felt there is no time a girls' school ever made fun of a boys' school. It would be very inappropriate to allow valley secondary school to get away with this act.

The whole school decided to go to Valley secondary School and take revenge. We ran saying valley secondary school is alone and we are up! We entered the gate and damaged many things. We escaped through another route.

The Valley students took hostage of one boy from our school. They beat him up. We had planned to go back and revenge but this time round we did not manage. We were mad at that act.

(This narrative was in Gikuyu and then translated).

All the six selected sites had experienced from one to more than 15 riots between 1990 and 1995. To investigate the problem, it was difficult to isolate the phenomena from its contexts. I contacted people by visiting the sites where the riots had been experienced. This research problem involved multiple units of analyses. First, I examined a school site as a unit of analysis. During the initial investigation, the phenomenon was defined in terms of the incidents of riots and boycotts that had taken place within a specific time. Secondly, the individual became a unit of analysis. To learn the individuals' perception of the phenomenon I organized oneon-one interviews with persons who had experienced the phenomenon. The in-depth interviews revealed opinions, values, morals, feelings, and ideas about the disruptions. During the process I sought to understand why students 
engaged in activities that disrupted the normal schooling processes from their standpoint.

The research problem entailed understanding intricate human behaviors that can only be understood in the concrete, naturally occurring situations. This involved reviewing the activities that are hidden from the public view. In most cases, this included trying to confront a strange language and certainly uncommon beliefs. The overall experience at the field revealed that preconceived questions were inappropriate and the best strategy was to have open-ended questions. In all cases, I appeared naive about the issues and incidents and allowed the subjects to provide fresh commentaries (Yin, 1989).

Each school site and respondent contributed in the overall understanding of the research problem. The problem demanded that one also understands the meaningful characteristics of real life events. One needed to have an overview of the complexities of the phenomenon and ultimately discern the issues that corroborate and maintain the problems. For example, the records at site $c$ revealed a distinct preoccupation with inter-school conflicts. Consequently, the subjects were given an opportunity to provide their feelings and their opinions about the topic. At site $A$, students were unusually protective of their turf. They vigorously kept the gulf 
between the staff and themselves. This context provided a concrete situation for the interviews with site $A$ subjects.

Although the subjects across the six sites had different concrete situations, there were similarities in their interpretations and in what they took account of.

Considerations Leading to the Design of the study

This section addresses the context of the study. The cultural, social, and political issues affect everything that happens in a human society. In this section, there is a brief description of the background that influences education of the district. The background preview allows the reader to appreciate the holistic view of schooling in a natural context. The description portrays the district as a part of central province and indeed the country while the preview of a boarding school structure depicts the environment which is infused with conflicts and disruptions.

In this section, I locate myself as a researcher in the schooling context. The reader's attention is drawn to my sensitivity about my influence on the subjects of this study. My sensitivity was on the subjective interpretations that may affect the findings. Additionally, the assumptions and the role I conveyed to the respondents are explained. 
Schooling in Kirinyaga

Kirinyaga is the smallest of the five districts that comprise Central province. Central province is home to more than one million people of the Gikuyu ethnic group. More than one fifth of Kenya's secondary school students attend a school in Central province. Central province comprises Nyeri, Kiambu, Muranga, Nyandarua, and Kirinyaga districts. One may argue kirinyaga shares similar sociocultural and economic factors with other districts in the province. The district is situated on the slopes of Mt. Kenya, the second largest mountain in Africa. The mountain feeds the many rivers and creeks that cross the district and finally empty into the Indian ocean. The rich volcanic soils and moderate rainfall makes the district agriculturally and economically vibrant. It is home to many tea and coffee factories, two crops that are the mainstay of Kenya's economy. A sketch map depicting the relative position in the province is in appendix $D$.

To understand the educational setting of the district one must contrast the primary schooling and secondary schooling. Primary schools cater to six to 15-year-olds. The system is structured in such a way that one has to pass a very competitive examination to qualify for admission to a secondary school.

When a child enters school at the age of six, the major experience in her school life is to prepare for the 
Kenya Certificate of Primary Education (KCPE) which she will take in standard 8 (grade 8 ). She is often reminded of its importance by her parents and teachers. She has to work extremely hard so that she may be admitted into a good secondary school. The 1994 Ministry of Education reported 112,990 children in Kirinyaga primary schools in 184 schools. Children in primary schools attend a school that is located within a mile or so of their homes. Parents do not pay tuition fee for their children to attend a primary school. However, parents have to pay for the building and maintenance of the school buildings. They are also required to buy school uniforms for their children. Some parents are not able to pay for these items and this means education is not accessible to all school age children. According to the 1994 Ministry of Education statistics, the country's enrollment was $82.4 \%$ of school age children. Kirinyaga's rate of enrollment was about $95 \%$.

Most primary school students are admitted in the district secondary schools after they pass KCPE examination. The children's ages vary because many of them repeat the KCPE examination or other classes along the way. On average, it is estimated children enroll in secondary school at the age of 15.

Most parents prefer boarding schools to day schools (non-residential schools). There is a belief among 
Kenyans that when a child is in a boarding school (residential school) he studies more effectively and efficiently because his attention is not distracted by the many chores that he may have to attend to if he lives at home. Additionally, the poor commuting conditions add to the desirability of boarding schools. This background of events corroborates the reason why boarding schools have better teaching facilities than the day schools. often, the day schools are so inadequately equipped that the students do not know what a science laboratory looks like. It is therefore mandatory that one attends a boarding school if a good education is a major goal.

once a child is admitted to a secondary school, the parents have to pay tuition and boarding fees. The average fee paid in a Kirinyaga secondary schools is Kenya shillings 20,000 annually (US $\$ 500$ ). For an average family, Kenya shillings 20,000 is equivalent to one third of one family's annual earnings. The fact that parents must pay fees means fewer students are able to obtain secondary school education. According to the Ministry of Education statistics of 1994, there were approximately 12,030 students in all Kirinyaga secondary schools. This was approximately one tenth of the primary school population. Receiving a secondary school education is still a privilege to be appreciated. 
The transition between primary schooling and secondary schooling is sudden. A child who has been living with his parents is suddenly made to live in a dormitory with his school mates. He has less variety of foods to choose from and has to eat what the school provides. Additionally, there is a sudden curriculum change. In primary school, a student has about four subjects to contend with while at secondary school he studies 13 subjects. Primary school teachers normally teach to the test while secondary school teachers expect students to apply themselves in their work.

There are about 48 secondary schools in Kirinyaga district according to the information obtained from the district central office. Of these, 24 are boarding schools. The 24 boarding institutions are the focus of this study since historically, this is where disruptions of the normal schooling processes have occurred. Of the 24 schools, eight are all boys' secondary schools, 12 are all girls' schools, and four are co-educational institutions. The other 24 schools are non-residential and are characterized by small student populations and have virtually no riots or class boycotts.

The terms that appear in the discussion. There are terms used in this discussion that differ from terms commonly used in the American schooling system. Instead of grades, the Kenyan system uses the term "standard" in 
primary schools and "form" in secondary schools. "Standard one" in the Kenyan schooling system is equivalent to grade one in the American system. The term "form one student" defines a high school freshman, a "form two student" is the sophomore. A junior in high school is referred to as a "form three student" and a "form four student" is a senior in high school. All explanations and descriptions in the analyses and discussion of data use the Kenyan terms. An academic year commences in January and ends in December. The head of a school is a headmaster or a headmistress. A head teacher is the term used regardless of the gender of the school administrator. A District Education officer is in charge of the education matters in a school district and a secondary school's management team is known as the Board of Governors. The term bhang is a East Indian name for the hemp plant Cannabis sativa, but applied specially to the leaves dried and prepared for use as a narcotic drug. Its violent effects are delirium of a peculiar kind, and the production of a cataleptic condition (Encyclopedia Britannica, 9th Edition).

Organizational structure of Secondary Boarding Schools

Every secondary school has a Board of Governors which is composed of 10 appointed officials and 2 ex-officio members. All members are recruited from local 
organizations and churches. The head teacher of a school and the District Education officer are both ex-officio members. The Board of Governors hires the support staff. However, teachers, including head teachers, are employees of the central government under the national Teachers' Service Commission. Additionally, since the early 1980s all schools have parents and teachers associations, commonly known as PTAs. Technically, every parent is a member of the PTA of the school his child attends. Normally, parents elect a committee of 10-12 parents to oversee their interests in each school. Since parents pay the money required to operate a school, the elected PTA members are expected to endorse any fee increases.

The everyday administration of a secondary school is the responsibility of a school's head teacher. The girls' schools are more likely to be administered by women while co-educational and boys' schools are administered by men. A head teacher is the instructional leader of his institution and is assisted by a deputy head teacher, teachers, and support staff to manage the boarding and academic affairs of a school. The deputy head teacher is pivotal in this study because he is the person in charge of disciplinary matters pertaining to students. Rioting is viewed as a gross breach of the discipline code, therefore deputy head teachers are more likely to be involved in attempts of controlling behaviors or actions 
that often precipitate riots. Whereas teachers supervise the students in the boarding areas, the support staff are ultimately more responsible for the boarding facilities. The matrons are in-charge of the dormitories, and a caterer supervises the cooking and serving of the meals while a school nurse dispenses medication for minor ailments. To ensure that students do not walk out of the campus without authority and no unauthorized people walk into the campuses, schools employ security personnel who are popularly known as watchmen. On financial issues, a school bursar is in charge of the school receipts, but all expenditures must be authorized by the head teacher.

A school head teacher has a daunting responsibility. He or she is expected to consult with the Board of Governors for the appointment of the support staff and the central government for matters concerning the hiring of teachers. To get any additional money, a head teacher has to have a good working relationship with his school's PTA. He is expected to see that the teachers perform their work satisfactorily and that the bursar, the matron, the caterer, and the watchmen are well coordinated to produce a conducive living atmosphere for the students.

The boys and girls are expected to do all the cleaning and grounds maintenance. School prefects' main role is to assist both the support and teaching staff in ensuring that students do their cleaning and gardening 
duties. The prefects also assist the school

administration in ensuring that students obey the school rules. It is their responsibility to report the students who violate rules to the teachers or administrators. This background clarifies why prefects are ostracized in some student cultures.

There are no standard procedures for all schools. Some schools are rural and others are urban. Each school has its own rules and regulations depending on its unique and special circumstances. For example, some school rules state: "no smoking in the campus" and "all food should be consumed in the dining hall and not in the dormitories." A sample of rules appears in appendix B.

Everyday life in a secondary school is intricate. A school administrator must coordinate the boarding and tuition sections of the school so that the students learn without any difficulties or hindrances. For example, a head teacher has to make sure on a daily basis that the students perform their daily cleaning duties, eat, and go to class. If students do not eat on time, fail to do their cleaning duties, or have a complaint related to food, health, or teaching, then the normal learning processes are disrupted. Thus, the everyday concrete situation in a secondary school evolves around a complicated, contradictory, dynamic, and interwoven context. It is against this background that I tried to 
understand why students engaged in riots and class boycotts.

Rules and regulations, the prefects, the food, the watchmen, the deputy head teachers, the teachers, and students were the concepts and constructs that emerged in the data obtained from the interviews and school documents. Ultimately, these terms and concepts were used in the construction and the discussion of the substantive grounded theory in the next chapter.

A good secondary school in the mind of Kenyans is the school where students pass the national fourth form standardized examination. This examination is the sole determinant of whether a young man or woman will be qualified for admission to the state colleges and universities. There are more than 250,000 students who sit for the examination every year and only 10,000 students can be admitted in the state universities because of the limited space. Only the best students are able to compete for this limited opportunity. There are about three private universities in the country. Many Kenyan families cannot afford to pay the tuition and boarding fees required by the private colleges, so students have to compete for the heavily subsidized state university education. Additionally, the middle and low level colleges are too few for the 250,000 annual form four graduates. It is no wonder that many of the subjects that 
I interviewed expressed resignation at the thought of making it to college.

A good school is also fairly visible in the national drama, athletic, and music competitions. More importantly, a good school does not have any school disruptions. The performance of every school in the areas mentioned is under constant scrutiny of the public assisted by the local media. The members of the public are quick to judge and therefore many head teachers are under enormous pressure to deliver. Some of the head teachers try as much as possible to make their schools work. They know their promotion and further advancement in their careers is dependent on the public perception of their institutions.

\section{Locating Myself as a Researcher}

I was born and raised in Kirinyaga district. After completing my bachelor's degree at Makerere University, Kampala, I worked as a school teacher and administrator for a total of 15 years. As a teacher in the mid-1970s, schools were generaliy calm but in the early 1980 s some students started to disrupt the normal schooling processes. The disruptions were more likely to occur in boys' secondary schools. The incidents became common as years went by. In the 1990s, particularly during this investigation, some respondents remembered 15 or more incidents in their four years of secondary schooling 
careers. The school disruptions have become part of the schools' landscape and many people do not consider riots in schools as an extraordinary feature any longer.

My involvement in the education of Kirinyaga added to my enthusiasm and interest in the field study. I remember making a suggestion to the District Education officer in one of our meetings that we study the problem of the disruptions before offering any quick remedy. He endorsed my suggestion but there was no follow through. Although I was very interested in studying this phenomenon, I was never too involved to be unable to distance myself from personal concerns or common-sense understanding of what was going on (Bogdan \& Biklen, 1992). I was aware that my previous involvement in the district as a teacher and an administrator may be a hindrance to my being an objective researcher. Due to this awareness my chief task was to try to remain non-judgmental. The temptation to counsel during the interviews was overcome by conscious deliberation.

Obviously, I entered the field with some assumptions. One of my assumptions was that the behaviors of students are influenced by the joblessness that confronts many young people when they graduate from secondary school. While this assumption was significant in the attitude that students held toward learning, it was never expressed as the reason why students engaged in extensive disruption of 
the normal schooling processes. None of my respondents overtly described schooling as worthless, a remark that I had expected.

Secondly, I had assumed that teachers instigated most disruptions. Conventional wisdom stated that every successful riot was instigated by an adult who was more likely to be one of the disfranchised teachers in a school. I had believed this statement and it was one of my basic assumptions. Except in one instance in school B, where two teachers were reported to have incited the students to riot, the motivation to riot was located in the student "underworld." This discovery was a surprise. A detailed explanation of the term underworld is discussed later in the next chapter. In general, underworld is the term used in this study to describe the students' turf, or the territory that belonged to students and where the adults' influence was deliberately shut off. Upon investigation, the student culture and their everyday life fueled much of the conflicts which resulted in school disruptions. The instances where a teacher sparked a confrontation was dependent on the interwoven, complicated, and contradictory underworld of the students. In other words, an adult who was able to organize a riot worked with the students to accomplish his or her goal. There was a concern that subjects may be influenced in their responses if they knew I was once a school 
administrator in the district. However, my identity in the field was and remained a female university student who was interested in learning about what happened in the secondary schools. Except for one female subject, all the other subjects did not recall my position as a school administrator in the district. Since I had quit the position more than six years ago, most of the subjects in this study were not enrolled in secondary schools then. While all the subjects in the study belong to the same ethnic group as I do, their school underworld culture and experience was inexplicable to me. As a secondary school student in the late 1960 s and early 1970 s I did not witness any disruptions in my school or surrounding schools. In general, students were likely to be subservient to their teachers. We did not question the teachers' or the head teachers authority let alone blatantly disobey them. Most of the behaviors I encountered during this study were unimaginable during the late 1960 s and early 1970s. Therefore I confronted the present day school culture as an outsider. It was only after four weeks of work at the pilot school that I began to see a pattern emerge. The initial puzzlement disappeared as I began to understand the actions and behaviors of the students and to categorize relationships and events (Wax, 1971). The fact that I could speak the primary language of my subjects was an advantage. Many of 
the subjects could barely express themselves in English, although all of them had used English as the medium of communication in their schooling. I attributed this feature to the fact the students were not enthusiastic about learning.

\section{Topic}

Riots and class boycotts are viewed negatively in the community. The nature of this study meant that I would ask the subjects personal questions. The subjects and I had to discuss issues about the consumption of an illegal drug amongst students. Additionally, the nature of this study obliged me to ask the subjects to talk about violent and brutal behaviors. These were very sensitive issues. Trust and good rapport were key to a fruitful investigation and had to be cultivated. The subjects needed to feel at ease to talk about personal and negative issues, while the school administrators needed to feel confident that their confidential information did not become public knowledge. There are no explicit legal requirements for research and scholarly work as long as the researcher has a permit from the office of the president. Despite the fact the permit authorized me to ask any questions that were pertinent to my study, the cooperation of the respondents was essential. If subjects became either suspicious or wary, the purpose and the intent of the study would have been jeopardized. 
Students who engaged in violent behavior were expelled from school. It would have been unethical and impractical to organize interviews with the students who were enrolled in the schools during the study period. It is likely that those students would have felt intimidated if asked about violation of school rules, the usage of bhang, and violent behaviors. All these issues were at the core of this study. It is more likely that the students would have been less candid and would have painted a false picture of events in order to protect themselves and their friends from any suspected fallout. To protect the subjects and the integrity of the study, I interviewed the ex-students. In all cases, the subjects left the institutions between 1990 and 1994 . Most of them recalled the key events and incidents clearly. The memory of the student culture and the everyday life in a school context was vital. Most students recalled the general schooling experiences vividly and they remembered the roles they played in disruptions that occurred in their schools. Besides, they had opinions, ideas, and strong feelings about the student collective culture that instigated most of the riots and boycotts. The fact that this was a multiple perspective and multiple method type of study gave me confidence in the emerging theory. 
The examination of school records authenticated the stories that the subjects narrated. Many incidents and experiences of the respondents were triangulated by the intensive examination of the school records and the teachers' interviews. The unique experiences of each site, the dates of significant incidents, and the descriptions of the major events contextualized the interviews. The fact that I had read and knew the happenings gave the respondents the impression that they were conversing with an acquaintance and not a total stranger. They responded with enthusiasm and excitement as they told their stories about significant incidents and behaviors. The rapport enriched the data.

\section{Research Design}

A research design is the logic that links the data to be collected to the initial questions of the study. It is a logical model of proof, or a blueprint of research. The design addresses the issues concerning what questions to study, what data are relevant, what data to collect and how to analyze the results (Yin, 1989). This investigation was informed by the sociology of everyday life as established by the social interaction framework. Therefore the nature of the study and the analysis of data made a naturalistic investigation necessary. A naturalistic investigation has two modes of inquiry, the 
exploration and the inspection phases (Douglas et al., $1980)$.

In the exploration phase, the researcher seeks a firm ground on which to stand and to reconstitute a "self" with which to operate. Although I had been a teacher and a school administrator, I could not operate in either of these roles during the field study. I needed to seek a definition of who I was and what I was doing in the research sites (Wax, 1971). My former positions as a teacher and a school administrator in the district were both an asset and a liability. They were an asset because some gatekeepers related to me and trusted me to access their school records. It was a liability when I needed to enter the field and obtain candid and unbiased data from one-on-one interviews.

In the field, I went through relearning in order to establish relationships that would help me learn what I wanted to find out. I learnt how to engage young people to discuss about themselves and their friends in an atmosphere devoid of suspicion. During this period, I discovered what I could not do that I had hoped to do. Other avenues of investigation were discovered and exploited (Wax, 1981).

The design of the study called for flexibility (Marshall \& Rossman, 1989; Biklen \& Bogdan, 1992). The study plan proposed prior to the field study was modified, 
altered and changed during the exploration phase. The research design evolved as I learnt more about the setting, the subjects and the sources of data through direct examination. As Biklen and Bogdan (1992) advised, I made several decisions throughout the qualitative study. Among the decisions made, the major decision was to employ a pilot study and abandon the survey study conceived during the planning stage.

The pilot study utilized case study strategy for the sole purpose of understanding disruptions which are a complex social phenomenon. The case study as a tool for investigation allowed me to obtain holistic and meaningful characteristics of the incidents that precipitated and accompanied riots and class boycotts. Since the disruptions and boycotts under investigation were an intricate social phenomena and there was no clear boundary between the phenomenon and the context, a holistic view was necessary for an overall understanding. It was difficult to separate some variables for a survey construction because the context and the phenomenon were entangled and intertwined. Administrators, teachers, the support staff, and the local community were all part of the broader context.

Since the administrators and teachers were a part of the context, I decided to interview the deputy head teachers and a few teachers in some sites. This decision 
was made during the field study because I had not planned to interview the staff before entering the field. Given the nature of the phenomenon, it was mandatory to listen to the adults' stories in order to cross check and validate what the respondents said in the open-ended, oneon-one interviews. Additionally, the observations and perceptions of the staff members enriched the data because they provided a perspective that differed from that of the students.

Pilot Study Employing the

Case study strategy

The school coded school A was selected as a pilot study site on the basis of theoretical sampling. The intent of the case study of school A was to obtain multiple perspectives about various forms of disruptive activities. Teachers and students were interviewed and all school documents pertinent to the study were examined. Because school A had experienced riots and boycotts since 1979, it served as a suitable theoretical sample. Theoretical sampling as exemplified by Glaser and Strauss (1967) is:

a process of data collection for generating theory whereby the analyst jointly collects, codes, and analyzes his data and decides what data to collect next and where to find them in order to develop his theory as it emerges. (p. 45)

school A is a large all boys' boarding secondary school. It has 640 students. There are 42 teachers of 
whom 30 are male and 12 are female. The school was selected because it had experienced riots and class boycotts since 1979. From a theoretical sampling perspective, I was confident I would obtain data which would provide the initial insight into a very complex social phenomenon. The use of a case study strategy allowed me to employ qualitative methods of inquiry which comprised open-ended interviews and examination of records and documents.

In addition to obtaining theoretical insights, school A was physically accessible. In a country where many roads become impassable during the rainy weather, school A was near an all weather road. More importantly, the gatekeepers were willing to accommodate me in their daily schedule. They willingly permitted me to have access to the school records.

school records. There were three categories of school records at school A. These comprised a school disciplinary book compiled by the deputy headmaster. This document had the names of the boys who had been expelled or suspended for misbehavior and actions that defied the school rules or rules of etiquette. Individual student files were the second category of school records that I examined in school A. If a student was in the deputy headmaster's summary sheet, his personal file was 
requested from the school clerk. The third category of school records at school A was the headmaster's log book.

School disciplinary records of the pilot school. Disruptions of normal schooling processes are conceived as a gross misbehavior in Kenya's education system. The disciplinary cases compiled and kept by the deputy headmaster in school A contained the names of the students who had been suspended or expelled for leading or actively being involved in the riots. These records contained a chronology of other misbehavior that were catalysts of the violence that accompanied disruptions. The detailed information about student covert activities included: reports about boys apprehended by the watchmen as they sneaked out of the campus, anonymous literature, smoking and bhang peddling cases, and cases about the harassment of form one students. Included in these reports were the reasons that the boys gave to teachers as to why they engaged in disruptive acts. Some of these included: boys wanted to be given what they defined as "free" weekend, some boys complained that they had been retained in class, others complained that they were made to draw water from the river, and that punishment was too severe.

The records obtained from the school files gave me information about the major disruptions that had occurred in the school. Some of these incidents included what the boys defined as "three days" hunger strike which commenced 
on September 14, 1992 and ended on September 18, 1992 when the school was temporarily closed. The other major incident was the attack on the Riverside secondary School by the school A students.

Every subject in the sample remembered the "hunger strike" vividly. It was an excellent context for discussing the everyday reality of school $A$. The respondents were able to provide anecdotes and stories pertinent to this disruption and why they participated in the activities that precipitated the riot. In the indepth interviews I requested the subjects' opinions and meanings of all recorded incidents of disruptive behavior. All the incidents that were memorable because they were dramatic, violent, or weird were recorded in the field worker's memo and used to provide a context for the interviews. The fact that I knew some happenings and indeed the argot that the students used made the subjects feel comfortable and at ease. The cooperation enabled the interview process to transform into an opportunity for the respondents to reflect and to reminisce on old jokes and their school experiences that in most cases provoked humor.

student files at pilot site. The personal files of students contained biographic information of the students which included: their date of birth, date of entry to the 
school, their church and villages, the last primary school they attended, and their parents' names and occupation.

The material in the individual files comprised letters of suspension or expulsion and any other punishments given to a student. I also found letters of apology written by some students when they were asked to do so by the school authorities. In the records, the penalties given to student for wrongdoing included orders that the culprits pay for articles or money grabbed from the weakest members of the community, normally the form one students. The data from the individuals' files enabled me to see the human beings in an intertwined and intricate scene. The effect that the riots have had on the education of the young men was reflected in a rather personal way. The social phenomenon had a human face as I reviewed the personal files. I managed to get information on 27 students who would be potential candidates for recruitment as respondents.

Headmaster log-book at the pilot site. A head teacher is expected to keep a log-book in which he notes the important events in a school year. If a log-book is well kept, it should contain all incidents of school disruptions. However, many head teachers are not keen to keep entries about disruptions because a school disruption is perceived as a reflection of some weakness in a head teacher's leadership. Fortunately, there was a 
substantial number of entries at school A. The outline of the school's disruptions could be grasped by merely reading through the log-book. However, the history and the detailed accounts of disruptions were in other school records.

It was recorded that riots and class boycotts started in 1979 at school A. The headmaster then attributed the problems to the sudden increase of student population and the fact that the school admitted more local students than it did before. The term "local students" means students whose homes are in Kirinyaga district and are more likely to be less than 20 miles radii from the school campus.

Recruiting subjects for pilot study. After spending three weeks studying the documents at the pilot school, the topic became familiar, and I started to focus on the relevant data. There were many events and incidents since 1979 that were related to disruptions. The volume of the material would have blurred the intent of the study which was to understand why students engaged in actions that disrupted learning and other school processes. Since the main goal of the study was not a description of the entire field but to gain enough understanding to discover the grounded theory (Glaser \& Strauss, 1967), I limited the period in which this study would be located to make the goal more focused. 
Accordingly, I focused on the period between 1990 and 1994. This time frame was significant in a number of ways. First, it was more likely that the students who went through the school during this period had not forgotten the incidents and behaviors that led to disruptions because the period between 1990 and 1994 was not far removed in years. Secondly, many of the students who left school during this period were unemployed and were likely to be at home. They would therefore be available if requested to participate in this study. Last and most important, the records showed this period had the most visible and frequent incidents of school disruptions. As Keniston (1965) argued, one has to study the extreme in order to understand the typical.

The goal in the recruitment exercise was to obtain subjects who would help in the development of theoretical insights. To accomplish this goal, the plan which was conceived before the field work began intended to recruit respondents from a pool of students who had been suspended or expelled from the school for engaging in disruptive activities. It was hoped their stories would help me to build a grounded theory concerning students' perceptions of riots and class boycotts.

The biographic information from the personal files of students was used in the task of contacting the exstudents so that they would be requested to participate in 
the study. In Kenya, it would be futile to contact people through mail or telephone. Telephone communication is almost non-existent for the larger part of the population. There are extremely few individuals who have telephones in their homes. As far as mail communication is concerned, many people use public post office boxes. The use of public post office boxes is inefficient and not dependable. Mail is not delivered to homes. I could not therefore depend on the easy and convenient methods of communication with the ex-students.

I designed three stages to enable me to recruit respondents. Initially, I contacted an acquaintance in the nearby town who was likely to know a number of the exstudents of school A. This school is situated about 500 yards from the town center. The second stage was to interview the recommended ex-students and find the most suitable person to use as chief informant. The chief informant's duty was to contact and request any of the students recorded in my field notebook to participate in the study. These were the students who had been expelled by the school authorities for leading or being participants in disruptions.

After I identified my chief informant, I invited him to study the 27 names on my notebook's list. He identified six students and agreed to contact and request them to participate in the study. My chief informant was 
a prefect during the 1993 school year. He was cooperative and willing to contact all the students that I wanted to interview. I instructed him to tell the participants that my intention was to discuss their views about schooling and the information was to be used in writing about the feelings of secondary school students in my dissertation. I informed him that the participation was voluntary and that no payment would be made for interviews. However, I would compensate the individuals who participated for the transportation costs from their homes to the interview site in the town center.

My chief informant contacted six students and I scheduled an interview for each of the six young men. Only three of the six subjects turned up. Three days were wasted because the expected respondents did not turn up. I discussed the situation with my chief informant who informed me that he knew other students who were not expelled or suspended but were very active in planning and executing school disruptions. I told him to invite those other individuals. Fortunately the individuals he contacted agreed to participate in the study resulting in fruitful one-on-one interviews.

The three subjects who were not on my original list provided critical insight not previously considered. I learned from those very respondents that the majority of ring leaders and the active participants were not expelled 
or suspended. Many of the subjects confirmed "innocent students" were expelled because teachers were unsuccessful in penetrating the underworld of students. There was evidence that some of the many ring leaders were not caught or punished. For instance, one of my three respondents who had not been suspended or expelled gave information on how he and his friends participated in the invasion of Riverside secondary school. He revealed that he and his friends damaged the television set and stole video cassettes from the Riverside's school hall. To use his words, he said: "we damaged everything we could find and then we beat them."

The chief informant asserted that it was difficult to find a student who did not in one way or other participate in the riots and boycotts. The student underworld was structured in such a way that every student had to participate in the disruptions or risk being labeled a "traitor" or "team-seller." These terms are explained in detail in the next chapter. If one received that label, the price which he paid was enormous. In boys' schools, the perceived "traitors" were likely to receive a thorough beating and sometimes paid fines. I did not talk to any respondent who did not feel strongly that he would have done anything and not risk the danger of being labeled a "traitor." The concept traitor was a taboo to many respondents. Given the nature and structure 
of riots and boycotts, the pool of possible respondents was bigger than I expected.

Teachers as respondents in the pilot study. Rioting is an intricate social phenomenon. An investigator of this problem soon realizes how difficult it is to divorce the phenomenon from its context. In order to have a grasp of the issues, I realized a multiple source of evidence was not only essential but mandatory. The original plan before the field study was to specifically determine the perspective of the student population without indulging into what teachers thought or felt about the disruptions. However, the reality in the field became clear that the deputy head teacher was fully entangled in his schools' disruptions. In fact many of the respondents at the pilot school blamed the deputy head teacher for the problems at the school. Other teachers were blamed as well. Teachers and school administrators were undoubtedly part and parcel of the phenomenon. If the context of the phenomenon was overlooked the study about disruptions would have been incomplete and possibly lopsided.

Consequently, the nature of the phenomenon forced me to interview the deputy headmaster and one selected teacher in school A. The multiple perspective brought into the study was valuable because as Yin (1989) asserted it is difficult to determine the boundary between a complex social phenomena and its context. 
Due to the nature of his duties, the deputy headmaster often confronted the crises; trying to find who the culprits were and what punishments were appropriate for them. He was always a part of the larger context of the phenomenon. The records indicated that if the students planned to boycott meals or classes, some boys surveyed the deputy headmaster's movements to make sure he did not note their activities. Sometimes students staged riots for the sole purpose of challenging and confronting him. Many of the subjects interviewed were discontented with the way the deputy headmaster handled them and their affairs. One of the subjects bluntly said that until the deputy at school A left that school the students would continue to express their displeasure through activities that disrupted the normal schooling processes.

The information obtained from the deputy headmaster clarified, described, and explained the issues from the texts that were difficult to grasp. For instance, I was puzzled about why students generally appeared to admire their informal leaders although they were academically weak. The deputy headmaster explained that although the informal leaders were academically weak, they inspired admiration from the average students because they had a special ability of antagonizing school rules with impunity. He clarified that the informal leaders became popular because they used their leadership skills to 
entertain and humor their colleagues. They articulated what students cared about in a language that the students understood and admired. Ultimately, these students used popularity and leadership skills to influence other students to disobey the school rules and regulations. After all, they were the leaders in the informal sector of the school establishment the "underworld" which did not believe in the school rules.

When I was reading the notes, I learned one of the reasons that instigated students to riot was the fact that a teacher on duty had seized T-shirts. From my experience this did not appear to be a justifiable reason for students to want to boycott classes. I asked the deputy headmaster to explain the significance of the T-shirts incident. He explained that although the T-shirt issue was relatively minor, it was used to spark a riot because boys were unhappy and were looking for any reason to cause trouble. He also explained the boys' unwritten code of "never informing a teacher or any person in authority anything that may put a school mate into trouble." His experience was that if he asked any student to disclose a name of a wrongdoer, the answer was expected to be "I don't know his name" even if the wrongdoer was the student's closest confidant.

The interview with the longest serving teacher who had witnessed the changes in school A was illuminating. 
This teacher had been in the school since its inception in 1961. He had lived through the everyday reality of that school for the last 34 years and had witnessed the changes in the society and the school over the years. His perspective was convincing and insightful. He shed light upon the generation gap. According to this teacher, the last generation admired and honored learning because schooling gave hope. Today the school was pervaded by an air of uncertainty and what he called "hopelessness." The values had changed but the school's way of doing business had not been restructured to accommodate the changed values. He said boys would rather have a piece of land than secondary education. His comments signified the enormous changes that have occurred in the society in the last 20 years. Twenty years ago, secondary school education was considered a great treasure. All young men then looked forward to enrolling in a secondary school. According to this teacher, many students are not hopeful as they used to be in the past.

Researcher as Instrument

Glaser and Strauss (1967) hold the position that a theory that emerges from the data and the analysis of qualitative data is in one sense equivalent to what the researcher herself knows systematically about her own data. This position emphasizes the fact that a researcher who hopes to analyze the qualitative data systematically 
must be the principal and most reliable instrument of observation, selection, coordination, and interpretation. To become an efficient instrument the researcher must be able to record, categorize, and code (Sanday, 1983). From this perspective of researcher as instrument, the examination of archival records and interviewing were tools that were employed for better understanding of the phenomenon.

To study the perception of students about school riots and class boycotts was complicated because all the incidents had already taken place and no observation was possible. However, the examination of records, the interviews with the ex-students who made the incidents happen, and with teachers who saw them happen, were the only strategy available to me to become immersed in the everyday realities of each school site. This strategy was invaluable in enabling the understanding of incidents and anecdotes in the data.

The case study helped me to focus on the emerging categories which would fit and be relevant to the data. At the end of the pilot study, I identified four core categories. According to Glaser and Strauss (1967), a core category has the most explanatory power while other categories exist, a researcher's goal should be to ensure the core categories are "saturated as completely as possible." (p. 70) 
More evidence of the key concepts was needed to establish the authenticity and validity of the experiences and explanations. Using theoretical sampling technique five other sites were selected for further data collection and data analyses. The goal was to discover a sound grounded theory. According to Glaser and Strauss (1967) a grounded theory:

fits empirical situations, and is understandable to sociologists and layman alike. Most important, it works - provides us relevant predictions, explanations, interpretations and applications. ( $p$. 1)

To arrive at a grounded theory that "fits" and "works" I had to constantly compare common and divergent incidents and events in all sites. This methodology is technically known as the constant comparative methodology.

Biklen and Bogdan (1992) have described the constant comparative method of data analysis as "pulsating," first with the interview, then the analysis and theory development, another interview, and then more analysis. The steps for constant comparative method described by Biklen and Bogdan (1992) were employed during the field investigation. The activities involved in the process were:

- begin collecting data

- look for the key issues, recurrent events, or activities on the data that become categories of focus 
- collect data that provides many incidents of the categories of focus with an eye to seeing diversity of the dimension under the categories

- write about the categories explored attempting to describe and to account for all the incidents in the data while continually searching for new incidents

- work with the data and the emerging model to discover basic social processes and relationships

- sample, code, and write as the analysis focused on core categories

By constantly comparing the evidence from the subjects' stories and the data from the records, I was able to generate conceptual categories and their properties because the underlying uniformities and diversities that accounted for the disruptions, developed a conceptual framework. The conceptual framework identified four core categories which emerged from the data and are labeled: "spontaneous reactions," "organized reactions," "the community interference" and "the loss." The goal of the case study. Through the case study I was able to establish a pattern for gathering data in the other five sites. Upon gaining entrance to a site, I started the reading of school and official documents that were made available to me and those that I requested. After recording the significant data I went outside the 
school campus and made arrangements to contact the exstudents.

From the experience gained at school A I decided to locate the investigation on incidents and events that had occurred between 1990 and 1995. The information prior to this time period was not to be included in other school sites. The subjects who did not experience the riot happenings between 1990 and 1994 were not to be selected for the interviews. The experience at the pilot school had demonstrated that ex-students who had been absent from school for two to four years had fresh memories about the everyday life in the schools. The intent was to select respondents who would be able to describe and explain the student culture vividly, as well as provide their opinions about the riots that occurred at the sites.

The knowledge gained from the pilot study gave me confidence that I did not need to interview the exstudents who had been expelled or suspended. Accordingly, there was a re-definition of the subjects to be selected for interviews. The respondents to be selected had to be individuals who recalled the student culture vividly, and who related to the events and incidents that precipitated riots in respective schools. The selected persons would be able to tell their personal stories, narrate their experiences and the experience of others before and after the disruptions. 
After the case study, I determined to interview deputy head teachers and some teachers because students were often the actors and in most cases they did not have a mental picture of the disruptions' impact. The members of the staff filled this vacuum and enabled me to conceptualize the holistic view of the disruptions. They also helped me clarify puzzling incidents or the incidents that were difficult to grasp. Moreover I came to learn that some teachers were victims of the riots and boycotts. The one-on-one interviews with selected teachers was an opportunity for them to tell their personal stories and the impact that the riots had on them and their careers. This process gave me an insight into some areas that a student-respondent would not comprehend. Teachers' perspective was important to the overall picture of the disruptions. For example, during the interview with Mr. Bridge of school $B$, he said he could never reside in the staff houses on campus because of the terrible experience he had when students attacked him. This comment gave me an insight into the teachers' trauma. The studentrespondents would not have been able to know the impact the disruptions had on teachers.

\section{Interview Guide}

Rationale: Interactive interviews were philosophically compatible with the objective of this study. That is, the study was intended to be an 
interpretative inquiry: generative rather than conclusive and inductive rather than deductive. In this study, the aim was to understand the phenomenon and the concern was as much with the process as with the product. Thus, in the design and the analysis of result, credibility was to be given to respondents' subjective experience and idiosyncratic constructs (Bancroft, 1994).

In addition to the philosophy underlining the interviewing process, the general questions that gave focus to data collection were formulated to give the core categories and their properties more evidence. The questions that gave focus to the data collection and helped to organize the data from site to site were:

1. Describe the things that students did in their dormitories, dining hall, classrooms, and the field when the teachers were absent?

2. Who planned the boycotts or "strikes?" How were they planned? What do you think the boycotts and strikes accomplished?

3. Describe the teacher-student relationship in your school. Did students work closely with teachers? Why or why not? Give your personal feelings.

4. Did you feel the outsiders interfered with your school? If so, how? Did any outsiders initiate strikes? If so, describe the event and describe your feelings and the feelings of the other students. 
The above interview protocol is a mere guide to an in-depth interview. In-depth interview, according to Bogdan and Taylor (1984), is a repeated face to face encounter between the researcher and informants directed toward understanding informants' perspective on their lives' experiences as expressed in their own words. Far from being a robot-like data collector, the interviewer, not an interview protocol, is the research tool. In-depth interviewing method of collecting data was necessary because the school-disruptive behaviors under investigation were past events. During the in-depth interviewing of the ex-students, the subjects were encouraged to relate their personal experiences about the school's everyday life. The everyday life context included the events, incidents, dramas, and the issues that often precipitated riots and class boycotts. Through the in-depth interviewing strategy, the ex-students revealed the student culture, that is, what students do, their myths, values, and morals (Douglas et al., 1980). The method that was used to conduct the in-depth interviews was face to face, one hour to an hour and half long. Substantive area questions relating to incidents and events that led to disruption of the normal schooling events provided the context for the interview process. open-ended and non-directive questions were asked and the subjects were encouraged to give their personal stories 
and experiences in their own words. They were also encouraged to speak about their classmates' feelings, experiences, and views. The goal was to make the tape recorded interviews as corroborative as possible to give the subjects an opportunity to provide fresh commentary about the issues.

While the organizing and thinking was done in English, Gikuyu was used during the interview session. The use of Gikuyu allowed the subjects to feel at ease as they expressed their feelings and their thoughts in the narratives. Although all students used English as the medium of communication in their schooling, their expression in English inhibited the expression. Later the interview transcripts were translated into English for analysis and interpretation of the findings.

As the respondents gave their personal stories, their opinions and feelings, core categories, and their properties were explored in this multiple site study. Ultimately, the data were scrutinized for the purpose of determining the diversity and commonalties of the categories and their properties. Categories were given fullest possible development achieved by comparing many groups, irrespective of differences or similarities as long as the data applied to a similar category or property (Glaser \& Strauss, 1967). 


\section{The Sample}

The criteria of selecting the schools that were included in the theoretical sample were multifaceted. First, the school included in the sample had experienced a disruption between 1990 and 1994. Secondly, the school was physically accessible and the gatekeepers were willing to accommodate me in their school schedule. This is because I required a table or a desk to work on and moreover I needed the assistance of a clerk to access files and other necessary materials for examination. Thirdly, each school was required to represent the crucial descriptive data which were: history and gender composition. Since disruptions had occurred in boys', girls', and co-educational schools and in both catholic and Anglican schools it was critical that the selected schools represented these features. To make the grounded theory fit all empirical situations different types of schools had to be considered during the purposive sampling.

Included in the sample were three boys' secondary schools, two girls' schools, and one co-educational institution. Three schools were started by the Anglican church and three were initiated by the catholic church. A theoretical sample with diverse schools enabled me to suggest inter-relationships and to build a conceptual framework. 
The selected schools were diverse in terms of student history and the gender composition. Schools A, C, and F were started and therefore sponsored by the catholic church while Schools B, D and E were initiated and therefore sponsored by the Anglican. The role of a church sponsor is political because if a church is the sponsor of a certain school, it has a political advantage in the selection and appointment of the Board of Governors. However the Education Act allows any student of any faith to attend any school of his or her parents' choice. Before Kenya's independence, school admission was determined by a person's faith. Catholic students were more likely to attend Catholic schools, while the students of a Protestant faith were more likely to enroll in the schools sponsored by the Protestants which included the Anglican church. In the sample, this historical background was taken into account so that schools started by various churches were equally represented in the sample.

Despite the diversity in the historical backgrounds, the data collected from the three boys' schools revealed a pattern of similar categories and properties. The properties of the identified core categories had very slight variations. The co-educational institution had other categories of interest but the four core categories identified with most explanatory power were developed 
further. In the two girls' secondary schools, the diversity in the properties of the four core categories was clearly noticeable. There were other categories of interest in the girls' schools as well. The investigation that took four months of field work enabled the researcher to "saturate" the core categories and to provide sufficient evidence of the categories. Continuous coding, analysis, and collection was adopted as the underlying operation in the field study. The operation was in keeping with the notion of theory as process (Glaser \& Strauss, 1967). The end product of the exercise was intended to be a discussional theory with the final analysis covering many properties of each category.

School $E$ and school $F$ are the codes that are given to the two girls' schools that are included in the sample. School E has had two disruptions between 1990 and 1995 while school F had only one disruption during the same period. On the other hand, all the boys' schools coded A, $B$, and $C$ included in the theoretical sample had more than 10 disruptions during this period while the co-education institution coded $\mathrm{D}$ registered about five disruptions. Although the driving force behind the selection of the sites was their potential in building a sound grounded theory, I would argue the sample is also fairly representative. In the district there are 8 boys' boarding secondary schools. If three of these schools are 
in the theoretical sample then this is an approximate $35 \%$ representation. There are 12 girls' boarding secondary schools in the district. of these, two are included in the sample which is approximately a $16 \%$ representation. on the other hand, there are four co-educational schools in the district and one is included in the sample, an approximately $25 \%$ representation. Overall, the sample included an approximately $25 \%$ of the boarding schools in Kirinyaga district. Table 4 shows the distribution of the sampled schools according to the criteria used in theoretical sampling.

Table 4

Distribution of Students According to Type of School and Number of students

\begin{tabular}{|c|c|c|c|}
\hline School & Type & History & Student Population \\
\hline $\mathrm{A}$ & Boys & Catholic & 640 \\
\hline B & Boys & Anglican & 465 \\
\hline $\mathrm{C}$ & Boys & Callolic & 480 \\
\hline D & Co-Educational & Anglican & 140 \\
\hline $\mathrm{E}$ & Girls & Anglican & 460 \\
\hline$F$ & Girls & Catholic & 321 \\
\hline
\end{tabular}

Criteria used in the selection of subjects. The selection of the subjects was based on the willingness of the subject to participate in the study. Secondly, the respondent was required to have attended a school in the sample during the period between 1990 and 1994. Every 
student was assured that the information given during the interview would remain confidential and would in no way be used against him or her. The total number of ex-students who were interviewed was 29. Most of the subjects were between 20 and 26 years of age. The names of the subjects were disguised to hide their identity and to maintain the confidentiality promised at the beginning of every interview.

The pseudonyms adopted are not Gikuyu but are names that the readers would easily pronounce. All the names of the subjects at site $A$ have $A$ as the initial letter. They are Anthony, Arnold, Andrew, Alex, Arthur and Alfred. At site $B$, the names given to subjects are Bosco, Benson, Bernard and Burt. At site $c$, the subjects are chuck, Chase, Charles, Cook, Cooper, Castro, and chris. At site D, they are Dick, David, Doris, Dorothy, Diane, and Daisy. At site $E$, the names given to the female respondents are Elizabeth, Elaine, and Edith while at F, Florence, Faith and Flinder were selected. Table 5 shows the distribution of respondents by school sites.

All the interviews with the ex-students were taperecorded, translated, and transcribed. The transcripts were hand-written in a clear and intelligible style by another person who was not associated with any of the sites. 
Table 5

The Distribution of Subjects

by school sites

School Site Codes

Number of Subjects Interviewed

\begin{tabular}{|l|l|}
\hline School A & 6 \\
\hline School B & 4 \\
\hline School C & 7 \\
\hline School D & 6 \\
\hline School E & 3 \\
\hline School F & 3 \\
\hline
\end{tabular}

The total number of interviewees was 29

Interviews with staff members. Since deputy head teachers are the custodians of the disciplinary matters of the students, the deputy head teachers in selected sites except site $E$ were interviewed as informants. The interviews with deputy head teachers site $A$, site $B$, site $C$, and site $D$ were tape recorded and transcribed. The interviews with the deputy headmistress of school $\mathrm{F}$ was not tape-recorded; instead notes were taken during the interview. The interviews with the longest serving teacher at school A was not tape recorded, but notes were taken during the interview. The decision not to tape record some interviews was based on the content of the material to be discussed. If the discussion was expected to be straight forward and did not entail detailed and complicated explanations or descriptions, note taking was adopted for convenience. The interviews with two teachers 
at school $B$ had to be tape-recorded because the content of the descriptions and explanations were detailed. The teachers' interviews complimented the ex-students responses where I felt an idea or a fact needed further clarification and explanation. In connection with this, I interviewed the ex-deputy headmistress of school $D$ because she was the sole target of a brutal school riot that occurred on March 26, 1995. After this incident she requested for a transfer from school D. Her personal story regarding this phenomenon provided some insight for the analysis. Table 6 shows the distribution of the staff members that were interviewed.

Table 6

The Distribution of Staff Members Interviewed by site and status

\begin{tabular}{l|l|l|}
\multicolumn{2}{l}{ Site } & \multicolumn{1}{l}{ Status } \\
\hline \hline School A & Deputy H/M and a Tcacher & 2 \\
\hline School B & $\begin{array}{l}\text { Deputy H/M and Two } \\
\text { Teachers }\end{array}$ & 3 \\
\hline School C & Deputy H/M & 1 \\
\hline School D & Two Deputy H/Ms & 2 \\
\hline School E & None & 0 \\
\hline School F & Depuly H/M & 1 \\
\hline \hline TOTAL & & 9 \\
\hline
\end{tabular}

Interview with the Deputy District Education officer. The Deputy District Education officer works at the district central office. I sought his comments and 
feelings about the happenings in the schools. He was kind enough to accept my request for an interview for which I did not request tape recording. Instead, I wrote notes during the discussion because there were not many issues that required detailed explanation. His comments were surprising but I learnt the official view of school disruptions. The information gained was invaluable for the interpretation and analysis of the data within the broader societal context.

The field notes. The theory as process strategy adopted in this study allows theory to become rich, complex and dense making it fit and relevant. It is based on the philosophy that theory is an ever-developing process and not a perfected product. This point of view in doing research made note-taking a valuable tool for me. The field notes were reflective in nature and allowed one to code, collect, and analyze data at the same time.

I noted the unique and peculiar situations in each of the six sites. For example, in site $B$ the subjects were not as forthcoming as the subjects in other sites in talking about bhang. Bhang is an illegal drug in the country. It acts as a depressant in the human body and makes the users more likely to be violent. Additionally, people who use bhang are held with contempt and scorn. I consulted the teacher interviewees to explain to me as to why the subjects were inhibited in discussing bhang 
use. The teachers suggested that the village where the subjects were residing was the major supply avenue of the drug and the respondents could not trust an outsider with information that had the potential to indict their neighbors, themselves, or their relatives. The subjects were aware that if I were an undercover police officer any information given to me may be used to send them, their relatives, or their neighbors to jail.

The two riots that occurred at site $A$ and $B$ on July 25, 1995 and october 21, 1995 respectively were recorded in the field notes because they took place long after I had moved from those sites. The sites were visited later on and the deputy headmasters were requested to explain and describe those incidents.

The fact that the disruptions were current further confirmed my theory that the strong, negative, and integrated student culture was the major source of many disruptions. Until the student culture becomes positive toward the normal schooling processes, the absence of riots even for a year is only a break but not a lasting solution. The student culture is like a timed bomb which can go off at the slightest provocation creating a scene of an uncontrollable riot. For example, when doing the field study in school $A$ and $B$, there was an apparent calm that pervaded these sites, however the calmness was a 
blanket of a integrated and complex culture which set off the riots in July and october respectively.

In the field notebook, information about four other riots in the district which occurred in schools not in the sample was noted for analysis because they took place while I was still in the field. Information that I received indicated that some schools had such violent riots that the head teachers had to temporarily close the institutions. Others had to suspend the trouble makers. These occurrences while I was still gathering data in the field further confirmed my contention that one can generalize the findings of this study to all district schools. I have given pseudonyms to other Kirinyaga schools discussed in my notes and referred to during the interviews to protect their identity. Some subjects had been to other schools in the district not in the sample so these schools were mentioned constantly. Other schools were discussed by various informants while I was doing the field study. Since the information about other institutions was relevant to this study, I noted the happenings as narrated by informants in my field notebook (see Table 7).

Additionally, there were other schools mentioned in the data because the students had attacked them during the inter-school conflicts. Inter-school conflict is one of the several types of riots identified in this study. It 
was surprising to learn so much about other schools not in the theoretical sample but the process gave more evidence to demonstrate the generalizability of the study. The field notes were also records of the dilemmas, problems, and surprises. They were also a collection of new ideas and what I took account of and thought about during the course of the field study.

Table 7

To Map Disruptions Outside the Sampled Schools Mentioned During the Field Study and Recorded in the Field Notes

School Type and/or Result of Disruptions

\begin{tabular}{||l|l|}
\hline "Riverside" Co-Educational School & - invaded by site A students \\
\hline "Valley" Co-Educational School & - invaded by site C students \\
\hline "Lakeview" Co-Educational School & - a riot occurred in Sept. 1995 \\
\hline "Crest" Boys' School & - disruption causcd closure Oct. 1995 \\
\hline "Forest" Boys' School & $\begin{array}{l}\text { - students transferred to site B led } \\
\text { disruptive activities }\end{array}$ \\
\hline "Roadside" Boys' School & $\begin{array}{l}\text { - riots and violence have resulted in the } \\
\text { diminishing of student population }\end{array}$ \\
\hline "Rice" Boys' School & $\begin{array}{l}\text { - making demands and threatening to } \\
\text { boycott }\end{array}$ \\
\hline "Mountain View" Boys' School & $\begin{array}{l}\text { - form two students destroyed staff-room } \\
\text { July 1995 }\end{array}$ \\
\hline Mt. Kenya Secondary School & $\begin{array}{l}\text { - head teacher cannot use his house at } \\
\text { school because of the behaviors of students }\end{array}$ \\
\hline
\end{tabular}


CHAPTER IV

DATA ANALYSIS

The analysis in this study was informed by the

constant comparative analysis. Glaser and strauss (1967)

asserted that theory in sociology is:

\begin{abstract}
a strategy for handling data in research, providing modes of conceptualization for

describing and explaining...the theory must also

be readily understandable to sociologists of any

viewpoint, to students and to significant

[laymen]. Theory that can meet these

requirements must fit the situation being

researched, and work when put into use. By

"fit" we mean that the categories must be

readily (not forcibly) applicable to and

indicated by data; by "work" we mean that they

must be meaningfully relevant to and be able to

explain the behavior under study. (p. 3)
\end{abstract}

In order to collect data that would describe and

explain the phenomenon under study, the research sites

were selected for the purpose of deliberately accumulating

evidence to build hypotheses and categories established in

the pilot study. Glaser and strauss (1967) argued that to

generate a grounded theory a researcher does not require a

random sample. According to these authors, a single case

can indicate a general conceptual category or property,

while a few more cases confirm the indication. The

purpose of this study was to generate conceptual

categories and to confirm the cases by constantly

comparing the categories in various sites. 
To accomplish the dual purpose, the research sites selected had unique qualities and characteristics. There were distinct difference and similarities in the integrated student culture particularly in all boys' secondary schools investigated. At the same time, there was a distinct absence of an integrated student culture in girls' schools.

\section{Research Sites}

All the six sites sampled are representative of the three types of boarding schools, boys', girls' and coeducational institutions. The gatekeepers of these institutions were willing to allow me to have access to the school documents. In some cases, some records were poorly kept and at times the information lacked coherence and structure. However, the information that was obtained from all the schools was significant. It gave me an opportunity to experience the unique everyday life of each site. The data collection exercise took approximately four months of field work, that is between June, July, August, September, and october 1995.

The descriptions depicted the basic uniqueness of each school site. This brought the essence of the phenomenon under study to the foreground. The design involved a progressive building up from facts provided in each site, through analyses of the emerging categories to 
substantive grounded theory. Every school included in this study was selected on the basis of its theoretical relevance. Thus, the schools' diverse backgrounds and populations helped further the development of the categories and their properties. An adequate theoretical sample was judged on the basis of how widely and diverse the categories were saturated. Saturation of categories means that no additional data were being added (Glaser \& Strauss, 1967). Below are the descriptive accounts of the individual school sites. The descriptions are not detailed but they depicted the outstanding features that distinguished each site from the others.

\section{Research Sites}

Site A: Boys' secondary school. This is a large all boys' secondary school. There are 640 boys in this school and 42 teachers. Of the 42 teachers, 30 are men and 12 are women.

This was the site used for pilot study. The study's plan was conceived before the field-work was tested for feasibility and practicality in this site. The total number of days spent in this school during the case study and afterwards was more than 40 . Most of the records in this school were comprehensive and detailed, thanks to a very efficient and dedicated deputy head teacher.

School A was opened on January 20, 1961, by Catholic Church missionaries as a secondary school for boys. In 
1962, it was taken over by the government and had 30 students. In 1966, the enrollment rose to 70 and the school became two-streamed. Today the school has four streams or tracks. The term stream means that a class of 160 students is divided into four groups for instructional and organizational purposes. In effect, a four-streamed school has a student population of 640 .

In 1979, this school experienced the first disruption of the normal schooling processes. The reason on record for this disruption was that students did not want to pick school coffee. Some schools grow crops for subsistence or cash. School A has a large 50-acre compound, and the Board of Governors resolved to plant coffee and keep cattle for the purpose of generating some additional income from the farm. Some schools have agricultural projects, others do not. Agricultural projects are not mandated by the Ministry of Education.

In 1983, another major riot occurred and no reason for the uprising was reported. The records indicated that on June 4, 1984, a student from this school was killed by several school B boys after a soccer match. Another entry in the log book suggested that in February 1987, the situation was so bad that the students were asked to go home. There was no concrete description of that situation. Additionally, in March 1987, it was reported some boys formed a protest march to the district 
headquarters. Soon after that protest march the head teacher was transferred to another institution.

To capture the essence of what plagued this school, the summary of the happenings between January 28, 1991, and November 1994 compiled by the deputy head teacher provided a comprehensive picture of the disruptions and how they affected the 1991-1994 cohort. In his analysis of the happenings, the deputy head teacher of school A gave the gist of the riots' effects and their widespread influence on the education of the young men.

The class that graduated in December 1994 experienced the first disruption in their first year on July 16, 1991, six months after enrolling on January 28, 1991. The next disruption occurred on February 18, 1992, when the cohort was in form two. It was recorded that the entire form two class was suspended. They stayed at home from February 18-27, 1992. Consequently, three students from the cohort were expelled. During the suspension, the 1991-1994 cohort lost a lot of instruction time. on september 11, 1992, some boys from the cohort burnt the school cow-barn and on september 14, 1992, the entire school boycotted meals and classes for three days. The school was temporarily closed and was re-opened on october 12, 1992. The students in the 1991-1994 cohort lost more instruction time and the normal schooling processes were severely affected. 
On January 20, 1993, the form two class disrupted the normal learning process affecting the learning of the entire school. The form two students were suspended for one week. They reported back to school on January 26 , 1993. Around this period some members of the 1991-1994 cohort were expelled because they were involved in bhang trafficking. on March 27, 1993, the entire student body invaded Riverside Secondary School. Some members of the 1991-1994 cohort were deeply involved in the damage caused to Riverside's property. No one was suspended but the incident disrupted the normal schooling processes for the 1991-1994 cohort. On May 22, 1993, a "terror gang" was exposed and members of the 1991-1994 cohort were involved. The activities of this gang were described by the deputy head teacher as "beastly acts." The gang members terrorized the lives of the form one students by severely beating them and demanding money, cigarettes, and bread from them.

On January 28, 1994, there was intense class warfare but the details were not recorded. While on February 21, 1994, the students defied the school authority and refused to have their luggage searched for illegal drugs and clothes that were not part of the school uniform. The mood of defiance pervaded the campus although the luggage of the students was not searched. Anonymous literature urging the students to boycott classes was littered on the 
campus. On May 1, 1994, the students interfered with the electric transformer and the evening studies and meals were disrupted. These disruptions continued for the entire month of May 1994. It was reported that another series of disruptive activities started in october 1994. The records indicated that the 1991-1994 cohort defied school rules and decided to walk out of the school campus any time they chose. It was indicated that the students walked to the town center instead of concentrating on their studies during the scheduled evening study time. The deputy head teacher's analysis shows that the 1991-1994 cohort had 182 students on admission day. On the graduation day, the number of that cohort had dropped to 125 students. This was a drop-out rate of more than $30 \%$. The drop-out rate resulted from the fact that many students were expelled after the riots while other students opted to leave the school. Table 8 depicts the disruptions that were analyzed by school A's deputy head teacher.

The analysis by the deputy head teacher underlined the adverse effects of disruptions on the learning process for all students. The systematic disruptions to the normal schooling processes was not the only unique feature of this institution. A detailed study of the student culture revealed that the students in this school perceived themselves as members of a team. As a team 


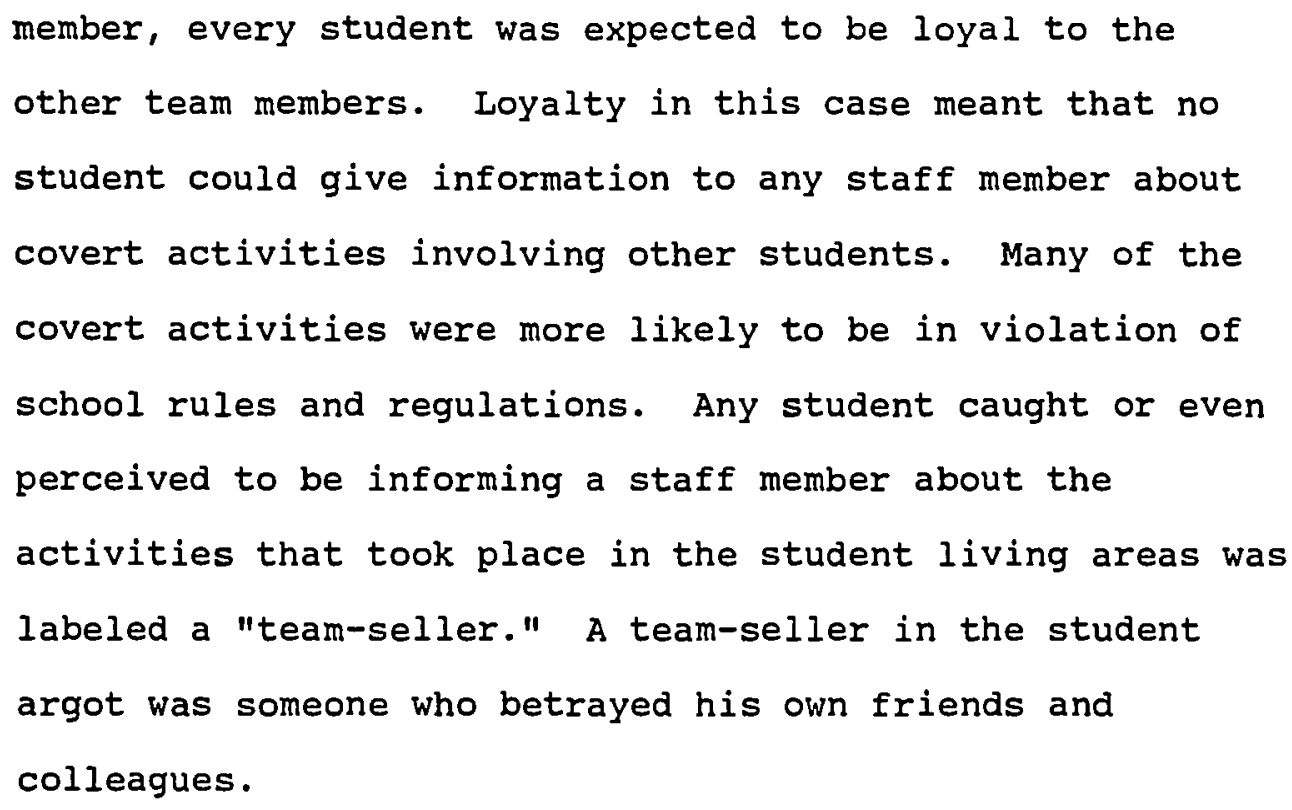

Table 8

Boycotts Affecting 1991-1994

Cohort in School A

\begin{tabular}{||l|l|}
\hline \multicolumn{1}{|l|}{ Year } & Disruptions \\
\hline 1991 & - July 16, 1991 \\
\hline 1992 & $\begin{array}{l}\text { - Feb. } 18 \text { form two suspended } \\
\text { - Scpt. 11 cow-barn burnt } \\
\text { - Sept. } 14 \text { students boycott meals } \\
\text { - Sept. 18 students sent home }\end{array}$ \\
\hline 1993 & - Jan. 20 form 2 disrupts normal schooling \\
& processes \\
& - Mar. 27 Riverside invaded \\
& - May 22 terror gang exposed \\
\hline 1994 & - Jan. 28 class warfare \\
& - Fcb. 21 refuse luggage search \\
& - May 1 "black out" \\
& - May constant boycotts \\
& - Oct. blatant disobedience \\
\hline
\end{tabular}

When I asked the deputy head teacher to explain the team-seller concept, his remark was that "students are 
devoted to the student solidarity." I later learned from my respondents that any student seen talking to the teachers was later quizzed by other students. During the quizzing, the students established whether they were sold or not. The idea of "team-selling" established a strong division between the teachers and students. The us versus them mentality pervaded site $A$. The team spirit that should be apparent in a learning atmosphere was clearly absent.

Site B: Boys' secondary school. This school was initially started as a co-educational institution in 1964 by members of the Anglican Church. The intent was to help the local boys and girls obtain a high school education. In 1971, the girls moved to a newly started girls' secondary school about six miles away, and school B became an all boys' secondary school. In 1983, the school expanded and became a two-streamed school. Today, the school is three-streamed with a population of 465 boys. There are 28 teachers of whom five are female and 23 are male.

The history of this school is the epitome of disruptions and their negative effect on learning and teaching. In 1991, the frequency of riots and class boycotts forced the government to close this institution for more than one academic year. On July 7,1992 , the government ordered a re-admission of students and the 
school re-opened with 282 students. I was not able to retrieve any information pertaining to 1990-1991

disruptions, the period before the school was closed. However, one of my subjects who was a student in 1990 and 1991 school years described the atmosphere of his school as "confusion all the time."

The story about riots and boycotts were not a thing of the past even after the school was closed for a full academic year. With a re-opened school, January 1993 witnessed boys rampaging through the campus causing damage to property. According to the records, the boys were embittered by the head teacher's announcement that the school television would be used for educational matters only. Later that night, the boys attacked the head teacher's house and killed his chicken. A female teacher's house was also broken into and her household items were destroyed or stolen.

Another disruption occurred on January 31, 1994. The boys threw stones on to the school administration block but the records did not indicate the reason for that outrage. On February 13, 1994, the students decided to punish the prefects. They caused chaos after deliberately destroying the electric transformer and thereby submerging the school into total darkness. After there was darkness, the boys threw stones on all school buildings and in the confusion some students set the prefects' dormitory on 
fire. The prefects escaped unhurt but the fire destroyed their belongings. The deputy head teacher informed me that the boys wanted to destabilize the perceived close relationship that the prefects had established with the teachers. Students felt their activities and actions which violated the school rules and regulations were being reported to teachers by the prefects. Thus, prefects were punished because they cooperated with the staff to create a suitable learning atmosphere.

On June 1, 1995, through the instigation of two members of the teaching staff, the students decided to take an unauthorized day off. It was indicated that the boys walked out of the school campus in the morning and returned at 5:00 p.m. This was a public holiday in the country but students were not supposed to go out without the head teacher's permission. In July 24, 1995, while I was collecting data at another site, the boys demanded that the school should not cook "githeri." "Githeri" is the dish commonly cooked for students in all boarding schools because it is cheap. The demand was unrealistic and was being used to spark a confrontation with the school administration. To make their point clear, they walked to the local trading center and harassed the traders. The traders were angered by the actions of the students because they lost their merchandise in the ensuing commotion. 
This school did not possess an efficient record keeping system. However, I managed to obtain information about individual students and their misdeeds from their files and other documents maintained by the deputy head teacher. Unlike site $A$, there were no comprehensive written narratives about what happened during any particular riot. Individual student files contained chronology of misdeeds and wrong doing. The chronology captured the essence of the problems experienced at this site fairly effectively.

In order to provide the essence of the disruptions in this school, I quoted three entries of the misdeeds of three ring leaders. I have disguised their names in order to protect their identity.

\section{"Bedan Camp"}

He was admitted to Forest Secondary school in 1990 and joined school $B$ in 1992. He uses bhang. On the morning of January 29, 1993, the head teacher addressed the students and instructed that the school television would be used for educational programs only in the future. After that announcement, Bedan and his gang started to block the other students from entering their classrooms. He participated in the discussion organized by other "new students" (This means the students who were not originally admitted at school B. These are the students who sought 
transfer from other Kirinyaga schools to school B.) The meetings organized by these new students addressed the fact that students at school B were under oppression because they were made to wake up early in the morning. These students also discussed the traitors issue. After the meeting, a riot occurred on the night of January 29, 1993.

"Brian Gate"

Brian ordered students not to go to class but go to the school hall to watch the television in defiance of the head teacher's instruction. He was one of the students who broke into a teacher's home and stole her photographs. He also participated in the killing of the head teacher's chicken. Brian instructed the students to cut coffee trees and use them as weapons in breaking into the teachers' houses and if possible hurt them. He also suggested that the teachers' belongings ought to be stolen. He along with others broke the main gate to the school on January $29,1993$.

"Baton Treetop"

Baton ordered other students to throw stones at the teachers' houses. He was heard cursing and shouting at the teachers. He was the person who destroyed the electric transformer and thereby caused 
a "black-out." (A black-out is the state of total darkness. This is the term used in many schools.) Along with others, Baton broke the main gate of the school and proposed to the other students that they should set the head teacher's car on fire. He was heard saying that, should they manage to capture a certain female teacher, they should rape her. Baton damaged the television aerials and was responsible for destroying the doors of the public tea-buying center to which they took refuge after fleeing the school on the night of January 29, 1993. It was reported that Baton sought to move to another school. He was therefore prepared to do anything so that he would be expelled by the school authorities of site B.

Among the schools in the sample, school B was the only site where students attacked the teachers. The records depicted a strong informal leadership in the student underworld. The concept of the informal leadership is explored further in the analysis.

Besides being the only site where students physically attacked teachers, school B was marked by an unusually high number of inter-class conflicts. One subject gave me the reason for inter-class conflicts. Using a matter-offact tone, the subject remarked: "In this school, the form three students had more power than the form four 
students." When asked to clarify what he meant, the respondent explained that there was no way the form four students could beat the third form boys. This was not in reference to any athletic or academic competition as one might imagine--the subject was talking about physical fights between the form four and form three students. It was not imaginable to the students how one could put up with the thought of being referred to as weak or cowardly. In the course of asserting their power and courage, disruptions to the normal schooling processes proliferated.

Site C: Boys' secondary school. This school was started by a Catholic Bishop as a single-stream school. In 1978, the school expanded and became a two-streamed school. Today the school has three streams with a population of 480 boys served by 28 teachers of whom nine are female and 19 are male.

When consulted about the beginning of disruptions at this site, the respondents implied there was no trouble in the school until the issue of a school bus came about. In Kenya, Boards of Governors of individual schools are expected to organize fundraising drives or require that parents donate money for the purchase of school buses. A school bus is a very valued item because it provides students the means to tour and to attend occasions without 
the trouble of hiring the expensive and often inconvenient public transportation.

Accordingly, when the head teacher organized to buy a school bus, the boys in school $\mathrm{C}$ were anxiously awaiting it. The parents were required to make their donations for the purchase of the bus in installments. According to my respondents, parents started to donate money to buy a school bus in 1983. The intention was to accumulate enough money over the years. The installment payments eased financial burden on parents but were vulnerable to abuse. According to the respondents, students suspected that the head teacher and the chairman of the Board were misappropriating their parents' money because the bus had not been bought after six years of the installment payments. The students felt wronged, cheated, and taken advantage of by the school management. They protested and disrupted learning. According to many of my respondents, the riot was a lesson to the head teacher. Apparently, he learnt his lesson and the bus was bought in 1990.

one may imagine that the students were happy and contented after the bus was bought. They were not. My respondents informed me that they were displeased because upon their thorough inspection of that "new" bus they discovered it was old. After this incident, it seemed the boys resolved to indulge in school disruptions with impunity in response to the perceived double standards of 
the adults. According to the subjects, there have been probably one or two riots every semester since the beginning of 1990. Not all the disruptions were related to the bus issue, but that issue provided the avenue for future demands.

The management of this school appeared to have contributed to the disruptions in one way or another. The evidence of mismanagement was portrayed by the very fact that the head teacher had ordered the destruction of all student files with the excuse that there was no space for their storage. He did not record the disruptions in the log book. In fact the information about riots and class boycotts was contained in one file! The subjects were instrumental in my understanding that this school experienced so many disruptions that sometimes they rioted twice a semester.

Additionally, the head teacher's peculiar philosophy seemed to accept that if students were allowed to do whatever they pleased, they probably would have no reason to riot. The subjects are aware of two incidents when their school attacked the neighboring co-educational secondary school and the head teacher denied the events. Reportedly, the head teacher claimed to have bought sugarcane for the boys when actually the students themselves knew they had stolen that sugarcane from the surrounding community as they went to attack valley 
Secondary school. The philosophy of the head teacher did not work. The students took advantage of his apparent laxity. They gave him written ultimatums contained in anonymous letters that I found in the file.

The unique feature of the students in this school was noted in the interviews. There was evidence in talking to the boys that they liked to assert their power by attacking Valley secondary school because they spoke of the attacks with pride and a feeling of accomplishment. They were not remorseful that they had hurt other people. What appeared to matter was the satisfaction that they experienced. They certainly felt that they had asserted themselves as tough, brave, and daring.

Like the preceding schools, site $C$ students had very little patience with traitors. They wanted their underworld to be left unscathed by teachers. They managed to do this by attacking and demoralizing prefects. In 1993, the school was governed without any prefects because all students turned down the offer for the appointment. The records examined in this school mentioned a few incidents. The incidents were significant because they provided the characteristic nature of the disruptions at site $C$ in a nutshell. On June 6, 1991, school C attacked Valley secondary school. On August 9, 1991, the students beat and burnt the prefects' belongings. On November 3 , 1991, the students invaded Valley Secondary school for the 
second time in six months. During the second invasion, the students caused extensive damage to the school property.

In the records, it was reported that the boys rioted on June 30, 1992. The reasons for this riot were not indicated. However, an anonymous letter gave a picture of the student perceptions. Together, all the anonymous letters provided the undercurrent situations that precipitated disruptions in school c. On June 27, 1993, the form two students refused to go to class and went home, while in October 1993 the form one students decided to boycott lessons and meals. As mentioned earlier, it was the intent of the head teacher to hide the school's problems by not recording in the log-book every incident that amounted to a disruption of the normal schooling processes. A table of the incidents quoted above would give a false picture because the number of incidents of riots and boycotts in this site was greater. However, the anonymous letter quoted below gives the essence and the climate of school c.

1991 Memorandum to the School Headmaster school C Ref.: Grievances Written to Headmaster

First, I want to express frustration that we students are experiencing here on campus. The prefects are useless, they do not present our problems. Instead they bring to you their personal views. Please do the following:

- issue uniform 
- radio cassette you promised last week should be bought immediately

- morning studies should not be compulsory

- you should not take law into your own hands and expel students without reasonable cause, the students you victimized should be recalled as fast as possible

- we are fed up with the "pig-like" food that is cooked at this school

- we do not want to make lines during the parade

- the dart and chess games kits and any other games kit should not be made available for teachers, they earn their own money and they should be responsible for their own game kits

- do not raise the costs in our bus as if we are paying public transportation

- our school's fee is much higher than the authorized fee structure, thus we pay Kenya shillings 4,000 (approximately US $\$ 90$ ) more

- do not harass any students in public, therefore stop carrying that cane outside your office, we are not children

- there should be a meeting of students to present their views

These demands are few but failure to act on them may cause a memorable chaos marked with bloodshed if possible.

Yours Sacred Movement

"Young Strikers"

The other anonymous letters written to the head teacher were more fierce in tone. In them, students threatened to cause "disruptions," "chaos," "boycotts," and "riots." In some cases, the threats were carried out. School D: Co-educational secondary school. The head teacher's log book entries of the disruptions depicted the 
nature of disruptions in this school. The student files were not comprehensive and I was unable to trace the misdeeds attributed to individual students. School $D$ is a co-educational institution whose riots were particularly unpleasant to the female population. Many girls were traumatized by the incidents that accompanied the riots. The organizers deliberately planned the disruptions in the darkness to hide the identity of the ring leaders. In the cover of darkness, the boys invaded the girls' dormitories and drove them out into the dark. Consequently, the girls were vulnerable to many other problems. Some girls reported they had been raped; others were hurt by the tea-stumps as they ran through the neighboring tea-farms and still other fell in the creeks that transverse the area.

The very existence of this school was threatened. When the school started in 1980 under Anglican Church sponsorship, its mission was to serve the local population. It grew steadily and in 1989 the school's population rose to 501. During this study, the population had diminished to 140 with about $79 \mathrm{girls}$ and 61 boys. There are 18 teachers of whom 12 are male and 6 are female. I observed many empty rooms in the school. It is my feeling that the future of this school is bleak because many parents are not prepared to risk the destiny of their children in this unpredictable climate. 
The history of the disruptions depict a volatile atmosphere. On March 18, 1990, there was a riot in the school that forced a temporary closure. The reasons for this were not indicated in the log book. The deputy head teacher informed me that disruptions started to afflict this school in 1990. On May 24, 1992, the students boycotted classes with the demand that the 5:00 a.m. study time should be made optional, while on June 27 and July 21 of the same year, several sections of the student body had uprisings. The causes of the problems were not indicated in the head teacher's log book. The records however indicated there was a temporary school closure on July 22, 1992.

The 1993 academic year had its share of problems. on May 2, 1993, a riot occurred and the school lost several pieces of home science department equipment. After this incident, the school was also temporarily closed. on May 21, 1993, there was a protest, the second disruption in 1993 academic year, while on July 6, 1994, form two students staged a walk-out in which they invited the entire school for an "exodus." Running battles ensued between the rest of the school and the form two students. The entire form two class was suspended and about 37 students were later expelled.

The last recorded incident occurred on March 26 , 1995, when some male students who were upset for being 
punished by the deputy head teacher organized a riot. According to the 51-year-old female deputy head teacher, the boys decided to "teach her a lesson." They planned to attack her house on March 26, 1995, after midnight. The incident that was supposed to vindicate one incident of punishment plunged the entire school into chaos. During the fracas, the boys attacked the deputy head teacher's house and broke into the girls' dormitory. After this incident, the school was temporarily closed and the deputy head teacher was forced to seek a transfer to another school, this time to a girls' secondary school.

While the head teacher's log book was well kept, the individuals who organized the riots were not described or analyzed. Unlike other schools where individual files indicated the roles played by individual students, school $D$ records did not portray the individual roles. What was unique in this school was the trauma that the girls had to endure during the riots. I asked the female subjects to recall what went through their minds when they realized the boys were staging a riot. The four respondents recalled the utter terror and sense of being violated that they experienced the nights the boys forced them out of their dormitories.

School E: Girls' secondary school. This school opened its doors to the first girls' class in 1971. The intention was to provide the local community with an all 
girls' secondary school. The first girls to join this institution had been enrolled in the neighboring school B. After the girls moved to this school, school B reverted and became an all boys' school. The school was started by the Anglican Church members.

This was the only school where I did not have direct access to school documents. The head teacher did not allow me to study the schools' files and her log book independently. She chose to dictate the data from her file. The notes dictated helped me to establish the fact that there was a disruption on November 16, 1994. During the one-on-one interviews with three former students, I established that the school experienced a minor disruption on June 1, 1992, as well. Head teachers do not like to reveal boycotts or riots to the members of the public because these activities are negatively perceived. The essence of the disruptions in this school were deduced from the interviews with the subjects.

The girls did not depict an integrated student culture or a strong informal leadership in their milieu. There was a common thread of subjects' responses in both girls' schools. Young women in E and F schools spoke about tolerance, perseverance, and putting up with discomfort as they looked forward to graduation. Two of the subjects present during the June 1, 1992, disruption at school E said the girls were unhappy because 
they had been denied a half-term break. However, the teachers and the head teacher calmed the students down and the situation was contained without any major problem. Later, the girls suspected to have masterminded the disruption were punished. However, there appeared to have been a lack of leadership among the student population to organize a walk out. Nevertheless, the pattern of a boycott's plan observed in other sites emerged. First there was a black-out, and second, some students threw stones onto the roofs of school buildings.

On November 16, 1994, some girls were unhappy and were determined to take action against the perceived lack of concern by teachers and administrators. They left the school campus without the permission of the school head teacher and went home. According to the stories told by the subjects, the students in forms one, two, and three felt frightened by what they described as strangers who constantly appeared in the school dormitories at night. Apparently, the form four students had left the campus after completing their standardized examinations. One of my respondents, a form two student in 1994 told me she spotted a stranger on campus. The stranger was a man who appeared to have been smoking behind the school laboratory.

The stories depicted fright and terror experienced by the forms one, two, and three girls. However, the school 
administration denied there was such a phenomenon in the school and that the girls were lying. The truth in this matter was not easy to establish. The data collected established that when there was a real or perceived terror, girls would take action in reaction to any threat. School F: Girls' secondary school. School F was started as a co-educational institution on March 2, 1982 . It was initiated by members of the catholic church and consequently it fell under the Catholic Church sponsorship. The first class comprised $16 \mathrm{girls}$ and seven boys. In 1989, the boys were phased out and the school became an all girls' boarding secondary school. Today there are 321 girls who are served by a staff of 22 teachers, of whom nine are men and 13 are women.

The only reported disruption occurred on June 24, 1992. In the school documents, it was reported that a riot was organized by some girls as a response to what they perceived as unfair school rules and regulations. Girls knew about the strike because it had been thoroughly organized. When a black-out occurred, the campus was enveloped by "exaggerated coughs, screams, and all of a sudden stones were thrown onto the roofs of the school buildings." One of the respondents, a form two student in 1992, indicated that there was a thorough prior planning. According to that ex-student, the riot had been organized to take place on June 23 , but the presence of the watchmen 
made it difficult for the leaders to damage the electric transformer and "cause a black-out."

The respondents explained the role the informal leadership played in directing the students actions on the night of June 24,1992 . The systematic structure of first "black-out" then the "throwing of stones" and finally the "walk-out" were similar to the pattern observed in the boys' and the co-educational institutions.

However, there was no identifiable and integrated student culture similar to the one observed in the boys' schools. Due to this, when the school authorities punished the girls, the school was returned to normal. The subjects pointed out to me that they would not have dared to participate in another disruption because they were severely beaten by teachers as a punishment for their actions. On the other hand, the boys' school appeared to be controlled by a strong and integrated student culture and the school administrators' punishment was not a deterrent to further disruptions. In fact the punishments, especially beatings, were more likely to fuel more disruptions in boys' schools.

The success of the disruption in school $F$ on June 24, 1992 could be attributed to the strong leadership provided by one student and her friends. Since the female students did not have a rich, complex, and integrated culture that was likely to fuel further disruptions, the teachers and 
administrators were able to restore order and control in the school. According to the respondents, every girl was severely beaten as a punishment for the June 24, 1992, disruption. The girls were afraid of reacting negatively to the punishment inflicted upon them and it appeared they resolved to endure the wrongs and misdeeds of the school which had motivated them to riot on June 24, 1992.

The riots in other schools outside the sample. As indicated, the riots that took place in other schools outside the sampled institutions were noted. Any school disruption in the district wherever it occurred was relevant to this study. This was in keeping with the notion of theory as an on-going process that underlies this investigation.

While I was examining documents at school A, I was informed that the head teacher of a boys' school code named Mountain View Secondary School suspended his form two students in July 1995 because the students attacked the staff-room and destroyed the teachers' workbooks and other vital school documents.

In addition, while I was at school $C$, I met a teacher from Rice Secondary School. This teacher informed me that the students of Rice Secondary School, a boys' secondary school, had demanded bread, and if the headmaster did not buy it, the students threatened to riot. Bread is an expensive food item in Kenya. Although students like it, 
schools cannot afford to buy bread for students every time they demand it. My informant indicated that Rice was pervaded by an air of uncertainty and a riot was imminent. I also learned that the student population of the school had diminished so rapidly that unless positive steps were taken, Rice was in danger of losing adequate financial support. This is because when a school's population diminishes, tuition and boarding fees are also reduced. Another informant told me that the head teacher of Crest secondary School, a boys' school, had been forced to close the institution in October 1995 because the students attacked the prefects. It was not clear when the head teacher was likely to recall the students. In september 1995 the head teacher of the Lakeview Secondary School, a co-educational school, temporarily closed his school because the form four and the form one students were engaged in a running battle. It was reported that this fight spilled over to the neighboring community and in the process a disabled young man was hurt.

The other schools listed in my field notebook were mentioned by the respondents during the in-depth interviews. Valley and Riverside were victims of attacks by the schools $C$ and $A$ respectively. One of my respondents at school D told his story of why he transferred from the Roadside secondary School. This subject narrated that Roadside was on the verge of 
closure. According to the Education Act, a school must have at least 10 students to be registered as a school in Kenya. It was feared Roadside was likely to have fewer than 10 students. The respondent's feelings and memory of this school were negative as he recalled when students in the school hurt the senior prefect because he disclosed to the head teacher the spot where students bought bhang. In the students' language the prefect was a traitor.

Documents at school $B$ revealed that some of the students who had transferred from the crest and Forest secondary schools were responsible for some of the most nasty incidents of riots in school B. Two of my respondents in school A were former students of the Rice Secondary School. Both respondents indicated that the traitor punishment and monolization acts at the Rice Secondary school were more fierce and radical than at school A. The term monolization as defined in the later chapter includes all acts of harassment practiced by students of upper level classes against students of lower level classes in any school. The student transfers from one school appeared to be random and unrestricted. The Deputy District Education officer suggested that the head teachers fail to scrutinize their applicants' backgrounds because of the overriding desire for head teachers to increase and solidify population growth in their schools. My contention is that the easy movement of students from 
school to school in the district results in a common and easily identifiable negative culture among students in all schools in the district. At the end of my experience in the field, I felt that the differences between schools was minimal except for the nuances.

The Research subjects

It is through the eyes, the ears, and the memories of the subjects that this study was possible. I relied on them to narrate their experiences so that in the end I was able to understand their everyday life in their respective schools. At each site, the subjects had many similar answers and reactions, but these were individuals who had significant differences in their personal demeanors and characteristics. The descriptions depict the demographic information and only the most telling contribution that each subject made in the overall understanding.

Since this study is based on constant comparative analysis, it is by constantly comparing what individuals told me that I gained confidence about the emerging grounded theory which described and explained the substantive area of this study. In the discussion about the inter-relationship between categories and their properties, I will quote from the transcripts, and from the school and official documents for confirmation and illustrations. 
Site A subjects

Alex. This young man was born in 1974. He joined this school in 1991 and was expelled in 1993 when he was a form three student before he graduated. Alex was retained in several classes in the primary school and it is unlikely that the recorded date of birth was correct. This was an issue in many case histories. It is very difficult to establish the correct dates of birth because parents conceal information about the age of their children so that they can hide the number of retentions a student has had in the primary school. Culturally, age is not used as a significant mark of identity so people tend to downplay questions about dates of birth.

In the school documents, Alex had a long history of misdeeds. On March 19, 1992, Alex was suspended because "he switched the lights off and threw stones on the form one classrooms." On May 7, 1993, Alex was suspended again because "investigation" revealed that he was actively involved in the organization of a "strike." On May 24, 1993, the Board of Governors gave Alex one more chance. It was likely that Alex fell into more trouble and was expelled from the school sometime after he was granted a second chance.

During the interview, Alex did not admit he used bhang. However, he told me that his friends who consumed bhang "looked like mad men or beasts" and afterwards they 
would beat a form one student "until he bled." Alex was candid in narrating how the outsiders used him and his friends to stage a riot in the school. He said, "Myself I received Kenya shillings 300 (US $\$ 10$ ) as a payment to organize a strike." In economic terms, this money could buy ten restaurant meals in 1992. Asked why those people paid him and his friends to plan a strike he explained, "Some people in the community did not want the head teacher, they wanted him to go elsewhere."

During the 1992 riots that lasted three days, Alex narrated the story of how he demanded money from the motorists. He declared, "I made Kenya shillings 150 (US \$5) from the motorists during that period." He explained that the motorists had to pay or risk their automobiles being hit with stones.

Albert. The record shows that Albert was born in 1974. He joined the school in 1991. Albert was a school prefect. I asked him why prefects did not report those boys who broke the rules. In response, Albert said prefects "were too scared." This is because they were suspected by students all the time. When asked to comment about the harassment of the form one students, Albert replied: "It is like a tradition, a form one student is seriously harassed, it is something that is obvious in Kirinyaga." 
When I suggested students could deposit their pocket money with the staff for safe keeping, Albert revealed the deep distrust the boys had for their teachers. He said, "It is very hard because teachers do not co-operate with students."

Arthur. He was born in 1973. In his personal file, Arthur was described as a cigarette and bhang user. The record about Arthur portrayed a student "actively involved" in the organization of the strike on February 1, 1993. He was suspended on May 21, 1993, and was finally suspended indefinitely on May $24,1993$.

During the interview, Arthur explained how he began to use bhang. He stated that after he used the drug he "started to experience changes" and had no alternative but to continue using bhang. He confessed that he had influenced other students to use the drug.

Arthur's comments fit his school profile. The school records showed Arthur was one of 30 students who belonged to the "Ngwai" group (gang name for bhang). During the interview, Arthur informed me about the commerce that prevailed in the school dormitories. One of the selfproclaimed retailers supplied the students with bhang. When asked why no student reported those illegal businesses to the staff, his comments fitted the pattern of the expected response. He explained that any person who dared to report would automatically invite student 
wrath against himself. Arthur gave further evidence of the outsiders who used students to disrupt normal schooling process. According to Arthur, the 1992 strike was "abrupt." He remembered that "stones flew everywhere." When the police arrived, the students dispersed in all directions and the school was eventually closed.

When Arthur was asked whether he would like to complete his high school work, his response was that "it is too late." This comment meant he could not fit into the school system any more. It underlined the negative feelings that students have about schooling. Anthony. Anthony was born in 1975. He transferred to school A from the Rice secondary School because Rice was plagued by too many strikes, ironically. Anthony's name was not on the list of the suspended or expelled students. However, he played a key role in the strikes that took place in site A. When I asked him to comment about the raid the boys made to the Riverside secondary School on March 27, 1993, Anthony spoke in the first person, saying, "We went to revenge." In a matter-of-fact tone, Anthony explained that the entire school population ran to Riverside. It was certain that although Anthony was not suspended or expelled, he actively participated in the school riots and boycotts. 
According to Anthony, whenever the informal leaders pinned posters calling for a strike, "every student became suspicious of one another." Therefore, no student would have had the courage of walking to the dining hall to eat because everybody was "afraid he will be accused of being a traitor and pay the price." An atmosphere of fear and suspicion pervaded the campus if the informal leaders decided to call for a boycott of the meals and eventually the classes. When asked what would have happened if someone dared to defy the odds and go to eat, Anthony's response was explicit. He said such a person would "see dust," meaning that he would be severely beaten. Asked why students harassed the form one students, Anthony gave the response that was echoed by the respondents across the field study, that form one harassment was "a kind of tradition." Since everyone was beaten in form one, he felt justified to beat the form one students.

The perception that strikes happened in every school in 1992 was further confirmed by Anthony. He said, "In 1992, almost all schools in Kirinyaga district experienced strikes." About the inter-school conflicts, Anthony said, "Boys like to show their power." In the course of the field-work, I witnessed many incidents when boys showed their power. 
Arnold. Arnold was born in 1975 and transferred to school A in 1992 from the Rice Secondary School. He was suspended on March 21, to "finalize his case with the courts." Arnold was indicted for rape charges. He committed the crime when he went out of the school campus without permission. I did not want to lose the confidence of my respondent by delving into the details of the rape case. It was obvious he would have felt intimidated since his case was pending in the court.

Other school reports about Arnold indicated that he "forced the form one students to sign papers that they owed him money." This information was corroborated in the one-on-one interview with him. When asked to comment about the harassment of the form one students, his reaction was not surprising. He said, "I think they deserve the beating." He went on to tell me how he "beat them up until they gave [him] money." He also confessed that he consumed bhang, saying, "Personally, I started smoking bhang when I was in form three." He said the drug was sold in school and only about four boys in his class of 40 students did not consume bhang.

Andrew. Andrew was another example of an organizer who was not expelled or suspended. He was born in 1975 and was a student from 1991 to 1994. He was very dramatic in his narrative. He revealed how he and his friends used to plan the disruptions. They would meet in a place that 
was "secretive" and discuss "what must be done." on the day planned for "action" one of his friends would "spy on the deputy head teacher."

Andrew was actively involved in the invasion of Riverside School Secondary on March 27, 1993. He told me that after they entered the Riverside's hall they "destroyed everything" that they could see. They "beat up" the Riverside's students and "stole video cassettes and damaged the school television."

His information indicated that this respondent was well practiced in the art of quizzing the perceived "teamsellers." If a student was suspected of "selling out" other students to teachers, Andrew and his colleagues would quiz him. Asked how they did it, he said, "A teamseller would look guilty and frightened" and would not "have words" when asked questions. Like all other respondents, Andrew was certain that any student suspected of "selling others out" was guilty, a perspective that surprised and frightened me. I was not sure that all those students suspected to be traitors were actually traitors.

When asked to comment about the refusal to take tests and examinations, Andrew referred to his own experience and said: "I can remember we used to refuse to do the tests, we would write our names on the answer sheets and 
walk out of the test room." According to Andrew, "Tests were a kind of a bother...just wasting time."

When asked about the harassment of the form one students Andrew described the action, saying, "Last year, form ones were given a hard time...to make them respect the senior boys."

\section{Site B Subjects}

Only four ex-students were requested to participate in the study in this site. The four subjects lived in the village which is the next door neighbor of the school. The village and the school had a symbiotic relationship. The villagers were the chief suppliers of the illegal drugs and alcohol to the students. Sometimes when a riot occurred, the villagers would go to the school campus and steal from the dormitories anything from electrical items to the personal clothing of the students.

This relationship between the village and the school affected the data collection exercise. Two of my four respondents did not want to disclose any information about bhang use or theft that occurred in the school. Thus, both the school reports and interviews with the deputy head teacher and two teachers were crucial at this site.

Benson. He was born in 1974 and joined this school in 1991. At the time of this interview, Benson was a student at a local day school. He felt happier at his current school. Referring to his current school he said: 
"I find it better...one feels free and is able to read hard." Asked whether he had witnessed any disruption since he had been to his current school, his response was "they have never striked."

When I asked Benson to comment about the violence against teachers in site $B$, he replied, "The reason for the violence is because boys felt hatred toward a particular teacher." The reason for the hatred was similar to the one expressed by the students at school A. That is, teachers were unnecessarily very strict and often reported students to the administrators when they broke what they perceived as "minor school rules."

Asked to comment about the use of nicknames such as "Saddam," Benson said that the names were given according to the character of the student. For example, the student who was nicknamed saddam got his name from the perceived semblance of his conduct to that of the Iraqi dictator. He earned his name because he used to beat up the form one students "very severely." According to Benson, if a student wronged "Saddam" or his friends, he was "in great danger."

Bernard. Bernard was born in 1973 and joined the school in 1990. He was a resident of the village and was kind enough to allow me to use his room for the interviews. He was working as a blacksmith in the local trading center. 
Bernard was a victim of the virtual shutdown of this school in 1991. He informed me that his class of 1990 enrolled 130 students but only 20 students graduated four years later. The dropout rate as can be expected was very high because parents withdrew their sons and took them to other schools. Bernard described school life between 1990 and 1991 as "confusion all the time." The exact nature of the confusion was not on record but the general picture of this school as portrayed in the records reflected chaos. Bernard was extremely defensive about bhang. He denied that students consumed the drug. To clarify Bernard's fear one teacher told me that bhang, an illegal drug in Kenya, was not an easy topic to talk about. Bhang trafficking carries a maximum sentence of ten years of imprisonment. The boys did not want to risk that punishment if they spoke probably to an undercover police officer about the sale of an illegal drug.

The individuals who live in villages are among the poorest people in the society. The villages are therefore crowded and the residents are more likely to engage in illegal activities such as dealing in illegal brew and bhang trafficking. The police officers or law enforcement officials are more likely to be resented by people who live in the crowded villages. It is therefore not surprising Bernard was distrustful of a stranger making inquiries about illegal activities. 
Asked to comment about the education he received at school B, Bernard explained that although he knew education was important, he and his school mates realized they could not make the grades for further education. Bosco. This young man was born in 1972. He was enrolled at the school in 1979 and left in 1992. He was working as a motor mechanic in the local town center. When I asked Bosco whether students attempted to recover the work lost during the disruptions his answer was insightful. He explained: "Even if teachers were ready to do extra work, they were helpless because no student wanted to be in class after 4:00 p.m. for an extra hour...they felt it was their time to rest." Asked whether students did not realize they were wasting a valuable learning opportunity, Bosco replied, "They did not care."

Bosco believed teachers "hated students" because if a student did anything however minor, teachers "made a mountain out of it." According to Bosco, when a student walked out of the campus without authority, that was "not something serious."

Burt. Among the four students interviewed in this site, Burt was the only student who had been suspended for being involved in misbehaviors which led to a disruption.

His attitude to formal schooling was characteristic. Asked whether he would accept an opportunity to go back to 
school, Burt said, "I would not want to go back to school at all." Referring to what he witnessed during his school days, he said that it was not difficult to find students "who did not go to class for two weeks," especially the bhang users.

His answer to the inquiry about the attack on teachers was similar to the response given by his school mates, he said teachers were attacked because they were "hated."

Regarding the use of nicknames, Burt said that the boy whose nickname was "Saddam" was "feared very much." He and his friends gained their trademark for "severely terrorizing the form one students."

According to Burt, the reason for frequent interclass fights was unprovoked attacks from students in other classes. He said, "If form two students beat third or fourth form students, the students in the upper grades felt degraded." A fight between entire classes ensued even when the conflict involved two individuals originally.

Burt described the effect of bhang and said, "One feels he can do anything, nothing is impossible." This referred specifically to organizing riots and boycotts, and not to learning. He explained that the students who used bhang were "tough," especially in the harassing of the form one students. They were also capable of walking 
out of their classes for a month and rejected tests and examinations because they knew they had not studied. Boycotting tests and examination was the prudent thing to do in order to conceal poor performance and lack of academic preparation from family members.

\section{Site C subjects}

Seven ex-students were interviewed at site c. The big number of the respondents complimented the lack of detailed school records. The subjects were candid and they corroborated each other's interpretations, ideas, and facts. Most of the respondents at this site knew their beliefs or values very well. They referred to them as the their "mottos."

Chuck. This respondent was born in 1973 . He joined school $C$ in 1989 and left in 1992. He is currently unemployed.

Chuck mentioned about three mottos in the course of the interview. The first motto was "students must do what others have done in the past." This meant that all students were obliged to follow the traditions and rituals of their predecessors. The second motto was "if students read posters asking them to do something, they must not question information on the posters but must follow the instructions given on them." This meant that if the informal leaders organized a boycott, the regular students were expected to join in without questioning. The final 
motto was "a student does not need permission to walk out of the campus."

According to Chuck, the form one students were harassed so that "they transform their behaviors." When asked to explain why his school invaded Valley secondary School, Chuck's response was that they just followed the instructions of the informal leaders who he referred to as "champions." He said that the regular students would do "anything," they just followed the instructions from the "champions." During the November 3, 1991, invasion of Valley, the "champions" gave instructions and directed the students. They instructed them how to get to valley in the shortest time possible and what they should do upon their arrival. According to chuck, the champions "knew a lot" and they "made things better."

The only regret that chuck expressed was that one of his school mates was apprehended during the last attack on Valley. The capture of one of the school mates was the only evidence that it was school $C$ that had damaged the property at Valley. Eventually, school C students were made responsible for the repairs.

Chase. This young man was born in 1973. He joined this school in 1988 and graduated in 1992. Chase told me that when he was a form two student, boys started to "complain about the bus." To solve the bus stalemate and 
make the head teacher listen to them, "the students went on a strike."

After the bus was delivered "at night" there were rumors that the "new" bus bought for the school was taken by the chairman of the Board of Governors for his personal use. He had delivered an "old truck" in the place of the expected "new" bus. The disruptions that followed after the bus problem indicated how the boys determined to amass power and attack the organization and power structure that had betrayed their trust.

According to Chase, the strikes were formed as a result of what he described as "oppression." He insisted that the food the school authority gave them was below the standard maintained in other district schools and therefore students in other schools referred to them as "fools." It was obvious that the students from other schools in the district met during the school vacations and during the inter-school festivals and competitions to compare their school experiences. They were able to assess where their school administration had failed them and protested if they perceived that they were being unfairly treated.

Cooper. This ex-student had joined school C in 1991 and left in 1994. He was born in 1975 . According to cooper one of the reasons why ring leaders persisted in their behaviors was because the 
administrators "would never know them." No student would have dared to report them to authorities for fear of the reprisals dealt on the perceived "traitors." Cooper explained that the informal leadership in their school was so fierce that it had "silenced all the traitors."

Cooper stated that if the head teacher expelled their leaders, the students demanded that they be recalled. There was evidence of this type of demand in the anonymous letters. The demands were often accompanied by threats to riot or boycott classes.

When asked if they threatened to boycott classes if other students who were not leaders were suspended, Cooper said that the regular and sober students were not given similar support because they "did nothing for the school." There was a strong belief among the students that their informal leaders worked for the advancement of the students' cause, whatever it was!

cook. Cook was born in 1973. He was enrolled in 1989 and left the school in 1992 after completing his fourth form examination.

According to cook, he was in the school for only two peaceful semesters before "strikes started." During these strikes, cook complained that he had "to sleep in the woods and felt like seeking transfer to another school." He estimated that there were about 20 or more disruptions during his school career. The frequent disruptions 
sometimes occurred at the rate of "one or two strikes a semester."

When asked why he thought there were so many disruptions, he said, "We felt the administration was unjust and conditions were unfavorable." According to cook, the school authorities gave them "pig-like food." He felt the money paid by parents for the boarding fee was adequate for better food.

Referring to the traitor issue, cook said, "No traitor was to be allowed to live amongst us. This was our motto." Like many of his schoolmates he felt the strikes gave them leverage to discuss their problems. The respondents expressed the feeling that if students did not disrupt learning, their complaints fell on "deaf ears."

Castro. He was born in 1975 and was enrolled between 1991-1994.

I asked Castro to explain how a regular student survived school life without any problems with the school administration or the informal leadership that existed in the student underworld. In his response, Castro said one had to seek the center. The center according to castro was the safe position where one did not challenge the administration or the student informal leadership. The best position was to follow the informal leaders "like sheep," that is, with a docile and passive attitude. 
Castro gave information that many students respected their leaders and gave them moral support. It appeared many informal leaders were regarded as heroes. A student that one may describe as a bully was viewed as a "champion" by his fellow school mates. They were perceived as important ingredients for the advancement of the cause advocated by students.

Castro felt their "head teacher was a liar." He lied that the boys did not go to Riverside for a football match and yet the whole school had gone to watch the soccer game when they beat up school A's soccer players. Since Riverside supported school $C$ in the fight, school A students attacked Riverside school to retaliate for the attack on their soccer players.

Chris. This young man was born in 1975. He enrolled in 1991 and graduated 1994.

During his first year, Chris recalled that he did not attend the evening studies because there was a ritual organized where "form ones would be beaten from 7:00 p.m. up to 8:00 p.m." As a form one student he was forced to do laundry for the second, third and fourth form students. He was expected to take food to some upper grade students as they lay in their beds in the morning. According to Chris, monolization was the tradition created for the form ones." 
Since Chris was a form two student in 1992 I asked him why 1992 form two students rioted. In his response Chris said, "The whole school hated us and we had to run away."

Charles. Charles was born in 1970 and was the oldest of the respondents at site $c$. Unfortunately, he was the only subject who was less outspoken in the discussion about the student culture.

Despite himself, charles allowed me to confirm that there were many disruptions in this school. According to Charles, it was difficult to satisfy some students. They made many demands time and time again. From the school file I noted students were accused of being rude and impolite to teachers. I asked Charles to comment on this issue. According to charles, the students were rude only to teachers who were harassed them or who "beat" them.

\section{Site D Subjects}

School $D$ is the only co-educational school in the sample. I decided to interview more girls than boys at this site. The decision was based on the need to have diversity in the properties of the core categories as much as possible. Four girls and two boys were interviewed.

Dick. This interviewee was enrolled at school D as a form two student in 1991 and left in 1993. He was a student at Roadside Secondary school for his first form studies. Ironically, the reason he came to school $D$ was 
the violence he experienced at Roadside as a form one student. He explained that he was forced to use bhang at Roadside and was brutally beaten by other students. The climax of his terror came when "the senior prefect was burnt." Apparently, the senior prefect had disclosed where students bought bhang to the school administrators. After the senior prefect was hurt, Dick explained, "I could not tolerate being at Roadside any more." He sought a transfer and joined school $D$.

When Dick was asked why boys invaded the girls' dormitories, he explained that the boys did not want to bear the blame as the sole cause of the problems that plagued the school. The boys forced the girls out of their dormitories because they knew the girls would not join them voluntarily.

About the general goals for students in education, Dick's comment was, "Going to college was not among their goals." He narrated a story to illustrate this fact. He said in the 1993 school year, when the fourth form students were asked to complete college application forms, "only a few students participated." The majority of the students had plans to leave school and "get married." According to Dick, use of bhang was common among the boys. The students made it a habit to smoke the bhang at the break time during the evening study period. Evening studies are not supervised by staff members in all 
schools. Students do their homework and private studies during the three-hour evening study.

The interview revealed that this school did not have a strong and integrated culture. Dick spoke less enthusiastically about monolization or traitors than the respondents from boys' schools. The respondents from all boys' schools were more likely to speak enthusiastically about their culture. Their responses depicted a strong devotion and belief in the actions of their underworld. Although Dick said that boys in school D practiced monolization and summary actions, my perception was that rituals were not as well organized and coordinated as in the boys' schools. Although it is not possible to measure the specific degree of cultural traits, Dick and David expressed less excitement in discussing cultural issues. Additionally, Dick's descriptions were not accompanied with detailed anecdotes and illustrations.

David. David was enrolled in the school in 1990 and left in 1992 after he was expelled. He was born in 1972. He went outside the Central province for the remaining part of his career. He had good grades in the national examination and was admitted to a theological college to train as a church minister.

About educational goals, David said many students in school D expressed the need for obtaining "only certificates." This phrase means that the students were 
not worried about making good grades which would qualify them for admission into the state universities and other middle level institutions which are very competitive. David explained that there was a strong belief among students in this school that "the best grade they could make was either grade $D$ or $C$, however hard they worked in their school work."

About the boy-girl relationships, David explained that it was an "obvious thing" that boys wanted to have girlfriends from among the school girls. Asked why boys broke into the girls' dormitories during the riots, David explained that boys did not want to leave girls in school for three weeks. During the duration that the boys were suspended, the girls would study and possibly defeat the boys in the tests.

David expressed the fact that the girls were often made to feel inferior in class by the boys. Sometimes the girls were ordered to keep quiet because "men are superior to women." Culturally, the males dominate the social scene. To date, men dominate most of the important positions in the government, corporate, and political arenas. Some women achieve these positions but they have to work harder. The superiority complex expressed here is typical of the attitudes that prevail in the society. According to David, once the boys took bhang, they "eagerly waited for an informal leader to give them 
orders." To galvanize the support of everyone, food was the target of severe criticism. In order to attract attention of the regular student population, the organizers complained that the food had "crabs, kerosene, or worms."

Doris. Doris was enrolled as a form one student in 1989 and graduated in 1992. She was born in 1972 . Doris confirmed Dick's view that the boys attacked girls because they did not want to be blamed as the sole cause of the school's problems. On educational goals, Doris felt that most students were discouraged because "they could not make the grades for admission to the colleges." According to Doris, most students wanted to "start businesses such as dressmaking."

"Bhang changes character" was the observation that Doris made. She felt that the bhang consumption made many male students feel "nothing is impossible for them." Doris commented that during her school career, there was no female student who joined in the organization of riots or was punished for participating in disruptive activities. She remembered that when the girls' dormitory was broken into, many girls were hurt by the broken glass that sprayed the hallways.

Diane. Diane joined school $\mathrm{D}$ as a form one student in the 1990 school year and left in 1993. 
She gave the impression that the team spirit among the students in the co-educational school was not as strong as it was in all boys' schools. The term "traitor" was not used to include all students who were perceived as betraying other students to teachers. During the normal schooling period and when there was no disruption, students at school D freely associated with teachers without fear of a reprisal from the other students. However if a person betrayed the leaders of a strike, other students "isolated" that person or, as Diane put it, a traitor was subjected to a "cold war." An isolated person did not have friends. This was a peculiar form of punishment in the co-educational school which was not mentioned by the male respondents in the boys' schools. Asked why girls did not lead strikes, Diane's opinion was that the "boys may nullify it." She also said that the girls did not harass or torment the first form students as the boys did to the male newcomers.

Daisy. Daisy enrolled in the school in 1990 and left in 1993. She was born in 1972 .

Daisy described the trauma that the female students endured on the nights that the boys invaded their dormitories. She reported that once the boys entered the girls' dormitory, they would search under the beds using a flash light to ensure that no girl was left behind. The male students threw machetes under the beds to hurt any 
girls who hid. Daisy narrated that as the girls dispersed into the neighbor' tea farms, some were "hurt by tea stumps" while others fell into the creeks "as they tried to cross the valleys in darkness." Daisy depicted the misery suffered by girls.

About traitors, Daisy expressed the same viewpoint as Diane, that "no one talked to a person who reported the strike leaders to the administrators." It appeared that there were no reprisals against students who reported regular matters to the staff. The term traitor did not carry the loaded meaning and implication at school $D$ as it did in the boys' schools $A, B$, and $C$, where any conversation between a teacher and a student was suspect.

The only inter-class fight Daisy recalled was in the 1993 school year when the form three male students became hostile to their female counterparts. The girls earned the hostility because they performed better than the boys in the class tests. This could not qualify as an intensive inter-class warfare that was characteristic in the boys' schools.

Dorothy. Dorothy enrolled in the school as a form one student in 1990. She left in 1993 after completing her final national examination. Dorothy did not bring any new perspective but she confirmed what the other respondents had explained or described. She felt the love affairs between the girls 
and boys in her school were "very common." Referring to bhang, she commented that when the male students consumed a lot of bhang, it was an indication that "something was going to happen." She stated that a boy who used bhang was identified by his sudden radical behaviors that were usually out of character. This confirmed the view that excessive use of bhang precipitated a riot or a boycott.

Dorothy described the traumatic experience endured by girls when riots occurred. She said, "After lights went off, within ten minutes the boys would be running toward our dormitory and at that time we knew things were not good." The drama unfolded immediately after the girls awoke. Dorothy recalled, "At that moment, some girls started to pray, others to scream, and others tried to hide." The reaction of the girls depicted sheer horror and feelings of desperation.

\section{Site E Subjects}

The three female subjects interviewed in site $E$ were Elaine, Elizabeth, and Edith.

Elaine. Elaine was enrolled in school $\mathrm{E}$ in 1993. She was a victim of the disruptions that occurred in this school on November 16, 1994. The contention was that although Elaine did not walk out of the campus, a new rule instituted after November 16, 1994, stated that no student would be re-admitted unless she paid all fees owed the school before the disruption occurred. Elaine's parents 
were unable to pay the outstanding fee because as she explained, her father was sick and unable to raise the money .

Although the school authority denied that there were any strangers on the school campus several nights before November 16, 1993, Elaine was convinced that she saw a man who was smoking behind the school laboratory. She said, "I was scared and afraid when I saw that man." That night, many students screamed, complaining that there were strangers invading the dormitories. According to Elaine, the teachers did not help them and the watchmen ignored their crying and screams. As stated earlier, whether there were strangers in the campus or not was still an issue for debate among the adults, but to the girls, the invasion was real.

After the teachers appeared not to care, many girls packed their luggage and left the school on the morning of November 16,1994 . Only 80 girls persevered and were left in the dormitories. Afterwards, the school administrators ensured the dormitories were guarded.

When asked to comment about the educational goals of the majority of the students, Elaine said that since the past students had begun to perform well in the national examinations, many girls were hopeful and some had goals of becoming doctors, lawyers, and teachers. However, some girls were in school "for the sake of it." This phrase 
conveyed the meaning that some girls were not interested in learning but had to be in school anyway because that was what was expected of them by their families and the community.

Elaine said the form one students were not tortured or given any punishment at site $\mathrm{E}$ nor did girls use bhang or cigarettes. She insisted that although the girls were not happy about being beaten by teachers when they failed to get $40 \%$ of scores in a test, there was nothing the students could do but persevere. Apparently, it was a school policy that students had to maintain $40 \%$ on school test scores.

Elizabeth. Elizabeth was a student at school E between 1991-1993. She was born in 1974 .

According to Elizabeth, many girls had "lost hope" during their early school years because their past performance in school was poor. Her memory of the teacher-student relationships was one of normal interaction. She said, "Students were very close to teachers, especially the Kiswahili teachers." Kiswahili is Kenya's national language and it is taught at all school levels. When I asked her how students reacted to the beating, Elizabeth replied, "Even if one felt it was not o.k., one could do nothing about it. Students were helpless." 
The general attitude that girls have toward any form of punishment was that they could endure it. On the other hand, the boys felt that they can do something about any perceived unfair punishment. They did not feel they were as helpless as the girls.

On June 1, 1992, the girls at school E staged a riot. According to Elizabeth, some girls shouted, "Even if [we] do not get a half-term break [we will] still go home." Some students followed the usual pattern of an organized revolt that had been observed in other schools. They disconnected the electricity supply and started singing and shouting. However, the girls did not walk out. Some girls locked the classrooms so that no student would be able to go for the morning studies. After the brief disorder, since the girls did not have the courage to walk out of the school campus, the teachers restored order and resumed teaching.

The lack of a student informal leadership and the absence of an integrated student culture appeared to be the cause of that poorly managed "strike." The end result of that disruption was that the girls did not have the desired half term break and about 200 girls were punished by the school administration for that disruption. When I asked Elizabeth whether the $200 \mathrm{girls}$ led the strike she replied, "I don't think so." 
Edith. Edith joined the school in 1991 and left in 1994. This is the only subject who identified me as a former school administrator. However, that did not make Edith less outspoken or affect her usefulness as a participant in this study. She contributed toward the development of the categories and their properties as well as any subject who participated in the field study.

About the teacher-student relationship Edith said, "In our school, if one needed to ask questions, the teachers were helpful." The other students did not suspect that they were being reported if they saw a student talking to a teacher.

The perception of a naughty student is different in the girls' schools. According to Edith, a "criminal" in school $\mathrm{E}$ is the student "who does not go for studies on time, and does not do her cleaning duty well." This departs radically from the boys' description of a "criminal." A "criminal" in the boys' schools was the student who terrorized the form one students, organized disruptions, and violated school rules and regulations. Edith was not willing to comment about the disruption of 1994. At that time, she was busy completing her examinations and she did not appear to have paid much attention to this ever-continuing controversy of whether there were strangers invading the dormitories or not. 


\section{Site F subjects}

At site $F$, three respondents were interviewed. Their code names are Flinder, Florence, and Faith.

Flinder. This young woman was enrolled in this institution in 1990 school year. She left the school in 1993. It was critical that students who had experienced the 1992 riot be interviewed because this was the only reported disruption at the school.

According to Flinder the riot was organized by some form three students and they "arranged the riot on an evening." The observed pattern of an organized revolt emerged. First, some riot planners disconnected the electric power and caused a black out, while others members of the planning team threw stones onto the roofs. As Flinder suggested there was identifiable leadership. The rioting gang was led by a form three student described by Flinder as a "very rude and radical girl." Flinder used the Gikuyu term "mangaa" to describe her. This Gikuyu term describes a person who departs radically from the norm.

According to Flinder, the leader of the revolt kept a knife with which she threatened "to kill anyone who would report [her] to the school authority." Flinder said that this form three student led a group comprised of "newcomers" to school F. By "newcomers," Flinder meant that the group was comprised of students who had 
transferred from other schools in the district to school

F.

Asked to comment about the grievances of the students, Flinder explained that the major problem was the "mistreatment by teachers," particularly the beating. The other complaint was the "constant water shortage" that forced the girls to fetch water from a river down a steep valley.

After the strike, Flinder said the girls were so severely beaten by the staff that they never dared to organize or to participate in another riot. That observation was correct because there were no other recorded disruptions by the time this investigation was done three years later.

Florence. Florence enrolled as form one student in 1991 and left in 1994 after doing her national examination. She confirmed Flinder's story about the riot. Florence was a form two student in the 1992 school year. From her comments about her role in the riot, it appeared she followed the lead of other girls, particularly her cousin.

Her story indicated there was a thorough planning of the disruption. Florence said that her cousin had told her when a black-out occurred, they should collect their luggage and leave. 
The punishment given by teachers when the students returned to school was fresh in Florence's mind. She said after the beating the girls felt they had no alternative but endure their problems. She stated that the girls in her school did not complain about food or rules.

Faith. Faith enrolled as a form two student in 1991 and left in 1993. Her reason for the transfer from another Kirinyaga school was that she wanted to be near her home after her mother died. Faith confirmed most of the issues that Flinder and Florence discussed. She said the girls were unhappy with the punishments. She also said the water shortage made their lives uncomfortable because they had to carry water from a steep river valley. The girls felt the head teacher was not concerned about the water shortages. If she cared, then something ought to have been done to alleviate the difficulties.

Faith felt the beating that the girls received as a punishment for participating in a strike on June 24,1992 , was "very unfair." She contended that the students' complaints against water shortages and unfair punishment were justified. But like her schoolmates she "decided to persevere." Faith did not recall any major complaints against food or the school rules and regulations. 
Teachers as Respondents

\section{Introduction}

In research, if diverse data obtained from diverse sources such as teachers, ex-students, and school documents support the same conclusion, confidence in the data is increased. Basically, the teachers were interviewed because they were a part of the context of the happenings. In addition to this purpose, data obtained from the teachers' interviews, school documents, and official material enabled cross validation and triangulation. Data source triangulation involves the comparison of data relating to the same phenomenon but derived from different phases of field work. This is in effect different accounts of different participants involved in the setting.

For example, Mr. Craig of school C said that the disruptions in his school between 1990 and 1993 were so frequent that teachers spent a lot of time "screening" students to identify the ring leaders and the causes of the disruption. "Screening" was the term used to describe the process where a panel of teachers questioned and scrutinized individual students in order to unearth the truth. The information about the frequency of riots was not in the school documents, but the deputy head teacher's remarks confirmed the subjects' stories, which asserted 
that students organized a strike every semester and sometimes twice a semester.

As mentioned, disruptions are a complex social phenomenon and difficult to separate from their context. In the field study, teachers and particularly the deputy head teachers were an important part of the context. Some staff members were victims of the riots as well. Their information enriched data as they explained what really happened from their perspective. The student respondents were more likely to be the actors and the teachers were the audience in the unfolding dramas.

Code names of the teachers were assigned so that the initial letter of the subject matched the site code letter. The code names are Armstrong for site A; Bridges, Baker, and Barrozi for site B; Craig for site $C ;$ Dean and Draco for site $D$.

Mr. Armstrong. He was a 52 year old man who was the deputy head teacher of school A, a boys' school.

Armstrong authenticated the us versus them feeling that pervaded the school. The students felt they were members of one team against the teachers' team. From his personal perspective Armstrong was firm when he said, "I cannot personally trust students. There are no students who I can trust." He explained that all the rituals that prevailed in the students' "underworld" were done "secretly" and the staff "did not get to know." 
About the student culture, Armstrong was cynical. He said whatever the students did, their goal was always to "have an upper hand" in the school, but the school could not accept their moves to do that. Armstrong was convinced that school administrators could not accept the "standards" or the "beliefs" that the students advocated. He described the student informal leadership as a "pyramid." A few leaders of the pack were "at the top" and many were on the "base." It was his feeling that many students did not disclose their standpoints to their colleagues. Therefore the majority of the boys did not know how the leadership "rotated" or "operated." speaking about riots, Armstrong explained that if the boys had any grievances or were unhappy about anything, they waited for the slightest provocation to rally the whole school for a riot. He confirmed what was observed during the interviews, that every student in the school was expected to participate in strikes because if a student failed to join in he was accused of being a "teamseller." Later after the strike, team-sellers were targeted for punishment. To use the deputy head teacher's words, "No student would want to lose his skin and therefore every student followed the orders of the organizers."

Armstrong was aware that boys were not happy with his stand and firmness. He explained that the teachers felt 
intimidated and some staff members chose to look the other way. As a deputy head teacher, he felt obliged to do what was right.

The deputy head teacher confirmed that most organized disruptions often started in the dining hall. The organizers of the disruptions used threats and intimidation to make sure no student went to eat. After the food boycotts, it automatically followed that there would be no classes that day. More often than not, the school campus was made so chaotic by the disruptions that the administrators were often forced to temporarily close the institutions.

Mr. Barrozi. He was 47 years old and the deputy head teacher of school B. Regarding disruptions, Barrozi described the events as sudden. Most often the school administrators were taken by surprise because the students did not complain or indicate their grievances. Mr. Barrozi blamed the irrationality of the disruptions to the bhang use. He explained that after they did their inschool investigations in response to a riot and/or boycott, they found the students were under the influence of bhang.

According to Mr. Barrozi, the us versus them attitude is a tradition. He clarified that statement further by stating that in the school years 1990 to 1991 the boys did not trust the presence of teachers around their dormitory 
areas. He said, "No teachers could enter the boys" dormitory." If anyone tried, the students threw objects and stones at him. The students claimed the dormitories were "solely theirs."

Boys had such a strong fraternity that no student would report any wrongdoer to a teacher or school administrator. According to Barrozi, the fraternity made it a problem for the teachers and the school administrators to penetrate the territory of the students; "the underworld."

Speaking about the village that is the "next door" neighbor of this school, Barrozi confirmed that some villagers were trade partners of a few school boys. Bhang peddlers and the local beer brewers sold their merchandise over the school fence. The boys likewise stole blankets, electrical gadgets, and mattresses from the school and sold them to the villagers over the school fence. Mr. Barrozi was convinced that the riot organizers often communicated with the villagers for the bhang supply. Additionally, when the villagers heard the screams and shouting, they knew their drug supply was required. They also seized the opportunity to steal and/or loot school property.

Mr. Barrozi believed that the disruptions were organized by a small group of students. He remembered an incident when a few hard core "criminals" who started the 
trouble decided to leave the school after a destructive riot and "up to this day they have never come back."

Mr. Barrozi did not feel his students had "high hopes in life." He said the students confessed that even if they worked very hard, it was "impossible for them to make good grades." He described the majority of the students as "hopeless." Some students have seen some of their schoolmates working very hard and passing their examinations fairly well, but to date those hard working students are "rotting" at home because they were not admitted to a college due to high academic competition. By "rotting" he meant that the good grades that those students acquired did not propel them to good job-training opportunities. This sort of trend was discouraging to many students in the system.

Speaking about the teachers, Mr. Barrozi felt teachers were discouraged by the mocking and intimidation they received from the students. Some teachers regretted that the Teachers' Service commission deployed them to the school. They did not have the enthusiasm they had anticipated when they got into this profession. To make matter worse, it was the supportive and keen teachers who were prone to student attacks. Many teachers had quit the living quarters because they did not want to be victims of the brutal riots. 
Mr. Bridge. He taught in school $B$ and was in-charge of the curriculum matters. Mr. Bridge was 35; his viewpoint was sometimes amazing and different from that of other members of staff.

Bridge said that the inter-class conflicts were natural. According to him, form four students had a superiority complex which influenced them to feel that the form two students were of a less status. If a form four student was attacked by a form two student his status was violated and that became a problem for the entire form four class. The form four students defended their classmates and in doing that they protected their status. Accordingly, the form two students supported their own kind. In these class conflicts, there was no one willing to concede defeat without a fight. Bridge described student fights as "status war."

When asked why students were so loyal to their classmates, Bridge's comments shed light on the rather intricate pattern of behaviors. He said that students felt a "oneness" with others in their class because as form one students they had "suffered" in an identical manner. They were also "monolized" together by the older boys in the school. During the first year of secondary schooling many students learned to be close to one another in form one as they consoled each other when they were beaten and/or humiliated by students in the other classes. 
The closeness and friendship learnt in the first form class was the base for the solidarity in class levels observed in this study.

He felt most riots were caused by "idleness." He commented that the students who were not good in class or in games disturbed the peace in school and attracted attention to themselves. When there was peace and quiet no one noticed or recognized the importance of the riot leaders. In other words, riots were organized and led by boys who felt the need for attention and recognition. Bridge, like other members of the staff, blamed the behaviors of the students on the failure to "attain the goals expected in education." This had rendered schooling "meaningless" to many students. A few students did not mind if "they missed the useless learning" by disrupting the normal schooling processes. He also attributed the problems to the local politics that were volatile.

Ms. Baker. Ms. Baker was 36 and among the longest serving members of staff at school B. She had taught at school B for seven years. She told me that she was once a victim of the disruptions but did not wish to clarify what happened to her.

According to Baker, most of the problems were a result of the interference of the local people who felt "this was their school." She attributed the 
dissatisfaction of the local people to politicians who wanted to get rid of the head teacher.

Speaking about student solidarity, Baker confirmed Barrozi's statements that no student reported any other student for wrongdoing to the administration. According to Baker, the boys were ready "to die" to maintain that loyalty. She explained that some form one students were initiated into taking cigarettes and later bhang by the older students and monolization was an evening ritual which took place from 9:00 p.m. after the evening studies. Concerning riots, Baker felt students had a "lot of steam" and looked for someone to lead them in the attacks. She described the informal leaders as outspoken, articulate, and most of all convincing. She corroborated what many subjects had said about the informal leaders, that regular students "feared them." She also authenticated Bridge's views that when a student was beaten by a student from another class, that seemingly minor issue was turned into a widespread disruption. The disruption was motivated by the feeling that one was obligated to defend one's classmates.

Ms. Baker felt students were not keen to learn. They wanted to be left alone to "rest." She confirmed the feeling of other staff members that the joblessness in the society had contributed to an air of "hopelessness" among students. 
Mr. Craig. Craig was 43. He had served as the deputy head teacher of school $c$ for a year at the time of the interview.

He authenticated the subjects' remarks that the riots and boycotts in school $C$ were sparked by the bus issue in 1990. Many boys felt the money their parents had paid for the purchase of a bus had been taken by the chairman of the Board of Governors. This particular politician did not win the confidence or the trust of the parents or the students, hence the suspicion. After the bus was bought the boys became activists. It was as if they realized activism was the language the school administration understood.

Craig did not attribute riots that happened in school C to outside interference. He attributed the disruptions to what he described as "gangs." He explained that whenever students felt a need or had a complaint pertaining to food or anything else, they used the need as a rallying point and disrupted the normal schooling activities.

He described the informal student leadership as a group of about five boys, "rough" and who "did not care." As in other boys' schools, the informal leadership of the underworld inspired loyalty through intimidation and fear. For example, among the "gangs" that intimidated students was the "Saddam group" a name also used in school B. The 
goal of this group according to the deputy head teacher was to "mobilize the school so that they would intimidate anyone who opposed them." The "Saddam group" made sure that students did not sit for the final tests. The group was effective because the students boycotted tests and examinations for two years in a row. This terror group also kept knives and used bhang. According to Craig, they threatened other members of the school community with impunity.

speaking about the inter-school warfare common at this site, Mr. Craig explained that school $C$ students did not "believe that valley could beat them in anything." He expressed shock and surprise at the speed with which the invasions used to take. For instance, the invasion of November 3, 1991, took at most 15 minutes, yet valley is about three miles from the school $c$ campus.

His comments about the student informal leadership complemented the views of most teachers in the other sites. He described the leadership as a "pyramid," a term used by Armstrong of site $A$. He expressed surprise at the leadership skills of one particular boy. He explained that that particular boy had "a lot of command over the others." He also had the ability to convince, organize, and "drive the entire school to action." According to Craig, the student leaders "enjoyed appearing tough" and "being able to beat the administration." 
Mr. Dean. Mr. Dean was the deputy of school D for less than five months at the time of this study. He felt his students were lazy, that they did not want to study hard and deliberately fought the morning study time. Hence, the administrators made the study time optional. He suspected that "outsiders," that is, people who were not associated with the school in any way, entered the home science room and made away with the sewing machines. He felt the outsiders took the advantage of the riots in the school for their own personal interests.

When asked about the boys' motive in storming into the girls dormitory, Dean explained that the behavior was a "tradition." The boys wanted to take advantage of the girls and sometimes harass the girls perceived as "proud." He felt that girls acted as "catalysts" in the disruptions. A few girls complained to the boys if they had any grievances and thus incited the male students to organize a revolt. However, Mr. Dean explained that the majority of the female students were actually victims of threats and the riots.

Ms. Draco. Ms. Draco was 51. She authenticated the surprise element in the riots. She explained that the night she was attacked the students looked "very normal" during the day. During the night under the cover of darkness, the students "became wild." 
She expressed a feeling of "helplessness" and "hopelessness" during the riots because as a teacher, there was "very little one could do." She felt that majority of the students were "actively involved in the actions but were not in the organization of the disruptions." As far as she was concerned "the organizers are able to cover their activities."

Ms. Draco felt very strongly that the students at school D were "very lazy." To use her words "they want to just sit down and rest. They do not like to strain or to work under any pressure."

However, when asked to compare it with incidents in the boys' schools, Ms. Draco expressed the feeling that perhaps the students in her former school did not have a strong underworld culture. She did not feel the terms such as "traitors" or "team sellers" bore much significance in the school. According to Ms. Draco, students were free to consult a teacher without the fear of a reprisal. Additionally, she felt the students had no significant rivalry as individuals or in groups.

\section{The Conceptual Framework}

In discussing the grounded theory, the suggested core categories and their properties will be elucidated. The properties of the categories include causes, conditions, consequences, dimensions, types, and processes of the 
disruptions (Glaser \& Strauss, 1967). The categories and properties are intertwined, blended and combined to provide a rich, complex and dense grounded theory. The discussion will be a blend of quotes directly from the interviews and conversations, dramatic segments of on-thespot field notes, quotes from telling phrases dropped by respondents, and the summary of events and anecdotes. Each category will be discussed in the context of the evidence obtained in the data collected from the sites $A$, B, C, D, E, and F. I will refer to the sites for evidence where necessary.

The conceptual framework provided the backdrop of the grounded theory and depicted four themes which spoke to the different types of the riots and the consequence of the riots. The first theme was that the disruptions were sudden and not provoked by school administrators. The second theme spoke to the idea that the students used riots to create a platform for their demands. This type of riot was planned and manipulated to serve a purpose. The third theme addressed the issue that a few members of the community took advantage of the volatile nature of the riots and actually instigated the young people to disrupt the schooling processes. The fourth theme addressed the consequences of the riots. That is, the price paid after the students staged the riots that were more likely to be violent and destructive. Each theme was depicted as a 
core category. In the final analysis four categories emerged from data, which were: "the spontaneous reactions"; "the organized reactions"; "the outside interference"; and "the losses."

The "spontaneous reactions" core category was comprised of the happenings in the student underworld. The underworld, as the term implies, was hidden from the public view, it was the covert aspect of schooling. This was the territory that was occupied by the students often in the absence of teachers or when deliberate effort was exercised to exclude the adults in the school system. The underworld was dominated by a strong informal leadership which was controlled, influenced, and regulated by a gang of individual students who earned recognition by being unruly, brutal, but popular and humorous. Those adjectives are contradictory because the student world was often complex, interwoven, and difficult to decipher. All students were forced to participate in the activities of the underworld or suffer being ostracized by their community and their friends as well. The spontaneous riots that characterized the student underworld were as a result of power clashes and what may be described as the conflicts of interest groups. The issues that illuminated the theme of spontaneity and suddenness in riots were: informal leadership, activities that made the underworld, inter-class fights, and inter-school conflicts. 
The core category named "spontaneous reactions" in the data, and the issues that illuminated it, were overarching. Without a strong student culture created through complex, contradictory, and intricate social interactions and relationships, it appeared it would be difficult to organize any riots or have the "spontaneous reactions." It could be asserted that it was the creation of an integrated student informal leadership and a complex student culture that produced the incessant disruptions in the schools.

The second core category was the "organized reactions." organized reactions were boycotts and riots arranged by students to fight the formal and overt school establishment. In many cases, the students rallied to protest against unpopular school rules, forms of punishment perceived as unfair, shortages of water and other essential commodities or against what was described as unfit food. Further, in the "organized reactions" category, students showed dislike for administrators, teachers, rules and regulations, or the learning and teaching processes. Often, the revolt was inspired by a desire to create leverage. Students felt they needed a platform so that the administrators and teachers could listen to their demands. The disruptions were exhilarating for the students because the administrators had no alternative but to pay attention to their demands 
as lessons and other schooling processes were halted by the disruptive activities. The properties discussed in this core category are: student-teacher relationships, rules and prefects, and teaching and learning.

The third core category discussed was the "outside interference." Throughout the field study, it appeared some members of the public played a significant role in inciting students to arrange riots and boycotts and thus destabilize the institutions. Additionally, some members of the public took advantage of the volatile nature of the riots in order to access the campuses during the disorder for the sole purpose of stealing and/or looting school property and the personal belongings of the students. The data indicated that the intent of destabilizing the schools was to ensure that head teachers were accused of inefficiency by the community and the employer. If there were constant disruptions in a school, it was more likely that the school's head teacher would be deployed to another position in a different institution. The data indicated that members of the public who desired to have a head teacher deployed elsewhere did not hesitate to organize riots in some secondary schools.

The final core category was "the loss." This category was significant because it portrayed the consequences of the riots and boycotts. At the end of every riot, however minor, there was some loss 
experienced. The disruptions negatively affected learning institutions. It was obvious the riots resulted in the loss of instruction time. Notwithstanding the loss of learning time, during the riots the students destroyed the school property and damaged personal belongings of fellow students. Often forgotten are the psychological losses. Some students and teachers lost confidence and trust in the system of education that allowed them to be traumatized. other persons lost certainty, faith, and hope at the perceived failure of the system to deliver what it promised them. Some girls lost a lot more when they were raped, one of the most brutal traumas known to humanity.

\section{Spontaneous Reactions}

The properties of the spontaneous reactions as mentioned earlier dominated the properties in other categories because they determined whether a school would have a riot or not. These properties are: Informal leadership, activities that make the underworld, interclass fights, and inter-school conflicts.

Informal leadership. The activities and incidents that took place in the student underworld would not have stood without an effective social structure. The data indicated there was a social organization in the underworld described by the deputy head teachers in schools $B$ and $C$ as a "pyramid." Mr. Armstrong of school A 
depicted a picture of a few leaders "at the top" and many on the "base." Mr. Craig of school C referred to the leadership as comprising about five boys who were essentially "rough" and "did not care."

During the interview, the respondents variously

referred to these leaders as "top criminals," "born criminals," "champions," or simply as "ring leaders." At site A, Andrew pointed out that the group of the top criminals stayed together and ate together. At the same site, Arnold was emphatic when he said that disruptions were organized by a group of about five to six boys. Chuck at site $c$ explained that the group of "top criminals" used "to walk together" and they "were always planning evils." These comments from the subjects portrayed a pattern of a strong leadership formation. The leaders bonded and interacted closely, enabling them jointly to gain more efficient and effective organizational and leadership skills.

The personality of the leaders was also defined by the subjects. Mr. Armstrong remarked that one characteristic of the boys who achieved leadership in the underworld was the power to convince. According to $\mathrm{Mr}$. Armstrong, a student informal leader was able to convince his school mates that the food served "was contaminated because there was a rat's tail in the food." Other students were convinced even if the tail he was displaying 
was fresh and raw and did not appear to have been in the cooking pot. The power to convince was evident because the regular students believed the demagogues without disputing falsity of claims and joined in the protest against the school administration.

The other common feature among these informal leaders was their humor and ability to articulate the student grievances. According to Andrew, the top criminals were likable and "very social." Albert remarked that many students approved the ring leaders because they articulated their needs and desires. They were visionary and charismatic. This feeling was also expressed by David in school D. The informal leaders in David's school spoke for the entire school community and represented the feelings that the community shared.

According to Mr. Armstrong, the regular students were "devoted" to their leaders. The audacity of the informal leaders and their ability to antagonize the school administrators made them heroes. To the regular students, the boys who challenged the teachers and school administrators were daring and courageous and therefore powerful. The ability to acquire power and use it endeared the leaders to the average students.

The popularity and admiration were perhaps best explained by Chuck who explained that their informal leaders "knew so much" and that "they made things better." 
According to Chuck the regular students "waited to be commanded" whenever a decision was made to form a riot or to invade another school. cook remembered the self appointed leaders "went 'round the campus telling people to refuse this and that."

On the other hand, the leaders did not succeed simply because they were popular and convincing, they also terrorized the students so much that no student would have dared to oppose their orders. Many of the respondents used the terms "feared" to describe the informal leadership. When Anthony was asked to comment on why some students did not beat the odds and determine to eat despite the posters asking them not to eat, he said "one was afraid...one felt watched." This statement indicated the intimidation that governed the underworld. Benson of site B explained that the students in his school who bore nicknames such as "Saddam" or "Kijini" were "very much feared." He confessed he would not have dared to report any student to the school authorities because anyone who dared to report people of Saddam's caliber "was in danger."

Mr. Craig confirmed that the boys who organized disruptions kept knives and were so rough that the majority of the students felt intimidated into submission. As chuck explained, "We did not know what had been planned...but when stones 'rained' on the roofs of the 
school buildings, that was a sign of something." The students halted the activities in their daily program and "waited to be commanded." Chase said that the leaders appeared to have used bhang as they forced other students out of the dormitories. Anthony remembered that once the stones hit the roofs "one had to wake up." The ring leaders gave the orders and threatened that if anyone opposed the protest he would "be burnt with kerosene."

At the co-educational school, the girls had no alternative but to take the orders. Daisy remembered that whenever the boys forced them out "they came out like cows." This meant the girls were docile and followed the instructions without question or complaint. They did not make any decision for their destiny. Their destiny was in the hands of the demagogues. The female respondents of school $D$ expressed a feeling of lack of control and helplessness. This feeling underlined the fear and sheer terror that the informal leaders instilled in the regular students.

At school E, the June 1, 1992, disruption did not have an identifiable ring leader. It appeared the riot was a reaction against the fact that the school administration had denied the students a half-term break. The absence of an identifiable strike leader hindered the attempt by the female students to cause a widespread disruption. There was a reasonable cause to rally the 
support of the regular students but they needed a leader to organize the "strike." The head teacher and the teachers took control and the girls went to class.

On the other hand, in the 1992 disruption at the campus of school F, the other girls' school, there was strong leadership. Following the logic of this framework, the presence of a leader contributed significantly to the success of the 1992 revolt despite the fact that this was an all girls' secondary school. A form three student described by Faith as "rough" and "rude" was able to use her group to organize a successful riot. One of the respondents indicated that on the night of June 24,1992 , some girls directed the actions that the students should take. Accordingly, when a black-out occurred, the girls ran to their dormitories, collected their luggage, and walked out of the campus in the darkness. Undoubtedly, the presence of the leadership was an important underlying catalyst in enabling the strike to happen.

Additionally, when the girls at school E were terrified and afraid they walked out under the leadership of the senior school prefect. The senior prefect tapped on the girls' fear and terror of the strangers who were supposedly seen peeping through the dormitories at night. It appeared even in the generally milder girls' schools, whenever there was a strong leadership and a perceived reasonable cause, a disruption occurred. 
The above remarks underscored that presence of a strong leadership in the student underworld was an inevitable component in the execution of a riot or a boycott.

Activities that made the underworld. Most of the activities that the students did in their dormitories, the dining hall, and the other school areas when the teachers were absent were characterized by secrecy. Teachers and administrators were not supposed to know or to decipher what was going on because many of the actions were clearly in violation of the code of discipline and against the ethics of civilized behaviors. Some of the activities were violent and resulted in fights that drew the attention of the staff to dormitories and other areas of the student's turf. The detailed description of the activities in the underworld is important because it shows the integrated, dense, and contradictory nature of the student culture. The integrated culture played a key role in shaping the perceptions of the students and was ultimately responsible for the riots.

To protect their turf from the public view, the leadership of this underworld invented actions that inevitably limited the access of the teachers and the support staff. One of their most efficient and accessible tools was the use of threat. Any student who reported anything to the staff was commonly referred to as a 
traitor or team-seller. These terms coined by the students carried the power equivalent to that of the term "atheist" among staunch believers. A traitor was ostracized from the community. The respondents in this study conveyed their feelings of detest and abhorrence for traitors or team-sellers. What was revealed in the interviews was that the respondents themselves did not respect traitors or team-sellers and would have done anything not to be identified with those most often perceived as rejects in the underworld. In general, the respondents from the boys' schools felt rather strongly that the students who betrayed their fellow school mates were "liars and pretenders." When identified, a traitor was prone to brutal punishment. That brutality acted as a deterrent force and therefore the would-be team-sellers were intimidated. The attitudes born out of the concept of "team-selling" effectively shut off the teachers and administrators from the student turf. Sometimes the happenings in the students' turf went out of control and the administrators came to know exactly what took place behind the closed doors. When the happenings went out of control and the administrators and teachers intervened, the school documents showed that the underworld leaders were identified and punished. The punishment and exposure of 
the underworld was temporary and afterwards the secrecy and restrain was restored.

The theme of intimidation and the use of the labels "traitor" or "team-seller" emerged in the data collected from boys' secondary schools. Arthur reported that the fate of a team-seller was that "everyone attacked him at night." His safety according to this respondent lay in the eventual transfer to another school. To confirm Arthur's perspective, Arnold said that students acted in unison when the task involved the punishment of a teamseller.

The actions of students solidified their feelings as members of a team. Speaking about the students in school B, Ms. Baker said "no student would report another student to the teachers, they had a very strong fraternity." Ms. Baker explained that students were "ready to die" rather than report their school mates. Bernard and Bosco described an incident when the entire school flocked into the school office to curb the suspension of students they perceived as innocent. It appeared it was a common practice for the male students to use their brute force to defend their classmates against an administrator's punishment.

Cooper explained that in his school the informal leadership of the underworld had succeeded in "silencing all traitors." He added "no one could dare to report to 
the head teacher anything because if he was discovered he would die." It was Castro's perception that the beating of traitors was somehow expected because it was a tradition. "A person bled very much" were the words that Castro used to describe the punishment a traitor received at site $c$.

In the co-educational school, the term traitor did not mean the same idea as in the boys' schools. It appeared the girls factor played a role in neutralizing some aspects of the student underworld. To the students in this school, "traitors" were students who betrayed the strike organizers. Definitely the term traitor was not all inclusive, defining any student who reported to teachers or administrators anything that happened in their underworld. According to the subjects in site $D$, the traitors were "isolated" or given a "cold war." A person who received a "cold war" or was "isolated" was unpopular and did not have many friends. Dick confessed he once reported a strike plan to the administrators. Had he been discovered, he probably would have been isolated. This was a rather mild form of punishment compared to the punishment of the traitors in the boys' schools.

In girls' schools $\mathrm{E}$ and $\mathrm{F}$, the terms "traitors" or "team-sellers" were not used in the same context as in the boys' schools. According to the respondents, girls were free to talk to teachers as they chose. There were no 
reprisals feared if a student was seen talking to a teacher, as was the case in the boys' schools. Elizabeth remembered that the students "were close to teachers." When asked to define a traitor, Edith's definition was blurred. She said, "if you are a prefect and are seen mostly with teachers, you will be thought to be a traitor." The same observation was made in school F. Girls did not barricade their turf because they did not have much to hide. Besides, girls did not have the strength or the force to restrain teachers from entering their territory.

on the other hand, the boys had a lot at stake in their territory. It was not surprising that they coined words to scare students against informing teachers what was really happening in their dormitories and other school areas outside the public view. Once the boys had barricaded their world from the public view, they consolidated and integrated their culture. If culture is what people do, their patterns of behavior, values, and myths, the students under study had a fully integrated culture. The most significant aspect of the student culture that sparked controversy, conflict, and sometimes disruptions was what may be defined as "rites of passage." The rites were practiced under the supervision of the informal leaders. The rituals in the rites of passage comprised efforts to control and subjugate with the intent 
of bringing to subjection those perceived as lesser, weaker, or inferior. It was a struggle to maintain power, seniority, and status.

status. The underworld had a firm social structure. The structure was graded according to various status. A form one student had the least power in the emerging social structure while a form four student was perceived as most powerful. A form one student was fresh and ignorant and his role was to receive instructions from older boys. The rules and regulations in the underworld were not civil and may be commonly defined as the "rules of the jungle," where only the fittest survive. The form one students were subjected to harassment, unjustified beatings, and were forced to do the dirty chores for the older students. Additionally, they were defenseless because they could not report the harassment to the staff. The process of putting the form one students in their right place was called monolization.

The respondents spoke about being "monolized." This term was all inclusive; it defined the torture, harassment, the beating, and the bullying that a form one student was expected to bear. The idea was to give newcomers punishment that would enable them to become tough and resilient in daily living around the schools. However, in most cases the punishment went over the line and became torture. Therefore, the term monolization 
cannot be defined as bullying. It was a systematic process designed by the senior students in a school to give them a feeling of power and control. At site A, Arthur defined monolization as being "locked up in the dining hall and being beaten." Andrew defined the process as giving the form one students a hard time so that they would "respect the older students." Andrew recalled that he did not do his own washing "when a mono could do it for me." Alex explained that the beating of form ones was "with anything, for example rods, sticks, etc." To Anthony's perception, monolization was somehow a "tradition." Arnold, one of the most ardent "monolizers," proudly stated that a form one student should "wash his shirts" and there was nothing he could do to avoid that task.

The story at site $B$ was not different. Benson spoke of how he was beaten as a form one student and said, "Some slapped us, others used wires, sticks etc. and demanded money from us." He also described the process as a tradition. At site $c$, Chris categorized the process as a tradition and pointed out that as a form one student he himself did not attend the study time in the evening because each day the newcomers were "gathered from 7:00 p.m. until 8:00 p.m. for a beating." sometimes the form one students were initiated into cigarette smoking and eventually into bhang use. The school records of school c 
reported two boys who were suspended because they forced the form one students to take bhang. The documents in school A indicated the form one students were forced to give the older students money. other times the older students forced the form one students to sign documents indicating that a form one student owed a senior student some money. Monolization process resulted in psychological, physical, and social torment. Some newcomers could not bear the punishment and had no alternative but leave the institutions. Castro estimated that about one third of the students in form two, form three, and form four did not do their washing. Instead they demanded that the forms ones should do it for them. Both David and Dick in school D acknowledged there was harassment of the freshmen. When responding to the question about monolization David said that he himself received a bit of harassment from one or two people. He claimed, "I was not monolized much." The extent of the harassment in site $D$ was difficult to measure because the stories given were not accompanied with the experiences narrated in sites $A, B$, and $C$. The students in the boys' schools valued the monolization process. It was part of their lives and they described it as a tradition. In the co-educational school, monolization was not as highly acclaimed, and the interviewees did not view it as a 
tradition. Additionally, it appeared to be an insignificant part of the student life.

According to the female respondents at site $D$, the form one girls were not monolized at all. When Doris was asked why girls were not harassed, she said, "It is just the way we found it." This statement meant that traditionally girls were not beaten and that the tradition was in place when Doris went through school. Daisy observed that the boys used to harass their fellow male form one students. The statement was not accompanied with illustrations or anecdotes, a feature which made one feel that when monolization occurred it was perhaps milder and less important in the co-educational institution. In both schools $\mathrm{E}$ and $\mathrm{F}$ monolization was not an issue at all. In school E, Elaine said, "We were not harassed in form one." Both Elizabeth and Edith confirmed that the monolization was not practiced or condoned in their school.

The interviews and school records indicate that monolization was a brutal and fierce rite of passage. The long discussion about this aspect of student culture underlined the backdrop of the culture of violence. It is more likely that the experience of monolization process changed some regular students into brutal human beings. It is not surprising that the form two students were likely to be perceived as most brutal. It is likely the trait of brutality was acquired in the form one class when 
generally students were made to go through brutal acts of the so called monolization. As form two students, the former newcomers sought revenge and the culture of violence was perpetrated. Monolization may be partly blamed for the acts of violence and the lack of remorseful feelings observed in the data.

Form two syndrome. When the form ones entered the form two class they were subjected to the second and final rite of passage. This beating was appropriately referred to as "summary" or "promotion." The data collected from the boys' schools indicated that the summary officially gave authority to the form two students to beat up the newcomers who were enrolled in early February. The data also suggested the form two class was the most volatile and unpredictable. The nature of the form two student behavior was significant and emerged as form two syndrome in the data. Because of the terror that the form two students were subjected to in the form one class, they were determined to revenge by not only beating up the form one students but by disrupting the normal schooling processes. In fact, the data indicated that the form two students disrupted the normal activities in different schools every school year. It could be suggested that the form two student memories of the events they suffered while in form one were fresh and graphic. 
School A suspended the form two students in 1992 and in 1993 school years. As late as October 21, 1995, there was a violent fight that pitted the form two class against the form four class. In the records at school $c$, it was indicated that form two students had running battles with the school administration in 1992 when they refused to go to class or to obey the regulations of the school. The respondents who were form two students at site C in 1992 reported that their class felt discriminated against by the teachers, the administrators, and the other students. They decided to cause chaos and then go home. In school D, the 1994 school year was disrupted by the acts emanating from the form two class. The form two students wrote posters and pinned them in the dormitories demanding an "exodus." The rest of the school was not ready for the exodus and the form two students were literally chased out of the school campus by the staff and other students. Respondents agreed that the form two students were responsible for the most brutal monolization acts. Respondents from the boys' schools felt the form two students had the most solid comrade spirit. Mr. Bridge offered the best explanation for the solidarity of the form two class. He said the students bonded extremely well because as newcomers they comforted and consoled one another in the midst of overwhelming odds caused by the monolization acts. As form two students these members 
established their independence and with it they became uncanny and disruptive.

The behaviors of the form two students were detested by other classes as well. In the inter-class conflicts, the form class was blamed for instigating most of the fights. The fights were sometimes motivated by revenge and/or power challenges. However, before the inter-class fights are discussed, there are other activities to be investigated which occurred in the underworld that fueled both the spontaneous reactions and organized disruptions. These are the drug use and other activities that contributed to the malfunctioning of schools.

Drug use. If monolization was perceived as a tradition, the use of bhang was perceived as inevitable for bringing about disruptions. Bhang was the glue that cemented the student behaviors and social structure in the underworld. After bhang was consumed, it appeared the students lost discretion in their actions. The effect of the drug seemed to be a catalyst for irrationality. Cook stated that after consuming bhang, students "did not reason properly." The students were prone to follow the instructions of their informal leaders once they were under the influence of the drug. Describing the effect of bhang, Castro said "those who took it became wild...they behaved badly and incited others to do horrible things." Chase explained that most attacks were planned when a 
majority of students were under the influence of bhang "so that they would appear wild."

Alex claimed that his friends "looked like mad men or beasts" after they consumed the drug, while Albert described the effect of bhang as "drunkenness, just the same way as alcohol does to a person." From a personal experience, Arthur said he experienced changes and was consequently expelled from school. He confessed that he recruited many other students into the habit. Respondents attributed form one harassment and disruptive activities to bhang consumption. Alex stated that a bhang user "would beat a form one until he bleeds."

Mr. Bridge acknowledged that the boys who attacked the staff-room took a lot of bhang as a catalyst for the violence. Whereas the co-educational school was milder in terms of monolization and traitor punishment, it appeared the drug use was very widespread. Dick explained that the male students consumed bhang every day at break time during the three-hour evening study period. The boys bought the bhang from a cook employed by the school or from a person who was a well known supplier who lived near the school campus. The female students did not use bhang but some girls stored it for their boyfriends. Doris claimed that any time the boys consumed bhang in large quantities, "something was going to happen." David connected the violence that accompanied the 
disruptions with the bhang. He said, "A strike was connected to bhang." The female respondents described the wild behavior that the boys indulged in after they used bhang. Dorothy observed that the normally quiet, regular male students became "noisy, jumpy, and weird" under the influence of the bhang. Daisy's perspective was that boys "changed a lot" and "became brave and did not fear" after they consumed bhang. Daisy also believed the effect of bhang influenced the male students to attack girls' dormitories. All the female respondents denied that school girls used bhang. Likewise, the respondents representing the all girls' secondary school, E and F denied that any bhang was used in their school campuses. Mr. Barrozi blamed bhang for the numerous incidents of school disruptions that rocked his school between 1990 and 1991 before the school was closed for an entire academic year. There was adequate evidence for one to argue that bhang gave the male students overwhelming courage to break school rules and to wreak havoc on the school establishment.

Rules that governed the underworld. One of the reasons students barricaded their underworld from the teachers and the school administrators was to have an opportunity to establish their own code of behavior. Going out of school campus without authority was a common behavior in the underworld. Once the students broke 
loose, they engaged in activities that were not only illegal but clearly outside normal schooling functions.

For instance, the records indicated that some students in school A went to town center any time including class hours to buy merchandise which they traded in the dormitories for a profit. Some of the commodities sold were cigarettes and bhang. Arthur explained that there were about four students in every dormitory who sold cigarettes, bhang, and bread. The self-styled traders were not interested in the orderliness of an atmosphere conducive to learning. Instead they went to town any time convenient to them. One of the respondents in school A described those students who established the illegal trades as "hard nuts." When asked to clarify that description, he indicated that those responsible did not care. The school authorities had suspended them so many times that they had become hardened. It was recorded that Arnold raped a girl in the village close to the school during one of the escapades from the school campus. He was facing some serious court charges during this field study. The school documents indicated that some other boys lured girlfriends into their dormitories, a clear indication of a school's malfunction.

In site $C$, respondents explained that some students had large quantities of cigarettes which they sold to others. Chuck's comment during the interview was, "Taking 
beer, bhang, and cigarettes was very common and very regular." In fact, some boys had a makeshift brewery in a coffee plantation near the school campus. The school records at site $B$ also described the trading patterns of the school and the village next door. The boys had an adequate supply of the local beer and bhang.

The discussion about the abnormal code of behaviors that governed the underworld is relevant to this study. The abnormal code of behavior underlined a school's malfunction and its inability to fulfill its obligation as a learning institution. It was difficult to decipher the mission and the vision of schooling in the labyrinth of the malfunctions. It appeared some students had a different definition of what a school was and should be. To some students, schools were recreation centers or shopping malls and to others they were disorganized youth camps. This background knowledge gives a holistic view of the disruptions and places them in a broader perspective. The broader perspective defined the meaning and interpretation of schooling to some students. It was obvious some students invented their codes of conduct and did not respect schools as institutions of learning. It was not surprising that they disrupted learning at the slightest provocation. The disruptions gave them opportunity for a business boost because the students bought bread from them during a meal boycott. During the 
disruptions, the amount of bhang consumed was higher and the bhang seller made more money. There is evidence to suggest that some of the traders worked closely with the strike organizers.

On the other hand, there was no evidence that the female students in school $E$ and $F$ created their codes of behavior. The data indicated that the girls felt a desire to have more outings but they were not daring enough to go out when they wanted. In any case, their underworld was not well barricaded and the staff was in a position to control the happenings in their dormitories and other school areas.

Inter-class conflicts. The theme of inter-class conflicts emerged because it was noted that some conflicts were not aimed at the school administration but were the result of in-fighting between student groups. To illustrate how class conflicts occurred, an example from school A is presented.

On October 16, 1995, while this study was ongoing, a major form four and form two rift occurred that erupted into a running battle. The fight between the two classes involving approximately 320 boys started over an extremely minor dispute. What happened was that a form two student demanded a loaf of bread from a form one student. To use their language, the form two student was monolizing the form one student. A form four student intervened in order 
to protect the form one student from the unnecessary harassment. Unfortunately, the fourth form student was weaker and smaller bodied but the form two student was stronger and bigger. During the ensuing fight, the fourth form student was given a resounding beating by a second year student.

The interpretation and the meaning of this incident was the sole source of the collective fight. The entire form four class interpreted the fight as a degradation to their seniority. Explaining the incident, the deputy head teacher said it was simply unthinkable how the form four students could bear such a blatant insult to their seniority and pride. The beating of their classmate by a second year student was tantamount to an intolerable insubordination and humiliation. The form four students were determined to respond to that insult. on the other hand, the volatile form two students took the opportunity to challenge their detractors and prove their worth. The form twos were prepared to defend their classmate. The fight began. It was a fierce conflict as boys in various camps pursued their perceived enemies. The running "battle" took the students ten miles from their campus. The conflict was spontaneous and was not provoked by what the school administrators did or did not do. It was sudden and motivated by revenge and anger. Some boys were seriously injured in that ensuing fracas. 
At school B frequent disruptions were characterized by spontaneous types of disruptions. Explaining the source of inter-class conflicts, Burt said that if a student from the lower classes, for example, a form two student, beat a student in the third form, the form three students felt scaled down. It was normal for the entire third form to feel aggrieved by such acts and to join in the defense of their colleague. The fights were used as the means of preserving and restoring pride and higher status which was measured in terms of brute force in this culture.

It was not surprising when Burt in a matter-of-fact tone said, "In our school, form threes are more powerful than form four students." The measure of power was how many fights a class won against its opponent. Burt's comment underlined the thought process of the majority of the young men in the secondary schools. The protection of one's turf, and the perception that someone could not live with what was perceived as a demeaned status, led to frequent fighting. Referring to the fights between the form three students and the form four students, Burt noted that "the form fours were beaten by the form threes in the 1991 school year."

The battles in school B forced the school to close temporarily many times. According to another respondent in site $B$, every student had an obligation to defend his 
classmates because he may need to be defended in future. This was what Bosco was thinking about when he said, "One needs the help of his classmates in case one is beaten by students from another class." When asked why students fought so much between themselves Bosco responded, "I cannot explain because that is how I found things." This comment emphasized the picture of the frequent proliferation of inter-class fights in site B's landscape.

Inter-school conflicts. The theme of school conflicts emerged in the data collected from schools $A$ and c. However, the inter-school conflicts appeared to be the preserve of site c. Inter-school conflicts were rare and infrequent and cannot be defined as characteristic. However, they deserve mention and analysis because they contributed to the spontaneous nature of school conflicts and what may be defined as "the defense of perceived status." The reported incidents of inter-school conflicts involving the students from site $c$ were four. The most detailed conflicts are two invasions of a co-educational school about three miles from the site $C$ campus. The other two conflicts were mentioned in the interviews and the details of the invasions were not recorded.

The invasion of Riverside school by school A was well documented in the school reports. The nature of that invasion made the incident become imprinted in the minds of the respondents. Many of the respondents remembered 
that during a soccer match on March 27, 1993, at Riverside campus, school A players were attacked and beaten. The players arrived back to their school campus at 7:00 p.m. just before darkness fell. They reported to their colleagues that they had been severely beaten at Riverside during the soccer game. According to the respondents, school A student body unanimously decided to go to Riverside and retaliate.

The decision was sudden. The underworld leadership urged the student body to fight back so that they could restore their honor and status. Like the inter-class fights, the inter-school fights were motivated by anger and determination to seek revenge at whatever cost. The cost comprised running 15 miles to Riverside campus, destroying that school's property, and beating up unprepared and defenseless girls and boys.

According to Andrew, after arrival at Riverside campus, the school A students "surrounded the hall." Some of the school A students entered the hall and damaged the television and stole the cassettes. They beat the Riverside students severely. When asked whether the Riverside noted their attackers, Andrew gleefully answered that the Riverside students did not know what was happening because the school uniforms of the two schools were identical. 
The boys were happy because according to Anthony, school A students had demonstrated their power over what was perceived as a weaker school. Anthony explained that after the fight, the other neighboring schools "feared" their school. In other words, the fight was worth it because school A students proved to their perceived enemies that they were not cowards or wimps. Some respondents felt the fight served as a warning to any other school that may attempt to humiliate school A's students in future. Anthony was confident no school in the vicinity would dare beat up a school A student. The characteristics of the attack of Riverside were similar in all respects to the attacks on valley, another co-educational institution, by school c. Information from the school documents and interviews indicated that the school c students attacked Valley Secondary School twice in the 1991 school year.

During the interview, chuck described the relationship of school $\mathrm{C}$ and the valley school which set the tone of the feelings that sparked the confrontations. According to chuck, the students at school $c$ "had the power" and were superior to the students in the coeducational school. Normally, the site $\mathrm{C}$ students expressed their superiority by visiting the valley campus regularly and giving "orders to the Valley students." 
Asked what orders they gave to them, chuck replied, "To give us chairs and food."

This feeling of superiority was underlined by the deputy head teacher when he said that the conflict between his school and the Valley school was centered on the fact that the school $\mathrm{C}$ students believed that the Valley school was weaker and inferior. One respondent described it as a "girls' school," although it was a co-educational school. Asking a rhetorical question, he wondered when a girls' school ever outdid a boys' school. Since the valley was perceived as weaker and inferior, the school C students refused to accept any form of challenge from the valley students.

Valley students challenged school $c$ boys on November 3, 1991. What happened was that some school C students went to valley school on that saturday afternoon. It was not clear what they had gone to do. Given the attitude of their school toward Valley, it may be deduced the gang of school $C$ boys became rude and intolerable to the hosts. Whatever happened, it is clear the visiting gang must have been humiliated and beaten.

Upon returning to their school campus the gang reported their nasty experience to an enthusiastic audience. According to the respondents, the entire student body rose to the occasion. They were prepared to defend their superior status at whatever cost. According 
to chuck, the underworld leaders whom he referred to as "champions" organized the invasion of Valley instantly. To use one of the respondent's remarks, the leaders convinced the other students that they "should not keep quiet like children." The entire crowd led by the demagogues agreed that "there was nothing that would hold them back from going to the Valley secondary school and demand a response."

According to the stories narrated by the respondents, their leadership distributed responsibilities to various classes. The form one entered the valley campus first, and when the valley students screamed, the other school c students went in and attacked the students. During the attack, the school c students "caused a lot of damage to the school buildings and school equipment." The only remorse the respondents expressed was the fact that one of their colleagues was apprehended and school $\mathrm{C}$ was made responsible for the repairs.

The patterns of the inter-school conflicts that emerged from the data were similar. After students attacked the targeted institutions, they caused damage and destruction so that they could be "feared" by their victims. For as chase explained, no matter what precaution the perceived weaker valley Secondary School took, the superior force of school c "overpowered" them. Valley was bound to have less resistance because the male 
population comprised only 200 boys and the other 200 students were girls. When over 400 strong and determined school $C$ boys set out to destroy, a formidable destructive force was at work at the valley campus. The brute force was interpreted as power and it made the boys feel very good about themselves.

It was interesting to note the virtual absence of inter-school conflicts involving school D. The neighboring boys' school did not plan to attack school D. The respondents expressed satisfaction with the existing relationship between school $\mathrm{D}$ and its neighbor. There was a boys' school about ten miles from the school D campus, code-named in the data "Forest Secondary School." It may be argued that the definition of power of the students at Forest was not similar to school C's definition. The data recorded in the field notes indicated that Forest was one of the most disruptive schools in the region. However, this school did not attack the neighboring school $D$.

The inter-school conflicts were placed in the spontaneous reactions because they were sudden, demagoguery, and the planning took only a few minutes. The plan to attack was not deliberated for a week or several days, a feature common in the organized reactions. However, the success of the attacks lay on the organizational ability of the informal leadership. The leaders wielded unquestioned influence and power and their 
decision was the decision of the entire school. This was why it was stated that the leadership and the student culture were overarching. It was the enabling force in the execution of riotous behavior.

The other feature that made the attacks so successful was the integrated student culture in the underworld. As illustrated, that culture was based on fear and intimidation. Thus the "fear" of being labeled traitor or team-seller forced all students to join in. When strong teenagers were aroused to do damage, their number and strength was an overwhelming force of destruction.

The third element that ensured the success of the inter-school raids was the use of the illegal drug. The effect of bhang that the students used before these attacks acted as a catalyst. All respondents agreed that once they took the drug, their reasoning ability was dulled and they had no ability to question the moral value of their actions.

It appeared in the final analysis about four factors interpolated in the inter-school conflicts: the presence of a strong underworld culture governed by fear and intimidation, the leadership that wielded unquestioned authority and whose decisions become the decisions of the entire student body, the perceived need to accumulate power through raw and brute force, and the use of bhang that acted as catalyst in most activities rendering the 
participants the incapacity to have moral or ethical

judgment. Table 9 summarizes category 1 and its

properties.

Table 9

Properties of Category 1: Spontaneous Reactions

\begin{tabular}{|l|l|}
\hline 1. Informal leadership & $\begin{array}{l}\text { - accumulated power } \\
\text { - controlled the underworld } \\
\text { - fearcd and respected }\end{array}$ \\
\hline 2. Activitics that made the underworld & $\begin{array}{l}\text { - drug use } \\
\text { - status fights } \\
\text { - form } 2 \text { syndrome } \\
\text { - rites of passage rituals }\end{array}$ \\
\hline 3. Rules of the underworld & $\begin{array}{l}\text { - retail shops } \\
\text { - blatant disobedience of the rules and } \\
\text { regulations }\end{array}$ \\
\hline 4. Inter-class conficts & $\begin{array}{l}\text { - e.g., form } 2 \text { versus form } 4 \text { a status related } \\
\text { fight }\end{array}$ \\
\hline 5. Inter-school connicts (rare) & $\begin{array}{l}\text { - "Vallcy" versus site C } \\
\text { - "Rivcrside" versus sitc A }\end{array}$ \\
\hline
\end{tabular}

\section{Organized Reactions}

Organized reactions were fights against the formal

and overt school establishment. The riots which students referred to as "strikes" were meticulously planned. These so-called strikes were motivated by a deep-seated belief among the students that their problems would not be solved unless they organized a boycott of meals and classes. often the boycotts turned violent and were disruptive of the normal schooling processes. 
During the interview, Arnold argued constantly that without a strike, administrators "would ignore us, they will not listen to our grievances." Students perceived riots and boycotts as opportunities to act in oneness and challenge the adults in the school system. Thus the "oneness" of the students gave them "strength" so that teachers and administrators had no alternative but to listen to them. Arguing from the same standpoint, cook of site $C$ believed that school administrators would only listen to them if the riots occurred. As he stated "complains would fall on deaf ears" if students did not organize strikes. Chase reiterated cook's statement and said "we went on strike to make our demands heard." Subjects at site $\mathrm{B}$ also indicated undoubtedly that some strikes were organized so that the students could create a leverage with the school administrators. Bernard explained that one time they demonstrated against the school administration because they felt the administrators charged higher fees than the amount recommended by the Ministry of Education. Other respondents at this site spoke about feeling "dissatisfied and confined" at the school campus. They therefore created commotion so that they could go home. Bosco explained that it was normal for the students to come back to school in the morning and in the afternoon "they would go back home." In fact the disruptions at this school were so common that Benson 
described the riots and boycotts as "tradition," while Bernard recalled a school life which was pervaded with an air of "confusion all the time."

The riots in the co-education school were characterized by violence, especially against the female students. According to the deputy head teacher, students complained about food even when their grievance was something else. For instance, the respondents stated that some students deliberately dumped a crab into the already cooked food and insisted the food was unfit for human consumption. A riot ensued. After investigation, it was discovered the students had other demands. According to one of the respondents, students wanted to have their uniform changed and "a week off for the half term break." Asked why they demanded a week off, the respondents said students wanted to compensate for the shorter than normal break during the previous semester.

In schools $E$ and $F$, the three riots documented occurred because the girls were unhappy with the school rules. On June 1, 1992, the girls at school E protested against the idea that they were not allowed a half-term break. It was an accepted tradition in many schools that a half-term break was necessary to give students a relief. The students went home to be with families during a halfterm break. A half-term break, literally speaking, was a four day weekend. It appeared the girls at school E were 
aggrieved that the administration had refused to give them that break. The decision whether a school should have a half-term break depended on the feelings of the school's PTA. Some parents complained that half-term breaks were unnecessary. If the PTA of a school decided to eliminate the break, the head teacher implemented the decision. However, students were more likely to blame the head teacher if they were not allowed to go home for the halfterm break.

Elizabeth explained that during the protest, the girls shouted that they would go home whether the administration permitted them or not. The second disruption at this school was motivated by feelings of insecurity. The girls felt the teachers were not protecting them and they decided to take matters in their own hands. They simply packed their luggage and went home. Both these reactions fall in the organized reactions category because they were planned ahead of time and the students had clearly thought and considered their grievances before the disruptions occurred. According to the records, the protest at site $F$ was organized by a few form three students led by a "mangaa." The respondents explained the grievances expressed by school F students. According to Flinder, the girls were protesting against the "teachers' mistreatment." Additionally, the girls wanted more liberty in deciding 
who should visit them during the open days. The school authorities had imposed a restriction that young men were unacceptable on campus. The respondents indicated that the riot was well organized. Florence explained that someone directed them exactly what to do when a black-out occurred. The riot at school $\mathrm{F}$ fell in the organized reactions category. The girls engaged in disruptive behavior because of a perceived grievance. The informal leaders of the disruptions wanted to create a platform upon which they would argue their case with school administration.

In a meticulous organization of disruptions, a series of systematic steps were taken to bring about the boycotts or riots. A systematic and thorough organization emerged in the data collected from all six sites. The most important component in any planning was a leader. The leader, who may be compared to a general in the military, distributed responsibilities to his or her faithful lieutenants.

The data indicated that the leader gave the responsibility of informing the rest of the students about the intended strike to some of the friends in his or her gang of the faithful lieutenants. Those students who were given this duty made sure they wrote posters and had them pinned on the most frequented areas of the dormitories. It appeared the larger student body obeyed the 
instructions written on the posters without any question. If the poster indicated they should not eat dinner every student abstained from the dining hall. As one respondent said, many students were afraid of disobeying such orders because the strike leaders may have them punished. Or as Anthony pointed out, he had to obey because he was afraid and he "felt watched." The intimidation and the fear that ruled the underworld were responsible for the response of the majority of regular students. As Mr. Armstrong put it, no student was prepared to "lose his skin," so he obeyed without question.

After the students had boycotted the meals or the classes, the leaders planned and allocated duties for other activities intended to cause chaos. According to Albert, strike planning was an exercise where "some planners incited the boys, others disconnected the electricity, others threw stones on the roofs." Meanwhile the majority of the students prepared for the worst. Some took extra sweaters and good running shoes because most strikes occurred at night. The preparation for the worst was motivated by the fact that the boys knew from experience that once the school was plunged into chaos the police officers were normally called in. The fear that the police might arrest someone forced students to disperse quickly as they ran and sought places to hide. Many students spent such nights in the open. 
Since the planned attacks were deliberately organized to seek leverage with the school administration, the properties that emerged in this theme were found in the formal establishment of a school. They were: teacherstudent relationship, school rules and prefects, and finally learning and teaching. Using these three themes, the organization and planning of riots by students were explored. In this context, the effect of riots on the teacher-student relationships, the disciplinary code and ultimately formal learning and teaching was examined. Teacher-student relationship. In the discussion, the attitude of students toward teachers and the teachers' attitude toward students dominated the topic defined as the teacher-student relationship.

Us versus them. In schools where students took stringent measures to create a coherent, strong culture in the underworld, the student conflicts with teachers were marked by negative and hostile feelings. The us versus them stance underlined most behaviors and feelings. On the other hand, in the schools that did not have an integrated underworld culture, the us versus them feeling was mild if not totally absent. Thus, the lack of a strong underworld culture in the all girls' schools allowed the girls to talk and work with teachers without the fear of any reprisals from school mates. 
At site A, Andrew summed up the feelings most students had about the teachers. He said the teacherstudent interaction was a "sort of competition." To clarify that statement, Andrew explained that if a teacher asked a student to go out of class because he was rude the student would "refuse to obey the teacher." If nothing happened to the student after such a blatant disobedience, it meant the student had won the contest. Anthony used the same terminology in conveying his observation, he said "students wanted to compete with teachers."

According to Albert, the teachers used to accuse the students falsely and "they interfered with our affairs." This feeling seemed to justify the blatant disobedience of students to the teachers' instructions. So when Albert refused to obey a teacher in their class, the classmates "hailed him as champion." It was also Albert's perspective that the use of bhang greatly accelerated the anti-teacher feelings in school A.

on his part, Andrew felt the teachers treated the students "unfairly." He repeatedly used the phrases "teachers should understand," "they should not ignore our issues," and "they should not give a deaf ear to our complaints." on the other hand, Anthony felt teachers punished students unnecessarily. According to Anthony, teachers who often insisted that the students should "kneel down" and "lift hands" provoked the distasteful 
feelings of students. According to Anthony, boys did not like such directions, so a teacher who gave such orders "was hated."

The students did not hesitate to organize a disruption to make their points known. According to Arnold, there was an instance when students once organized a strike to impress upon the teachers that they should never beat up a student in the teachers' lounge commonly known as "staff-room." As Arnold mentioned, if a teacher caught a student doing wrong and asked him to see him in the staff-room, when the student responded, he was beaten up by all the teachers in the staff-room at the time. The subjects interviewed were particularly offended by that habit, which they described as unfair and distasteful. The students organized a riot to display their negative feelings about the issue.

At school B, the us versus them stance remained unchanged. According to Bosco, "Teachers hated students." He felt misdemeanors were turned "into a mountain." Bernard was even more specific, he felt the teachers hated the boys from the village. He felt it was unfair that teachers often concluded the boys from the village trafficked bhang. On the other hand, Mr. Barrozi said the teachers at school B felt mistreated by the students. Barrozi stated that students laughed and mocked teachers constantly and that made the teachers feel demoralized, 
while Mr. Bridge expressed the feeling that it was difficult if not impossible to befriend students because once a teacher punished a student the punishment was interpreted as "hostility."

The feeling that the teachers interfered with student affairs was pervasive. Subjects at site B were emphatic that the code of education did not authorize teachers to cane the students. The respondents claimed that it was only the head teacher who could legally beat up a student. On the other hand, if a teacher took a student forward to the head teacher, he or she became unpopular among the students. The respondents said it was customary to have the unpopular teachers' names on posters crafted sometimes with the demagoguery messages that their heads should be "blown off." These behaviors and feelings definitely motivated many students to develop negative responses toward the teachers and to strengthen the us versus them attitude. Ultimately, the negative feelings and responses contributed toward the attacks on teachers' houses.

The picture of the teacher-student relationship is not different in school c. Cooper felt that most often teachers were unfair when they reported students to the administration. He said emphatically that teachers often forgot that some students "have no motivation to do well but to destroy a school." Chuck gave the impression that the students deliberately refused to work with teachers 
for a conducive atmosphere. He said, "A new teacher would be sure to meet very stubborn people." To clarify his statement, Chuck explained that a new teacher perceived to be proud was "verbally abused or shouted at in class."

The male students complained that the female teachers were harsh or had "mistreated" them. Other subjects observed that the female teachers were too young to instruct them or give them orders. One respondent in school A said the female teachers "attracted his attention." Generally, the subjects did not appear to be comfortable with the female teachers and the young graduates.

The teachers did not trust the boys either. To sum up the distrust the deputy headmaster of school A perhaps expressed the teachers' feelings best when he said, "Even us teachers would not trust any boy." He added, "There is no student who I can really trust." It appeared the lack of trust on both sides heightened the us versus them feeling. The distrust was expressed in bad taste, particularly in school B when students physically attacked the teachers during the riots.

On normal school days it appeared the students and teachers at school $D$ had what may be termed as a normal student-teacher relationship. Ms. Draco explained the students were "very normal" on regular school days. She described the teacher-student relationship as "friendly." 
The respondents interviewed at the site did not convey any us versus them feeling expressed in the boys' schools. The attack on Ms. Draco at school D was motivated by extreme anger and not necessarily by a deep seated feeling that the teachers belonged to another camp. The incident was isolated but violent. One may attribute the violence to the fact that students consumed a lot of bhang that made them irrational. Ms. Draco's attack fell under the organized reactions category because I was made to understand that the incident was planned during the weekend. On the action day, some boys who were on suspension were seen on the campus. There was evidence that the leaders of the strike planned it with the assistance of boys who had been suspended. These activities indicated that the reaction was organized and not spontaneous. In other words, the students sought to make a point by attacking the deputy head teacher's house. The female students expressed a very different view regarding their attitude of their teachers. At school E, although the girls were not happy when beaten by teachers, Elaine observed that students "did not resist, they accepted it." At school F, Flinder and other respondents felt that the beatings inflicted on students as punishment being disruptive on June 24, 1992, were "not fair." However, the girls expressed a general resignation and a feeling that no one could dare to challenge the teachers a 
second time. It appeared there was an agreement that although the beatings were "not fair," they were prepared to "persevere."

"Perseverance" was absent in the boys' vocabulary. They felt they could do something about anything perceived as problematic. It was indicated in the records of school B that some students attacked teachers' premises on January 29, 1993. One of the teachers attacked was a woman. It appeared there was no physical attack during this raid. When Ms. Baker was asked to comment how teachers protected themselves during the attacks, she said, "There is nowhere to hide, they just lock themselves in one room." The attacks on teachers' homes prompted many teachers to move out of the campus. They preferred to commute to school each day instead of the convenience of a having a home near the workplace.

The records at school A revealed a plan to attack the deputy headmaster's home on May 27, 1994. Posters in the boys' rest rooms notified fellow students of the proposed attack. The invasion did not take place as planned but the boys threw stones at the headmaster and the deputy headmaster on the night of May 27, 1994, as the two walked around the campus. No one was seriously injured.

In most cases students perceived the enforcement of school rules as unfair. It is not surprising that the student-teacher relationships were sometimes marked with 
incidents of bitterness and anger. It is clear students would have preferred a situation where no rules were enforced.

Prefects and rules. Prefects who were appointed to enforce school rules were targets of frequent attacks on the boys' campuses. The prefects were punished by their fellow male students if they were perceived as being too close to teachers. There is no case perhaps that better demonstrates the terror that prefects endured as one incident recorded in site $c$. In the school documents, some students were accused of "beating and burning prefects' belongings," and the respondents were asked to comment about the incident during the interview.

According to cooper, the prefects were punished because they felt "superior." cook recalled that the prefects had become "too strict" and the rules had "drastically changed for the worse." The prefects accused those who broke the rules and they worked closely with the deputy headmaster to restore order and discipline. As a result of this, cook observed, "strikes failed to succeed," and therefore "grievances expressed by students fell on deaf ears." The perception of cook and his school mates was that the prefects were not helping the students and had all become "traitors."

The boys arranged to ostracize the prefects perceived to be traitors. According to cook, it was resolved by the 
underworld leadership that the "prefects would not be allowed to live in the dormitories." The earmarked prefects decided to run for their lives. In turn, the student informal leaders took the prefects' belongings and set fire to them. The three prefects did not dare to return to the dormitories after this incident. They felt their lives were threatened, hence they commuted to school for their standardized national examinations.

A similar situation was reported in school B. A disruption was organized with the express purpose of "burning the prefects." The reason given for this incident was identical to that in school $c$, that is, the prefects were too close to the teachers and especially the deputy headmaster. Mr. Barrozi thought the incident was prompted by the deep distrust that characterized feelings of students toward the teachers. The prefects suffered because they were communicating with the teachers and perhaps reporting the affairs and activities of students to them.

Deep distrust and suspicion did not pervade the girls' institutions. It appeared the female students perceived prefects as a legitimate liaison between teachers and students. Therefore, if the prefects reported anything, it was their duty to do so. The girls did not make the reporting an issue of contention. As analyzed before, the girls did not have many activities to 
hide. Their territory was not as secretive as the boys' turf. The boys had monolization, bhang, cigarettes, beer, and other activities to hide from the teachers. The girls did not have anything at stake whether their territory was open to public scrutiny or not.

The behavior of the boys toward teachers and prefects demonstrated their general attitude toward school rules and regulations. Many students in the all boys' secondary school did not care for an organized, orderly atmosphere where rules and regulations were obeyed without question.

Perhaps Bosco summarized the attitude of the students toward school rules the best. He felt that going out of the campus to the town center was in order and should not have been restricted because the students "felt very much confined and dissatisfied." According to this subject, walking out of the campus without authority was "not a serious breach of rules," but rather a "very minor thing." Whereas smoking was against the school rules Arnold reported that "there were only four people who did not smoke cigarettes and bhang in his class of 40 students." He felt peer pressure forced many students to acquire the habit while in school because there was a feeling that "if my friend is smoking, why shouldn't I?"

The records show the students wanted to have authority to walk out of the campus of school $A$ on the weekend. Despite the fact the administrators did not 
allow the students to walk out, the students went out anyway and visited the beer and video show halls on weekends. Other students refused to wear the school uniform as required. In the mind of the students, absence of school rules indicated freedom. The self-imposed freedom gave many students the opportunity to indulge themselves in pleasure. They smoked, danced, drank beer, and viewed violent videos and movies in the towns near their schools. As Mr. Bridge noted, the merit of delayed gratification was not in the minds of most students. The biggest percentage of the male students desired this "freedom." According to the deputy head teachers, the boys who managed to frustrate the school rules were heroes and influenced many others to fight the school rules and regulations. There was a localized distaste for rules. In school $\mathrm{D}$ the entire school fought the rule requiring that the students wake up at 5:00 a.m. The school was plunged into a disruption as students fought to keep the morning study time optional. On the other hand, the students at site $c$ believed they could walk out of the campus without permission because they had what they described as "self-discipline." However, the meaning and interpretation of their "self-discipline" is not identical to the one found in the English dictionaries. Explaining what "self-discipline" meant, chuck said it was the 
"freedom" to walk out of the campus as long as one came back.

The freedom gave some students the license to spend most of the class time "roaming in the villages." Chris described the boys who roamed the villages as "very tough students." They specialized in dealing in bhang and other illegal and unruly activities.

The attitude of the girls toward school rules was dramatically different. The general impression at sites E and $\mathrm{F}$ was, whereas some rules were unnecessarily strict, the girls persevered and obeyed them.

Learning and teaching. The comments about rules and teachers indicated that the students were more likely to be cynical about what the school system offered them. As Spady (1974) argued, many students who riot do not feel they have a stake in the world of academic opportunities and market placement. If the schooling structure loses its power to control students when it does not possess critical resources such as good certificates to manipulate, students do not fear any future and negative consequences due to poor academic performance. It appeared the system that controlled the subjects of this study had lost power to control them. The respondents indicated the student did not fear negative consequences attributed to poor academic performance. 
An analysis of the perception of students toward learning indicated that the students were aware of their insecurity in the face of the ever-growing competition in the modern professional life. The feeling that there was no point of exacting oneself in class pervaded the discussions about learning and the future.

School D students portrayed this attitude the best. Commenting about the idea of further college aspirations, Dick said that in the 1993 school year no student was interested in going to college. In fact all students refused to fill in the application forms. College education was not a goal for the majority of the students. This view was authenticated by Diane, who said no one paid for the college application forms because "we felt we could not make the grades required for college entry." According to David, many students felt "however hard they worked, they could not score anything better than a $D$ or c." This feeling was shared by all the other respondents in this site. It is not surprising that the students did not want to wake up early for the morning studies. In fact they organized a strike to make the study period optional. It was also not surprising that the deputy head teacher described the students as "very lazy." This attitude was conveyed by one female respondent who observed that her school mates never hurried to class, especially on warm and cozy mornings. 
The negative attitude toward learning and schooling in general was expressed by the students at school B. According to Benson, students in his school did not feel they could pass the examinations. Many students "had no hope." Bernard felt that although a majority of students knew it was important for them to go to college, "we were in a situation where we could not make it." He blamed laxity and the constant riots for the poor performance. on the other hand, Burt attributed the poor performance on bhang use. He commented that "a bhang smoker may be out of class for a month." When asked why the students did not work hard to recover the learning lost during the riot Bosco's comment was that "even if the teachers were ready to do extra work, they were helpless because no students wanted to be in class for an extra hour." Asked why they did not want to work an extra hour Bosco said "students felt it was their time to rest."

While the other sites did not display a strong dislike for learning, the general attitude was not very positive and would not have made the students competitive. Alex was philosophical in his argument. He said that many students felt that the college graduates were "also jobless." According to Albert, the college duration takes such a long time that when a graduate left college he had only a short time to work and then he retired. 
According to the school A documents, it appeared many students rebelled against tests and examinations. When asked to comment about this, Andrew gleefully recalled, "We used to refuse to take the tests. We would write our names in the answer sheets and then walk away." Asked to comment why students behaved that way, Andrew retorted, saying, "Students did not care...they found tests as a sort of bother and did not want to do them." Perhaps Anthony was more candid in explaining why students boycotted the tests. He said, "Because the test will examine what we did not know... hence we refused to do them." The underworld did not want any measurement of what they had learnt, so they led the successful test boycotts so that they did not have to explain their poor performance to the parents. Anthony also made the comment that many students "are in school for the sake of it." This phrase meant that the students attended school because it was the only thing they were expected by their parents and society to do. They themselves were not motivated to be in school.

The attitude that many students go to school "for the sake of it" was apparent in school F. Flinder commented that "Learning was not their choice and is like they were being forced." It appeared the influence of the past performance influenced the attitudes of students toward schooling. According to Florence not many students talked 
about going to college; a majority thought they would seek skills training institutes after obtaining high school education. Faith shared this perspective. She felt there was no dire need to work extremely hard to make college grades when the college graduates were "jobless."

The respondents at school $\mathrm{E}$ had a different attitude toward learning. According to Elizabeth, during the earlier years between 1990 and 1992, many students did not aspire to go to college, but today many girls aim at becoming lawyers, doctors, nurses, etc. When asked the general goal of the majority of the girls, Edith said, "To go to college." The enthusiasm to further one's education was sparked by the improved performance that the school had experienced in the last two years.

The general observation made about learning was that the students did not hesitate to disrupt learning because they had not invested their future on the results of schooling process. The disruption gave them an opportunity to go for an extended holiday if their institutions were temporarily closed to restore order. Given their attitude toward schooling, it is obvious the underworld leaders forced temporary closures with impunity! Table 10 provides a summary of the properties of category 2 . 
Table 10

Properties of Category 2:

organized Reactions

\begin{tabular}{||l|l||}
\hline Student-Teacher Relationship & $\begin{array}{l}\text { - us versus them ideology } \\
- \text { teachers belong to the opposing camp } \\
\text { - outdoing a teacher signifies heroism of } \\
\text { sorts }\end{array}$ \\
\hline Student-Administrator Relationship & $\begin{array}{l}\text { - disruptions create an opportunity to be } \\
\text { heard } \\
\text { - platform is established for issues that } \\
\text { students care about }\end{array}$ \\
\hline Prefects and Rules & $\begin{array}{l}\text { - if prefect reinforce rules they pay a price } \\
\text { - blatant disobedience of rules } \\
\text { - hostility toward prefccts }\end{array}$ \\
\hline Learning and Teaching & $\begin{array}{l}\text { - lack of interest } \\
\text { - divergent group } \\
\text { - signs of alienation }\end{array}$ \\
\hline
\end{tabular}

\section{outside Interference}

The interference discussed in this category emerged from the data when one considered the roles that members of the public played, instigating students to engage in disruptive activities. On one hand, some members of the public stirred the disruptions with impunity, and on the other they took advantage of the volatile nature of the disruptions. Whichever way one examines the issue, some outsiders played significant roles in the riots and boycotts.

The information about the outside interference was confirmed by the minutes of the District Education Board. The Board, a policy making body, was concerned about the numerous school disruptions in the district in 1993. Some 
members of the board under the central education office toured several schools. The document, which was not dated, contained the recommendations and observations of the board members. In the document, the Board members were reported to have expressea concern that outsiders were providing a steady supply of bhang to students. The leaders noted that there was no follow up on cases of drug trafficking reported to the district administrators such as chiefs and their assistants. The members of the Board recommended that "local community members should not use students...to destabilize the schools for personal interests." They also recommended that "no political meetings should be held in the school campuses as this was counterproductive."

The Board's recommendations appear not to have had any impact in the local schools, as it was ascertained that the disruptions continued to be fueled by the local community members. The Board's minutes confirmed some of the findings in the interviews and school documents concerning the outsiders' factor in the disruptions. School A respondents gave the most detailed accounts of how the outsiders influenced the riots. In 1992, the three-day disruption that forced a temporary closure was caused by some outsiders. According to one of the respondents, some members of the public wanted the head teacher of the school transferred to another institution. 
As Alex put it, those people wanted to ensure the head teacher "was out."

The outsiders contacted the student informal leadership with the intention of paying those who could organize a disruption that would destabilize the school and consequently the head teacher's career. The informal school leadership and a strong student culture in the underworld were the ingredients necessary for a disruption of whatever magnitude to occur. It was not surprising that the outsiders contacted the informal leadership to organize the disruptions.

The outsiders contacted the informal leadership and paid the "top criminals" some money for the task. In one recorded instance, Alex, a respondent from site $A$, was a recipient of some of the money dished out. According to him, he received 300 Kenya shillings (equivalent to us $\$ 10)$, enough money to buy ten meals in a local restaurant in 1992. After the payment, Alex and his group organized a strike.

The results of the disruption were devastating not only to the members of the school community but also to the motorists who used the road next to the school between September 14 to september 18, 1992. This is because after the boys plunged the school into chaos, some of the organizers blocked the road near the school and threw stones at any driver who refused to pay for a safe 
passage. Alex claimed to have made an additional 150 Kenya shillings (US \$5) for engaging in the business. Alex's story was corroborated by the school records. According to the school records, boys boycotted meals and classes for three days in a row. The school was closed for almost a month. The boys returned to the campus on october 12,1992 . Other respondents recalled this strike and their response was a confirmation of the information obtained from the school documents. Arthur remembered the incident as a "hunger strike for three days." He said the strike was sudden and complicated. He was not aware of what really happened, but he remembered hearing that some boys had been paid for the task of organizing the strike. According to Andrew, the people who wanted to topple the head teacher had inside knowledge of the grievances of the students. They approached some form four students and the strike succeeded because the outsiders "gave a lot of money." There were other forms of interference recorded in the school A documents and reported during the interviews. The respondents noted that some ex-students were fed from the school dining hall by their friends. Of course one of the persistent complaints about food was that the portions were not adequate for the students. When the respondents were asked about that problem, their feeling was that the blame was directed against the administrators and not to 
the students who fed outsiders. Since the students blamed the administrators anyway, it did not really matter. Indirectly, the outsiders were a factor in the school disruptions.

As the members of the District Education Board noted, the steady supply of bhang by outsiders was persistent and had not abated, despite the recommendations of the District Education Board. Every school had a spot in the local towns or villages where the students bought their supply of the drug. In the data, these places emerged as "attracting spots" and the boys had constant supply from these corners. The bhang supply was located somewhere near the school campuses where students had access to the drug with ease. Since bhang is illegal, the government machinery should have arrested the individuals who supplied the drug to the students. However, the corruption in the police force acted as a hindrance to the establishment of an efficient and effective deterrent. The bhang was still accessible to the school boys. Sometimes the outside influence was a blend of politicking and the desire to steal. According to Ms. Baker and Mr. Barrozi, the members of the public near site B felt the school was their property and they should influence the decisions made on the behalf of the institution. Those feelings fueled the local people to cause destabilization so that the head teacher could be 
declared ineffective. The two teachers blamed local politicians for the disruptions that wreaked havoc at the school in the 1990-1991 school years.

The village near school B was another source of outsiders' interference. As Mr. Barrozi noted, the people who lived in the village kept their ears open. If they heard screams and shouting in the school campus, they stocked their supply of bhang and alcohol because the students needed the drug. Once the school was plunged into chaos, the villagers entered the campus and looted or stole property belonging to the students and the school. Mattresses, electrical equipment, and blankets were looted or stolen. It was the earnest feeling of Mr. Barrozi, who was also the schools' deputy head teacher, that the leaders of the student underworld normally contacted the villagers and discussed among other things the timing of disruptions.

Mr. Dean of school D felt the outsiders were responsible for the theft that occurred in his school in 1993. During the interview, Dick reported that some outsiders had approached him and talked to him about a strike that had been planned to occur in the school. Ironically, the outsiders thought Dick was one of leaders in the underworld. Dick was not one of the strike organizers and he decided to report the matter to the school administrators. 
In 1993 school year, in the midst of the chaos that accompanied school D's disruptions, some outsiders slipped into the school's home science room and made away with some sewing machines and other home science equipment. They also entered the school laboratory and stole two microscopes. Some respondents felt some of their school mates played a significant role in the theft. There was a feeling that some students must have corroborated with the thieves to rob the school of those valuable resources.

There were other ways that the outsiders affected this co-educational school. After the girls were forced out of their dormitories, outsiders took advantage of the defenseless female students. Some girls reported that they had been raped. In fact, it appeared the outsiders waited for the girls upon learning a riot had ensued. Every respondent confirmed that the outsiders looked forward to a riot because they had an opportunity to molest the female students.

Besides the stealing of school equipment, the subjects reported that outsiders also stole the personal belongings of the students. In the midst of the chaos created by the strike, the outsiders entered the dormitories and made away with shoes, blankets, and mattresses belonging to students.

School C did not experience the direct outside influence as did other schools in the sample. However, 
the bhang sale in school $c$ was blamed on the outsiders as it was in other schools. School E, one of the girls' schools in the sample, was also indirectly affected by the outsiders' interference. Although the school administrators denied the fact, the girls were terrified that they had seen some strangers in their dormitories at night while they slept. The girls were convinced beyond any doubt that some men had entered their dormitories and the teachers had failed to protect them. There was evidence that some people had resolved to disrupt the school by frightening the girls in the darkness. It is reasonable to feel more investigation should have been carried out before the administrators dismissed this case as fake.

The above category indicated that the disruptions were not solely the creation of students. Some adults in the society played as significant a role in some of the disruptions as the young people. However, the students were responsible for the creation of a culture that was so conducive to violent and remorseless behavior. However, it is my contention that the complex, interwoven, and contradictory culture of the underworld was the single most important ingredient in the incessant disruptions. Although the adults who interfere with school affairs should be made accountable, the schools should address the issues concerning the students' integrated culture and its 
leadership. Table 11 summarizes the properties of category 3 .

Table 11

Properties of Category 3:

outside Interference

\begin{tabular}{||l|l|}
\hline Outsiders Instigated Riots & $\begin{array}{l}\text { - political influence } \\
\text { - financial benefits }\end{array}$ \\
\hline Bhang Trafficking & $\begin{array}{l}\text { - from a well known local spot } \\
\text { - sold to the students in the school }\end{array}$ \\
\hline Thefts & $\begin{array}{l}\text { - some students arranged with outsiders to } \\
\text { disrupt learning } \\
\text { - looting occurred during the fracas }\end{array}$ \\
\hline
\end{tabular}

Loss

A category to review the effect of the disruptions is necessary, especially because the riots occurred in schools, the institutions which the public invests with a lot of hard-earned Kenya shillings. In addition, the discussion revealed there were a lot of psychological losses that could not be measured in terms of the shillings. There were stories and anecdotes that revealed pain and trauma. The feelings conveyed by respondents portrayed a sense of loss of confidence and trust at the very institutions that have been assigned the difficult duty of the socialization of young people. The obvious loss that the schools experienced was the waste of instructional time. The deputy head teacher of school A illustrated this concept well when he analyzed 
the instruction time lost by the school's 1991-1994

cohort. He revealed that this cohort lost a total of approximately five months of instruction time. He felt this loss of instruction time negatively affected the general performance of 1991-1992 cohort in the national standardized examination. Besides the loss of instructional time, the cohort lost about $30 \%$ of its members. The loss of that significant number of students had an adverse effect on the school's financial standing because the entire school budget depended on the school fees paid by the parents. The disruptions which were accompanied by drug use, violence, and uncivil behavior caused other hidden losses. Most of the male respondents indicated that before they went to the secondary schools they did not use bhang. The use of the drug had changed their outlook on life and certainly their character. The bhang and influence of their classmates made them remorseless and violent. It may be argued that the riots in the schools contributed to the general loss of the young adults' good and reasonable behaviors.

The other psychological loss that emerged from the data was the loss of confidence and trust. When the students disrupted the normal schooling processes at school D, it was not just the academic studies that were negatively affected, the human spirit took a heavy toll as 
well. Those most affected by the school D disruptions were the female students. The respondents expressed the traumatic feelings as they narrated the happenings in the dormitories the nights they were driven out.

When Dorothy was asked what girls did when they learnt the boys were breaking their dormitories' doors, she said, "Some girls cried and screamed, others prayed, others tried to hide," but the boys were "very fierce and irrational." This sheer terror and fright was confirmed by Daisy who responded, "Girls were so scared when the boys banged the doors that some passed urine on themselves." As if the ordeal was not over, some girls "fell into the creeks" which they tried to cross in the dark. Still others were hurt by tea stumps, which they stepped on as they ran through the neighbors' farms. One of the most horrifying memories is of the severe injuries of one girl who ran on top of broken glass which had fallen when the boys broke the dormitory windows. The trauma the girls suffered made them lose confidence in the security of what was supposed to be a safe learning environment. In addition, the girls who were raped felt violated and abused. Their self-worth was lost at the very institution that was supposed to build their self confidence and self-worth.

The teachers were also traumatized by the actions that students took in the schools. The deputy head 
teacher of school $D$ had no alternative but to leave her administrative assignment at the school after the boys attacked her house with impunity. There was therefore the loss of career growth for Ms. Draco, who should have been promoted after serving five years in the administrative position as a deputy head teacher.

According to Ms. Baker and Mr. Bridge, both teachers at school B, after teachers were attacked on school B's premises, many lost the feeling of security in the staff quarters. Mr. Bridge decided to vacate his school house. During the interview he emphasized the fact that he would never occupy a school house. When Ms. Baker was asked to comment about the attacks, she said when boys attacked they ravaged through a house and "damaged whatever they could find." Ms. Baker confessed that she was once a victim but was not willing to give the details of her trauma.

The school documents reported that the head teacher was verbally abused by boys when he announced that the school television would not be used for non-educational programs. The boys who were responsible for the verbal abuse incited the other students to attack the head teacher. This incident precipitated other attacks on the teachers. One female teacher lost her clothes, kitchenware, and other personal items during the fracas while the head teacher's chicken was killed. Reports indicated that 
some boys had planned to rape the female teacher before the attack occurred. Fortunately, there was no physical harm that occurred, but the fear in anticipation was traumatic. The deputy head teacher said that the behavior of the students toward the teachers made the teachers lose the morale for effective teaching, the very soul of the teaching profession. Accompanied by the loss of morale was the loss of confidence and trust that one was safe in a school atmosphere.

The damages to property at school B was Kenya shillings 12,590 which was approximately U.S. $\$ 410$ in 1993. This was equivalent to two month's salary for a teacher who had earned a bachelor's degree. The cost of the head teacher's chicken was not indicated. Although there was no price tag, the damages caused in each school were substantial.

Additionally, when the students attacked other schools they incurred heavy expenditure in repairs. The motivation to attack was to destroy the premises of the perceived enemies. They did so with vengeance. When school A attacked Riverside, Riverside lost its television set and other items. Tables, chairs, doors, and windows were damaged in the ensuing commotion. In like manner, when school $c$ attacked Valley, the boys destroyed the school's buildings which incurred a lot of expenditure in repairs and replacement of the items destroyed. At school 
D, the loss of the sewing machines and microscopes was a heavy blow to a struggling school. Given the fact that school D's population has diminished to only 140 students, it may be true to predict that the school will not be able to replace these items for a long time to come. When most parents struggle to raise enough money to pay the school tuition, it was most unfortunate that the unnecessary repair costs were added on the already heavy financial burden. It is true to state that the average Kenyan parent sacrifices not less that one third of his or her income per year to pay the money required by schools in tuition and boarding fees for one child. The devotion to education gives the parents the motivation to make the sacrifice. The unnecessary repairs are a tremendous loss of funds for families.

The general effect of the riots and boycotts was widespread. Every fabric of this society felt the effect of disruptions. The families paid for an education that was not attained and taxed themselves to pay for uncalledfor repairs. That money could have been put to more constructive use such as buying medication, food, and clothes.

The schools were adversely affected as well. Some schools have had their enrollment drastically reduced, a trend that has affected the income that sustains the dayto-day management. The existence of some schools was 
hanging in the balance. This is because parents withdrew their children from these institutions due to the riots and boycotts that occurred constantly.

The society and the communities have also been affected adversely. As more young people use bhang, violence has escalated in the countryside. More than any other time in the district's history, armed night robberies in the rural areas have increased. The most recent feature was bands of more than 30 young men congregating and attacking defenseless home owners in the rural areas in the darkness. According to the stories, people feel less secure in their rural homes. Some individuals have sought residence in the more crowded towns. Table 12 shows the properties of the category 4 the losses.

Table 12

Properties of Category 4:

The Losses

\begin{tabular}{|l|l|}
\hline Instruction Time & $\begin{array}{l}\text { - lost class time if students } \\
\text { decided to boycott food or } \\
\text { classes }\end{array}$ \\
\hline Psychological & $\begin{array}{l}\text { - feelings of violation } \\
\text { - disruption of career } \\
\text { fulfillment } \\
\text { - loss of certainty and security }\end{array}$ \\
\hline Monetary & $\begin{array}{l}\text { - repairs after damages } \\
\text { - replacement of lost or stolen } \\
\text { items }\end{array}$ \\
\hline
\end{tabular}


CHAPTER V

\section{INTERPRETATION, IMPLICATIONS, AND CONCLUSION}

\section{Interpretations}

Interpretation is a reflection of the meaning found in data as well as an examination of the processes involved in making meanings (Stiegelbauer, Goldstein, \& Huling, 1982). The interpretation of this study is multifaceted. The first phase of the interpretation comprises the social meanings of the qualitative background. There was evidence that cultural influences embodied some actions, behaviors, and attitudes that were expressed by students. To a person born in the Gikuyu ethnic group, some of the actions of the students bore some remote semblance to Gikuyu people's cultural experiences. The experiences occurred in the more recent and past history of the Gikuyu people.

The second phase of the interpretation relates the substantive theory to the theories, perspectives, and understanding discussed in the literature review chapter. The literature review illuminated schooling, psychological, learning, and sociological theories and perspectives. One of the schooling theories discussed in 
the literature review was the micro-political perspective of education. This framework is used as the backdrop in interpreting the everyday life experiences in the sampled schools. Since this research study was primarily about the everyday life of a secondary school and the data indicated that much of the happenings were about power and control, a micro-political perspective is used to interpret the incidents in the data. As Iannaccone (1991) has stated, the micro-political perspective on schooling is about the interaction and the political ideology of social systems of teachers, administrators, and pupils.

\section{Cultural Influences}

During the period before colonization in 1895 , the birth of a Gikuyu baby signaled the first of many rites of passage that marked a child's whole life (Leakey, 1977). Colonization brought with it the christian faith, and the missionaries interpreted the rites as evil and unacceptable. However, some beliefs and customs lived and continue to influence the thinking of the Gikuyu people to this day. It was not surprising that students in the secondary schools were likely to imitate some of cultural meanings in their rituals.

Meaning of "monolization". In the empirical data, the first rite of passage, "monolization," was directed at the newcomers particularly in the boys' schools. The respondents explained the purpose of the process. Some 
subjects said the purpose was to force the form one students to respect the older students. Others said the form ones were raw and foolish and needed to be enlightened through the monolization acts. In general, there was a feeling that form one students had to be forced to forsake their primary school behaviors and adopt the secondary school behaviors.

In the traditional Gikuyu culture, the Gikuyu people adored the initiation rite. The circumcision rite signified the beginning of the respected life of an adult man. To date, the Gikuyu acclaim this form of initiation. In fact, a young man who is not circumcised is derided and scorned. However, the parallel in the meaning of the student's monolization was observed in what would be referred to as "the new initiates' ceremonies." The traditional ceremony entailed that the new initiates "file ceremonially into the headquarters' hut and out again in order that they might go to the ceremony of having the foolishness and ignorance of boyhood removed" (Leakey, 1977, p. 631).

It appears the tendency to interpret young initiates as foolish and ignorant is culturally influenced. The young initiates, according to the understanding of students, were the form one students. The feeling that form one students or young initiates were foolish was pervasive in the boys' schools investigated. It is 
possible that cultural interpretation influenced the monolization actions, although there was no understanding that new initiates in the traditional society were terrorized. The meanings may be parallel, but the actions adopted by students were out of the line.

In addition to the individual rites of passage, the Gikuyu had what Leakey (1977) has defined as group rites of passage. According to Leakey, when a new initiation age-group had been formed as a result of a series of initiation ceremonies, it became a part of a junior regiment. As soon as a regiment was complete, ceremonies took place which marked the assumption of power, authority, and responsibility by the new regiment and the retirement of the senior regiment. These ceremonies may be regarded as a group rite of passage.

clearly, the "summary" rite of passage when the form two students were beaten in a group may be interpreted as an adulterated form of the regiment group rite of passage (Leakey, 1977). Although remote, the parallel exists between the meaning of the traditional group rite of passage and the "summary" ceremony defined by students. Some respondents claimed that when the form two students were given the final beating or summary, they were actually "promoted" and received the authority to "beat the form ones." In other words, the form two students assumed power, authority, and responsibility previously 
confined to the form three and form four students before the purported summary ritual.

Meaning of "traitor". In the early 1950s the Gikuyu led kenyans in the fight against colonialism. The insurgent was led by the "mau mau," a group of disenfranchised persons (Maloba, 1993). The mau mau battle was fierce and was accompanied by fear and witchhunting, according to the stories of witnesses. Since some of the Gikuyu had converted to Christianity and lived in apparent western-style comfort, they did not collaborate with the often younger and more disenfranchised militant members of the mau mau movement. Among the conservative group were those who were the employees of the colonial government. They sought to be loyal to their employer, and therefore declined to support the rebels and collaborated with the colonialists in the capture of the perceived terrorists. Some of the employees of the colonial government and the conservative members of the community worked closely with the government machinery to have the mau mau rebels arrested. In this sense they were the government informants. The mau mau fought a guerrilla war. They attacked the government installations and in turn the government tracked the mau mau and killed the young men and women. The informants, commonly known as traitors, played a key role in the government campaign against the mau mau. 
Through the informants or traitors the colonial government was able to capture the mau mau rebels because its soldiers were able to penetrate the guerrilla activities of the mau mau.

In those days, many people were terrorized by both the colonial governmental machinery as well as the mau mau operatives. On one hand, the government punished any person who was accused of dealing with the mau mau. That meant supplying the mau mau soldiers with food or strategic information. On the other hand, the mau mau punished anyone perceived to be a government informant or a traitor. Members of the older generation recall that during the mau mau days people spoke in low tones and the entire community was pervaded with an air of suspicion and distrust. They did not know the traitors who betrayed their kinsmen to gain favor with the colonialists. Whichever party one belonged to, there was a price to pay. However, quietly and surely the mau mau rebels were given aid and many activities of the mau mau camp remained secret. The government employed people to guard the villages. These government security staff commonly known as the home guards limited to a certain degree the insurgency. However, the mau mau relentlessly intimidated the perceived traitors. The punishment prescribed by mau mau rebels was a death sentence. The term traitor was loaded because it connoted the betrayal of ones' own 
people and curtailment of the quest for freedom. It was a painful prospect that a person sold out his own comrades to gain favor with the hated colonial master. The home guards earned scorn and derision from the average person. To date, the term "guard" is synonymous with traitor. A guard was perceived as the very representation of what was evil in the colonial regime.

When the students used the term "traitor," it carried the loaded meaning. The traitors who sold their "teammates" were more likely to be seen as the very personification of what was wrong with the school administration. The traitors were perceived as having sold out the students' guarded secrets and the administration was able to penetrate the well-protected barricades of the students' turf. When the happenings of their secret territory were leaked to the administration, their freedom was curtailed. Borrowing from their older kinsmen, the mau mau rebels, traitors in the school settings received brutal beatings. If a student was identified by others as a traitor he was more likely to run away from the expected torture. The informal leaders burnt the traitor's belongings and planted a cross at the burning site. According to the respondents, particularly in school $c$, the cross signified death. So if the runaway traitor came back to the school campus he may have received "death" as a penalty. Though no student had been 
killed, the threat intimidated and terrorized the would-be traitors. Despite the student culture, administrators depend on the traitors for information about the living areas of the students.

The cultural influence on the meanings of the terms traitors and monolization illustrate connotations of the terms. The interpretation explained why students felt strongly about some apparently minor and insignificant issues. However, the interpretation is not a reflection of the state of the Gikuyu society. The Gikuyu people by any standard are friendly and well-meaning.

\section{Micro-Political Perspective}

The major goal of this study was to understand why students disrupted the normal schooling processes. According to Blase (1991), a micro-political perspective of organization enhances our understanding of what he terms as "the woof and warp" of the fabric of the day-today life. Therefore, the micro-political framework is useful in delineating the complicated and interwoven tapestry of conflicts that emerged in the data.

According to Everhart (1991), in discussing micropolitics, one is examining a variety of politics but at a usually more focused and circumscribed area. In this study, the circumscribed area was the perspectives of students about riots and boycotts. In essence, this was the area of study where the views of the students as 
conflicts and confrontations were explored. Describing the micro-political perspective, Blase (1991) underlined its merits, saying, "It highlights the fundamentals of human behavior and purpose showing how people acquire power and use it to influence others and to protect themselves." Additionally, micro-politics is about conflict and how people compete with each other to get what they want. It is about what people in all social settings have strong feelings about and what they think about, but what is so often unspoken and not easily observed. The substantive grounded theory discussed in chapter four demonstrated that the actors portrayed the feelings and perspectives that Blase (1991) referred to, making the micro-political framework appropriate for interpreting the happenings brought to the fore in the data.

According to Pfeffer (1981), the definition of power and politics is controversial and problematic. Thus, power and politics are neglected in social science literature because of the:

competing perspectives for understanding organizational decision-making. These perspectives are frequently persuasive... because they conform to the socially held values of rationality and effectiveness. And third, the concept of power is troublesome to the socialization of managers and practice of management because of its implications and connotations. (p. 2)

Ironically, if the management of any social organization neglects the issues of power and politics it is more 
likely to be overwhelmed by conflicts requiring a political resolution. In other words, conflicts in organizations often require a political strategy rather than the more preferred orderly and rational decisionmaking strategies.

In a political framework, power is defined as a relation among social actors in which one social actor, A, can get another social actor, B, to do something that B would not otherwise have done. Power becomes a force and, more specifically, a force sufficient to change the probability of B's behavior from what it would have been in the absence of the application of force. Put more succinctly, it is the ability of those who possess power to bring about the outcomes they desire (Pfeffer, 1981).

The data indicated that students, particularly the male students, were more likely to use force to bring about the outcomes they desired while the female students were likely to put up with decisions made by the teachers and head teachers of their schools. In other words, the male students politicized the issues that they felt they desired and demanded the attention of the administrators by using power and political strategies. Politics is defined as a study of who gets what, when, and how. This definition was quoted by Pfeffer (1981) from Harold Lasswell. Certainly, who gets what and how was the basic and fundamental question in the issues examined in the 
sampled schools. In effect, the issues that emerged in the data were indisputably about power and politics.

The phrase "micro-politics of education" was coined by Iannaccone in the late 1960s. He described it as politics that takes place in and around schools (Marshall \& Scribner, 1991). So the micro-political perspective of education is a new scholarly field with limited empirical studies (Everhart, 1991). Discussing the importance of the micro-political perspective, willower (1991) wrote:
While the ubiquitous writing on effective schools and to a lesser extent organizational cultures, torts strong leadership, shared values, symbols, and commitments, instructional activities and goals and orderly environments, getting from here to there [emphasis not original] remains problematic. It is that route full of pitfalls and detours, that is the interest from a micro-political standpoint. ( $p$. 451)

One may interpret the happenings in the Kirinyaga secondary schools as detours and pitfalls to which Willower (1991) speaks to in the above statement.

Perhaps Iannaccone (1991) gave an insightful perspective on the role of politics in a school site organization which he describes as a polity. He stated that politics is the process by which a society's persistent social values are translated into policy. A political perspective views organizational membership strata as constituents of a polity. The specific nature of a particular polity is defined by the relationship of its classes of persons to its politics. He wrote that the basic character of a polity is revealed by the rights and 
obligations in its governance. Its character is also revealed by politics which translate social values into policy and thence into a multitude of rules, regulations, and administrative decisions.

To understand the data from settings using Iannaccone's analysis, the schools portrayed three strata. The first stratum is students. The other two strata are the teachers and administrators. According to Iannaccone (1991), the central focus of a political perspective is the part played by teachers, students, and administrators in a schools' government. He argued that since the students constituted the largest category of a school polity and did not share in its governance, school polity was indisputably a "caste system." Therefore, the majority of the polity's members were subject to the laws without the right of making them.

Following Iannaccone's statement, one may argue that the rules and regulations in a school polity are the policies designed to keep the lowest caste in a subservient position. The data that emerged in the settings showed that the perceptions of students regarding rules and regulations were negative. They were more likely to view rules and regulations as unnecessary, questionable, and excessive and those who enforced those rules as enemies or "members of the opposing camp." Indeed most of the conflicts arose from the definition of 
rules held by students. The situations in this study were further complicated by the fact that students had created a polity of their own within the school polity. The adults in the school system were excluded from the polity created by students and were in effect powerless in dictating their terms. In other words, the school rules and regulations were ineffective in checking the behavior of students in their turf.

Some of the issues discussed by Optow (1991) speak to the adolescent nature of the conflicts. To many adults the conflicts among the students are precipitated by trivial gestures. Moreover, conflicts are justified by adolescents because they are perceived as the opponent's violation of rules for fair and interpersonal interaction. Optow (1991) argued that adolescents have a passion for moral concerns which are embraced in issues of social understanding, self-description, and decision-making. Indeed, the adolescents observed in this particular study were morally passionate about social understanding and self-description as much as they were in their decisionmaking processes. Statuses and the roles of persons in the everyday life dominated the processes that were investigated. The status of a person and his or her role in the activities of the underworld offered a complicated set of self-descriptions, social understanding, and decision-making strategies. 
In order to investigate the often complicated political underpinnings, this section on interpretation of the data is divided into three parts. The first part is the discussion of the head teachers' need for order and control. The discussion is centered on the meaning of order and control in political terms and how the administrators lost the legitimate power to impose orderliness and control in their institutions. The second section focuses on the teacher-student interactions in and out of the classrooms. The conflicts between the teachers and students are also interpreted in the political framework. The third part discusses the meaning of power to students, how they acquired it, and how they used it within their territory and outside. The discussion also focuses on the politically active underworld. The interpretation illuminates the structures as understood in political terms. It also suggests a political model of school governance, demonstrating how a political perspective can be used to unify people of diverse beliefs.

School order and student control. The literature on effective and efficient schools emphasizes student control and order to achieve excellence in learning. In the sites of this study, administrators expressed a sense of relief and accomplishment when there were no apparent conflicts in their schools. From a micro-political framework, 
absence of conflicts required that decision-making be orderly and rational. Absence of conflicts signified that the power exercised by the administrators was legitimate and acceptable. In fact, socialization in an organizational setting expects that an administrator makes both legitimate and acceptable decisions.

The reasoning embraced by the rational decisionmaking model differs in content and purpose from the political model of decision-making. The society and the employer expects that the administrators establish and maintain order and control in the schools in the most rational and least controversial ways possible. In social settings including schools, there are certain beliefs and practices that come to be accepted. Activities which are accepted and expected within an organizational context are said to be legitimate within that context. When power is so legitimated it is denoted as authority. Administrators and teachers are therefore expected to exercise the authority accorded them to restore order and control in their institutions using any means necessary including punishment, rewards, and force.

Leadership situations in the sampled boys' schools were problematic because male students were less likely to accept the headmaster's power as legitimate in all situations. On the other hand, in the girls' schools the administrators' power was more likely to be interpreted as 
legitimate. In essence, the administrators and teachers in the girls' schools had authority which the students responded to by complying, thus allowing the execution of the normal schooling processes. However, in the male and the co-educational schools investigated in this study, students made the administrators' use of power illegitimate by making demands for their compliance. In other words, the male students were more likely to make their demands political by forcing the administrators to concede to their demands. This means students played political games to bring about the outcomes they desired. For example, in school D, political demands forced the administrators to make the early morning study time optional. The private study time ceased to be compulsory as formerly stipulated in the school rules. In school $c$, the students forced the administrators to address the bus issue, an issue that was likely to have been neglected, delayed, or compromised.

The data that emerged showed that the power distribution resulted in conflicts because the adults and the students had heterogeneous goals. While the headmasters and teachers wanted order and control, the students preferred what they described as more freedom. In other words, students preferred a relaxation of order and control. The administrators were less likely to give in to the demands made by students. This is because the 
demands were incompatible with the expectation of the administrators' employer or the community that owned the schools. The administrators enforced rules and regulations as required by custom and expectations. Under the guise of rationality, consensus, and commitment, a position advocated by the rational decision making framework, the administrators were perceived as persons who could establish and maintain order and control. However, more often than not the rational mode of decision making was not cognizant of the politics of the situations. The teachers and school administrators were more likely to impose heavy penalties on the students if they broke the rules, administrative orders, and regulations. The penalties were expected to work as a deterrent with the hope that the students would feel so intimidated that no student would disrupt the established order and control.

While the girls were more likely to be intimidated by punishment and obey rules, the male students were less likely to do so. The young men believed the penalties inflicted upon them were unfair and they could do something about it. The penalties evoked more conflicts of values and beliefs exacerbating further tension and distrust. The political framework explains why the school landscapes were strewn with incessant conflicts. The diverse goals and preferences of the students and the 
adults, the differences in values and beliefs between the two parties produced a complex tapestry of conflicts and confrontations.

Another source of conflict as illuminated by the political underpinning was interdependence. It is impossible to eliminate interdependence in a school setting. In a school context, students depend on teachers and administrators in many ways. In a classroom situation, a teacher instructs the students and learning takes place when there is a mutual interdependence between a teacher and his or her pupils. In the boarding institutions, students depend on administrators for food, water, shelter, medical attention, and other essential services. The school is a very complex organization and interdependence particularly in a boarding school is the rule, rather than the exception. According to the micropolitical framework, interdependence is one of the sources of conflicts in a social organization. In fact, the student leadership used the areas of interdependence to demonstrate to the regular students the failings of the administrators. The data indicated that the complaints about food were often used to create contention. The demagogues often managed to convince their fellow students that they were either eating bad or low quality food. Other areas of interdependence, such as the provision of uniforms, transportation, and entertainment were also 
vulnerable to being used as points of dissension and conflict. The student leaders spoke to the issues which arose from the interdependent nature of boarding schools because they were more likely to evoke feelings of discontent and dissension.

The data also indicated the traditional and the expected centralization and institutionalization of power in the headmaster's office was challenged by the lowest caste of the polity. This made the matters complicated and problematic because the students did not and were not expected to share in the polity's governance. The conventional wisdom advocates that adults know what is good for the students, so power is centralized in the school administrators' offices. However, by constantly disrupting the normal schooling processes the subjects under this investigation were in essence making it clear that they wanted to participate in the decision-making processes. The demands made by students were problematic because they were challenging conventional wisdom. Undoubtedly, the students made disruptions the processes of creating platforms for discussing their needs and desires with the administrators. There was a strong feeling among the participants of this study that if the students did not threaten to boycott classes, or to cause disruptions, the issues that they cared about would fall on "deaf ears." In political terms, the boycotts and 
disruptions helped to disperse power from the head teachers' offices. In other words, the students forced the head teachers' offices to decentralize power. Although, many head teachers would deny that they dispersed their power and control, students knew the administrators' authority was limited in the midst of disruptions and boycotts. The administrators were unable to enforce control and order without the co-operation and compliance of the students. To a significant extent, order and control were restored on the terms that students spelt. They forced the issues that they cared about on to the Board meeting agendas. Their needs were heard at the highest level of any school's management.

Pfeffer (1981) stated that when a sub unit in an organization forces the management to discuss an issue or to put an issue in its meeting agenda, that unit has obtained power. The data indicated that the students forced the school management to discuss their issues particularly when the disruptions forced the head teachers to close the schools temporarily. The presence of a school's Board of Governors on campus was a physical demonstration that the students had become major players in the policy making of their school. In political terms, this demonstrated that students had power. Recent history bears witness to that fact. For example, in the late 1980 s male students protested the wearing of shorts 
because they preferred to wear long trousers as their uniform code. After numerous incidents of disruptions, today all secondary schools in the district prescribe long trousers for their school uniform codes. This indicated to students that disruptions worked and were in fact the only means that would force administrators to concede to the issues that students cared about. Many situations were problematic because the administrators and the teachers made decisions as if power and authority was concentrated in their positions. In political terms, this phenomenon portrayed the fact that administrators and teachers ignored the rapid changes in the school environment. The school environment is witnessing a rapid change due to the changing times as the world increasingly becomes transformed into a global village. Administrators and teachers have to adopt new strategies to deal with the students and new ways of addressing issues that students care about.

There was evidence in the data that as suspensions, expulsions, and caning increased, bitterness was aggravated and the conflicts became embedded and accentuated. Pfeffer (1981) argued, where conflicts are the greatest and decision-making most difficult, the introduction of rational decision-making procedures are more likely to be resisted and unsuccessful. The incessant disruptions were an indication that rational 
decision-making procedures were ineffective. However controversial the political model of governance, it is likely to be the cure for the incessant disruptions. The micro-political framework explained the disruptions and boycotts that emerge in the data as a complex interplay of power and politics. This political perspective delineated the school conflicts and confrontations as issues contributed by the interdependent nature of boarding institutions. conflicts and confrontations were accentuated by the determination of students to participate in the decision-making processes. The socialization of the administrators in the rational mode of decision making heightened the conflicts because they were likely to downplay the power and political issues in the conflicts. In reference to this study, the message is that school administrators must concede to the fact that conflicts will plague their schools unless they are willing to shift from the rational model of decisionmaking. The political model of decision making appears to be appropriate because the pertinent issues are about power and conflicts.

Teachers and classroom management. The goal of this study was not directed specifically to issues concerning class management. However, the respondents were specific about the teacher-student relationships in and out of class. The respondents' feelings and attitudes about 
teachers emerged in the data collected from the school documents and the interviewing process.

The theme of the teachers' interactions with the students had a distinct us versus them ideology particularly in the boys' secondary schools. Teachers and administrators were viewed as members of one team, while the students were members of the opposing team. If specifically examined, the relationship between teachers and students was strained by the interdependent nature of the teaching and learning processes.

Additionally, teachers confronted students who not only had varying academic abilities, but also varying goals and reasons for being in school. As some respondents explained, some girls and boys were in class "for the sake of it." In other words, these students went to school because that was the expected thing for them to do. Their parents and the community expected children between the age of 15 and 18 to be in a secondary school. They were neither interested in nor committed to the learning and teaching processes in their schools. There was another group described by Ms. Draco as being "very lazy" and who were not prepared to exact themselves and apply themselves to a challenging curriculum. A third category of students was described by a teacher in school A as "hopeless." Those who shared in the feeling of hopelessness are the young people who studied hard but 
failed to achieve their academic goals and consequently gave up. This group believed it could not make the grades no matter what it did. The fourth type of students were described by respondents and teachers as "stubborn" and did not care. This group walked out of class with impunity or failed to go to class regularly. Finally, there was the infamous category of the "top criminals" or "champions" whose career was to guide the student body in the anti-school feelings and reactions. They organized strikes and boycotts for their own recreation or to demonstrate a point of contention.

Given the composition of the students, the teachers were dealing with a great diversity of beliefs, values, and attitudes in their classrooms. The very diversity of the beliefs and values was the cause of conflicts and confrontations. It was incumbent upon the teachers to have a political outlook in their class management. The goal was to try and satisfy the different categories of the class population. However, because teachers were trained to view their students as having a shared perspective, common goals, and shared beliefs, conflicts in and out of class were bound to be frequent. Consequently, some students refused to take tests, others walked out of class, others were rude and unpleasant, and others organized attacks against the teachers that they "hated." 
Many of the respondents felt that teachers interfered with their affairs. When asked to comment specifically about the interactions between teachers and students, some respondents said that they viewed teachers as opponents in a competition of sorts. In some instances, when a student outdid a teacher that student was considered heroic by his or her classmates. Other respondents felt that some teachers, particularly the new graduates, were too young to give them instructions, let alone punishment. Respondents were more likely to feel strongly that the teachers should not report students to the administrators no matter what students did in class or out of class. Using a political framework to understand the student-teacher relationship, the students had politicized class activities. Since the students politicized learning and what it entailed, they had excuses to use power relations to absent themselves from the exacting demands of learning. Consequently, they had an excuse to walk out of class, to abandon homework, and ultimately refuse to take the tests.

Teachers possessed the expert power. If the majority of the students preferred learning and their major goal was to obtain good certificates, the teachers' expertise was adequate to control the class activities because the students would be keen to learn. However, the data indicated that many students "did not care" about the 
learning and its outcomes. The air of resignation which pervaded the schools started in the classrooms because the expert power of the teacher was not sufficient to control and organize the students.

The students were questioning the authority of teachers and politicizing the role of teachers. The nature of this conflict was fundamentally problematic because the students challenged the accepted tradition and custom of the learning and teaching structures. From a political standpoint, the values and beliefs of the students were different from those instilled in the teachers by custom and training. Additionally, the orderly rational decision model was ineffective in resolving the already politicized issues. As already pointed out in respect to the administrators, the teachers should make a paradigm shift in classroom management strategies. Pfeffer (1981) made the assertion that a political system required the use and formation of coalitions, co-optation, cultivation of extended allies, formulation of policies that would satisfy the important actors, and changes that would ensure that there would not be too much opposition.

The scope of this interpretation does not allow for a detailed examination of the specific alternatives. But the political framework is likely to offer some solutions to the dysfunctional classrooms. The next section shows 
how students played politics and legitimated some obviously distasteful activities. The discussion portrays how a political language using symbols and ceremonies united the students in the underworld. In fact, it seemed the students achieved a common perspective in their turf that was meant to be the goal in the classroom environment and in the overall school climate. Ironically, the informal student leadership articulated and practiced political maneuvers to unite students of diverse backgrounds and academic abilities.

students and politics. Like individuals, groups behave in terms of the way they perceive the world around them. In perceiving the world, they see themselves reflected in the social aspects of this world. They learn about themselves through the reactions of others toward them. This causes them to develop feelings about themselves and when these feelings are realistic the group will operate effectively (Levy, 1969).

The data indicated that the students in the schools under study had developed feelings about themselves and were able to operate effectively. The student culture was fully distinguishable from the rest of the school culture. The student culture was in effect a polity within the larger school polity. The student underworld qualified to be viewed as a polity within the larger polity because it had its own governance, rituals, ceremonies, and language 
that unified its members and made it identifiable.

Besides, the dormitories were more likely to be located in a specific area in the campus away from the tuition blocks and the administrative offices.

When closely and sensitively observed, the dialectical and interactive processes in the student underworld were underlined by micro-political underpinnings. The students' behavior patterns, meanings, and beliefs were a result of political maneuvers that legitimated and institutionalized what observers may describe as distasteful, violent, and brutal. People use power, language, and symbols to define reality. Persons with power determine which issues and questions are normal, relevant, and critical and which ones are illogical, irrational, and wrong. Such paradigm creation may be the most powerful micro-political process (Marshall \& Scribner, 1991). The data indicated that the informal leadership was established by students who believed in their positions and were forceful advocates of their views. The more the informal leaders advocated their views, the more the regular students believed in those views and became committed to the adversarial positions against school administrators. They used threats, alluring language, humor, and intrigue to convince and emotionally involve their fellow students. For example, when the participants were asked to comment on the steps 
they took for remedy if someone was mistakenly named a traitor, their responses were frightening. All respondents stated with absolute certainty that it was easy to identify a traitor and there was no chance of indicting someone who was not guilty.

A review of the political processes in the underworld portrayed the reasons that made the participants so adamantly convinced and undoubtedly certain. The political processes entailed how power, interplay with language, symbols, and ceremonies produced a politically active atmosphere. It is contended that the political practices in the underworld spilled over into the classrooms and administrators' offices to form a backdrop of the incessant disruptions.

Power in the underworld was acquired. This means power was obtained by the actors who were able to manipulate others into submission through coercion, language, ceremonies, and symbols. In other words, power was accrued by those who were able to use political gestures and to operate the political machinery for their own advantage. The respondents in this study were more likely to agree that the informal leaders had a convincing and alluring language. The subjects also confirmed that some of the "top criminals" articulated what students cared about and were able to define and describe the needs and desires of the student body. The language that 
develops a shared set of meanings is a political language. And as Pfeffer (1981) stated, shared philosophies and shared cultures are created through the development of shared meanings, beliefs, and shared organizational paradigms.

Thus the informal leadership of the underworld was able to use a language that conveyed in an evocative and emotional way the shared meanings of the student body in each school. The fact that the students viewed themselves as members of a team conveyed the effectiveness of the political language and therefore the shared perspective. To appeal to the regular students, the leaders demonized the administrators and teachers. The respondents in school B commented that if a teacher wronged the students his or her name was posted with the inscription that the students were demanding his or her head. Besides the acts of demonizing the staff members, the student leadership used a language that convinced the average student that after a boycott, the administrators would give in to their demands. In practical terms, the students would obtain more outings, better food, or relaxed rules and regulations. According to Pfeffer (1981), a language that is used this way is a political language "at work." Everhart (1991) stated that if we know anything, we know that social life is immensely complex, multicausal, and multidirectional. Indeed, the underworld was 
immensely complex and power was not maintained or obtained by the alluring language alone. Power was obtained through coercion and threats as well. The informal leaders used power to overcome the resistance of others and to get their own way. The unequal distribution of power was a cause of the numerous conflicts. Sometimes the school became a scene of running battles as the more powerful form four and form three students imposed their wishes on form two and form one students. Effective political language employs the use of symbols and ceremonies. According to Pfeffer (1981), ceremonies are activities that are performed to create meaning. Since reality is socially constructed, symbols and ceremonies were more likely to be used to create meanings and construct realities. As demonstrated in this discussion, the students manipulated symbols and ceremonies in order to justify their unacceptable actions and distasteful behaviors. The symbols and ceremonies provided a common frame of reference for the unjustified actions.

Although the acts that constituted the process commonly referred to as "monolization" were more likely to be distasteful and cruel, the acts were legitimated by the use of language. When the freshmen were monolized the language used connoted they were helped to become enlightened and acceptable. This meant if the freshmen 
were not beaten they remained in their raw and unsophisticated state. In other words, the newcomers needed to be monolized so that they could abandon their raw and unsophisticated "primary school" behavior and adopt a more sophisticated "secondary school" behavior. The acts of monolization were actually elevated to the status of the ceremonial. It was a sort of ceremony when, as one respondent in school $C$ illustrated, the beatings occurred in the school dining hall from 7:00 p.m. to 8:00 p.m. every evening. In fact, many respondents were more likely to describe monolization as a tradition. A subject from school A said that monolization was one of the "obvious" experiences for form one students in any Kirinyaga secondary school. Although the process was cruel and unpleasant, its ritualistic, ceremonial, and symbolic qualities desensitized the participants.

In addition to monolization, the student leadership justified the mistreatment of traitors by constructing a reality using the power of symbols and ceremony. In fact the respondents themselves believed that the traitors were such a horrible bunch of sell-outs, they deserved every evil that befell them. The punishment of traitors symbolized the maintenance of students' turf which in turn signified power and control. The reality constructed was that if the students held their turf, their plans against rules perceived as unfair would succeed. 
The punishment of a traitor was often turned into a ceremony. Fecause of the brutal acts inflicted upon suspected traitors, if a student knew he was a suspect, he ran away. once he ran away, his belongings were collected in one area and set on fire. A cross was then erected on the area to signify the death of the specific traitor. The ceremonies and symbols played a part in desensitizing the participants from any human feelings of remorse. undoubtedly, the symbols helped to construct a reality that to report a fellow student to the persons in authority was wrong and unacceptable.

The data also indicated that the activities that culminated in "strikes" were ceremonial and symbolic in nature. Respondents in school D said that if they saw male students consuming a lot of bhang they knew "something was going to happen." If a ceremony comprises activities that create meanings, then the whole process of executing a "strike" was ceremonial in nature. Consequently, if the students heard the roofs being hit with stones or they saw a "black-out," these activities signified that a strike had been staged.

To demonstrate the strength that the symbols and ceremonies had in impacting meaning, some respondents reported that once the stones hit the roof-tops, the regular students "were ready to be commanded." The activities connoted that the regular students would quit 
following a day's prescribed programs and await for the planned boycott of classes or food. It was not surprising that the respondents commented that strikes were planned and executed by a few "top criminals" who knew how to manipulate symbols and ceremonies to accomplish their goals. Symbols, ceremonies, and a political language were evocatively and emotionally used to involve every student in the disruptions that were witnessed on the campuses. Pfeffer (1981) noted that settings have effects on how organization's participants perceived the organization and their role in it. In the physical design of most secondary campuses, the dormitories and dining are located in one area of the school campus away from the school administrative offices and the classrooms. Therefore, when the students claimed the dormitory area was strictly theirs and the members of staff were not welcomed there, the physical setting reinforced this socially constructed reality. The informal leaders were able to draw the line and limit the access of the staff. The physical space conveyed separation of the teachers from the students. It also provided a continual and visual reminder of the power and control that the students had over their own affairs. So the physical separation of the dormitories from the classroom areas helped maintain the saliency of the conflicts. 
The social issues that schools confront are by nature uncertain and have conflicting expectations. These issues include examination and athletic competitions. In Kenya, examinations and what they entail have frightening consequences. They determine what a student will accomplish in her life. There are hardly any alternatives when a young person fails to pass his external examinations. There are no open admission policies in any training facilities equivalent to community colleges. The data did not indicate that there were any solid structures to deal with issues of uncertainty, although they were common among the students. The only available recourse were the rather eclectic guidance and counseling sessions. The group guidance and counseling sessions were conducted by teachers who were not trained in counseling processes and who took full teaching loads. There were no trained counselors or psychologists in the school sites or accessible to students.

To deal with the issues of uncertainty, the students had each other in their school's underworld. The nature and organization of the activities in the schools allowed peer pressure to influence the decisions of the majority of students. The students interpreted the meaning and role of schooling and the meaning of life after school from one another. According to Pfeffer (1981), "When confronted with uncertain standards for evaluation and 
decision making, decision makers will tend to rely on influence-based criteria such as similarity" (p. 77). Therefore many decisions made by individual students were influenced by their friends and other popular students. According to the participants of this study, the decision to boycott tests was based on the belief that tests were unnecessary and "waste of time." The methods and strategies that students used to reduce their feelings of uncertainty were as disruptive as they were destructive.

\section{Implications of the study}

Although the major goal of this study was to understand why students disrupted the normal schooling processes, there were some implications about learning and teaching in the data. The data indicated that learning was negatively affected when students went on rampage or when they defiantly walked out of their classes. Using a conceptual framework of what influences learning, the goal here is to explain how teaching and learning were affected.

Implications on the Learning and Teaching

Wang, Haertel, and Walberg (1990) reported a comprehensive meta-analysis that created a knowledge base comprising 11,000 statistical findings that showed a reasonable consensus on the most significant influences on 
learning. By compiling the result from content analysis, research analysis, and survey of experts, wang et al. obtained an average score for each of the 28 categories.

The most important influence on good learning outcomes was metacognition. Metacognitive processes were the capacity to plan, monitor, and, if necessary, re-plan learning strategies. Two additional student items accorded importance in the research literature were perseverance on learning tasks and motivation for continual learning.

The general discussion about learning with the respondents of this study did not convey an understanding or the use of capacity to plan, monitor and if necessary to re-plan their learning strategies. Although the study did not investigate learning strategies, a comment made by an ex-student was insightful. He said that students would not have availed themselves for an extra hour after the regular class time to cover work not done during the boycotts. Other such comments gave evidence that the students did not want to persevere on learning tasks and were not motivated for continual learning. other important influences on learning outcomes according to the meta-analysis by wang et al. (1990) were in the major category named "classroom instruction and climate." This category included learner accountability, smooth transitions, and the teachers' "with-it-ness." 
Effective classroom management increased student engagement, decreased disruptive behaviors, and made good use of instructional time. Other classroom influences included teacher and students' interactions which contribute to student sense of self esteem and foster a sense of membership in the class and school. These elements contributed to a good classroom climate, one which included common interests and values, the pursuit of common goals and a clear academic focus, and explicit learning objectives.

If the above features are needed for effective learning, the data that emerged from this study indicated that the students did not follow the rules that determine good learning. According to the respondents, the studentteacher interactions were characterized by competition and the feeling of the us versus them spirit. The disruptions shortened the schooling time, therefore time spent on task was inadequate. Students were more likely to prefer walking out of the school gate to doing homework. Campaigns were often lodged not to lengthen the study time but to shorten it as much as possible.

Among other instructional approaches that were frequently linked to positive learning outcomes were peer and cross age tutoring and cooperative learning. The data that emerged in this study showed strong peer pressure directed toward organizing riots instead of aspiring to 
school or academic success. The parents' involvement was carefully manipulated by the students. The disruptions were organized during or close to the test dates so the parents did not have any score card during the counseling session after the students arrived home from school for the vacations. The students disrupted tests to convince parents that if only they had done their tests they would have scored good grades. Since many parents like to believe the best for their children, they were hoodwinked. Given that only a small population of the parents understand what tests mean to learning, the students were more likely to succeed in their strategies.

The academic and schooling system in Kenya can be described as strictly examination and test oriented. The ability of a student's academic strength is solely measured by two competitive standardized tests. The settings where these data were collected, were district schools. Students enrolled in district schools are of mixed abilities. They are likely to have basic math, English, and writing skills for which they were tested in the Kenya Certificate Primary Examination (KCPE). If the boys and girls consistently worked under positive learning influences reviewed in this section, they would do well. However, the respondents conveyed the feeling that many students were more likely to feel unattached, uncommitted, and uninvolved in the learning processes. When the 
majority of the respondents were asked to comment about their goals in life, they revealed their cynicism in the world of opportunities for the academic and market replacement. The subjects' perspective indicated they did not have a stake in opportunities promised them. It was not surprising that the students in school $D$ refused to fill in university application forms during the 1993 school year.

When the theory of social bonding and school membership expounded by Wehlage et al. (1989) was examined, a link was established between the student attitudes portrayed in the data and the issues that speak to school membership. At-risk students were more likely to show lack of a social bonding with their schools. According to the theory of school membership, a student who was not attached did not care what teachers and administrators thought about him. A student who was unattached felt that the adults did not care about her, and that way she justified her rejection of the school. The data collected from the boys' school demonstrated that students felt their teachers and administrators did not care about them. It was indicated that a student was considered heroic by his classmates if he outdid a teacher to maintain what one respondent described as a "sort of competition" with the staff members. 
In the theory of school membership, commitment was considered as an element of social bonding. A student became committed to a school if he felt he could put up with demands that were unattractive and conformed to rules and regulations because the continued participation provided rewards in the future. As already noted in the research sites, students were more likely to find the rules and regulations intolerable. They were less likely to conform to the rules. The students perceived the school as incongruent and meaningless. The fact the students felt the school was meaningless meant their attitude toward school activities was negative. The negative attitude underlined the desire to walk out of class, to boycott classes, and the urge to disrupt learning. According to Wehlage et al. (1989), students lose involvement if the "success is awarded to a few" ( $p$. 118.) The data indicated that the lack of involvement experienced by students was motivated by the feeling that they could not get the grades however hard they studied. Ultimately, lack of involvement, attachment, or commitment led to the loss of faith in the institutions. The respondents were more likely to express the feeling that education was neither a goal to which they could aspire nor one which would have some pay-off. Thus students were more likely to have a weak or non-existent bonding. 
According to Spady (1974), students may reject grades as legitimate indices of their performance and competition as context for academic involvement. The data indicated that some students had in fact rejected competition as context for academic involvement. The deputy headmaster of school $c$ commented that his students had refused to take the end-of-year school tests and examinations for about two years between 1990 and 1993. There was evidence in the school documents in schools $A, B$, and D that some "strikes" were deliberately planned to coincide with the tests period.

According to Adler (1974), the desire of students to escape the tests underlined their disaffection, a condition that led to withdrawal of support and a manifestation of alienation. Adler explained that students were likely to feel insecure and uncertain because of the ever-growing competition of the modern professional life. In other words, the students experienced a deprivation resulting from social position and condition. The feelings of deprivation, uncertainty, and insecurity drove many students to search for a milieu of peers who were in similar positions, and as a group they sought to ease their anxiety through student militancy and disruptive activities.

The meaning of education and its value in Kenya needs re-evaluation. In 1985, the central government and the 
political leaders thought they had fixed the education system when they made the curriculum more "vocationalized" and increased the number of years a student spent in primary school from seven to eight years (Working Party, 1985). The change did not affect the Kenyan's attitude toward education. In fact, the perceived meaning of the so-called "vocationalization" of curriculum was that there was an unnecessary increase of subjects in the secondary and primary levels. The students and schools did not improve. The schooling processes have remained relatively the same for the last 20 years despite the politically acclaimed vocationalization of the curriculum in 1985.

\section{The Broader Social Context}

As already observed in the previous section, social life is immensely complex and therefore the events that influence it are multicausal and multidirectional. It would be foolhardy for anyone to limit the causes and consequences of the schools' riots and boycotts to a single viewpoint or theoretical underpinning. In the broader social context, the views of various persons are merged to illuminate other important influences that can be logically associated with the phenomenon under review.

Although Kenya's colonization which introduced the western style of education occurred some 100 years ago, the effects of that history continue to have a ripple effect in the modern Kenyan society. Siaka stevens, a 
former president of the western Africa country of Sierra Leone, captured Africa's transition the best when he lamented (Thompson, 1991):

The most serious danger which confronts us today as a people is the danger of losing our hold on our traditional past and heritage while we have not fully grasped the cultures and traditions presented to us...most of us are 'displaced persons' from the educational and cultural point of view. (p. 93)

The truth of the matter is that most African people have lost their hold on traditional past and heritage. To date, one may argue many Africans have not yet grasped the cultures and traditions presented to them by the west.

The data were collected from a Gikuyu community and the comments about Africa in general affected this community as any other community in the continent. In the traditional Gikuyu society, relationships among members of the community were subtle and complex but they tended to bind all members closely. As Kenyatta (1938) articulated, individualism among the Gikuyu was virtually unknown. The sources of solidarity in the Gikuyu were extended family and practical interdependence within the tribal unit. The culture did not consist of collections of beliefs and customs which existed independently of each other. The culture was an indivisible whole in which the various parts were interdependent. These parts included systems of land holding, education, kinship ties, religious beliefs and activities, and modes of decision-making. 
When the colonialists and missionaries affected one part of the culture, they affected the whole tribal unit. The introduction of the christian faith and modern economic sector replaced the tribal unit with an awkward individualism. Individualism was emphasized in the Christian faith which bases its cardinal principles on an individual's redemption and salvation. In addition, individualism was underlined by the western type of economy that stressed an individual's opportunity and endeavor. These processes replaced the tribal unit that used to enforce and maintain mandatory ethical and moral standards of living. Additionally, the christian doctrine gave the converts choice and preferences which disintegrated the people's obligations and duty as members of the tribal unit. Individual choice and preference did not exist in the traditional society. Every Gikuyu man, woman, or child was a keen and devoted believer because his or her very existence depended on the entire community. The religious beliefs not only pervaded the entire fabric of every day life, they also dictated how a person was born, lived, grew up, married, and eventually died. No person had any choices. The disintegration of the tribal unit affects today's generation, although it was born many years after the coming of the white men to the Gikuyu society. People are liberated from the mandatory tribal system of moral and 
ethical standards that bound them. The laws in the penal code keep a check on any excesses while the Christian faith only checks on the practicing believers. There is another big percentage of people who claim to be believers but do not feel bound to the rules of the faith. However, greed and discourteous behavior that prevails today would not have been imagined in the old days. The christian faith and English-styled courts cannot check on the distasteful behaviors and greed as the traditional tribal unit used to do. Since there were no choices then, everybody lived within the letter and spirit of the law or risked being ostracized by the community, which was tantamount to death. So as Siaka Stevens said, Africa lost her hold on traditional heritage having not yet grasped the cultures presented to her. One may also add that Africa lost her hold on traditional heritage and culture and grasped what was by far inadequate in solving her moral and ethical problems.

Today the secondary school students are not bound to any traditional ethical and moral standards. The standards that guide the young people are commonly the ones expressed by the family or by friends. Additionally, the young people are not bound by any law or obligation to obey their parents unquestionably. In general, children are growing up in a society where individualism is expressed in competition for scarce resources. They are 
also growing up in a society that does not enforce any one moral view. Depending on the family and friends, young people choose to be guided by the purely secular standards or religious beliefs, usually in the christian doctrines.

Data collection did not focus on the happenings in the larger society. But an interview with the Deputy District Education officer revealed that adolescents are aware of the activities of bribery and corruption that envelops the society. He said the adolescents' perspectives are expressed during the annual district, provincial, and national drama festivals. During the festivals, the young people portray their creative power in constructing drama scripts based on real life issues. According to the Deputy District Education officer, one out of four schools produce play scripts depicting corruption and the evils prevailing in the larger society. Additionally, the present day multiparty political system creates an awareness of young people's role in society. Since schools are a part of the larger society, the attitudes and beliefs in the society filter into the classrooms and into the dormitories making the school an even more complex place.

The data indicated that the members of the public delivered and sold bhang to the students. In fact, in each school setting the respondents named a spot in the locality where students purchased bhang, an illegal drug 
in Kenya. Bhang was sold to profit members of the public who were least concerned about its effects on the students. It appeared there was a deliberate attempt by the drug sellers to target the young people in the schools. According to the data obtained, the members of the District Education Board made comments that suggested some members of the public deliberately instigated disruptions for personal interests. The investigation revealed that the persons who instigated the strikes were prominent members of the community.

The personal interests that the Board members were referring to were multiple. Data indicated that some people wanted the replacement of head teachers who refused to give them favors. Favors included giving tenders for the delivery of essential goods and services to the schools. Other people sought to have the head teachers who did not subscribe to their political position replaced with persons friendly to their political views and beliefs. It appeared greed and political gains were the major motives of the people who instigated disruptions in the schools.

The fact that adults were involved in these activities must have contributed to the apathy of the adolescents in the schooling systems. How would they be expected to have confidence with adult systems which embraced corruption and double standards? How would they 
not use bhang if it was sold by responsible members of the community? Perhaps the parents are the adults who should advocate the school children's right to learn. Asked to comment about the role the parents played in restoring order, the deputy district administrator felt the parents had for the most part abdicated their parental guidance to the school administrators. Unfortunately, those parents who took any action were busy criticizing the school administration in the presence of their children. The parents' activism was either misdirected or ineffective in making the schools a safe place to learn.

According to Eisenstadt (1966), modernization entails continual changes in all spheres of society involving processes of disorganization and dislocation giving way to development of social problems, cleavages, and conflicts between various groups. The processes of modern economy that advocates competition and sometimes unfair gains has undoubtedly contributed to the observed attitudes, beliefs, and behavior in students.

Lifton (1970) argued that negative behavior of students may be a way to mock and express contempt at the accepted conventional behavior to which schooling is a part. According to Lifton, mockery breaks down false boundaries imposed by victimization, because through it people are able to tease the absurdity of accepted behavior. Adolescents were likely to perceive double 
standards and react to them. So, if prominent members of the society have the audacity of instigating disruption, perhaps the students justified the riots and boycotts as mockery to adult systems. Who would blame the boys when they hit the automobiles with stones and demanded money from the motorists if it was the adult members of the community who had instigated the disruption in the first place?

Schools reflect a society. As Larkin (1974) has argued, student unrest mirrored the larger society and the protests were not so much directed at the personnel who were in positions of power, but at the structure of power. Thus, one way to attack the structure was either to violate, circumvent, or ridicule the rules. By being rude and indecorous, disruptive, obscene, destructive, and disrespectful of people, the students were attacking the educational organization and its power structure. Disruptions attacked the moral basis of that power structure. Without being able to express it, the students confronted problematic situations that smelser (1962) defined as the unstructured situations. The strikes, both spontaneous and organized, spoke to the feelings of helplessness and anxiety among the actors. The anxiety purported to explain the uncertainty and reduced the ambiguity inherent in the situations. The outbursts gave relief, albeit temporarily. 
Conclusion

The focus of this investigation was to understand why secondary school students in Kirinyaga district disrupted the normal schooling processes. This section briefly summarizes the perceptions of students about riots and boycotts. In the concluding remarks, I have discussed the limitations of this study and what I believe are the limitations of the system of education that governs the schooling of the subjects investigated. MY recommendations are therefore based on what I perceive to be the underlying situation upon which disruptions take place.

\section{Summary}

The study fulfilled its purpose, which was to examine the students' perceptions of riots and boycotts in Kirinyaga secondary schools. The model of the investigation was deficit oriented and spoke to the types, consequences, conditions, and processes of riots and boycotts. Since the investigation was based on a sociology of everyday life methodology, issues of authority and power upon which schools are organized were highlighted. This led to an examination of the culture and network of relationships underlining teacher-student conflicts and confrontations. 
According to the majority of the respondents in this study, riots and boycotts were inevitable. This was partly because some of the processes such as monolization acts and traitor treatment were a part of what the students perceived as "traditions." The fact that these processes were perceived as traditions suggested that riots and boycotts were beyond the control of individuals. on one hand, the respondents did not take responsibility for the actions that precipitated riots and boycotts. On the other hand, the respondents were also less likely to blame any person or persons for the disruptions in schools.

Whereas the informal leaders were more likely to be blamed for the actions that precipitated disruptions, ironically, these individuals were regarded as heroes because they articulated the desires and wants of the students. In other words, to most students disruptive activities fulfilled a positive mission because they enabled students to obtain a platform for the issues about which they cared. Without disruptions, students were more likely to feel that the administrators disregarded them and that the issues they cared about fell on what they described as "deaf ears."

Although disruptions emanated from negative feelings, the perceptions of students about riots and boycotts was a blend of distaste and appreciation. On one hand, students 
were less likely to condemn acts that disrupted normal schooling processes. On the other hand, they were keenly aware that riots and boycotts in schools hurt their education. The fact students reacted to disruptions as both positive and negative made this investigation multifaceted. What adults may view as disruptive was interpreted by the participants as a demonstration of power and freedom.

Disruptions were also used as tools for taking revenge if students felt aggrieved by teachers or felt insulted or degraded by fellow students or students in neighboring schools. The fracas created during the disruptions acted as camouflage because it was difficult to identify individuals in a disruptive atmosphere. In other words, riots and boycotts provided avenues for punishing those perceived as unfair or insulting.

The investigation revealed that disruptions were both instrumental and recreational. There was evidence that some informal leaders instigated disruptions in order to maintain a contentious atmosphere in which they thrived. They sought reasons, ideas, and feelings which would excite and energize the average students to join in the riots and boycotts.

Additionally, the study illuminated the fact that riots and boycotts were also instigated by adults in the community who used the volatile incidents for selfish 
motives. However, I believe that without the informal and intricate culture of the underworld, it would be difficult for outsiders to instigate any riots or boycotts.

Outsiders depended on this contentious atmosphere to penetrate the schools. Additionally, bhang acted as a catalyst for the disruptive atmosphere that pervaded the schools under investigation. The effect of bhang maintained a contentious atmosphere because students were less likely to use any reasoning capacity when under the influence of that drug.

Recommendations offered by Education System

The last government report entitled Report of the Presidential Working Party on Education and Manpower Training for the Next Decade and Beyond was published in March 1988. Now more than seven years old, this document outlined the education and training needs of the country for this decade and beyond. It is in fact the blueprint of the recommendations that the government is likely to examine if education in Kenya is restructured. The recommendations I outline are based on the pertinent issues raised, but not exhaustively addressed, in the working Party's document.

A critical examination of the recommendations of the Working Party revealed the weaknesses of the present educational system more than it depicted the structures in 
the educational system that need attention and restructuring. Addressing the issues of social and cultural life, the Working Party did not address issues of corruption that have eroded the moral basis of our schools. If there is anything that needs redress in the social and cultural standpoint, it is the corruption that permits bhang trafficking, the adult-instigated school disruptions, and the general lack of moral indignation for bribery in the schooling system.

According to the Deputy District Education officer the secondary school students created scripts for the performing arts which portrayed that the adolescents were aware of corrupt practices in educational and other social organizations. Educators cannot afford to be complacent about issues pertinent to corruption. They must be willing to be leaders in the eradication of corrupt practices in their communities because they appreciate that learning does not happen only in a classroom situation; it also takes place in the community. on economic and educational development, the recommendations of the working Party did not address the issues of the curriculum. In fact, the Working Party welcomed the present day tracking of students based on academic ability. My contention is that a blueprint for government's role in education should be concerned about curriculum issues and the everyday life of the schools. 
It should address issues concerning learning and teaching and the actions that can be taken to curb disruptive behavior of students. It should also address the relevance of the examinations in the system and the meaning of learning and the purpose of schooling at the dawn of the 21 st century. The objectives that appear in this document were drawn some 33 years ago and are irrelevant to current and future generations.

The data that emerged in this study pointed to the national education system as a contributor to the ills and frustrations experienced by the teachers and students. The mass tracking based on academic ability after the initial eight years of primary education is likely to continue to contribute to the students' general lack of enthusiasm for learning. Sometimes the meaning of the tracking process played a more significant role than the actual tracking itself. The implication of tracking is that the students who enroll in the district schools are less capable than those who are admitted in the more prestigious provincial and national schools. However, the truth of the matter is that more than $90 \%$ of the district's children are enrolled in the so-called district secondary schools. Only a very small percentage of the above-average students join the provincial and national schools. The students enrolled in district schools are as capable as any others. For selection purposes, the only 
examination that should be retained is the form four standardized examination. The standard eight examination that tracks children after only eight years of primary education does more harm than good. It allows children to feel hopeless and frustrated too early in their schooling career, particularly when they acquire the perception that they are not as academically astute as the students admitted to the more prestigious secondary schools.

If the Kenya Certificate of Primary Education (KCPE) examination were eliminated, it would be possible for educators to harmonize the primary school and secondary school curricula. Today, when students enter the secondary schools they are likely to feel alienated because the transition from primary school is sudden and overwhelming. It entails that a 15-year-old child who had been living with her parents suddenly finds herself in a boarding school in an environment that is more influenced by peers than by adults. According to Wehlage et al. (1989), academic failure and alienation from the institution may result if students fail to adjust to the conditions. In the present configuration, the secondary school and primary schools are more likely to be perceived as separate islands without a common purpose. Since many students join a boarding institution for secondary schooling in an unfamiliar setting, the feelings of alienation are reinforced and the resultant social 
distancing is more likely to be a major source of strain for many students.

The connection between primary and secondary schooling is more likely to be difficult because the primary academic life for most children comprises the preparation for the KCPE examination. The standardized multiple choice questions that the teachers prepare them to pass are not relevant to the more independent work in the secondary schools. In fact, primary schooling is likely to increase KCPE tensions and frustrations. The preoccupation with the examination limits the opportunity for students to discover their own ideas, their own values and experiences, and their projected future before they enroll in a secondary school. With no reflection on goals made while the young people are still in primary school, students discover that they cannot fit in the secondary schools when they are already enrolled. Furthermore, because they have not validated their values or experiences while in the primary school, the adolescents are more likely to be carried away by anything that sounds popular or appealing in the secondary school.

Due to the dictates of the students' culture, many students in secondary school discover that their teachers are not their allies, but their opponents. According to Wehlage et al. (1989), of great importance in student persistence is the amount of warmth of teacher-student 
interactions outside the classroom. In their study, Wehlage et al. found that students who had persistent conflicts with adults, or who found no teacher with whom to establish a personal relationship, were at risk of dropping out. It is recommended that teachers make a conscious effort to minimize conflicts and try to demonstrate interest in their students' academic and personal matters, and to communicate a caring attitude. The standardized examination also increases the perception that one type of education fits all children. If the primary school examinations were eliminated, parents, teachers, and community leaders may be likely to concentrate their time and resources on the issue of making secondary school education accessible to all children. This is possible if communities established more day schools, because they are less expensive to run and maintain.

The Working Party on Education and Manpower Training noted that the curriculum was "overcrowded in terms of the number of subjects" and that there was a "superficial coverage of the curriculum." In fact, the primary and secondary curriculum is more likely to invite resignation and frustration in the classroom and less likely to inspire commitment and enthusiasm. The data suggested that many students gave up on certain subjects because they did not understand what the teachers taught. Wehlage 
(1989) described this phenomenon as difficulty in sustaining effort and interest. The difficulty created winners and losers and the majority of the students are not given an opportunity to learn. The atmosphere created when a majority of the students are unable to learn is conducive to disruptive behavior. In addition to the academic problems, the restructuring of the curriculum had financial implications. Upon the introduction of the so called "vocationalized" curriculum in 1985, curriculum doubled the school work for the students in the primary and secondary schools. It also doubled the number of text books a parent was expected to buy for her child. This forced parents to buy more books and bigger school bags for their children. Many parents are still disappointed about the financial implication of the "vocationalized" curriculum.

Another problem associated with the curriculum introduced in 1985 was that students were required to perform tasks which were beyond their comprehension. The Working Party could not address this issue because it was highly politicized. No one dared criticize the curriculum openly, in or outside government. This is why I feel politicians mishandled the 1985 school restructuring and that students were used as pawns to satisfy the insatiable desire for praise that characterizes African political 
leadership. Speaking to the students' ability, Wehlage et al. (1989) argue that students are likely to withdraw if the subjects become too difficult for their comprehension.

\section{School Governance}

The deputy District Education officer blamed the school disruptions on the school management. He felt that the school administrators were lax and not strict enough. According to the district level administrator, the headmasters would gain more control of their schools if they inspected the teachers and support staff frequently. He recommended that there should be more and better communication and information delivery systems in the schools.

The above comments reflect a management training that addresses issues of management efficiency and effectiveness. The district level administrator did not address any issue that spoke to the school leadership. However, the data indicated that even a school with a good management system, such as school A, was not immune to students' conflicts that sometimes culminated into disruptive activities.

The micro-political underpinning used to interpret the happenings in the schools demonstrated that the students had politicized the issues that were important to them. The rational decision making that the district level administrator advocated could not work in the 
already politicized environments. The data gave evidence that the deputy district officer and possibly the majority of the head teachers assume that the rational model of governance is the cure for the disruptions.

No one in the education district thought the answer to the problems lay in a thorough review of school leadership strategies. Neither did any of the leaders I talked to feel that an organizational culture that would unify the students and teachers to a common cause would heal the conflicts. Furthermore, no one attributed the disruptions to the culture that pits teachers against students and vice versa. Students themselves had a culture that helped them to hold shared perspectives and beliefs. Unfortunately, their shared perspective was negative toward the schooling structures. My contention is that administrators should borrow a leaf of the political strategies that the students used, and work to create a common school culture that views teachers and students as members of a team.

Effective schools literature advocates shared beliefs, goals, and values as the key to excellent and successful schooling. It seems logical to suggest that the language, symbols, and ceremonies that unite students be employed by the school administrators and teachers to unify the entire school for a common cause. In other words, instead of administrators and teachers engaging in 
power struggles with their students, they should find ways and means that will make the students use their power positively. In addition, a politically sensitive language that would create unity and a spirit of community should be sought and adopted. There is risk that is part of any paradigm change, but teachers and administrators should be willing to take risks on behalf of their schools. The major goal would be toward building shared goals as advocated by the effective schools and organizational culture literature. A common organizational culture should be the first building block toward the construction of successful schools.

\section{The Proposed Recommendations}

I feel obliged to describe briefly the background upon which my recommendations rest.

Kenya is among the rank and file of countries described as Third World nations. The implication of this term is that the country is still undergoing the processes of modernization. It is now 100 years since this country first fell under the British colonists. During the last 100 years, the people of Kenya have experienced three phases of dramatic and sometimes traumatic changes. According to olumwullah (1990), 1895 through 1939 was characterized by a search for a workable administrative framework. Then the second world War erupted in 1939 before the pertinent problems facing the Kenyans were 
sorted out. After the second World War, the young and disfranchised Kenyans started to clamor for freedom and human rights. Given these facts about Kenya's history, one can argue that Kenya started to seriously face her problems in 1963 when she regained her freedom from the British. If modernization starts with centralization of the polity, weakening of traditional cultural elites, and growing secularization (Eisenstadt, 1973), then Kenya is undergoing these processes all at the same time.

According to Eisenstadt (1973), modern society is replete with cases of unsuccessful adaptations of existing structures to new types of problems. The problems discussed in this study reflect what Eisenstadt (1973) views as the "inability of major institutions to incorporate even in a partial way the various changes and movements of protest inherent in the process of modernization" (p. 28).

Thus, modernization processes have affected land tenure, education, urbanization, government, and population growth. These processes have in turn affected the day-to-day lives of ordinary people, including the students investigated in this study.

In his views about education, Otiende (1990) noted the future education trends in Kenya will depend on how the country will deal with such matters as the economy, the population explosion, and unemployment. Referring to 
the problems in land acquisition, Kibwana (1990) said, "The major dilemma arising from individualization of tenure is that it necessarily renders large sections of the community landless (p. 238). Additionally, land becomes an "easily marketable commodity" (p. 239). But he was careful to note that the reversal of individual tenure in not feasible.

When people experience landlessness they turn to the sprawling urban centers for employment. Aseka (1990) noted that unskilled poor continue to stream away from subsistence agriculture to exchange the squalor of rural poverty for the even deeper miseries of the shanty towns in urban centers. The deeper urban miseries include slums, violence, rising welfare costs, air pollution, and a deteriorating social environment.

The picture of the modernization process is depressing. According to Gandhi's moral code, modernization is based on an insatiable desire to amass wealth in a situation marked by resource limitations, leading inevitably to violence both at the individual and the collective levels. The situation where a few individuals have a lot more than they need is the way of life in Kenya. This situation, according to Gandhi's moral code, creates a social order in which inequality, oppression, and deprivation prevail to mutilate and destroy human dignity. 
Eisenstadt (1973) argued articulately that when human beings are victims of institutions that cannot adapt to their problems, they often seek to burst the limits set by the institutions with the predisposition or fervor to go to the very foundation of the social framework.

My argument is that the Kenyan people have to go to their roots and question the very modernization process that is supposed to solve their problems. Is there anything in the traditional set-up that can address the malaise and squalor that accompanies modernization? The recommendations described have to be seen as suggestions of some of the ways to address the problems. It is my contention that the problems in schools and elsewhere are complex, intricate, and deep seated, and there is no quick fix of the difficulties that have inflicted kenyans for 100 years. The following recommendations are made with this acknowledgment.

1. Corruption

The issues of corruption which encompasses the selling of bhang to students, taking advantage of students for political or financial advantage, and bribery in school, should be addressed.

I know many Kenyans would be amused at the suggestion that schools can be rid of bribery and other practices devoid of honesty, integrity, and loyalty. I believe that although getting rid of these influences from our school 
system is extremely difficult, it is the only way to travel toward restoring trust and confidence in our schooling system. Our students are not going to trust us as long as the system that is expected to socialize them practices double standards. As teachers and administrators we ask our student to grow up to be men and women of integrity and honesty, but we never live up to these same standards. The apparent lack of moral indignation at the corrupt practices that pervade our schools should be addressed by the government, religious, political and civic leaders in our society and our local communities. If these issues are not addressed, children, and particularly the adolescents, will continue to defy our rules and regulations. As noted in the literature review of this study, students express contempt at the accepted conventional behavior, of which schooling is a part (Larkin, 1974).

The Gikuyu society lost its shared values with the demise of the traditional enclave. As noted in the literature review, the disintegration of the community brought about the loss of the group mission and purpose. People no longer have what Gardner (1990) described as a framework of values to bring meaning and a sense of power in their lives. The loss of a sense of purpose and meaning leads human beings into alcohol and drug abuse. 
It is true we cannot create another traditional society but we can create a sense of community. In order to create a sense of community people have to experience the need for it. Additionally, people must have an understanding of why they should invest their time and resources creating a sense of community.

I offer the following recommendations:

A. I suggest the best rationale is to connect the insecurity that people are having in their own homes with the erosion of a moral framework among children and adolescents in our schooling system. If people are made to connect the happenings in the schools with the thuggery that they experience in their homes, that logic would strike a raw nerve and motivate people who think they have no stake in the schooling system. This rationale is comparable to the anti-smoking campaign in the United States and around the world. Thirty years ago, the awareness that smoking was a health hazard was not as high as it is today because public awareness was not deliberately raised in society. Today there is a sense of community in dealing with the negative influences of tobacco in people's lives, and those who profit from tobacco sales are no longer invincible.

B. To create a sense of community, I feel that government, civic, religious, and school leaders should be involved. The leaders should feel the urgency to address 
all issues lacking in honesty and integrity including selling of bhang and alcohol to students and bribery in the school system.

c. At the governmental level, the members of the community can be involved through the use of "barazas." A "baraza" is a public meeting convened by a chief to give an address on an important issue. At the religious level, I suggest that all denominations preach this message to their congregations in their local churches and then hold inter-denominational services to underline the importance of this issue.

D. I suggest that the issues of security be made political so that the politicians can press for stiff penalties for people who use schools for personal and selfish motives. Concurrent with the raising of moral and ethical consciousness, the legal system should hold the police officers accountable should they fail to apprehend persons suspected of using schools for selfish gain.

E. The Teachers Service Commission has been effective in dealing with teachers who molest young girls. I feel this organization would be effective if it also deals with the teachers and school administrators who allow individuals to use the school system for their own selfish agenda.

F. Finally, I suggest that students in both primary and secondary schools should be made aware of the negative 
effects of corruption and bhang consumption in their lives through lessons addressing social and ethical concerns in the curriculum. This knowledge should be disseminated only by those teachers who believe in what they are saying; by those who passionately share the belief that these practices are evil and undesirable in our communities. Asking any teacher to teach this course will not serve the purpose.

2. Teaching and Learning Issues Throughout this study, I have addressed the competition that is ingrained in Kenya's system of education. I suppose there is nothing wrong with ensuring that only the best students get a chance to further their education. However, as an educator, I think there is something that can be done to improve a system that is so consumed in the selection of a few students that the majority who deserve to learn are ignored and, as a result, they fall through the cracks.

Today the Kenya Certificate of Primary Education (KCPE) does not serve the purpose for which it was established more than 30 years ago. At that time no district could sustain the secondary education of its adolescents. Today, the majority of standard eight graduates enroll in a secondary school within their own home districts. Many communities have built day secondary schools that are disregarded because they do not have 
adequate teaching and learning facilities. Parents seek

places in boarding schools because of the underlying

belief that these schools are better. After conducting

this investigation I did not find that parents were

getting what they pay for in the boarding schools.

KCPE motivates the desire for boarding schools. This

is because KCPE has an air of finality associated with it. Parents and students feel the examination is significant because ideally it paves the way to success. However, no employer ever seeks KCPE certificate holders. Therefore, KCPE sends the wrong message to parents and children

alike. Some children become complacent because they have passed an examination. Other children become unnecessarily discouraged and resign from the schooling enterprise because they failed to pass the KCPE as they had anticipated. Another large group categorize themselves as the "can't do group" because their performance in the examination was only average or below average. This group is prepared to "swim through" secondary school because that is what is expected of them. It is this kind of group of students that I encountered in school D and school F. The respondents described these students as people who are in school "for the sake of it." Kirinyaga is a district whose people have a high regard for the education of their children. Secondly, a large part of the population would sacrifice for a quality 
education. History bears witness to this fact because, since 1963, the district residents have constructed more than 47 secondary schools. Many of these schools are in the category referred to as day schools. The construction of these schools underlines the positive attitude of the people in this district toward education. The resources that would be required of the people is for funds to improve what is already available. If parents today use a third of their income to put children through a boarding school, I do not find it burdensome to ask the parents to use maybe half of that money to equip the next door day school. What is required are educators and other leaders who can assure parents that the education received in the day schools is good.

Given that background I would like to make the following recommendations:

A. Convert the boarding schools to day schools and double the intake in these schools.

B. Improve the existing day schools by providing the required learning and teaching facilities for communities located away from the current boarding schools.

c. Eliminate KCPE and give all children a chance to advance naturally to the form one class in all secondary schools.

D. In-service the primary and secondary teachers together. The goal is to ensure that both secondary and 
primary schools, with the assistance of experts, organize a curriculum that prepares children for the Kenya Certificate of Secondary Education (KCSE), the national standardized examination that is taken after four years of secondary education.

E. By eliminating $\mathrm{KCPE}$, it is hoped that we could also reduce the stratification of students according to academic ability. This aspect of the change will enable all children to invest their time and effort in the fourth form examination (KSCE) that really defines their future. Thus the children will not receive the message that they are "failures" or "just average" after the KCPE. To implement this policy, the following steps may be taken:

A. A pilot project in a school district that has the infrastructure in primary and secondary schools.

B. The pilot project would be allowed a five year trial. Evaluation analysis of the project should be vigorously carried out.

c. Private schools throughout the country would be encouraged to use the new approach.

3. How to Deal with Conflicts

As Optow (1991) suggested, adolescent children have a moral passion borne out of the fact that at this stage in their lives, they are building up their individual ideologies. Given the fact that conflicts and 
confrontations are bound to proliferate in secondary schools, teachers and administrators must be creative in dealing with conflict issues. I suggest that teachers teach children how to resolve their differences amicably. To implement this recommendation I suggest the following steps :

A. Train the teachers that, as class masters or house masters, they have a responsibility of resolving the conflicts that arise among the children in the group.

B. Make professional counseling services available for the children with major problems.

c. Make it a school policy that the house or class master meets his students regularly and monitors the problems that they experience in their school work and among their school mates.

4. Building School culture

A community is enhanced if it has a shared culture. A healthy community affirms itself and builds morale through ceremonies that honor the symbols of shared identity and enable members to rededicate themselves to shared goals (Gardner, 1990).

The students portrayed a shared culture that was determined to isolate teachers as members of another team. What is suggested here is that the teachers and administrators create a culture that celebrates shared identity of the teachers and students alike. since a good 
community nurtures its members and fosters an atmosphere of trust, teachers and administrators must work to eliminate the distrust that underlines the teacher-student relationship examined in this study. The following are suggestions toward building a school culture:

A. Study the "rites of passage" which have meaning for the students and create acceptable and positive rites of passage that speak to the meanings that students and teachers care about as a community.

B. Study the language and ceremonies that students care about and duplicate a language that celebrates their interests but serves to unite the entire school.

c. A common school culture creates a framework of values and norms which defines what is right and what is wrong. Rules and regulations should be based on the acceptable moral and ethical framework respected by all members of the school community, teachers, and students. Let the students be involved in the drafting of the rules and regulations.

D. In this investigation, the students expressed a desire to discuss issues with teachers in a climate devoid of witch hunting and reprisals. The common school culture should affirm to the students that they will be heard and that it is all right to speak out.

E. The culture created should try and define the meaning of learning, particularly the learning for life. 
The teachers and administrators are leaders. According to Gardner (1990), the role of leadership is to explain. Students want to know what the problem is and why they are being asked to do certain things, and why they face so many frustrations. As leaders, teachers and school administrators must explain to students why they have to study, do the tests, and why joblessness is pervasive among school graduates. As leaders the staff must explain the frustration of students and give meaning attached to learning and schooling.

\section{Limitations of the Study}

1. Common sense analysis deduced that the constant disruptions affected learning and teaching. However, the data collected cannot establish how an individual's behavior affected his or her performance. Additionally, the data collected did not establish with certainty the causal relationship between the collective behavior of students in one institution and that institution's overall academic performance.

2. The respondents in this study indicated that the teacher-student interaction did not promote a positive and mutual interdependence of teachers and students in the teaching and learning processes. However, the data collected cannot authoritatively address the classroom climate and its influence on the learning and teaching. 
3. Students and teachers live in the larger society and its influence on the schools is indisputable. The data collected speaks specifically to the students' concerns. It was inadequate in addressing the pressing community and society values and beliefs that affect the school population.

4. The socio-cultural characteristics of individual students were not developed to allow us to construct the personal histories of students and reveal patterns of behavior that are linked to the family and social background.

5. The teachers' feelings and frustrations would add to further understanding of what happens in schools. I suggest a study that speaks to teachers' perspective should be conducted.

The limitations of this study point to the direction of the recommendations for further research.

1. A quasi-experimental study to establish the effects of riots and boycotts on the learning process is recommended because it would outline the causal relationship of the processes discussed in this study.

2. Since metacognition processes are so crucial to learning, a study which establishes how students plan and monitor their work is recommended. What strategies do the students use in learning? Do they use revision, testing, 
and evaluation strategies in their planning and evaluation?

3. A study of personal histories of a few informal leaders would allow us to see the influences that can be attributed to the family and social background. This is because the students' disruptive behavior is a result of a complex web of student characteristics that interact with the characteristics of the school. 


\section{REFERENCES}

Adler, C. (1974). Student revolt: A Special case of youth culture in uses of the sociology of education. In H. G. Rickey (Ed.), National society for the study of education: 73rd yearbook of NSSE (pp. 123-139). Chicago: University of Chicago.

Aseka, E. M. (1990). Urbanization. In W. R. Ochieng (Ed.), Themes in Kenya history (pp. 44-67). Athens: Ohio University Press.

Bailey, S. K. (1970). Disruption in urban public secondary schools. Washington, DC: National Association of Secondary Schools principals.

Baird, L. L. (1970). Who protests: A study of student activists. In J. Foster \& D. Long (Eds.), Protest! Student activism in America (pp. 123-133). New York: William Morrow \& Co.

Bancroft, I. S. (1994). A study of personal attributes associated with marginality and failure of preservice teachers in the terminal field experiences. Unpublished doctoral dissertation, Portland state University, Portland, OR.

Bakke, E. W. (1967). Roots and soil of student activism. In M. L. Seymour (Ed.), student politics (pp. 54-73). New York: Basic Books.

Bengston, V. L. (1972). The generation gap: A review and typology of social-psychological perspectives. In $P$. G. Altbach \& R. S. Laufer (Eds.), The new pilgrims: Youth protest in transition (pp. 195-217). New York: David Mckay Co. Inc.

Bengston, V. L., \& Dunham, C. C. (1994). Married with Children: Protest and the Timing of Family like Course of Events. Journal of Marriage and the Family, 56, 224-28.

Blase, J. (1991). The micropolitical orientation of teachers toward closed school principals. Education and the Urban Society, 23(4), 356-378. 
Bloch, H. A. (1957). Disorganization: Personal and social. New York: Alfred A. Knopf.

Block, J. H., Haan, N., \& Smith, M. B. (1968). Moral reasoning of young adults: Political-social behavior, family backgrounds and personality correlates. Journal of Personality and Social Psychology, 10(3), 183-201.

Block, J. H., Haan, N., \& Smith, M. B. (1973). Activism and apathy in contemporary adolescents. In J. F. Adams (Ed.), Understanding adolescence: Current developments in adolescent psychology (pp. 302-338). Boston: Allyn \& Bacon.

Blumer, H. (1969). Symbolic interactionism: Perspectives and method. Englewood cliffs, NJ: Prentice Hall Inc.

Blumer, H. (1970). Sociological implications of the thought of George Herbert Mead. In G. P. Stone \& H. A. Faberman (Eds.), social psychology symbolic interaction (pp. 282-293). Waltham, MA: Ginn \& Blaisdell.

Bogdan, R. C., \& Biklen, S. K. (1992). Qualitative research for education: An introduction to theory and methods. Boston: Allyn and Bacon.

Bogdan, R. \& Taylor, S. J. (1984). Introduction to qualitative research methods (2nd Ed.). New York: John Wiley \& Sons.

Bowers, W., \& Kahn, R. M. (1970). The social context of the rank and file student activist: A test of four hypothesis. Sociology of Education, $43(1), 38-55$.

Carnoy, M. (1977). Education and employment: A critical appraisal. Paris Unesco: International Institute for Educational Planning.

Cohen, R. D., \& Mohl, R. A. (1979). The paradox of progressive education: The Gary Plan and urban schooling. New York: National University Publications.

Coleman, J. S. (1965). Adolescents and schools. New York: Basic Books Inc.

Coombs, P. (1968). The world educational crisis. New York: Oxford University Press. 
Craig, J. (1990). Comparative African experience in implementing educational policies (World Bank Discussion Papers, No. 33). Washington, DC: Africa Technical Services.

Cross, H. J., \& Pruyn, E. I. (1973). Youth and the counterculture. In J. F. Adams (Ed.), understanding adolescence: current developments in adolescent psychology (pp. 339-374). Boston: Allyn \& Bacon Inc.

Datta, A. (1984). Education and society: A sociology of African education. New York: St. Martins Press Inc.

Davison, J. (1989). Voices from Mutira: Lives of rural Gikuyu women. Boulder: Lynne Rienner Publishers.

DeMartini, J. R. (1983), Political Socialization: Generational Consciousness and Lasting Effects. Youth and Society, 15(2), 195-223.

DeMartini, J. R. (1985). Change agents and generation relationships: A re-valuation of Mannheim's problem of generations. Social Forces, 64(1), 1-16.

Douglas, J., Adler, P., Adler, P., Fonyana, A., Freeman, C. , \& Kotarba, J. (1980). Introduction to the sociologies of everyday life. Boston: Allyn and Bacon.

Eisenstadt, S. N. (1965) Archetypal Patterns of Youth. In E. H. Erickson (Ed.), The challenge of youth (pp. 29-50). New York: Doubleday \& Co.

Eisenstadt, S. N. (1966) Modernization: protest and change. Englewood Cliffs, NJ: Prentice Hall.

Eisenstadt, S. N. (1973). Transitions, change, and modernity. New York: John Wiley \& Sons.

The Encyclopedia Britannica (9th ed.). (1977). Chicago: Britannica Inc.

Erickson, K. (1969) Activism in the secondary schools: Analysis and recommendation. University of oregon: Bureau of Education Research and Service.

Eshiwani, G. (1990). Implementing education policies in Kenya. World discussion paper (No. 5). Washington, DC: African Technical Department Series. 
Everhart, R.B. (1991). Unravelling micropolitical mystiques: Some methodological opportunities. Education and Urban Society, 23(4), 455-464.

Fendvich, J. M. \& Lovoy, K. L. (1988). Back to the future: Adult political behavior of former students. American Sociological Review, 53(5), 780-784.

Flacks, R. (1967). The liberated generation: An exploration of the roots of student protest. Journal of Social Issues, 23, 52-75

Flacks, R. (1970). Student revolt. In E. E. Sampson \& H. A. Korn (Eds.), Social and cultural meanings of student revolt (pp. 117-141). San Francisco: JosseyBass.

Foote, N. N. (1970). Identification as the basis for a motivation theory. In G. P. Stone \& H. A. Faberman (Eds.), Social psychology symbolic interaction (pp. 480-489). Waltham, MA: Ginn \& Blaisdell.

Foster, J. (1970). Student protest: What is known, what is said. In J. Foster \& D. Long (Eds.), Protest: student activism in America (pp. 27-58). New York: William Morrow \& Co.

Freedman, M. B. \& Kanzer, R. (1970). Psychology of a strike. In E. E. Sampson \& H. A Korn (Eds.), student activism and protest (pp. 142-157). San Francisco: Jossey-Bass.

Friedenberg, E. Z. (1972). The high school as a focus of student unrest. In D. G. Altbach \& R. S. Laufer (Eds.), The new pilgrims (pp. 267-278). New York: David Mckay Inc.

Fuhrmann, B. S. (1985) . Adolescence, adolescents. Toronto: Little, Brown \& Co.

Gandhi, M. K. (1960). Trusteeship. Ahmedabad: Navajivan Trust.

Gardner, J. W. (1990) - On leadership. New York: Free Press.

Glaser, B. G., \& Strauss, A. L. (1967). The discovery of grounded theory: Strategies for qualitative research. New York: Aldine de Gruyter.

Gudridge, B. M. (1969). High school student unrest. Washington, DC: Education U.S.A. Special Report. 
Harlow, N., \& Wenk, E. (1978). School crime and disruption: prevention models. Washington, DC: National Institute of Education.

Havighust, R. J. (1973). A cross-cultural view of adolescence. In J. F. Adams (Ed.), Understanding adolescence: current developments in Adolescent psychology (pp. 1-29). Boston: Allyn \& Bacon.

Hirsch, E. I. (1990). Sacrifice for the cause: Group processes, recruitment and commitment in a school social movement. American Sociological Review, 55 (2), 243-254.

Iannaccone, I. (1991). Micro-politics of education what and why. Education and Urban Society, 23(4), 165471.

International Labor office Geneva (1973). Employment, incomes and equality: A strategy for increasing productive employment in Kenya. Geneva: International Labor office.

Keniston, K. (1965). The uncommitted: Alienated youth in American society (1st ed.). New York: Harcourt Brace \& World.

Keniston, K. (1968). Young radicals: Notes on committed youth (1st ed.). New York: Harcourt Brace \& world Inc.

Keniston, K. (1970). Sources of student dissent in student activism and protest. In E. E. Sampson \& H. A. Korn (Eds.), student activism and protest (pp. 158-190). San Francisco: Jossey-Bass.

Kenyatta, J. (1938). Facing Mount Kenya: The tribal life of Kikuyu. London: Secker and Warburg.

Kibwana, K. (1990). Land tenure. In W. R. Ochieng (Ed.), Themes in Kenya history (pp. 230-241). Athens: Ohio University Press.

Larkin, R. W. (1974). Protest and counter culture: Disaffection among affluent youth. In H. G. Rickey (Ed.), Uses of the sociology of education. $73 \mathrm{rd}$ yearbook of NSSE (pp. 17-35). Chicago: University of Chicago Press.

Leakey, L. S. B. (1977). The southern Kikuyu before 1903. New York: Academic Press. 
Leo, c. (1984). Land and class in Kenya. Toronto: University of Toronto Press.

Levy, M. J. (1969). The structure of society. Princeton: Princeton University Press.

Lifton, R. J. (1972). The new history. In P. G. Altbach $\&$ R. S. Laufer (Eds.), The new pilgrims (pp. 182194). New York: David Mckay Co. Inc.

Lofland, J. (1985). Protest studies of collective behavior and social movement. New Brunswick: Transactions Books.

Maloba, W. O. (1993). Mau mau and Kenya: An analysis of a present revolt. Bloomington: Indiana University Press.

Mannheim, K. (1972). The problems of generations. In D. G. Altbach \& R. S. Laufer (Eds.), The new pilgrims (pp. 101-138). New York: David Mckay.

Marshall, C. \& Rossman G. B. (1989). Designing qualitative research. Newbury Park: Sage Publications.

Marshall, C., \& Scribner, J. D. (1991). It's all political: Inquiry into the micropolitical of education. Education and Urban Society, 23(4), 347-355.

McAdam, D. (1986). Recruitment to high risk activism. American Journal of Sociology, 92, 64-90.

McAdam, D. \& Paulsen, R. (1993). Specifying the relationship between social ties and activism. American Journal of Sociology, 99(3), 640-667.

Mead, M. (1970). Culture and commitment: A study of the generation gap. New York: Natural History Press/ Doubleday \& Co.

Ministry of Education. (1994). Ministry of Education statistics. Nairobi, Kenya: Government Press.

Mitchell, D. E. (1984). Educational policy analysis: The state of the art. Educational Administration Quarterly, 20(3), 129-160. 
Newmann, F. M. (1989). Reducing student alienation in high school: Implications of theory. In L. Weis, $E$. Farrar, \& H. G. Petrie (Eds.), Dropouts from school: Issues, dilemmas, and solutions (pp. 153-177). New York: State University of New York.

Newmann, J., \& Newmann, G. (1980). Crime and punishment in the school process: A historical analysis of violence and crime in the schools. In K. Baker \& $R$. $\mathrm{J}$. Rubel (Eds.), Violence and crime in schools (pp. 1-27). Lexington, MA: Lexington Books.

Olumwullah, O. A. L. A. (1990). Government. In W. R. Ochieng (Ed.), Themes in Kenya history (pp. 88-116). Athens: Ohio University Press.

Optow, s. (1991). Adolescent peer conflicts: Implications for students and for schools. Education and Urban Society, 23(4), 416-441.

Otiende, J. E. (1990). Education since the early times. In W. R. Ochieng (Ed.) Themes in Kenya history (pp. 70-87). Athens: Ohio University Press.

Park, B. C. (1993). An aspect of political socialization of student's movement in South Korea. Youth and Society, 25(2), 171-201.

Paulsen, R. (1991) . Education, social class, and participation in collective action. Sociology of Education, 64, 96-110.

Pfeffer, J. (1981). Power in organizations. Marshfield, MA: Pitman Publishing Company.

Ramashay, R. (1984). Moral foundations of Hind Swaraj and non violence: Gandhi's soundings in political philosophy. Delhi: Chanakya Publishers.

Rubel, R. J. (1977). The unruly school. Lexington, MA: Lexington Books.

Sampson, E. E. (1970). Student activism and the decade of protest. In E. E. Sampson \& H. A. Korn (Eds.), student activism and protest (pp. 1-22). San Francisco: Jossey Bass Inc.

Sanday, P. G. (1983). The ethnographic paradigm(s). In J. V. Mannen (Ed.), Qualitative methodology (pp. 45-70). Sage Publications: Beverely Hills. 
Schattschneider, E. E. (1975). The semisovereign people. Hinsdale, IL: Dryden.

Schilling, D. G., \& Harik, E. M. (1984). The politics of education in colonial Algeria and Kenya. Athens: University of Ohio, Center for International studies.

Smelser, N. J. (1962). Theory of collective behavior. New York: The Free Press.

Spady, W. G. (1974). The authority of the school and student unrest: A theoretical exploration. In H. G. Rickey (Ed.), Uses of sociology in education. National society for the study of education 73 rd yearbook of NSSE (pp. 37-77). Chicago: University of Chicago Press

Spradley, J. P. (1979). The ethnographic interview. New York: Holt, Rinehart and Winston.

Stiegeìbauer, S. M., Goldstein, M., \& Huling, L. (1982, March 19-23). Through the eye of the beholder: on the use of qualitative methods in data analysis. Paper presented at the annual meeting of the American Educational Research Association, New York.

Thompson, A. R. (1981). Education and development in Afica. New York: St. Martins Press.

Travers, E. F. (1982). Ideology and political participation among high school students: Changes from 1970-1979. Youth and Society, 13(3), 327-352.

Travisano, R. V. (1970). Alternation and conversion as qualitatively different transformation. In P. G. stone \& H. A. Faberman (Eds.), Social psychology through symbolic interaction (pp. 594-606). Waltham, MA: Ginn-Blaisdell.

United Nations Children's Fund. (1972, November) - UNICEF News, (73).

Urch, G. (1968). The Africanization of curriculum in Kenya. Ann Arbor: University of Michigan.

Wang, M., Haertel, G. D., \& Walberg, H. J. (1990). What influences learning? A content analysis of review literature. Journal of Educational Research, 84(1), 30-43. 
Watts, W. A., \& Whittaker, D. (1968). Profile of a non conformist youth culture: A study of Berkeley nonstudents. Sociology of Education, 41(2), 178-219.

Wax, R. (1971). Doing fieldwork: Warnings and advice. Chicago: University of Chicago Press.

Wehlage, G. G., Rutter, R. A., Smith, G. A., Lesco, N. , \& Fernandez, R. R. (1989). Reducing the risk: Schools as communities of support. New York: The Falmer Press.

Willower, D. J. (1991). Micropolitics of the sociology of school organization. Education and Urban Education, $\underline{23}(4), 442-454$.

Working Party on Education and Manpower Training. (1985). Report of the Presidential Working Party on Education and Manpower Training for the next decade and beyond. Nairobi: Government Press.

Yin, R. K. (1989). Case study research: Design and methods (2nd ed.). Newbury, CA: Sage Publications. 


\section{APPENDIX A}

A SAMPLE OF RULES AND REGULATIONS AND A SAMPLE OF THE DAILY PROGRAM OBTAINED FROM TWO OF THE SELECTED SITES 


\section{A COPY OF SCHOOL RULES FROM SCHOOL B Rules and Regulations 1994 Revised}

1. All students in School B secondary school should be subject to the following rules and regulations in a bid to enhance our school "Motto"

SELF DISCIPLINE AND DEDICATION LEADS TO KNOWLEDGE RULES AND REGULATIONS

2. A student should be dressed in full school uniform at all times. Non uniform materials will be confiscated if found.

3. Students must be tidy and neat at all times. students must be punctual, that is, be at the right place, at the time, doing the right thing.

4. Staff quarters, the staff-room, kitchen, the area in front of the administration block is out of bounds to all students unless they have a special permission.

5. Sneaking out of the school compound for whatever reason is not permitted.

6. The school strongly prohibits smoking, consumption of alcohol and drugs when students are in or out of school compound.

7. Students should not steal or damage, public or school property.

8. English or Kiswahili should be the languages of communication in and around the school campus.

9. Students should respect all personalities regardless of status.

10. Students should only take orders given by those in authority e.g. teachers, the headmaster or deputy headmaster.

11. A student should not entertain visitors without the permission of the teacher-on-duty.

NB. the following areas are out of bounds to students on visiting days the staff quarters, laboratories, dormitories, the dining hall, and the school farm.

12. Every student should follow the laid down procedures of solving grievances should they arise. 
13. There are no weekend outings.

14. Parents and guardians are allowed to visit the boys on the first sunday of the month. Visitors are not allowed to come to see the students any other time unless they have special permission of the school administrator.

15. Monday to Friday evening and night study periods should start at 6:50 p.m. and end at 10:00 p.m.

16. All students should go to bed at 11:00 p.m. Lights should be put off at 11:00 p.m.

Weekend evening and night study period should start at $8: 20 \mathrm{p} . \mathrm{m}$. and end at $10.00 \mathrm{p} . \mathrm{m}$. unless these is entertainment.

17. Fighting, bullying, trading insults, and quarreling among students is not allowed.

All school rules and regulations must be observed at all times to succeed in school B. All students are subject to the above rules and regulations.

Any student who disobeys one or all of the above rules will be severely dealt with. The forms of punishment expected include: corporal punishment, suspension, or expulsion. 
A COPY OF A DAILY PROGRAM OBTAINED FROM SCHOOL A

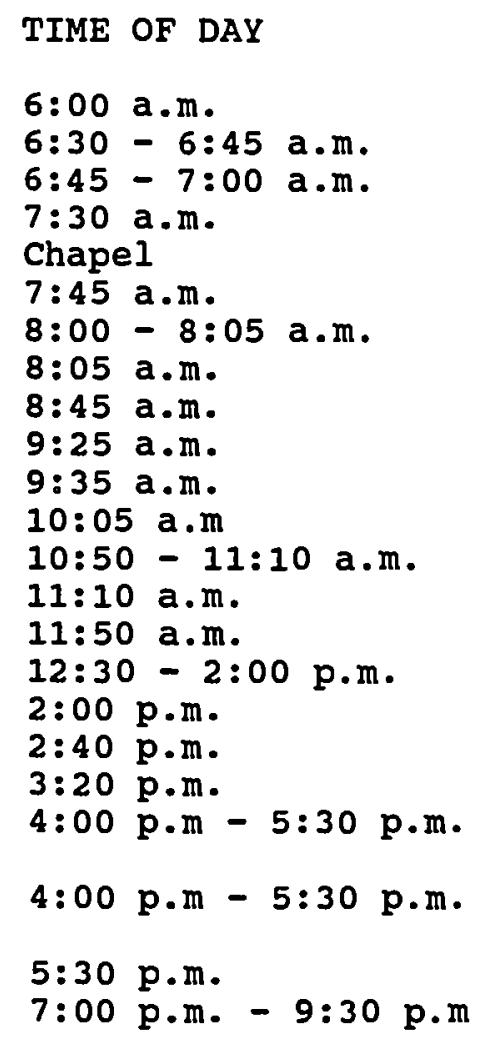

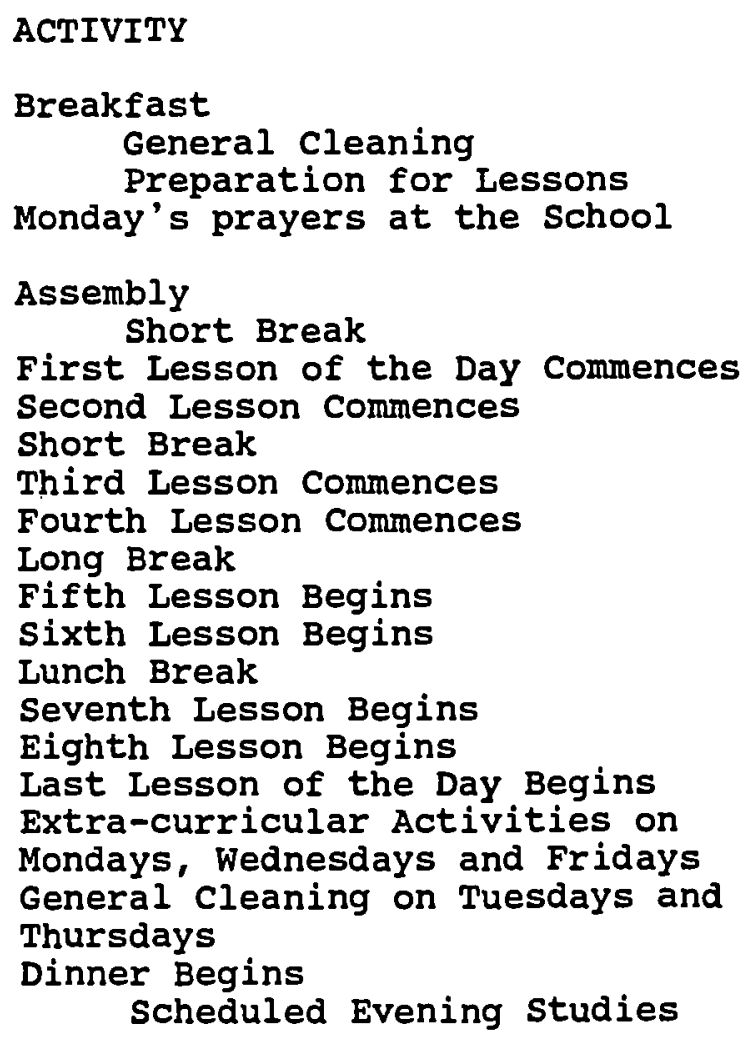


APPENDIX B

CHARTS 1, 2, AND 3 
Chart 1

The Conceptual Framework

Riots and Boycotts

\begin{tabular}{|c|c|c|c|}
\hline $\begin{array}{c}\text { Category } 1 \\
\text { Spontaneous Reactions }\end{array}$ & $\begin{array}{c}\text { Category } 2 \\
\text { Organized Reactions }\end{array}$ & $\begin{array}{c}\text { Category } 3 \\
\text { Outside interference }\end{array}$ & $\begin{array}{l}\text { Category } 4 \\
\text { Losses }\end{array}$ \\
\hline Informal leadership & $\begin{array}{l}\text { Teachers and students interactions } \\
\text { marked with us versus them } \\
\text { ideology }\end{array}$ & $\begin{array}{l}\text { Adult members of the community } \\
\text { instigated riots for selfish reasons }\end{array}$ & Psychological losses \\
\hline $\begin{array}{l}\text { Student activities of } \\
\text { domination and rituals }\end{array}$ & $\begin{array}{l}\text { Prefects were unpopular because } \\
\text { they represented the interests of } \\
\text { adults } \\
\text { Rules and regulations were } \\
\text { unnecessary burden }\end{array}$ & $\begin{array}{l}\text { The school and students' property was } \\
\text { stolen and/or looted during the } \\
\text { ensuring chaos by outsiders }\end{array}$ & Financial losses \\
\hline Inter-class fights & $\begin{array}{l}\text { Negative attitude towards leaming } \\
\text { and related school work }\end{array}$ & $\begin{array}{l}\text { Alcohol, bhang and cigareftes were } \\
\text { sold to students by the adult members } \\
\text { of the community }\end{array}$ & $\begin{array}{l}\text { Loss of security and } \\
\text { certainty in school }\end{array}$ \\
\hline $\begin{array}{l}\text { Inter-school conflicts and } \\
\text { interactions }\end{array}$ & & & \\
\hline
\end{tabular}


Chart 2

Match Between Characteristics and Type of Behavior

\begin{tabular}{|l|l|}
\hline Student Characteristics & \\
\hline - Gender & $\begin{array}{l}\text { Behavior } \\
\text { not fall on what they described as "deaf ears" boycotts are necessary to give } \\
\text { students a platform } \\
\text { - Girls were more likely to resign and to persevere the perceived wrongs and } \\
\text { look forward to the day that they depart from school for good }\end{array}$ \\
\hline - Deeply felt need or desire & $\begin{array}{l}\text { - The needs included anything from better food, more outings, better } \\
\text { entertainment, better transportation to demand that a certain leacher or } \\
\text { administrator leaves the institution }\end{array}$ \\
\hline - Identifiable leadership & $\begin{array}{l}\text { - Informal leaders acquired power through coercion and persuasion that worn } \\
\text { admiration and loyalty } \\
\text { - Informal leaders articulated students' needs and wants }\end{array}$ \\
\hline - Strong and identifiable students' culture & $\begin{array}{l}\text { - An identifiable students' turf where adults were unwelcome } \\
\text { - Militant, disruptive, and spontaneous } \\
\text { - Reactions to defend perceived higher and important statuses }\end{array}$ \\
\hline
\end{tabular}


Chart 3

Typology of Riots and Boycotts

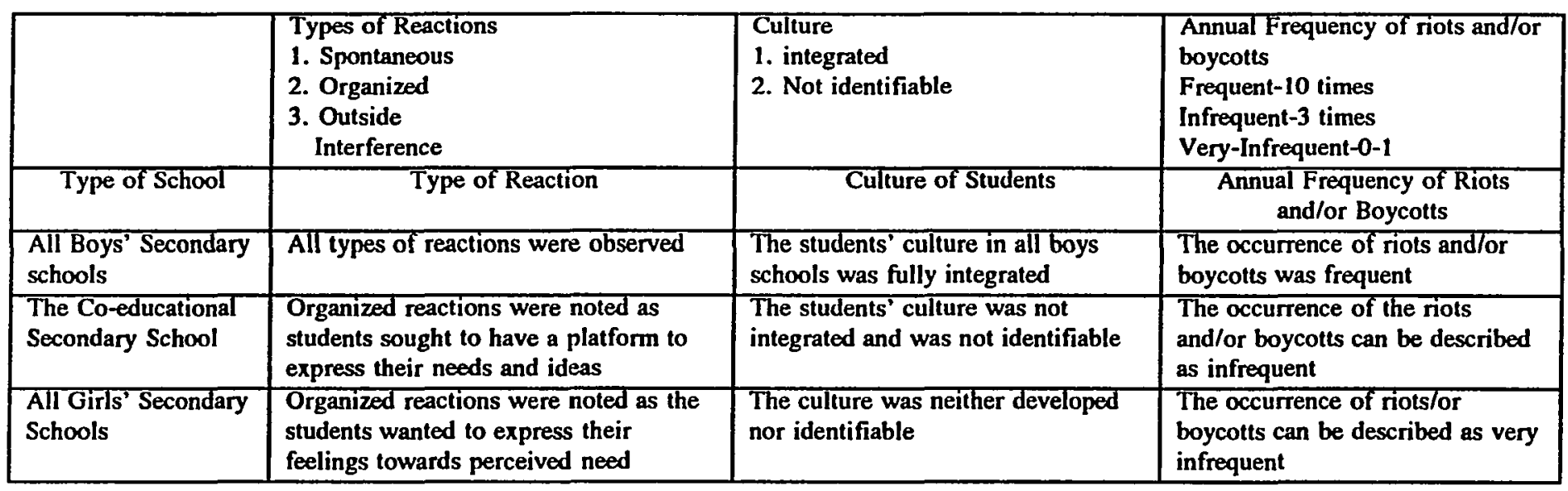




\section{APPENDIX C}

COPIES OF THE DOCUMENT OBTAINED FROM THE

KENYA GOVERNMENT FOR AUTHORITY TO

CONDUCT RESEARCH 
MINISTRY OF EDUCATION
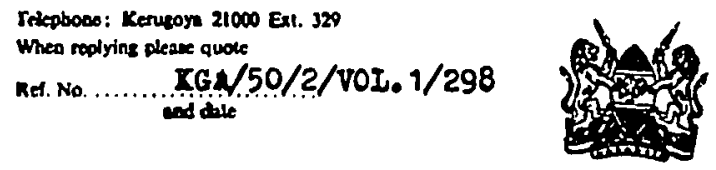

T9:

121 Secondary School Headteachers, IIRITYAGA DISTRICI

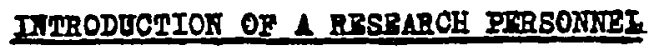

Y/S MARGARFR TANGECI GATIME.

The above named has been erented permlasion by the effice of the President vide letter ref, ep/13/001/250/44 of 16th June, 1995 to carry out regearoh on student unseat and ralated areas.

The purpose of this lettre, is to ask jou to accord the officer, all the aseistence that ahe mey require. Snch assiatance in the final analyois wl2l bo in our interest.

Thank jou.

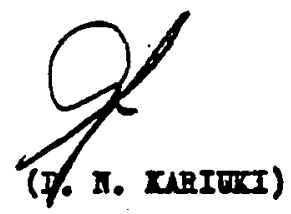

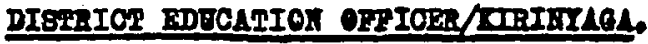

DNulok 
This is to Certify that :

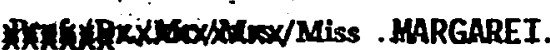

WAKGECT.GATT.MY

of (Adaress) :...P.0...BOX..53456.

has been permitted to conduct research in .... SECOHARY.SCHOQLS.

Location,

\section{Kirifirié.} District,

ching

Province,

on the topic ....SIUDEUTS..PERCEPTIOLS.OF..SCHOOL

RIOIS.AM. CLASS..BOYCOTTS.IH..JHE.

SECOWDARY.SCHOOLS.

for a period ending

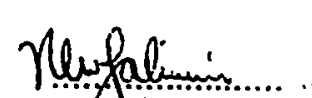

"* W JMONo

Research permit No. ..0P/.136001./25G..144..

. Date of issue .............6TH. HUWW...199.5.

Fee received .............SWHS.100/= 
APPENDIX D

MAPS SHOWING KIRINYAGA IN RELATION TO OTHER

DISTRICTS IN THE CENTRAL PROVINCE 


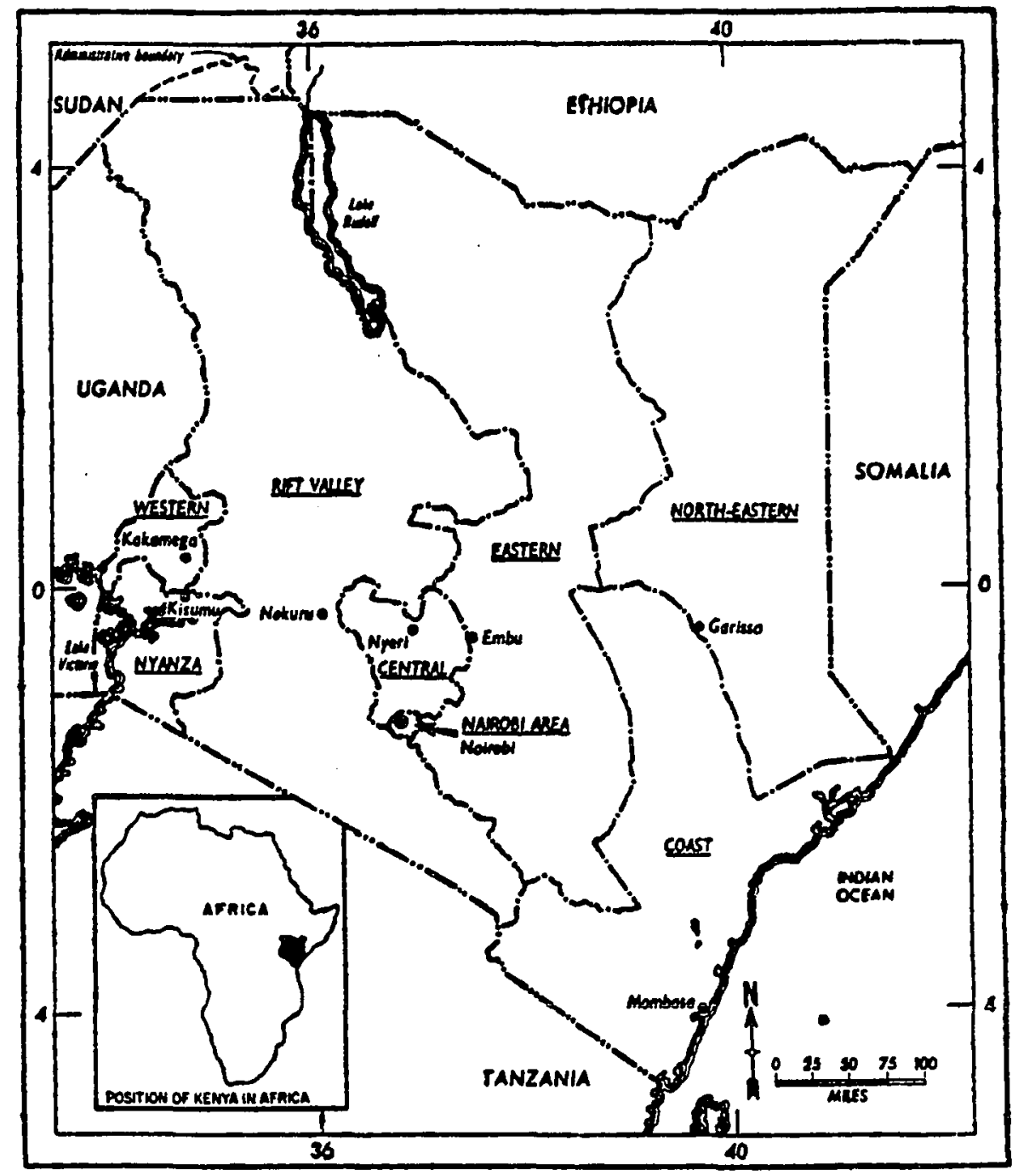

Figure 1. Republic of Kenya 
Kirinyage District within the Central Province's Other Four Districts

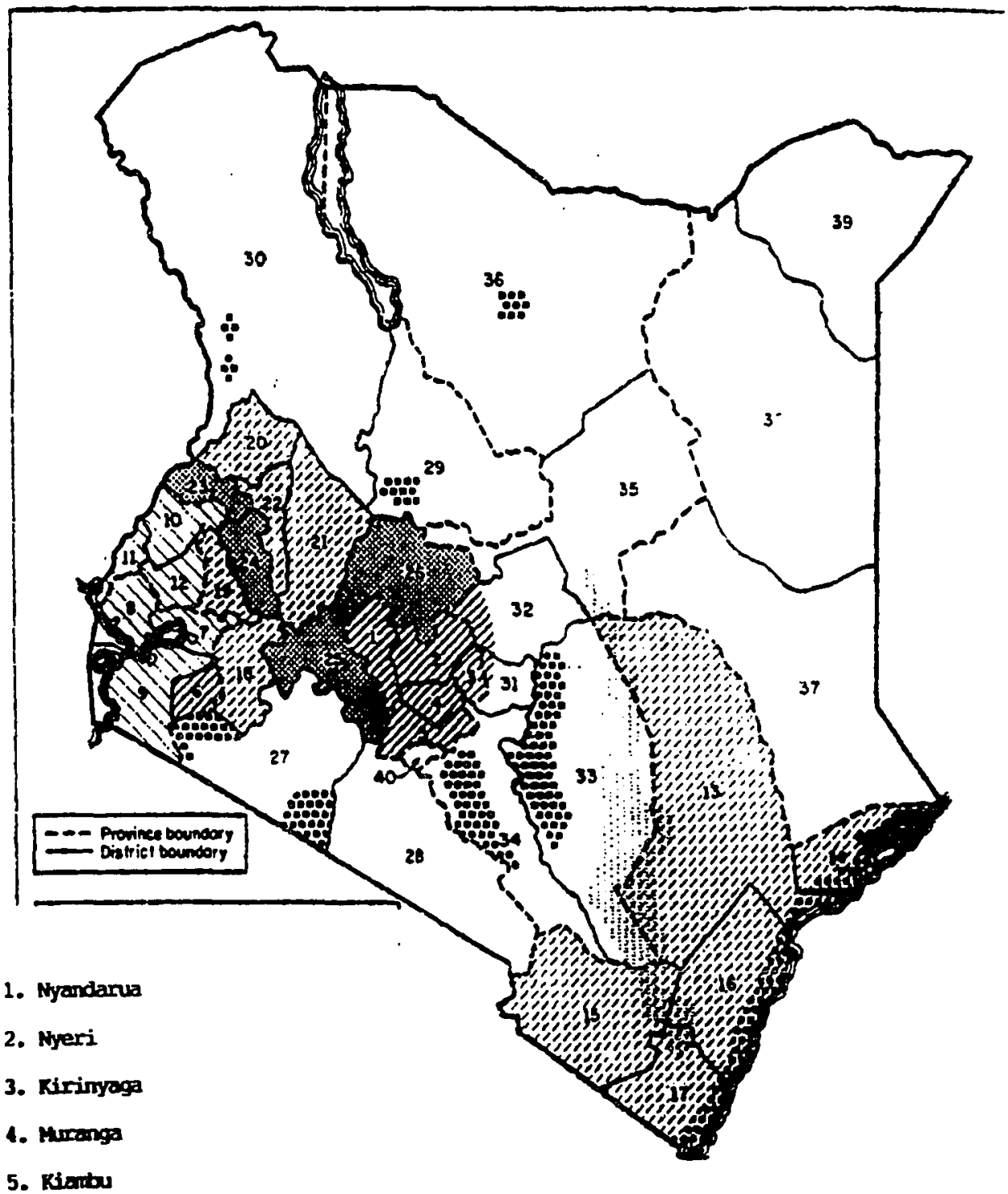

